\title{
At Home and Across Borders: Gender in Guatemalan Households and Labour Migration to Canada
}

\author{
By \\ Christine Hughes
}

A dissertation submitted to the Faculty of Graduate and Postdoctoral Affairs in partial fulfillment of the requirements for the degree of

Doctor of Philosophy in Sociology

Carleton University

Ottawa, Ontario

(C) 2014

Christine Hughes 


\begin{abstract}
This dissertation investigates change and continuity in household gender dynamics in the context of Guatemalans' labour migration to Canada. Thousands of Guatemalans have challenged circumstances of economic precariousness by working in Canadian agriculture through Canada's Temporary Foreign Worker Program. This study explores experiences of migrants and non-migrating partners and other household members through a social, critical, and feminist lens, specifically asking whether Guatemalan women's and men's seasonal migration to Canada has contributed to shifts in gender-related practices and relations of power in their households. The study is situated in 'gender and migration' scholarship, and rests theoretically on the idea that gender is expressed at individual, ideological, and institutional levels of society. I map this foundation onto the possibilities created by the temporary labour migration of individual household members. Specifically, I investigate shifts in the gendered selves of migrants and partners, gender consciousness and ideologies as social remittances, and the impacts of income and economic remittances. These lines of inquiry were pursued through critical feminist and ethnographic approaches to interview-based fieldwork in Guatemala with migrant-sending households in an indigenous community, complemented by organizational interviews in both Guatemala and Canada. Based on both during- and post-migration scenarios, this case study revealed that migration has reinforced the status quo much more than it has encouraged disruptions to patriarchal household gender dynamics. Although occasional signs of change did arise in thinking about and practicing gender, this dissertation demonstrates a great deal of continuity in women's and men's gender practices and relations of authority, and draws attention to the profound influence
\end{abstract}


of both transnational processes and local conditions that reinforce gender relations. In a context where Guatemalans' migration to Canada shows few signs of ebbing, this dissertation identifies the need for further research to assess both longer-term and intersectional gender-related impacts. 


\section{Acknowledgements}

Many individuals deserve thanks for supporting the completion of this dissertation. My exceptional supervisor, Daiva Stasiulis, led by example, promoted my development, provided intellectual direction, and offered unwavering support for all my scholarly endeavours. Other committee members, Xiaobei Chen and Laura Macdonald, made my work stronger by encouraging exploration, asking important questions, and adding new perspectives, and Janet Siltanen offered valuable guidance at earlier stages. I wholeheartedly thank all the study participants, with a particular expression of gratitude to migrants and their partners in Guatemala who were so kind to open their doors and share their experiences. Among those who supported my fieldwork, I want to extend a special agradecimiento to "Jane" and "Miguel" whose kindness and assistance were priceless, "Rafael" and "Miranda" who provided me a comfortable home base and insider insights, particular American academics, Peace Corps volunteers, and FLACSO researchers for their insights, and Lily Muñoz for our chats. On the personal side, my parents and sister have been constant sources of support, never doubting that I could accomplish this. My close friend, April Girard, provided lifeblood for tough times and the finish line with 'homework parties', a sounding board, and inspiring examples of tenacity in work and life. And coffee dates with Cathy Tuey gave me needed perspective time and again. To my partner in life (with cats), David Dorey, I thank you with every fibre of my being for your patience and encouragement, for steadying the ship, for celebrating the crests and bearing the extra load on the troughs, and for helping me look to the horizon toward what's next. This research was also supported by the Social Sciences and Humanities Research Council. Thank you again, one and all. 


\section{Table of Contents}

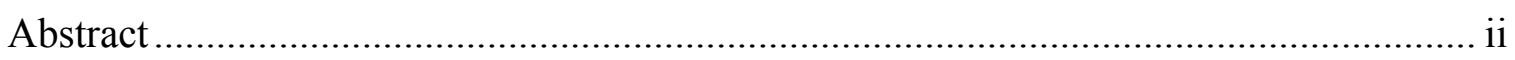

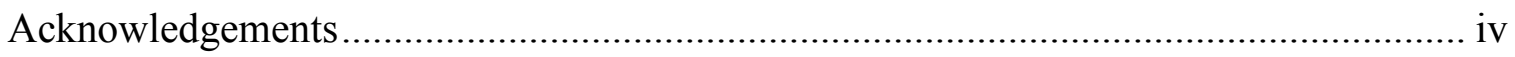

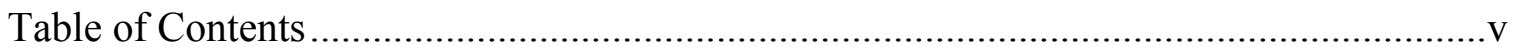

List of Figures and Tables.......................................................................................... vi

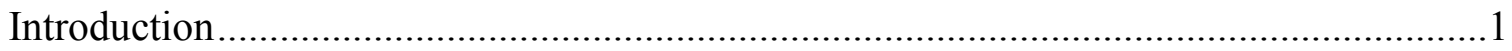

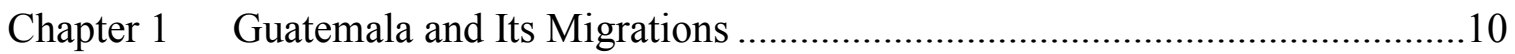

Chapter 2 Gender, Intersectionality, and Indigenous Households in Guatemala .........25

Chapter 3 Gender and Migration, and a Critical Engagement with Bourdieu...............66

Chapter 4 Critical and Reflexive Feminist Research in Highland Guatemala..............97

Chapter 5 Vista Hermosa: Gender Relations and Migration to Canada ......................135

Chapter 6 Investigating Habitus: Migrants in Canada ................................................162

Chapter 7 Investigating Habitus: Non-migrants in Transnational Households ........192

Chapter 8 Income and Economic Remittances: Whither Household Authority? …..232

Chapter 9 Gender-related Knowledge and Social Remittances ....................................261

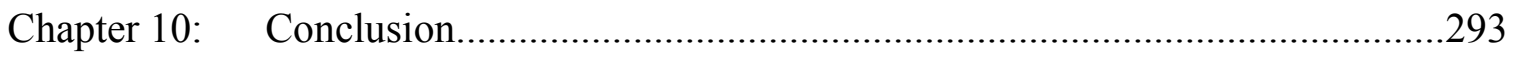

Appendix A Information Provided about the Study to Potential Participants .............301

Appendix B Consent Forms and Oral Consent Script ...................................................307

Appendix C Confidentiality Script \& Agreement - Research Assistants....................309

Appendix D Interview Guides - Migrant Households .................................................310

Appendix E Interview Guide - Organizational Representatives ..................................317

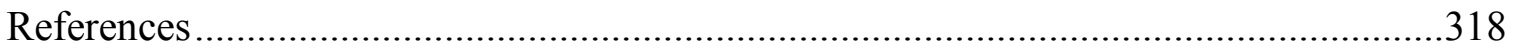




\section{List of Figures and Tables}

Figure 1: Theoretical Framework - Gender as a Structure and Avenues of Change and Continuity in Household Gender Relations

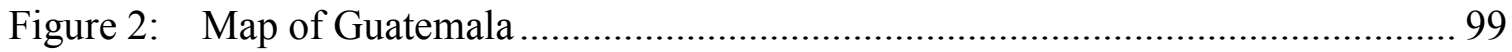

Figure 3: Map of the Municipality of Tecpán Guatemala ............................................. 100

Table 1: Female Migrants and their Households …………………………………... 118

Table 2: Male Migrants and their Households............................................................. 119

Table 3: Full List of Respondents and Research Encounters ...................................... 127

Table 4: Participants' Migration to Canada …………………………........................ 160 


\section{Introduction}

“'I'm going to go, but just for one time'," Yaneth ${ }^{1}$ recounted her husband Lucas' words with a laugh. After his six seasons in Canada, she had grown used to her husband's five-month absences, but professed "it's very hard for me when he's not here." Single-parenting four young children made it difficult to leave the house, and her increased workload caused her stress: "I have a bit more control over everything, and I have more to take care of as well... he only has to think about sending [money]." In addition to the material benefits that migration had brought - a house and land - she claimed Lucas helped her more around the house because in Canada, he "has to do the housework that I do, [that's] when he saw...that it's difficult." She approved of what Lucas had learned about women's paid work in Canada but "each place has its customs." She had some interest in migrating herself, but "the kids would die without their mom."

"The kids were a little abandoned," said Gloria, a migrant mother of three, about her household in Guatemala while she was in Canada. Her husband being too old to go, she had migrated to ease their financial situation. During her four-month contract she picked and packed strawberries up to fifteen hours a day - “QQué gran cansancia! (What exhaustion!)" - and had faced prohibitions from leaving the farm, where she also lived. Going home to her daughters in Guatemala was "like I returned to see the light of day." She had succeeded in buying land for the children and meeting day-to-day financial needs but denied having more household authority. When she had the opportunity to go for a second season, her husband, who had hired domestic help while Gloria was away, told her: "“ni una papelería vas a mover (you're not even going to do the paperwork)."”

\footnotetext{
${ }^{1}$ Names of all study participants in my research community are pseudonyms.
} 
Yaneth and Gloria poignantly introduce some of the issues explored in this dissertation on the shifts and continuities in household gender dynamics in the context of Guatemalans' labour migration to Canada. Amid economic precariousness, as many as one third of Guatemalan households depend in some fashion on international migration for their livelihoods (Hernández 2011), and beginning in 2003 because of changes to its Temporary Foreign Worker Program, Canada is increasingly a destination among Guatemalan migrants, the vast majority men, struggling for better life chances. Against this backdrop, I examine whether and to what extent the seasonal migration to Canada of indigenous Guatemalans - women and men - has encouraged shifts in gendered facets of the daily lives of their households.

This dissertation takes its departure from a concept of gender as a social construct that defines, in culturally-specific ways, the parameters of masculinity and femininity, and from there investigates household gender relations, the gender-delineated and powerladen arrangements of production and authority. My study enmeshes those arrangements in Guatemala with labour migration to Canada for agricultural work, and addresses three principal research questions: First, what happened in household gender relations in the context of migration to Canada, both during migrants' absences and upon return? Second, what were the primary avenues through which shifts and continuities in household gender dynamics occurred? And third, what factors and circumstances - in both Canada and Guatemala, both transnationally and locally - shaped the outcomes in these regards?

This study engages with an increasingly rich body of 'gender and migration' scholarship, that is, research on the multi-directional relationships between migration and diverse, multi-sited expressions of gender (e.g., Carling 2005, Piper 2005). This body of work is very instructive, and by examining the social implications of migration and 
attending to both women and men, provides an important counter-balance to the heavy focus in much work on male migrants and migration's economic impacts, wherein gender is not problematized. Within this area of investigation, literature specifically concerned with the independent ${ }^{2}$ migration of women or men and impacts on gender in households in the Global South has demonstrated a mix of promise and skepticism regarding whether migration promotes gender equality and alters patriarchal relations. It is within this broad area of inquiry that my dissertation sits. By facilitating, for instance, learning processes, skill-building, and the gathering of resources, women's and men's migration may contribute to enhancing the power and status of women vis-à-vis their husbands and fathers (José Alcalá 2006, Salazar Parreñas 2005). However, circumstances fostered by migration may well not encourage such outcomes, due in large part to the stalwart nature of gender ideologies (Boehm 2008) - including their transnational manifestations (Mahler and Pessar 2001) - and efforts of both women and men (both disparate and mutually-reinforcing) to uphold the status quo (Resurreccion and Van Khanh 2007).

Overall, the study that unfolds over the following chapters found much more continuity than change in gender relations of migrant-sending households, and I offer important substantive and theoretical insights into why this was so. I argue that in the wake of temporary labour migration to Canada, gendered divisions of household labour and authority remained relatively unchanged in most of the households in my study. I demonstrate that migrants' absences often impelled shifts in daily household practices and occasionally in gendered lines of authority - as Yaneth's comments illustrate above but that a 'return to normal' usually characterized household gender relations after

\footnotetext{
2 'Independent' here refers to situations where a migrant migrates without other household members, or if more than one household member migrates, they do not go together. The household remains anchored in the country of origin.
} 
migrants' return. I will highlight some exceptions that illustrated both a loosening and as with Gloria above - an intensification of gender divisions following migration. I contend and will show that conditions in Guatemala and Canada, as well as transnational processes, contributed to a relative maintenance of the status quo.

In relation to 'gender and migration' literature, itself diverse in terms of findings, the arguments made in this dissertation align with some studies while departing from others. My study offers contributions to this body of work and its sub-streams not so much by disputing particular findings as by addressing some of the gaps and weaknesses of other studies. First, this study examines the operation of gender both locally - in Guatemala and Canada - as well as in ways that transcend borders, thus responding to the need identified by Pessar and Mahler to examine "whether patriarchal ideologies and roles are reaffirmed, tempered, or both within transnational social spaces" (Mahler and Pessar 2001, Pessar 1999b:588). Second, seeking to counter-balance the overwhelming focus on migrants within this body of scholarship and relative neglect of other actors, my study responds to calls to better consider the challenges of and social impacts on nonmigrants, especially women (Hadi 2001, Munduate 2008). Third, 'gender and migration' scholars may be guilty of too much optimism about migration's promotion of gender equality (Loza Torres, Vizcarra Bordi and Lutz Bachère 2007, Pessar 1999b). My study contributes critical assessments by exposing the fault lines in the processes at work, and integrating into the analysis intersectional perspectives of oppression and privilege that complicate straightforward understandings of migration's 'impact' on gender relations. Fourth, seeking to go beyond a description of what happens during and after migration periods, my study contributes a needed dimension of explanation (Kunz 2008) by using theoretical insights as well as participants' experiences and perspectives to elucidate 
findings. Finally, my work makes two contributions to literature concerning labour migration to Canada in particular. Within highly gender-segregated migrant labour, scholars have tended to focus on women's experiences in female-dominated sectors, especially domestic work (e.g., Pratt 2004, Stasiulis and Bakan 2005). By focusing on male-dominated agricultural work, my study responds to contentions that the other end of the gender segregation spectrum is under-studied (Preibisch and Encalada Grez 2010). Second, within the limited but praise-worthy research on gender and agricultural work in Canada (e.g., Barrón 1999, Dunn and Gibb 2010, Preibisch and Encalada Grez 2010, Preibisch and Encalada Grez 2013), there is need to amplify the scant focus on Guatemalan migrants because their experiences in Canada and gender relations in Guatemala - often intersecting with indigenous identities - may be different than for Mexicans, for instance.

To make these contributions through the examination of the research questions outlined above, I have employed a theoretical framework moored in a structural understanding of gender, and ethnographic, feminist, and de-colonizing methodologies. Theoretically, I begin with the idea that gender is manifested at individual, ideological, and institutional levels of society (Risman 1998), and each of these shapes configurations of household gender relations. This study examines migration's influence on each of these three, specifically the gender habitus (Bourdieu 2001), gender consciousness (Sullivan 2004), and shifts in income generation (Vogler 1998). Transposed onto migration and transnational processes, I investigate shifts in gendered dispositions, gender-related social remittances, and - drawing on the resource theory of power - the impacts on household authority of economic remittances. Figure 1 on page 97 of Chapter 3 illustrates this overall framework. The integration in this study of a substantial 
theoretical component allows considerable explanation of the gender-related implications of migration, and a structural approach provides more insight than studies that follow a narrower conceptual 'avenue' (Risman 1998, Weinstein Bever 2002).

Methodologically, this study is based on considerable text-based research, but more importantly four months of fieldwork in Guatemala that entailed participant observation in an indigenous migrant-sending village, semi-structured interviews with migrants (married men, and married, single, and separated women) and non-migrating conjugal partners, as well as several organizational interviews, which were complemented by others in Canada. Based on both premises of patriarchal gender relations and attentiveness to the challenges posed by using Western feminist understandings in the Global South, my fieldwork espoused a critical and de-colonizing approach to feminist research (Martínez Salazar 2005, Mohanty 2003). The methodological value of my study lies particularly, first, in an analysis that engages emic with etic perspectives ${ }^{3}$ (Huberman and Miles 1998) - a joining of local understandings and my conceptually-informed approaches - to examine the issues at hand, and second, an attentiveness to and reflexive openness about the challenges of fieldwork, which will contribute to important dialogues among critical feminist researchers (Sprague 2005).

Although making several worthy contributions, this study does admit of some limitations, notably methodologically and analytically. First, it is a case study, and while valuable in drawing out important findings (Flyvbjerg 2001), delimited studies such as this, confined to a small sample of households in a specific, relatively homogenous community, cannot offer unqualified generalizations. Second, the study is not

\footnotetext{
${ }^{3}$ Emic perspectives are those espoused by cultural insiders or research participants themselves whereas emic perspectives derive from researchers' own understandings.
} 
longitudinal - it is situated in a snapshot of time - and relatedly is subject to considerable reliance on participants' memories (Coffey 1999). Third, because of constraints on my fieldwork process, I was not able to integrate non-indigenous or non-migrant households, which would have added worthwhile comparative elements. Fourth, although I address intersectionality in some ways, my study's entry point among social relations was gender, which likely resulted in missing ways in which other social axes - especially class and ethnicity - interacted with gender in the context of migration, and in under-recognizing the prevalence of these other axes of disadvantage in participants' everyday struggles. For instance, women's groups' activities suggested that, faced daily with poverty and financial uncertainty, women's primary acts of agency were not aimed at disrupting gender-based household inequality. Fifth, it is tempting to speak of migration's 'impacts' or 'outcomes' but there are methodological difficulties with seeking to isolate the effects of migration (Hadi 1999), given the host of other influences on household gender relations. Finally, although seeking women's experiences is inherent to feminist research (Sprague 2005), I somewhat problematically include fewer men's perspectives than women's because of the gendered work-related arrangements of daily life in my study community, but garnered considerable insight into men's lives and gender-related practices through interviewing women. Although I admit these limitations, the study that unfolds over the following chapters nevertheless makes sound and important contributions, and will inform further research.

This dissertation proceeds as follows. Chapter 1 introduces Guatemala through the lens of waves of migration, and describes the particular labour migration stream on which this study focuses. Chapter 2 details my conceptual approach to gender, agency, and intersectional understandings of gender in Guatemala, and by providing a historical 
substantiation of household gender relations there, with a focus on indigenous communities, outlines the ideological and institutional branches of my theoretical framework. Continuing with literature and theory, Chapter 3 situates this dissertation in 'gender and migration' and transnationalism scholarship, and elaborates a use of Bourdieu's gender habitus as my third theoretical tool, in conceptual collaboration with local and transnational 'fields'. I also map the resource theory of power and gender consciousness onto economic and social remittances respectively. Chapters 4 and 5 set the stage for addressing my research questions. Chapter 4 introduces the study region and community - Vista Hermosa ${ }^{4}$ - and describes my process of data collection and analysis. In so doing, it orients my fieldwork in its geographic and cultural setting and in literature on critical feminist methodologies, paying particular attention to de-colonizing approaches and reflexivity. Chapter 5 provides a picture of conventional gender relations in Vista Hermosa households so as to set comparators for my analysis, and sets the final contextual piece in place by detailing study participants' migration. The chapter demonstrates considerable gender-based division in household labour and authority although with elements of cooperation - and argues that economic necessity spurs migration to Canada but that gender influences migration decisions and patterns.

Chapters 6 to 9 address my research questions, focusing respectively on migrants' gender habitus, non-migrants' gender habitus, the resource theory of power and economic remittances, and gender consciousness and social remittances. Chapter 6 shows that despite considerable changes to their everyday reproductive and productive labour in Canada, migrants' gender dispositions did not shift much, with the exception of some migrant men returning to assist more with domestic work, and that economic and

\footnotetext{
${ }^{4}$ The village name is a pseudonym.
} 
ethnicity-based dispositions were perhaps more accentuated. Chapter 7 focuses on the daily lives of non-migrating members of transnational households, showing that they often undertook practices out of the ordinary for them - thus creating the potential for habitus shifts - but I stress the limits on women's spatial mobility and on men's 'gendercrossing' in particular. Chapter 8 argues that women generally did not assume greater household authority by virtue of either their migrant income or receipt of men's remittances, but there is greater potential in the latter circumstance. Moreover, I suggest that in a few cases, women's income-earning threatened men's masculinity and that men's migration intensified women's carework upon return. Chapter 9 engages in a three-step examination of the potential flow of gender consciousness as a social remittance, and argues that this was limited in large part because of migrants' restricted existence in Canada. I attend in each of these chapters to dynamics both during and after migration periods, and to explain the findings, I discuss both local and transnational influences and make use of Bourdieu's conceptual tools, which are valuable for explaining reproduction in social relations. That is the story that this dissertation overall presents - one of continuity and reinforcement - but I certainly illuminate limited instances where migration to Canada contributed to shifts in household gender relations. Chapter 10 recaps the main arguments, draws out key explanatory threads, re-visits the study's contributions, and suggests further research.

Next, I begin to set the context in place by providing an introduction to Guatemala and its waves of migration, and to the particular labour migration stream through which migrants in my study came to Canada. 


\section{Chapter 1 \\ Guatemala and Its Migrations}

A country of myriad contrasts, Guatemala boasts exceptional natural beauty and cultural richness, but is marred by a violent history, daily struggles for survival, and entrenched inequalities (Fischer and Benson 2006:91, Lovell 2000a, Martínez Salazar 2005, MENAMIG 2006). Guatemala is the largest and most populous and industrialized country in Central America, with a population of 15 million (Anderson 2003, INE 2011, Lindstrom and Muñoz-Franco 2005). In spite of a history of violence with "genocidal" aims (Nelson 1999:12), Guatemala's social landscape is a rich mix of four ethno-cultural groups - Maya, Ladino, Xinka, and Garífuna (Roncal and Ajquijay 2004:19). ${ }^{5}$ Of the three indigenous groups, Mayas ${ }^{6}$ are the largest by far, constituting approximately 60 per cent of the total population and 80 per cent of the rural population (Anderson 2003, Roncal and Ajquijay 2004). Ladinos are the population descending from colonial era 'mixing' of Spanish men and Mayan women and are generally considered nonindigenous. Revealing the attendant complexities, however, some Ladinos are "acculturated Indians" (Fischer and Hendrickson 2003:26), and the very idea and construction of 'mixedness' has been a topic of critique (Gould 1998, Hale 2000). ${ }^{7}$

Dating back centuries, migration is not a new phenomenon for Guatemalans

\footnotetext{
${ }^{5}$ I acknowledge that this presentation of four groups may simplify the complexities of Guatemala's social landscape (Fischer and Hendrickson 2003).

${ }^{6}$ For the purposes of this dissertation, the terms 'Maya' and 'indigenous' will be used interchangeably for ease of reference and to accommodate the interchangeability in the literature, although I acknowledge that Xinka and Garífuna groups are also indigenous. Nelson (1999) argues that in Guatemala, the term 'Maya' is used primarily to create and promote an identity for the purposes of social movements. As regards the term 'indigena' (indigenous), Maya-descendants are more likely to identify with their communities of origin, followed by their ethno-linguistic group, than they are to refer to themselves as indigena.

${ }^{7}$ Jeffrey Gould's work on ethnicity in Nicaragua shows that mestizaje (mixedness) figured prominently in dominant constructions of indigenous identity, and this "myth" (Gould 1998:ix) served to render indigenous peoples invisible, and thus their concerns and struggles not worthy of serious attention (Hale 2000).
} 
(Little 2005), and to frame the remainder of this introduction to the country, I outline three main 'waves' of human mobility and their surrounding circumstances: internal labour migration to plantation work, refugee movements during the civil war, and modern-day transnational migration (Montes 2009).

Life for the indigenous population after the arrival of the Spanish in the $16^{\text {th }}$ century was nothing short of a violent "destruction of bodies, cultures, built environments and bio-physical environments" (Martínez Salazar 2005:26) that set the stage for over 500 years of "new forms of the same injustices" (Anderson 2003:9). From the $16^{\text {th }}$ to $19^{\text {th }}$ centuries, Spanish colonizers imposed, although not without resistance, their economy, religion, culture, and ideology, exacting dramatic changes in indigenous ways of life (Fischer and Hendrickson 2003). Forced labour measures, fraudulent land claims, and mass relocation schemes resulted in considerable land loss for the Maya (Fischer and Hendrickson 2003, Martínez Salazar 2005, PNUD 2010), trends that continued well into the period following independence in $1821 .^{8}$ Ensuing liberal reforms that "consolidated Guatemala as a capitalist, racist, patriarchal nation-state" (Martínez Salazar 2005:58) entailed a focus on plantation agriculture. These developments gave rise, at the end of the $19^{\text {th }}$ century, to the first significant wave of post-'Conquest' migration in which thousands of increasingly impoverished, land-less or land-poor Maya migrated seasonally to Guatemala's coastal areas to work - often in indentured circumstances - on coffee, sugarcane, and tobacco plantations (MENAMIG 2006, Montes 2009).

The second major wave of migration came during the height of the 36-year civil war (1960 to 1996). Frequently referred to as la violencia (the violence) by those

\footnotetext{
${ }^{8}$ The official end of Spanish colonial rule came with independence on September $15^{\text {th }}, 1821$, and in 1825 came the first constitution of the State of Guatemala (PNUD 2010), followed by the country's establishment as an independent republic in 1839 (Grandin 2000).
} 
affected, the conflict has a complicated history, but stems in large part from the consequences of increased capitalist penetration by the United States in the early 1900s, most notably the United Fruit Company's (UFCO) expansion of land holdings and political-economic control (Martínez Salazar 2005, NISGUA 2009, Short 2007). Policies during the Ten Years of Spring from 1944 to 1954 challenged structures of land ownership, among other pro-poor measures that included more rights for workers in large-scale agricultural operations (Short 2007) and efforts to promote development through small-scale farming (Fischer and Hendrickson 2003). The response came with a coup in June 1954, backed by the United States government and fuelled by UFCO, followed by a string of brutal right-wing military governments (Fischer and Hendrickson 2003, Short 2007). A civil conflict 'formally' began in 1960, after a Marxist guerrilla resistance movement formed (la URNG) ${ }^{9}$ and was soon met with an armed counterinsurgency response (Anderson 2003, Nelson 1999). Efforts and resolve would escalate on both sides.

The horrifically violent, disproportionate measures enacted by the government and military at the height of the conflict - from the late 1970s to 1984 - involved scorched-earth attacks on Highland villages, massacres, and the 'disappearance' of tens of thousands of people (Nelson 1999). Believed to be communist enemies of the state (Martínez Salazar 2005), indigenous people represented the majority of the victims among the 70,000 killed, 40,000 'disappeared', and 1 million displaced in this period alone (Anderson 2003, Nelson 1999).

These massive displacements mark the second significant wave of Guatemalan migration, including internal migration to areas of the country less affected, and

\footnotetext{
${ }^{9}$ Unidad Revolucionaria Nacional Guatemalteca (The Guatemalan National Revolutionary Unity).
} 
international refugee movements, mostly to Mexico and to a lesser extent the United States and Canada (Montes 2009, Nolin 2006, PNUD 2008). Although la violencia disproportionately targeted the indigenous population - who made up 83 per cent of the total 200,000 lives lost (Martínez Salazar 2005) - liberal-minded Ladinos from civil society and academia were violently repressed and fled as well (Jeffries 2007). Many returned in the period leading up to and following the formal end of the war in 1996, and made important strides in rebuilding Guatemala socially and renewing spaces for proindigenous causes (Martínez Salazar 2005, Nelson 1999). However, and despite the "grand promises" of the Peace Accords, widespread violence, insecurity, racism, and inequality continue (Fischer and Benson 2006:91). Unions and civil society groups continue to face threats and violence (Avila 2013, Bevan 2013, Jeffries 2007, Jimeno 2001).

Added to the ongoing unrest in the present day are increasingly precarious economic situations for many Guatemalans. Although not in isolation from political insecurity (Menjívar and Agadjanian 2007), economic circumstances have in large part contributed to the third main identifiable wave of migration - transnational labour migration (Montes 2009) - particularly discernible since the 1990s. On the whole, "the meagre economic growth and the restriction of economic liberties of the majority of the population make up a socio-economic reality that pushes the Guatemalan population toward international migration" (PNUD 2008:22). Culminating in the present situation, a series of measures implemented since the 1950s in particular aimed at diversifying Guatemala's agriculture-dependent economy and generating economic growth have been less than successful at ameliorating poverty (MENAMIG 2006). Import substitution industrialization strategies in the 1950s and 60s (Fischer and Benson 2006) were 
followed by a crisis of poverty in the 1970s into the 80s (MENAMIG 2006), to which increasingly neo-liberal policies were seen to be the remedy from the late 1970s onward (Fischer and Benson 2006). Structural adjustment measures tied to World Bank loans from 1989 well into the 1990s involved trade liberalization, financial de-regulation, privatization, and contractions in public spending (Inter-American Development Bank 2007, Martínez Salazar 2005, PNUD 2008). In the 2000s, Guatemala has been increasingly open to foreign investment and export-led development (Fischer and Benson 2006, Little 2005, PNUD 2008). It has diversified its economy through expanding the export-oriented non-traditional agriculture and maquila (transnational factories) sectors in particular (Little 2005), and it signed the Dominican Republic-Central America Free Trade Agreement (CAFTA-DR) in 2006 (Inter-American Development Bank 2007). Despite generating employment, these latest strategies have mostly failed, with GDP per capita from the mid-1990s to mid-2000s decreasing by 0.4 per cent on average and jobs in transnational industries being hit by downward global trends (MENAMIG 2006). And amid the global recession in 2008-2009, economic growth fell due to declines in exports, foreign investment, and remittances, although recovery was discernible in 2010 (TaftMorales 2013). Adding to the difficulties, the potential in the Accord on Socio-Economic Aspects and the Agrarian Situation (Acuerdo sobre Aspectos Socioeconómicos y Situación Agraria), the longest of Guatemala's Peace Accords, has not come to fruition. It has been criticized for applying free-market principles to land reform (Gauster and Isakson 2008), and although it contained promising fiscal reforms (Spence and Vickers 1998), the Guatemalan government did not pass the tax-related regulatory changes needed to finance them (Tran 2011).

Guatemala continues to present a "national scenario with severe difficulties" 
(PNUD 2008:21). It is the second least-developed country in the Latin America and Caribbean (LAC) region, above only Haiti (UNDP 2012). In addition to income, the Human Development Index (HDI) considers indicators related to health and education. In 2012, Guatemala's HDI was .581, ranking it 133 of 187 countries. This HDI figure represents a 0.7 per cent increase between 1980 and 2012, but is considerably lower than the LAC regional average of .741. More than half of the population lives in poverty and 15 per cent live in extreme poverty (PNUD 2008, PNUD 2010). Guatemala's unemployment rate among the economically active population (EAP) stands at 3 per cent (INE 2013) (and it was allegedly 1.5 per cent in 2010, the year of my study (INE 2010)) but this figure hides the facts that approximately half the EAP is continuously underemployed (INE 2010, Rodríguez 2013) and that almost three quarters of employed Guatemalans work in the informal economy (PNUD 2010). Furthermore, half of workers earn less than the legal minimum wage, and the vast majority earn less than required for basic living expenses (PNUD 2010).

Behind these general indicators lie particular dimensions of inequality, especially along inter-related ethnic and rural-urban lines. Economic and political power in the country continue to be skewed in favour of Ladinos, making the country not just a poor but "impoverished one where wealth, land, and political power is concentrated in the hands of a non-Maya oligarchy" (Anderson 2003:10). An "ethnic group-cum-class" (Fischer and Hendrickson 2003:26) tends to control major government institutions, the military, and key economic sectors. Guatemala's indigenous population tends to fare worse in human development terms than Ladinos: "by virtually any indicator...Maya peoples make up the overwhelming majority of the Guatemalan poor" (Fischer and Benson 2006:52). Although the majority of Ladinos also live in poverty (Roncal and 
Ajquijay 2004), indigenous communities have higher rates of poverty, extreme poverty, illiteracy, and infant and child morality (Lindstrom and Muñoz-Franco 2005). In rural Guatemala, where most indigenous peoples live, poverty is more prevalent than in urban areas. Over 80 per cent of rural Guatemalans live on a daily income of less than US $\$ 2.00$ per day, and a quarter on less than US $\$ 1.00$ (Taylor, Moran-Taylor and Rodman Ruiz 2006). Explaining a lot about rural poverty, Guatemala has the most unequal land distribution in Latin America (Anderson 2003), with 60 per cent of arable land owned by a wealthy 2 per cent of producers and over 50 per cent of rural plots not being of sufficient size for subsistence farming (Taylor, Moran-Taylor and Rodman Ruiz 2006).

Thus, what emerges here is a picture of failed economic growth, lagging human development, and outright poverty for millions of Guatemalans, caused by a combination of land deprivation, unemployment, and insufficient wages (MENAMIG 2006), in which indigenous rural-dwellers have fared worst. In this context, many see international migration as the only option, as "a survival strategy that generates resources for sustaining poor families" (PNUD 2008:360). About 14,000 people emigrated from Guatemala in 2010 and 11 per cent of its citizens were abroad that year (Hernández 2011). Remittances are a mainstay of the Guatemalan economy, providing income of about U.S. $\$ 4$ billion annually (Banco de Guatemala 2013), and benefitting more than 30 per cent of the population (Hernández 2011). Over 95 per cent of Guatemalan emigrants go to the United States, often in an undocumented manner (Green 2009, Hernández 2011), followed by Mexico (Caballeros 2009) and more recently, Canada.

\section{Guatemalans' Migration to Canada}

The particular instance of Guatemalan labour migration examined in my study 
dates to 2003, in large part facilitated by shifts in Canada's Temporary Foreign Worker Program (TFWP), the overall regulatory framework and set of opportunities for international labour migration to Canada. As a whole, the TFWP reflects significant changes to Canada's immigration policies in recent decades. Successive governments, to a greater or lesser extent, have increasingly geared these policies toward economic benefits for Canada, and lessened commitments to family reunification and humanitarian classes of immigration. Furthermore, aimed at meeting employers' alleged labour needs in an expeditious manner, these policies have increasingly favoured 'temporary ${ }^{10}$ over permanent immigration channels, as evidenced in 2009 when, for the first time, the stock $^{11}$ of temporary foreign workers (TFWs) in Canada exceeded the number of new permanent residents (CIC 2013). Entries of TFWs in Canada fluctuate slightly each year, but have hovered recently around the 200,000 mark. In 2012, Canada admitted an alltime high of 213,000 TFWs, which represents a growth of 134 per cent compared to 2002, when just over 91,000 TFWs entered Canada (CIC 2013; CIC 2003).

Components of the TFWP are largely organized according to skill level ${ }^{12}-$ with important corresponding stratifications in rights and access to permanent residence (Nakache and Kinoshita 2010) - as well as occupation type, of which the Seasonal Agricultural Worker Program (SAWP) and the Live-in Caregiver Program (LCP) are examples. Prior to 2002, the TFWP was geared primarily toward high-skilled labour,

\footnotetext{
${ }^{10}$ Given employers' ongoing claims about labour shortages, many have alleged that these workers are 'permanently temporary' (Faraday 2012, Hennebry 2012). Citing unacceptable levels of unemployment among Canadians, especially young people, critics contend that labour shortages could be remedied by offering training programs and higher wages for work (McQuillan 2013).

${ }^{11}$ This refers to the number of TFWs present on December $1^{\text {st }}, 2009$, not the number of TFWs who entered Canada that year.

${ }^{12}$ Skill levels are classified according to the National Occupation Classification (NOC) system, used by Canada's federal government to categorize and stratify different types of employment.
} 
with the SAWP and LCP being the only streams for lower-skilled workers. ${ }^{13}$ Owing to pressure from Canadian employers claiming shortages of reliable and capable local labour in lower-skilled sectors not then included in the TFWP (Turbide 2010), the federal government introduced in 2002 the Pilot Project for Occupations Requiring Lower Levels of Formal Training (NOC C and D), often dubbed the Low-Skill Pilot Project (LSPP). The federal government introduced the LSPP initially to fill demands in the meat, construction, and tourism industries, but by 2003 had expanded it to other sectors, notably agriculture. This has been a boon to Canada's agricultural employers, challenged by the demands of an increasingly competitive globalized food supply system in which they need to minimize costs and retain flexibility in the management of their labour (Preibisch and Binford 2007, Preibisch 2010, Hennebry 2008). The particular avenue through which Guatemalans in my study came to Canada is no longer a pilot project; due to program re-structuring, ${ }^{14}$ they would be hired today through one of three new streams of the TFWP for agricultural workers (Employment and Social Development Canada 2013b). However, I will continue to use the LSPP terminology here, in keeping with the state of affairs during my fieldwork. For employers, the LSPP - compared to permanent immigration channels - was a far faster and soon more favoured way to remedy labour shortages and thus ensure the productivity or very survival of their operations. For Guatemalans, it would provide a hitherto unavailable opportunity to migrate to Canada.

\footnotetext{
${ }^{13}$ Under the NOC, skilled workers are grouped into levels $0, \mathrm{~A}$, and B, and low-skilled and unskilled workers categorized into levels $\mathrm{C}$ and $\mathrm{D}$.

${ }^{14}$ The first change of note was the inclusion in late 2010 of an Agricultural Stream within the LSPP, aimed at better aligning the working conditions and salaries between Temporary Foreign Workers in the SAWP and those in the LSPP (HRSDC 2010). In 2013, the 'pilot project' status was discontinued and four separate streams of the TFWP were established through which foreign agricultural workers can be hired: 1) the SAWP, 2) Agricultural Stream (for production on the National Commodities List), 3) Stream for Lower-skilled Occupations (for production not on the National Commodities List), and 4) Stream for Higher-skilled Occupations (Employment and Social Development Canada 2013a). For a comparison, see: http://www.esdc.gc.ca/eng/jobs/foreign workers/agriculture/comparison.shtml. Guatemalans could be hired through any stream except the SAWP, but most would enter through 2).
} 
Prior to the introduction of the Low-Skill Pilot Project, the long-standing Seasonal Agricultural Worker Program (SAWP), employing roughly 25,000 workers per year (CIC 2013), was the only formal avenue through which migrants could work in Canadian agriculture. However, it was, and continues to be, only available to workers from Mexico and a handful of Caribbean countries, based on bilateral agreements between the governments of Canada and these sending nations. In contrast, the LSPP was not based on bilateral agreements (Reed 2008), imposed no restrictions on countries from which employers could hire labour, and, as a further advantage for both employers and workers, did not limit work contracts to eight months. Initially, the LSPP permitted 12-month contracts (Canadian Bar Association 2006) but this was subsequently increased to 24 months (Fudge and MacPhail 2009). The federal and provincial governments according to their respective jurisdictions - have played regulatory, and to a lesser extent, enforcement roles in the LSPP (Reed 2008). However, this decided difference in the extent of formal government involvement and oversight, combined with significant employer direction and discretion, has drawn considerable attention from critics in both civil society and academia (Brem 2006, Flecker 2010, Fudge and MacPhail 2009, Preibisch 2010), including regarding Guatemalans' migration specifically (VargasForonda 2010a). The SAWP is certainly not immune from criticism (e.g., Hennebry and Preibisch 2010, Hennebry 2008) but its counter-part, the LSPP, has afforded workers even fewer rights and protections, which, critics contend, has contributed to rising levels of exploitation and a very precarious existence for them as TFWs (AFL 2007), subject to considerable employer authority and manipulation. Among the top concerns in these regards are employer-tied work permits and a complaint-based monitoring system in a context where employers have the almost unilateral right to repatriate workers at any time 
(Nakache and Kinoshita 2010). Overall, the imbalance between government and private sector control has some asserting that the LSPP (and its successors) constitutes a privatization of Canada's immigration policy (Gálvez 2010, Trumper and Wong 2010). In this critical vein, I have examined in recent publications Guatemalans' experiences of precariousness and alleged mistreatment, and of 'fighting back' through political mobilization (Hughes 2012, Valarezo and Hughes 2013).

Although the Guatemalans in my study came to Canada under the regulatory rubric of the LSPP and larger TFWP, the International Organization for Migration (IOM) played a key role. The IOM is an inter-governmental organization with over 150 member states that provides migration services and expertise to governments, and intergovernmental and non-governmental partners (IOM 2014). I discerned the following details through organizational interviews (Carrière 2010, Consular official 12010 , Consular official 2 2010, Cordero 2010, Field 2010, Turbide 2010) and available literature (IOM 2006, IOM 2008, Vargas-Foronda 2010b). The Government of Guatemala, wanting to send migrants to Canada, approached Canada in 2000 about a bilateral agreement, but Canada responded that it had laws in place that protected the rights of workers and therefore no special agreement was warranted (Cordero 2010), and furthermore, provisions of international trade law precluded such an agreement (Turbide 2010). ${ }^{15}$ The Government of Guatemala then approached FERME ${ }^{16}$ and FARMS ${ }^{17}$, private agricultural organizations in Quebec and Ontario that represent and assist

\footnotetext{
${ }^{15}$ The reason for this lies in the principle of non-discrimination in the General Agreement on Trade in Services (GATS) applying to World Trade Organization (WTO) members, whereby "no WTO member country is allowed to give preferential treatment in terms of trade in goods or services to another country" (Turbide 2010). In 1995, Canada released its relations with SAWP sending countries from this rule through the Most Favoured Nation (MFN) exemption, but no further exemptions have been allowed. As a result, Guatemala and Canada cannot establish a bilateral agreement on migration.

${ }^{16}$ Fondation des entreprises pour le recrutement de la main-d'œeuvre étrangère.

${ }^{17}$ Foreign Agricultural Resource Management Services.
} 
producers hiring foreign labour. These organizations were interested in Guatemalan labour, but it was soon acknowledged that Guatemala lacked the human resource and technical capacities to manage the sending of large volumes of migrants to Canada. With the idea that it would build its capacity to manage affairs at a later date, the Guatemalan government approached IOM-Guatemala, which initiated in 2003 the Temporary Agricultural Workers to Canada (TAWC) Project on the basis of a Letter of Understanding (LOU) with FERME. A subsequent LOU was signed in 2004 with FARMS, and the project was soon further expanded to Alberta and British Columbia. ${ }^{18}$ These LOUs established the bases of collaboration among the Canadian producer organizations, IOM-Guatemala, and the Guatemalan government, specifically the Ministerio de Trabajo y Previsión Social and Ministerio de Relaciones Exteriores (Ministries of Labour and Social Welfare, and of Foreign Affairs). The stated objectives of the project were to promote an "orderly and secure migration" (ostensibly contrasting with forms of undocumented northerly migration) that benefits both the sending and host country, and to improve the living conditions of the Guatemalan rural population through economic development (Cordero 2010, IOM 2006:7). The particulars of actors' involvement have subsequently changed somewhat, ${ }^{19}$ but as with the LSPP, my discussion of actors' responsibilities will be based on the arrangements in early 2010 .

The IOM adopted the leading administrative and logistical role in Guatemala, and the agricultural producer organizations coordinated most affairs in Canada. FERME and

\footnotetext{
${ }^{18}$ The involvement of Alberta and British Columbia producers was initially based on a partnership between IOM-Guatemala and the growers' association Western Agriculture Labour Initiative (WALI), but WALI no longer processes foreign worker applications and most employers in Western Canada now deal with the IOM directly.

${ }^{19}$ The IOM's role has changed recently with respect to migrant labour in Quebec. FERME has opened an office in Guatemala City to facilitate the migration of Guatemalans to Quebec and to some farms in Western Canada, without the assistance of the IOM.
} 
FARMS submitted requests for workers to the IOM on behalf of employers who had permission to hire foreign workers by virtue of positive labour market opinions from Human Resources and Skills Development Canada (HRSDC) ${ }^{20}$ thus confirming that employers had first sought Canadian employees. Western Canadian producers in British Columbia and Alberta contacted IOM directly. Meanwhile, the IOM regularly recruited and pre-selected candidates in Guatemala with agricultural experience - through regular visits of IOM staff as well as through contracted recruiters to villages and towns - and maintained a pool of workers to match to specific employer requests. The IOM also helped potential workers obtain requisite health tests and criminal records checks, filed workers' applications for work permits and Temporary Resident Visas with Citizenship and Immigration Canada (CIC) through the Canadian Embassy in Guatemala, and presided over the signing of labour contracts. The Guatemalan Ministries of Foreign Affairs, and Labour and Social Welfare played support roles, mainly in recruiting workers and reviewing proposed labour contracts. Finally, the IOM carried out predeparture orientation sessions and coordinated airport departures. When workers arrived in Canada, in the case of Ontario and Quebec, FARMS or FERME assumed responsibility for coordinating workers, while Guatemalan consular officials - principally in Vancouver and Montreal - offered support services.

Guatemalans participating in the IOM project worked in four Canadian provinces - British Columbia, Alberta, Ontario, and Quebec - in a variety of operations ranging from field crops to greenhouses to poultry farming, on contracts ranging from 4 to 24

\footnotetext{
${ }^{20}$ Human Resources and Skills Development Canada is now called Employment and Skills Development Canada. Also, in Quebec, because consent from the provincial government is also required in order to hire temporary foreign workers, the Ministère de l'Immigration et Communautés Culturelles is also involved in reviewing employers' requests for workers (Turbide 2010), and grants workers Certificats d'acceptation (Certificates of Acceptance).
} 
months. ${ }^{21}$ While working in Canada, Guatemalans were subject to and protected by provincial labour laws, such as those concerning minimum wage, occupational health and safety, and employment relations (i.e., unionization), ${ }^{22}$ however claims of labour law and contract violations are common and have arisen in both my study and others (e.g., Vargas-Foronda 2010b). Canadian employers hiring migrant labour through either the SAWP or the Agricultural Stream of the TFWP must pay at least the minimum prevailing wage rate (Employment and Social Development Canada 2013b). In 2010, in the four provinces where Guatemalans worked, hourly minimum wages were $\$ 8.00$ in British Columbia $^{23}, \$ 8.80$ in Alberta, $\$ 9.00$ in Quebec, and $\$ 10.25$ in Ontario (Canadian dollars) (Government of Alberta 2010).

At these rates and with sufficient work, labour migration to Canada has generally been economically worthwhile for Guatemalan migrants. They earn more in an hour in Canada than they would make in a day in waged agricultural work in Guatemala. While total earnings can vary widely, IOM sources indicate the net income figure to be at least CAD $\$ 1,500$ per month, coming out to $\$ 18,000$ in a 12 -month period (IOM 2006). However, Guatemalans incur significant expenses to work in Canada. Although employers pay for return airfare, each participant before departure has to pay for a Temporary Resident Visa application and work permit (CAD \$150) as well as medical testing, local medical insurance for family members, and an airport departure tax. Until later in 2010 , departing workers were also required to pay a USD $\$ 480$ deposit for each

\footnotetext{
${ }^{21}$ Among the changes to the TFWP since my research, effective April $1^{\text {st }}, 2011$, most temporary foreign workers (SAWP participants are excluded) are limited to four cumulative years of work in Canada, after which time they are ineligible to return for a subsequent four-year period (Government of Canada 2010).

${ }^{22}$ Workers do not fall under the same sets of labour laws in all provinces. For example, agricultural workers are covered under occupational health and safety legislation in Ontario and Quebec, but not in Alberta (UFCW 2010).

${ }^{23}$ It should be noted that British Columbia allows employers to pay agricultural workers by the piece instead of an hourly wage. See: http://www.labour.gov.bc.ca/esb/facshts/min-wage.htm.
} 
trip, refundable upon return under 'normal' circumstances. ${ }^{24}$ In Canada, workers pay for their food and, by law, a maximum of CAD $\$ 30$ per week for housing. Along with paying income tax, they also contribute to pension and employment insurance plans. ${ }^{25}$

Guatemalans' migration under the LSPP has grown significantly since a small group of 215 migrants (180 men and 35 women) went to Canada in 2003 (VargasForonda 2010b). In 2009, 3,800 Guatemalans arrived to labour in Canadian fields and greenhouses, followed by almost 4,300 in 2010 (CIC 2011). So significant is this growth that in 2010, Guatemala sent more workers to Canada under the LSPP than any other country. In terms of the composition of project participants, mirroring the facts that indigenous populations dominate among both the poor and rural farmers in Guatemala, the majority of participants are indigenous. Guatemalan women have accounted for between 3 and 5 per cent of total workers, depending on the year in question (IOM 2006, IOM 2008), numbering 170 in 2010 in agricultural occupations (CIC 2011). ${ }^{26}$

Having provided an introduction to Guatemala and its waves of migration, as well as the institutional and regulatory context of the labour migration in which Guatemalans in my study participated, I turn now to an examination of gender relations in Guatemala.

\footnotetext{
${ }^{24}$ The deposit was refunded unless workers had been repatriated for reasons having to do with their conduct or performance in Canada. After reassessing the TAWC Project amid growing political pressure and criticism, the Chief of Mission of IOM-Guatemala, Delbert Field, discontinued the deposit requirement. ${ }^{25}$ In a move much decried by migrant worker advocates, effective December 9, 2012, the federal government discontinued access to migrant workers' parental and compassionate care benefits through Employment Insurance while continuing to require that they pay into EI (Keung 2012).

${ }^{26}$ A limited number of Guatemalans working in Canada through the IOM project have worked in nonagricultural jobs, such as laundromat attendants (Consular official 1 2010, Field 2010).
} 


\section{Chapter 2}

\section{Gender, Intersectionality, and Indigenous Households in Guatemala}

This chapter provides a combined theorization and contextualized substantiation of household gender relations in Guatemala, with a focus on indigenous communities. By understanding the trajectory and principal shapers of Guatemalan gender dynamics, we can better ascertain what it is about migration that could contribute to changes and continuities. The chapter puts forward three main points. First, from a feminist perspective, gender relations in Guatemala are patriarchal - as they are globally, in different forms and to varying extents - but a solid understanding of indigenous women's lives, and their embedded agency, requires a recognition of intersecting social axes and forms of oppression. Second, non-Western and local perspectives on indigenous household gender dynamics must be recognized, both in attempts to de-colonize feminist research, and to better understand why women (and men) may not disrupt seemingly unequal gender relations. Third, recognizing that household gender relations must be historicized in order to be theorized, the chapter examines some of the key impetuses that have shaped those dynamics over time in Guatemala. The chapter integrates a conceptual approach to gender - including key concepts, and theory on change and continuity - with grounded examinations and examples from Guatemalan settings.

The first half of the chapter lays out my conceptual approach to gender, followed by a general look at patriarchy and its intersections with other social axes in Guatemala, and then I turn to the household level and illuminate how both Western feminist and local Guatemalan thinkers see indigenous gender arrangements in Guatemala. The second major section of the chapter examines key ideological and institutional shapers of indigenous household gender relations in Guatemala, and in so doing, lays out two pillars 
of my theoretical framework. I close with a discussion of women's embedded agency.

\section{Gender}

Based on extensive review of both gender theory literature and how the concept of gender has been deployed in migration research, this dissertation proceeds from a conceptualization of gender as ideological and structural, yet dynamic. I define gender as the socio-culturally constructed and ascribed characteristics, roles, and expectations for females and males in a society (Jolly and Reeves 2005, Luxton 2006, Riley 2008, Siltanen and Doucet 2008). In contrast to the biological basis of sex, gender is a social construct, one that describes, organizes, and prescribes the relational substance of femininity and masculinity (Boehm 2008, Luxton 2006, Perry 2001, Schiwy 2007). Because gender is not necessarily reducible to or derivative of biology (Bjerén 1997), the content of gender categories can shift and be defined otherwise, as history has demonstrated (Connell 2002, Siltanen and Doucet 2008). The mutability of gender is important for a project that investigates change and continuity in gender relations, and more generally because, from a feminist perspective, gender is tied up with power and is a key basis of relations of inequality (Cockburn 2001, Morgan 1999, Scott 1986, Wharton 2005). The foundations of inequality between gender categories are not entirely clear, ${ }^{27}$

27 Men's dominance may have originated as a way to transcend or make up for their alienation from the biological reproduction of human beings (O'Brien 1981, quoted in Scott 1986). Many arguments on this point, however, refer to shifts in modes of production. For instance, in the shift to plow-based agriculture, physically stronger men became more responsible than women for the provision of food, which accorded them more prestige (Wharton 2005). Men and their activities have become more highly valued than female ones because women became more dependent on men than vice versa for food and protection. More recently, with the rise of industrial capitalism, Parsons argued that men were assigned breadwinner roles because the fact of women's biological mothering was used to assign them to the domestic sphere (via VanEvery 1997). Breadwinning came to be seen as making a more important contribution to household sustenance; therefore, if breadwinning is defined as an element of masculinity, then masculinity - and men - are assigned more value. This can be contrasted with pre-industrial times when the household was the site of both production and reproduction and gender relations within families were more egalitarian, with less strict divisions or value assignments among the activities that males and females would engage in to support the family unit. Problematically, however, all of these possible explanations directly or indirectly 
but this dissertation proceeds from the assumption that masculinity and males are virtually universally privileged (i.e., receive greater legitimacy and rewards) over femininity and females (Lamphere 2007, Lindsey 1994). Although gender is such a key ordering principle in society (Connell 2002), the instantiations of inequalities that it creates are not uniform (Chodos and Curtis 2002, Siltanen and Doucet 2008), a point to which I will return.

\section{Gender in Guatemala: The Big Picture}

Such inequalities emerge in a big-picture perspective on the gender order (Connell 2002) in Guatemala. It will be emphasized and demonstrated below that generalizations in these regards hide significant differences among Guatemalan women and men owing to their multiple forms of relative oppression and privilege, based in their social locations. However, Guatemalan scholars and Guatemalan women's/feminist $\operatorname{organizations}^{28}$ generally agree that an overarching patriarchal system characterizes Guatemala (Martínez Salazar 2005, Menjívar 1999, Sector de Mujeres 2011, Tierra Viva N.d.). Patriarchy describes a social system of male dominance or authority over women, which manifests in both domestic and public spheres, and through various avenues, particularly men's control over women's labour power and sexuality (Chant and Craske 2003, Connell 2002, Luxton 2006, Walby 1989). ${ }^{29}$ Examples of patriarchal relations in Guatemala include sexist and misogynistic elements of major institutions (Martínez

root gender inequality in biology, such as men's physical strength or women's biological reproduction capabilities.

${ }_{28}$ Because of perceived problems with feminism, especially in its radical or Western forms, not all women's organizations in Guatemala identify as feminist (Cumes Jochola 2010), but for the ones that do, the feminist label is important to their identity and objectives. Hence, the need arises for differentiation when referring to organizations in Guatemala fighting for women's interests, within the broader women's movement.

${ }^{29}$ Debate continues over the origins of patriarchy, and the related extent of inter-dependence between capitalist and patriarchal relations. See, for instance Hartmann (1981), Scott (1986), and Walby (1989). 
Salazar 2005), specific ‘public morality' laws that limit women's opportunities (Carey 2008b), various forms of gender-based violence (Carey and Torres 2010, Kanakarajavelu 2010), men's honour-based vigilance over women in their households (Carey 2008a), restriction of women's work outside the home (Menjívar 1999), and their relegation to the domestic sphere (Taylor, Moran-Taylor and Rodman Ruiz 2006). Although Guatemala is overall characterized by these forms of male dominance and authority, the "local expression varies according to different contingencies" (Menjívar 1999:89), including the specificities of particular contexts, and the relative positioning of women and men according to the numerous axes of their social locations (Hartmann 1981, Martínez Salazar 2005, Taylor, Moran-Taylor and Rodman Ruiz 2006). Patriarchy is an always changing - and contested - social formation (Hartmann 1981), as the last section of this chapter will show by tracing some of the key moments in the entrenchment of patriarchy over Guatemala's history.

In addition to the examples from the literature provided above, elements of patriarchy in Guatemala can be discerned through gender-related human development indicators that demonstrate ongoing disparities between females and males (although the particular nature of these inequalities differs among ethnic and socio-economic groups). While Guatemala's constitution grants formal equality of rights and opportunities to women and men (Congreso de la República de Guatemala 2008, MENAMIG 2006, SEPREM 2009b), substantive equality continues to prove elusive for women. Women score lower than men on measures of literacy, educational enrolment, and income, and suffer deficiencies in indicators of empowerment, such as economic and political participation, decision-making, and ownership and control over resources, including land 
(UNDP 2009a, UNDP 2009b, UNDP 2010, USAID N.d.). ${ }^{30}$ Although no law restricts women's access and rights to land, land ownership in Guatemala is significantly skewed toward men, owing in large part to patriarchal and patrilineal customs (Fischer and Hamilton 2005). According to the UNDP's latest Human Development Report, the ratios of women to men with at least secondary education was 0.742 and of women to men aged 15-64 in the labour force was 0.555 , and women held 13.3 per cent of seats in parliament (UNDP 2012). ${ }^{31}$ (To add some context, the latest available rate of total adult literacy was 75 per cent, and of the total population with at least secondary education was 14.8 per cent (UNDP 2013)). Compared to Mexico and the six other Central American countries, Guatemala ranks in the bottom three on each of these three gender-based indicators, and worst among these countries on the Gender Inequality Index, which reflects women's disadvantage in reproductive health, empowerment and economic activity.

These and other indicators demonstrate that women's condition in Guatemala could be described as one of a spectrum of violence that takes many forms (Cockburn 2001, Martínez Salazar 2012, Menjívar 2008), of which structural (Galtung 1985) and inter-personal dimensions are the most apparent. Revealed by some of the UNDP indicators mentioned above, structural violence describes the largely invisible constraints on agency and the "unequal life chances" (Menjívar 2008:14) caused by the uneven

\footnotetext{
${ }^{30} 2009$ seems to be the most recent year in which the UNDP's Human Development Report (HDR) contained the Gender-related Development Index (GDI) and the Gender Empowerment Measure (GEM). See more on this at: http://hdr.undp.org/en/statistics/indices/gdi_gem/. Subsequent HDRs have used instead the Gender Inequality Index (GII), from which the following 2012 statistics derive. For information on how the GII is calculated, see http://hdr.undp.org/en/media/HDR 2012 EN TechNotes.pdf.

${ }^{31}$ Despite nearly trebling women's representation in its Congreso between 1980 and 2012, Guatemala is among the poorest performers in the LAC (Latin America and Caribbean) region in these regards (Malik 2013, Piscopo 2006). Aimed at enhancing both women's political participation and public policy, gender quotas in legislatures in have been increasingly on the agenda in the LAC region since 1990 (Chant and Craske 2003, Piscopo 2006, Schwindt-Bayer 2011). However, Guatemala does not yet have quota legislation (Piscopo 2006), and moreover, the relative weakness of its legislature versus its executive and military powers (Spence and Vickers 1998) and weak democracy in general, draw into question whether Guatemala would meet the stated goals of gender quotas.
} 
distribution of power and various resources (Cockburn 2001). Among manifestations of structural violence, poverty affects Guatemalan women disproportionately (Blacklock 1996, Sector de Mujeres 2011). Of total income earned from employment in Guatemala, nearly three quarters -72.2 per cent - goes to men (UNDP 2012). ${ }^{32}$ Added to structural disadvantage are various types of inter-personal violence against women (Moser and McIlwaine 2004, SEPREM 2009a). A "constitutive - rather than aberrant - feature of the social fabric" (Carey and Torres 2010:144), it is the most-reported human rights violation in the country (PDH 2011). Exceedingly low levels of investigation and punishment exacerbate high incident rates ${ }^{33}$ (Carey and Torres 2010, Jeffries 2007, Kanakarajavelu 2010).

Although it is acknowledged that on the whole, women in Guatemala live in unequal relations with men, gendered conditions in Guatemala are made far more complex by intersecting axes of social differentiation (Martínez Salazar 2005, Martínez Salazar 2012, Menjívar 2008). Intersectionality is an aspect of lived experience and social relations, as well as a conceptual orientation and tool of analysis, that aids in understanding the complexity and specificity of oppression and/or privilege (Cook 2007, Stasiulis 1999), and the "mutually constitutive character" of gender, race or ethnicity, class, and other social divisions (Perry 2001:7). In Chapter 4, I discuss how I employ intersectionality methodologically in this study. For the purposes of theory for this gender-centred analysis, I recognize the cultural, social, and historical specificities of

\footnotetext{
${ }^{32}$ The feminization of poverty in Guatemala has many contributing factors rooted in gender, such as disproportionately negative effects on women of economic reforms, and lack of income-generating options (Blacklock 1996, Sector de Mujeres 2011). It is important to see such disadvantages among women as structural, as derived from the gendered political-economic organization of society and often from systemic exploitation (Menjívar 2008, Pine 2008).

${ }^{33}$ Femicide numbers, for instance, are shocking and abhorrent: over 5,000 women and girls were murdered in Guatemala between 2000 and 2010 (Carey and Torres 2010).
} 
gender relations (Hurtig, Montoya and Frazier 2002), the classed, racialized, and sexualized construction of gender (Perry 2001), and gender's interactions with other social relations of power in the creation of overlapping forms of oppression and privilege (Hill Collins 2000, McCall 2005, Preibisch and Encalada Grez 2010).

In the Guatemalan context, gender both shapes and is shaped by experiences of race/ethnicity and class, in particular, but also religion (Metz 2001, Whiteford 2002) and sexuality (Carey 2008a). This results in mixed identities (Stern-Petterssen 1997) and the experience of multiple forms of oppression or insecurity, deriving from patriarchy, racism, and capitalism in particular (Carey 2006, Cumes Jochola 2010, Martínez Salazar 2005, Menjívar 2008, Sector de Mujeres 2011, Stern-Petterssen 1997, Tierra Viva N.d.). Within these structures, rural, indigenous Maya women are Guatemala's most disadvantaged and marginalized citizens (Martínez Salazar 2005), with indicators of poverty, land ownership, and access to health care being just a few examples (Kachika 2012, The World Bank 2004). Martínez Salazar examines the multiple axes of social inequality experienced by Mayan women that have constructed them as the "dehumanized other" (2005:iv), and I explore more of this history in the last section of this chapter. At this point, I note that gender inequality in Guatemala is part of a wider system of social relations, and that Guatemalan women and men experience patriarchy in distinct ways because of gender's intersection with other axes of differentiation.

\section{Gender in the Household}

Let us now bring this examination closer to the level of gender in Guatemalan households. Because of the pervasiveness of gender as an organizational principle, as a property of entire social formations (Morgan 1999), I follow those scholars who 
conceptualize gender in terms of a multi-levelled structure (Risman 1998, Sullivan 2006).

That is, the patterned forms or manifestations of gender (Connell 2002) are found at different levels of society: in individuals, interactions, ideologies, and institutions (Risman 1998, Sullivan 2006). The gender structure is integral to my theoretical framework, and I will return to how specifically I relate this to circumstances of migration. For now, I focus on the institution of the household, where, along with others such as the state and labour market, we can see the embeddedness of gender in rules, customs, and behaviours (Riley 2008). A term often used interchangeably with 'family' but conceptually different, ${ }^{34}$ I proceed from the definition of a household as a unit of coresidence, characterized by members who are usually but not exclusively related by blood or a conjugal relationship, and designated by certain functions oriented toward the wellbeing of its members (Bjerén 1997, Chant and Craske 2003, Koch 2001, McKie, Bowlby and Gregory 1999, Morgan 1999). This definition becomes less stable when migration creates a transnational household (Fouron and Glick Schiller 2001, Salazar Parreñas 2005). I will be focusing on groups of individuals whose normal and intended arrangement is to constitute a household in Guatemala. I will provide more precise delineations in Chapter 5 of household arrangements in my study community.

Although not unproblematic, ${ }^{35}$ a focus on the household in gender research is

\footnotetext{
${ }^{34}$ The term 'household' tends to be used interchangeably with 'family' because the two often overlap (McKie, Bowlby and Gregory 1999), but they do conceptually differ. A family is a group of people, usually related and/or committed to each other by blood, marriage/union, or adoption, and defined through functions of reproduction (Chant and Craske 2003), but they may not live in the same residence. In short, Bjerén (1997) describes the family in terms of kinship and the household in terms of functions. The intertwining of the two entities is visible when, for instance, members of the same family live in different households, and when social expectations about family relationships exert normative pressures on intrahousehold dynamics (McKie, Bowlby and Gregory 1999). As will be demonstrated in my analysis chapters, family relationships that spill outside of the household (e.g., parents and in-laws) are pertinent to my project.

${ }^{35}$ See further discussion by Carling (2005), Bjerén (1997), and Koch (2001) (2001) on why the household concept may be problematic, even ethnocentric.
} 
beneficial because it provides a fairly tidy unit to frame the analysis and it is one of the main sites, if not the primary social arena, where gender and its attendant inequalities are shaped and made manifest (Bourdieu 2001, Koch 2001, Luxton and Fox 2009, McKie, Bowlby and Gregory 1999, Morgan 1999, VanEvery 1997). We see therein, in many societies, a "model of traditional gender relationships with its enshrined pattern of the male as the head of the household and the female as homemaker" (Riley 2008:3). Such patterns exemplify household gender relations, the key object of analysis in this dissertation, which I define as the gender-based and power-laden arrangements of certain practices integral to how a household operates (Connell 2002, Morgan 1999). Gender relations can be delineated according to different dimensions (Connell 2002) ${ }^{36}$, but in relation to the household, I will be focusing on how gender manifests itself in both production and (inherent to production) power dimensions. Presently, I will outline what forms these elements take in Guatemalan households, but I continue briefly here with a conceptual overview.

The production or labour dimension of household gender relations concerns the performance of tasks integral to household maintenance, and who is responsible for them. Directly related to production because of the unequal values attributed to the performance of those tasks, power or control dimensions of household gender relations concern how authority is assigned and expressed (Connell 2002, Connell 1987, Risman 1998). The

\footnotetext{
${ }^{36}$ In an earlier work, Gender and Power (1987), Connell confines the dimensions to three: labour, control, and cathexis. I draw on a combination of these, and the four dimensions of the 2002 work, Gender. Emotional relations encompass types of affect and attachment among household members, including those expressed through sexuality (Connell 2002), as well as who has the responsibility for "keeping feelings alive and in check" (Risman 1998:105). Symbolic relations, drawing on insights from post-structuralism and symbolic interactionism, include the "world of meanings" (Connell 2002:65), discourse and language, and symbolic elements through which gender is expressed and enacted. While acknowledging the presence of emotional and symbolic aspects, in conceptualizing and analyzing household gender relations for this project, I focus on Connell's other two dimensions: production or labour, and power or control.
} 
production dimension is expressed most fundamentally in the gender division of labour, the partition of responsibility - if not always performance - between males and females of household-related tasks (Doucet 2009b, Luxton 2006, Ravanera, Beaujot and Liu 2009). This division is most often formulated along the lines of the type of labour reproductive or carework (feminine) versus productive or income-earning (masculine), and/or corresponding locations - private or domestic (feminine) versus public (masculine) (Cott 2009, Crompton 2006, Luxton and Fox 2009). When subjected to empirical scrutiny, these 'separate spheres' (Gazso-Windle and McMullin 2003) often break down, ${ }^{37}$ but these ways of interpreting households' production dimension continue "to be central in how many Guatemalans organize their daily realities and spaces" (Taylor, Moran-Taylor and Rodman Ruiz 2006:55).

Corresponding with the gendered division of labour in households, and indeed integral to creating and maintaining the divisions (Lindsey 1994), is an attendant "gender power dynamic" in households (Riley 2008:3). In patriarchal arrangements, while the distribution and exercise of power is not always clear-cut or uncontested (Carter 2004, Lamphere 2007, Morgan 1999), male household members have disproportionate say and control. Males' disproportionate power stems in part from the fact that gendered male contributions to the household are afforded more value societally than females'. Men's household authority manifests in myriad ways, of which I will be focusing primarily on decision-making and financial management.

Although this conceptual overview has drawn on generalizations that research has

\footnotetext{
${ }^{37}$ This is because of significant nuances within categories (Carter 2004), and because of discord between the actual performance of tasks and the normative gendering of them (Doucet 2009b, VanEvery 1997). Furthermore, there would be generation-based variations in which younger women may be more likely than their mothers and grandmothers to work outside the home.
} 
demonstrated to have widespread application, household gender relations must be specified and historicized in order to be operationalized empirically. I now turn to examining gender relations in Guatemalan households in more detail.

\section{Household Gender Relations in Guatemala: Intersectional Patriarchy}

To the extent that it is possible to generalize about present-day household gender relations in Guatemala - given differences arising from gender's intersectional character - they are patriarchal from most feminist perspectives, including Guatemalan (Blacklock 1996, Martínez Salazar 2005, 2012, Montes 2013). This is evidenced by domestic violence against women that crosses all social divides (Carey and Torres 2010), a gender division of labour not unlike that described above in reproductive-productive and domestic-public terms (Blacklock 1996, Montes 2013, Montes 2009, Palma Ramos 2004, Taylor, Moran-Taylor and Rodman Ruiz 2006), and men's disproportionate ${ }^{38}$ authority in the household, especially over finances (Carter 2004) and final decisions on certain family issues (Becker, Fonseca-Becker and Schenck-Yglesias 2006). Although Guatemalan women have taken part in economic activities in 'public' places for centuries (2008a, Carey 2008b), and increasingly entered income-generating work outside the home in recent decades (Blacklock 1996), ${ }^{39}$ these engagements could be interpreted as part of women's responsibilities for the "reproduction of the family as a social unit" (Blacklock:67), while men remain primarily responsible for economic provision. Taylor et al. (2006) agree that women's movement into public spaces for education and paid

\footnotetext{
${ }^{38}$ Although studies on household decision-making in Guatemala by Carter (2004) and Becker et al. (2006) demonstrate that household authority is disproportionately in men's hands, the relative weight of women's and men's say in decision-making depends on the issue at hand. For instance, it is more likely that women will have a considerable or even final say in decisions relating to food purchases (Carter 2004) and what to do if a child is ill (Becker, Fonseca-Becker and Schenck-Yglesias 2006).

${ }^{39}$ On the surface, this income generation puts women into the public sphere, but Guatemalan women often understand this extra-household work as integral to their family roles, and thus pertaining to the private sphere (Blacklock 1996).
} 
work have contributed to an erosion of gendered spatial divides, but emphasize that women continue to bear disproportionate responsibility for unpaid care work, whether or not they engage in income-earning activities. ${ }^{40}$

This is revealed by Guatemalan household surveys. Women spend more time than men on domestic or unremunerated tasks, and a considerably lower percentage of women than men perform paid work (29 versus 72 per cent) (Palma Ramos 2004). Similarly, the UNDP (2010) found that Guatemalan women ${ }^{41}$ do on average two hours more work per day than men, and of their total working hours, only 18.5 per cent are paid, whereas this figure is 69.6 per cent for men. In terms of power, because of these arrangements, women have less access to and control over financial resources than men (Palma Ramos 2004).

Although this survey and other research demonstrate the tendencies and proportional divisions characteristic of household dynamics in Guatemala, generalizing in this regard is further complicated by the ways in which gender intersects with other social axes that bear on labour and power arrangements in Guatemalan households. These give rise to considerable differentiations among them according to their ethnocultural, socio-economic, religious, and residential (i.e., rural versus urban) configurations. When gender relations constitute the focus of analysis, it seems that race/ethnicity - understood mainly as divisions between Ladino and Maya-indigenous groups, notwithstanding smaller Xinka and Garífuna minority indigenous groups - and to a lesser extent socio-economic status receive the most attention for the ways in which

\footnotetext{
${ }^{40}$ Although evincing change over time toward less rigid gendered models (e.g., Sullivan 2006), we observe similar patterns in many Western countries as well.

${ }^{41}$ Individuals represented in the study were those over 12 years of age, whether or not they did both paid and unpaid work.
} 
they may condition household gender relations and experiences of patriarchy in Guatemala (e.g., Carter 2004, Lindstrom and Muñoz-Franco 2005, Menjívar 1999, Menjívar 2006).

Demonstrating the influence of both ethnicity and poverty on issues of women's reproductive and sexual rights, Mayan women's higher fertility rates and resistance to use modern contraceptives compared to Ladina women may be explained, among other factors, by both higher poverty levels and beliefs that Ladinos may encourage contraception in an effort to curb the Mayan population (Lindstrom and Muñoz-Franco 2005, Metz 2001). Regarding ethnicity specifically, research sometimes compares gender dynamics of indigenous and Ladino households. In her study on household authority in Guatemala, Carter (2004) found that male sole authority was more likely to be found in indigenous than non-indigenous households, whereas Carey (2006) cites studies suggesting a high degree of independent household-related decision-making by indigenous women. Focusing on the division of labour, studies by Menjívar (1999, 2006) reveal less rigid gendered divides in indigenous households, rooted in beliefs on the part of both partners that women's work outside the home is acceptable and desirable. Just below, when I explore emic and non-Western perspectives on indigenous household gender relations, I outline some of the possible reasons given to account for these differences.

\section{Contestation of the Gender Inequality Characterization}

Although many scholars, Guatemalan academics, and Guatemalan women's/feminist organizations tend to describe indigenous gender dynamics in terms of patriarchy and inequality, at least in part (Carey 2006, Cumes Jochola 2010, Metz 2001, 
Similox 2010), it must be acknowledged that not all perspectives characterize those relations in equality terms at all. An important aspect of a de-colonizing (Mohanty 2003) or anti-imperial (Russo 2006) approach to feminist research is to see and consider emic perspectives, including those of people under study (Metz 2001, Shih 2002) and local critical thinkers (Martínez Salazar 2012). This increasingly acknowledged requirement of sound and ethical research stems from the recognition of the harms (or at least lack of benefits) that Western research has brought to indigenous populations (Tuhiwai Smith 1999), and that feminist research may impose Western viewpoints (Davis 2002, Mohanty 2003).

Here, I examine the contentions that it is inappropriate to apply Western feminist ideas to understand Maya lifeways, that their gender relations are not unequal but complementary, and to the extent that they are unequal, that gender may not be the most felt form of oppression. To begin, Mayan Guatemalan Rosa Pu Tzunux (2007) argues that to analyze Mayan gender relations from the categories prominent in Western feminism gives rise to inaccurate conclusions about Mayan women's reality. The Maya, she says, organize gender relations according to values of their Cosmovision, ${ }^{42}$ notably 'the collectivity' (Martínez Salazar 2012), equilibrium, and complementarity. Domestic patriarchy can be understood as the fulfillment of social roles for the collective good, roles "most important for maintaining the equilibrium between the family and society" (Pu Tzunux 2007:88). Relatedly, woman and man are separate individuals but "neither the woman nor the man... can be conceived of in an independent way" (Pu Tzunux

\footnotetext{
${ }^{42}$ A Cosmovision can be described as the understanding that a group has about the world (Roncal and Ajquijay 2004). The Maya Cosmovision is "an epistemology based on a set of philosophical, social, economic, political, and spiritual principles, the main axis of which is the articulation of the human and non-human worlds without any supremacy allocated to humans" (Martínez Salazar 2012:17). The Cosmovision is laid out in the writings of the Popul Vuh and conveyed inter-generationally through oral traditions (Fischer and Hendrickson 2003, Roncal and Ajquijay 2004).
} 
2007:24). She contrasts these ways of thinking with Western feminism's emphasis on individuality and rights (Pratt 2004), understandings that have informed the mainstream Guatemalan women's movement. She criticizes the tendency of Western feminism to universalize and impose its ideas, without sufficient research or understanding: "they deny the other, denounce it, qualify or disqualify it, in order to impose what they consider to be universal human values" ( $\mathrm{Pu}$ Tzunux 2007:82), critiques echoed elsewhere (Mohanty 2003, Shih 2002).

$\mathrm{Pu}$ Tzunux calls our attention to Western feminist tendencies and incongruities in understanding. Certainly her perspective seems incommensurate with many Western feminist assessments such as those that characterize Guatemalan women's lives as a "vortex of violence" (Carey and Torres 2010:142), although Western feminists could be accused of erring in their tendency to use Western ideas and practices as the standard. However, Pu Tzunux takes a cultural essentialist approach (Jaggar 1998) that is also problematic. Such an approach exaggerates the extent to which Maya culture has remained isolated from Western influences, and she falls too much into cultural relativism wherein "everything depends on the perspective from which things are seen" (Pu Tzunux 2007:76). Also problematically, she offers little possibility for engagement between Western feminist and Mayan perspectives. Below, after outlining the other two points contesting a gender unequal characterization of indigenous households, I speak to how we might respond to $\mathrm{Pu}$ Tzunux.

Related to Pu Tzunux's arguments is the contention that indigenous Guatemalans see their household gender relations in terms of complementarity, not equality (Bachrach Ehlers 1991, Carey 2008a, Carey 2006, Chant and Craske 2003). Carey notes through oral histories that while women and men "operate in separate social structures and under 
distinct cultural configurations," both are recognized as vital to mutual survival (2006:14). Carey stresses that the fact that men may not assist women with domestic tasks does "not detract from their perceptions of complementary gender roles" (2006:103), i.e., it is not seen as inequality. Inherent in this characterization of complementarity is a significant valuing in Maya culture of the work of various types that indigenous women do. While women's income-earning is generally accepted and appreciated, their reproductive work is held in high esteem, likely stemming from cultural values of work ethic and diligence (Carey 2006) and the importance assigned to the feminine principle in the Maya Cosmovision (Martínez Salazar 2012). Owing to this valuation, the domestic sphere is a space for women's exercise of power (Pu Tzunux 2007).

The third point in relation to emic perspectives is that, if one does look at inequality or oppression in relation to indigenous households, gender may not be the primary felt root of disadvantage (Carey 2006, Martínez Salazar 2005, Martínez Salazar 2012). This was one of the primary contentions raised by Black and other women of colour in the 1970s in response to Western (read: white, middle-class) feminism (Hill Collins 2000, Stasiulis 1999, Walby 1989); the dominant feminist movement tended to homogenize women and problematically analyze social life from the perspective of a single basis of power. Although often an instantiation of gender inequality, a household can simultaneously be a site of reprieve and relief from racist or ethnic oppression (Stasiulis 1999). Indeed, indigenous women in Guatemala tend to conceptualize their subordination in ethnic rather than gender terms (Carey 2006) and to feel racism as most central to their collective struggles (Martínez Salazar 2012), while at the same time being overwhelmingly poor. As a result, indigenous women are "subordinated to the state, Ladinos, and Mayan men but in different places, at different times, and in different ways" 
(Carey 2006:6).

The key point here is that women's relations with Mayan men in their households may not constitute their primary or even conscious concern. To focus singularly on gender inequality may not correspond with women's concerns, may result in seeing women in the Global South as "oppressed by their cultures" and in need of 'saving' (Martínez Salazar 2012:11); Martínez Salazar argues that the 'gender equal/gender unequal' binary has facilitated the justification of "genocides, wars, and imperial invasions in the name of liberating non-Western, Brown, Black, and Indigenous women" (2012:11). Furthermore, such analysis may erroneously suggest that women in the Global North have reached an acceptable level of gender equality (Mohanty 2003, Shih 2002) when in fact we have a long way to go, as Canadian feminist scholarship continues to make clear (e.g., Bezanson and Luxton 2006, Luxton 2009, McInturff 2013a, McInturff 2013b).

So, how does one proceed with a conceptualization and analysis of indigenous household gender relations in Guatemala given these three points contesting a gender inequality characterization? I explore and reflect on this further in more detail in Chapter 4 (methodology), and my analysis in Chapters 6 to 9 attends to particular cultural specificities and understandings that illuminate why migration dynamics affect household gender relations in my research community in the ways that they have. This approach responds to Shih's urging to try to adopt a "politics of partiality" (2002:119), to situate oneself in the Other's position and use their knowledge. On a descriptive and conceptual level, I view indigenous household gender relations as patriarchal, in the sense that the masculine and feminine are unequal in their symbolic and material values. I take note of the Maya Cosmovision's emphasis on complementarity and the valuing of women's work, 
but these principles do not mean that gender relations have been historically equal in terms of proportionate values assigned to the masculine and feminine, or in accompanying access to resources (Similox 2010); in short, gender role complementarity may well adhere to patriarchal principles (Carey 2006). Furthermore, by attending in the following section to how indigenous lifeways have been violently transformed by a host of patriarchal political, economic, and religious influences over the centuries, I demonstrate that indigenous women are not simply oppressed by their culture. Moreover, if women do not recognize gender inequalities in their lives, this may stem from symbolic violence, from a mis-recognition of how larger sets of social relations are organized (Bourdieu 2001, Menjívar 2008, Peláez 2010) as well as from their focus on perceived basic necessities, which may not include struggling against gender-based subordination (Jaggar 1998). Finally, in relation to Pu Tzunux's arguments and the legitimacy of my critical perspective as an outsider, I draw on Alison Jaggar's work on the challenges of critiquing "local norms" (1998:8) in the interests of a globalized feminist ethics. Locating debates such as this within relations of power to legitimize certain discourses over others, Jaggar in part legitimizes Pu Tzunux's view. Marginalized groups of women may have well-reasoned rationales for trying to exclude certain topics from more powerful outsiders' critical scrutiny, and cultural relativism "may be a means of expressing resistance to cultural imperialism" (1998:20). However, a "global feminist discourse" (1998:27) requires that any perspective of a 'closed community' undergo a further step of moral evaluation. Integral to this is a recognition that insiders do not hold exclusive evaluative privilege and "outsiders' concerns about the situation of women in specific cultures are not necessarily illegitimate" (1998:20). Furthermore, there are different types of outsider intervention: "raising questions about the moral justifiability of foreign 
practices is very different from peremptorily condemning those practices, let alone intervening unilaterally to change them" (1998:21). I certainly do not aspire toward the latter two purposes.

In moving forward here, I follow the example of scholars such as Martínez Salazar who recognizes patriarchy among indigenous Guatemalans while being sensitive to intersectionality, specificities, and historical formations. The latter in particular illuminate dynamics of the bases of the contesting arguments above, particularly the violent intensification of ethnic relations in Guatemala and the deterioration of the valuation of women and complementary approaches to gender relations. It is to an examination of the historical trajectory of household gender relations in Guatemala that I now turn.

\section{Shapers of Guatemalan Household Gender Relations}

Grounded in the fact that "everything about gender is historical" (Connell 2002:68), and that "an analysis of...the world outside the household is clearly vital to understanding of the spatial and temporal organization of relationships within it" (McKie, Bowlby and Gregory 1999:9), I review here some of the key events and processes that have shaped and continue to mold household gender relations in Guatemala, with particular focus on indigenous households. This examination has two purposes: to acknowledge the fact that dynamics of migration to Canada - the potential impetus under study here - are among, and cannot necessarily be isolated from, a broad range of processes in which Guatemalan household gender relations are continuously taking shape; and to aid in understanding what it is about migration that may also impel change or continuity in the gender dynamics under consideration. 
I proceed here by adopting both political-economic and socio-cultural perspectives (Martínez Salazar 2005, Menjívar 2006). This builds on contentions by Martínez Salazar that Maya women's lives in Guatemala are played out within "structural-cultural conditions" (2005:8), and by Menjívar (2006) that a combination of socio-cultural ideologies and macro-structural contexts affirm and transform Guatemalan gender relations. Arguing that an emphasis on the cultural-symbolic pays insufficient attention to material issues, while political-economic frameworks miss too much about culture, Martínez Salazar seeks to bridge approaches so as to grasp as much as possible about the "material-symbolic situations and conditions" in which gendered lives take place (2005:10).

I wed this dual-lens approach to theoretical explanations of change and continuity in household gender relations as I begin to draw out my theoretical framework in the following discussion. As mentioned above, integral to this approach is conceptualizing gender as a structure with individual, ideological, and institutional manifestations. In short, I will be examining how migration circumstances may effect change and continuity in these three domains of gender, and as such shape household gender relations. In the following chapter, I outline the individual level of this schema. In the following tracing of gender's trajectory in Guatemala, and consistent with combining the material with the cultural, I draw out and illustrate the approaches I will take to theorizing the ideological and institutional branches of my framework.

Gender is manifested in institutions - such as the household - but in a related process, gendered institutions influence each other (Crompton 2006, Risman 1998). Entities with patriarchal structures, including the state or government, religion, educational bodies, and systems of production (e.g., capitalism), constrain and enable 
household members' choices and actions (Bourdieu 2001, Crompton 2006, Luxton and Fox 2009, Neysmith, Bezanson and O'Connell 2005). This happens particularly through positioning people differently in relation to various resources, organizing their labour, and constructing and disseminating gender ideologies (Gazso-Windle and McMullin 2003, Pratt 2004, Pyke 1996, Risman 1998, Siltanen and Doucet 2008, Sullivan 2006, Vogler 1998, Walby 1989, Wharton 2005).

Ideologies can be defined as normative attitudes and beliefs about appropriate behaviours and power relations (Pyke 1996). Themselves residing at different levels society, community, household, individual, etc. (Risman 1998, Walby 1989) - ideologies strongly influence propensities toward "normative gender behavior" in the household (Salazar Parreñas 2005:4), especially through instilling feelings of correctness and morality (Crompton 2006, Doucet 2009b). In Guatemala, ideologies tying men to income generation and women to home-based care roles have been particularly impactful in shaping household gender relations and men's attendant authority (Martínez Salazar 2012, Menjívar 2006, Moser and McIlwaine 2004). Institutional and ideological influences cannot in isolation explain particular configurations of gender dynamics in the household; instead, they condition simultaneously - in a way that is sometimes discordant and other times mutually reinforcing (Risman 1998, Sullivan 2004, Sullivan 2006).

Here, I outline some of the ways in which, in Guatemala, the colonial era, religion, the state, the women's movement, and economic shifts have influenced household gender relations through institutional and ideological avenues, with a focus, when possible, on indigenous households. Although all of these processes are important to consider, I use the women's movement and economic shifts to explain in more detail the ideological and 
institutional pillars of my theoretical approach.

\section{The 'Conquest' and Colonialism}

Gender and colonization or colonialism are interdependent: gender has been central to "colonial projects" throughout history (e.g., Perry 2001:7, Stasiulis 1997), and nation-building processes premised on the dispossession and subjugation of indigenous peoples have been central to the formation of gender relations in both the Global North and South (Connell 2002, Martínez Salazar 2012, Perry 2001, Schiwy 2007). In Guatemala, the context that followed the arrival of the Spanish in 1524 marked the establishment of a patriarchal, capitalist, and racist system of social relations and the "institutionalization of gendered colonial racism" (Martínez Salazar 2005:20). Such characterizations point again not only to the intersecting varieties of oppression for indigenous peoples, particularly women, but also the interdependency of gender, race, and class in colonial projects more generally (Perry 2001). Gender is usually racialized in a way that benefits women among the colonizers and their descendants (Perry 2001) and indeed, in Guatemala, indigenous women would become "the Other of the Other", ranked at the bottom of the colonial social order based on the use of both gender and race as classification tools (Martínez Salazar 2005:41). Martínez Salazar's most recent work (2012), through terms like 'modern/colonial', emphasizes that the violent processes of the colonial period continue to be interwoven into present-day intersecting disadvantages for indigenous Guatemalan women.

Regulatory systems are central to how colonialism transforms gender relations toward patterns desired by colonizers (Perry 2001). Colonial rule in Guatemala instituted a gender system in some ways discontinuous with pre-'Conquest' configurations, 
contributing to the growth of unequal economic and household gender roles (Martínez Salazar 2005). In particular, Spanish ideologies urged a strict male/female binary, which emphasized the reproductive roles of women and de-valued their existing economic or productive roles (Lindsey 1994). In Guatemala, indigenous women's work was integral to the colonial system, but was often forced and unpaid, and its importance unacknowledged (Martínez Salazar 2005). Furthermore, integral to the Conquest project, and later to the creation of mestizos (mixed-race population), was the rape and abuse of indigenous women by Spanish men. Indigenous men considered this as damage to their honour, and in Guatemala as elsewhere in Latin America, men's need to re-affirm their power and dignity (Schiwy 2007), coupled with Spanish feudal and religious ideas about men and women, contributed in great part to the rise of machismo, a patriarchal ideology of "exaggerated masculinity" (Chant and Craske 2003:14), although one with differing meanings and expressions across class and ethnic lines (Gutmann 1996, Sault 2001).

Certainly these ideas and practices were not imposed upon the Maya without contestation and modification (Martínez Salazar 2012); scholars continue to struggle with how to both acknowledge indigenous peoples' agency and recognize their subjugation (Perry 2001). Overall, however, the influences of Spanish ideologies and practices have contributed to greater polarization of gender roles and gender inequality in Guatemala.

\section{Religion}

The role of organized Western religion in shaping indigenous household gender relations in Guatemala spans the centuries since the arrival of the Spanish. The introduction of Christianity was one of the most influential tools of the colonizers in their efforts to re-structure (or eradicate) indigenous ways and space of life (Martínez Salazar 
2005), and different instantiations of the Guatemalan state since independence have used religion as a means of social control, with gendered consequences (Manewal 2007). So powerful has been the repression of Mayan spirituality that indigenous people today who adhere to tenets of Western religion define themselves in opposition to the 'brujeria' (witchcraft) and Paganism of Mayan customs (Fischer and Hendrickson 2003, Martínez Salazar 2012). Roman Catholicism brought by the Spanish ${ }^{43}$ has marked many indigenous households with a more patriarchal character, including men's authority over decision-making (Similox 2010) and women's sexual reproduction (Metz 2001), and the 'enclosure' of women in their homes and families (Martínez Salazar 2012).

The picture of Western religion in Guatemala has become much more complex over the years, owing to a combination of state objectives and missionary influences (Manewal 2007). The contemporary situation is largely a divide between Catholics and Evangelical Protestants - with Mayan spiritual practices being in the distant minority following massive conversions to Protestantism since the 1960s (Fischer and Hendrickson 2003, Metz 2001, Whiteford 2002). Manewal (2007) provides an excellent illustration of the factors that contributed to these conversions during the civil war years, including the state's violent repression of Catholic adherents to social justice-minded Liberation Theology, and the state's promotion of Protestantism for its fundamentalist emphases on conformity and obedience to authority (Turner 1994). Compared to Catholicism, Evangelical Protestantism is now the more conservative and reactionary force in the country, grounded in fairly strict interpretation of biblical principles (Fischer

\footnotetext{
${ }^{43}$ A practice that continues to this day, many indigenous households adopted a combination of Western religious and Mayan spiritual traditions (Martínez Salazar 2012). Whiteford (2002) argues that the imposition of Catholicism by the Spanish did not radically change indigenous people's relationship to the supernatural, just the gods to whom they prayed.
} 
and Hendrickson 2003, Martínez Salazar 2012, Whiteford 2002) and moral behaviour in the quest for redemption and salvation in what are often termed as apocalyptic times (Manewal 2007).

In terms of gender, relationships between adherence to either Evangelical Protestantism or Catholicism, on one hand, and attitudes or practices of gender equality, on the other, are not straightforward. Despite its social progressive stance in certain important regards - especially under Vatican II and Liberation Theology ${ }^{44}$ Catholicism's patriarchal social conservatism has remained strong (Blacklock 1996), and its gender-related edicts continue to be influential in indigenous Guatemalan households, for instance by outlawing contraception (Metz 2001). Some research suggests that Evangelical churches have made considerable strides in breaking down traditional machista male roles in particular because of the ascetic lifestyle that requires giving up drinking and 'womanizing', and in assigning more importance to the domestic sphere (Brusco 1995). However, to the extent that attitudes toward gender equality may have a lot to do with doctrinal orthodoxy, Evangelicals - focused as they often are on close biblical interpretation - may be less inclined toward gender equality (Steigenga 2001). Furthermore, in communities where complementary gender roles are emphasized, a conversion to Protestantism may rob women of forms of authority and cooperation in their social networks and community life (Sault 2001).

In the main, despite its churches' shifting locations on the ideological spectrum, Western religion's influence on indigenous households in Guatemala over the centuries is appreciable in more marked divisions between masculinity and femininity, men's

\footnotetext{
${ }^{44}$ Although Liberation Theology is generally said to denounce gender oppression and prejudice (Turner 1994), due to the overriding Marxist-inspired concern with poverty and class issues, its proponents have not done much to disrupt gender hierarchies in Latin America (Pui-lan 2003).
} 
authority, and the ideal that women should dedicate themselves primarily to familial roles.

\section{The State}

Historically, the Guatemalan state has exercised its patriarchal foundations in several ways that have contributed both ideologically and practically to hardship for women, although it has made strides toward formal gender equality in recent years. Although a great deal could be said in these regards, I focus here on implications for household gender relations. Martínez Salazar emphasizes the ruling classes' gender ideologies and discourses in the early years following independence in 1821 that constructed non-indigenous women as "the feminine model of respectability and moral decorum that all women should aspire to" (2005:63-4) while looking upon indigenous women with disdain, as well as indigenous men's “violent, heteropatriarchal, masculinist indoctrination" to the new Guatemalan military in the late $19^{\text {th }}$ through which they were “socialized to exercise power and control over women's bodies" (2012:49).

In the war years of the 1970 s and 80 s in particular, exclusionary citizenship regimes emphasized women's domesticity and obedience, while also scorning Mayan women. Counter-insurgency ideologies portrayed Mayan women as "primitive" and "backward", but at best constructed them as a "stoic prototype of caring and nurturing" who should be obedient and content to be alive (Martínez Salazar 2005:360). Their duties to the 'nation' were to be docile and patriotic women and mothers who would bear patriotic and obedient children. However, to the extent that Mayan women were seen as “dangerous wombs giving birth to 'subversive delinquents"” (Martínez Salazar 2005:245), their reproductive roles - so valued in Mayan lifeways - were denigrated, often violently.

Women in Guatemala, whether involved in the conflict or just the representatives 
and carriers of the culture at which the state's genocidal efforts took aim, were subjected to horrific patterns of gender-(and race-)based violence during the war on the part of the state, and indigenous women suffered disproportionately (Kanakarajavelu 2010, Martínez Salazar 2005). Rigoberta Menchú, a leader in Guatemala's struggle out of war and in the promotion of human rights, documents that many indigenous women fiercely defended their families and communities $(1984)^{45}$ and in response experienced incomprehensible levels of rape, torture, murder of fetuses, and loss of life at the hands of military personnel and men from indigenous communities who had been forced into civil defense patrols. The use of violence against women as a counter-insurgency logic and weapon, and the resulting culture of sensationalism, indifference, and impunity, is key to understanding the scourge of gender-based violence - including domestic - in Guatemala today (Carey and Torres 2010, Kanakarajavelu 2010). Also connecting household gender relations today to the horrors of la violencia was the widespread widowing of women (Anderson 2003, Martínez Salazar 2005), resulting in considerable disruption in household gender configurations. While some women would have moved in with other relatives or had other men assume their husbands' responsibilities, widowing did often result in female household headship.

Recent gender-related legislation and state bodies have ostensibly sought to improve the condition of women in Guatemala, and are important to consider in that household gender relations both reflect and shape states' apparatus and laws (Chant and Craske 2003, Hurtig, Montoya and Frazier 2002, Neysmith, Bezanson and O'Connell 2005). Until reforms in the 1990s, the Guatemalan Civil Code contained stipulations that

\footnotetext{
${ }^{45}$ Menchú's work has been subjected to some scrutiny, especially with respect to the truth of the accounts she provides. See Ahmed (2003).
} 
tied women to carework in the domestic sphere and upheld men's authority (Congreso de la República de Guatemala 2008). Recent legislative changes and new state bodies aim at promoting formal gender equality ${ }^{46}$ and refer to household gender relations in ways that emphasize shared responsibilities and equal rights (MENAMIG 2006; Congreso de la República de Guatemala 2008; Congreso de la República de Guatemala 1999). Importantly, among the handful of women- or gender-related government bodies created since $2000^{47}$ is the Defensoria de la Mujer Indigena (DEMI), charged with promoting and defending the rights of indigenous women against the violence and discrimination they experience. These political developments have the potential to shift patriarchal household gender relations in Guatemala, for instance through educational programming that DEMI and other government bodies claim to offer. On the legislative and punitive side, however, there is an enormous gap between paper and practice, resulting in little in the way of enforcement, and leaving women's advocates with many unfulfilled demands toward the state (Jeffries 2007, MENAMIG 2006).

\section{Women's Movement}

Women's and feminist organizations ${ }^{48}$ in Guatemala, as elsewhere in Latin America, have played pivotal roles in these political developments by bringing women's demands to the fore and pressuring the state (Chant and Craske 2003). Just as

\footnotetext{
${ }^{46}$ The Peace Accords of 1996, the revised Civil Code, articles of the Constitution, the Labour Code, and women-specific legislation such as policy against intra-familiar violence and the Ley de Dignificación y Promoción Integral de la Mujer are all cases in point. This last piece of legislation translates as the Law for the Dignification and Comprehensive Promotion of Women and promotes the rights and development of women, and their participation in all levels of economic, social, and political life.

${ }^{47}$ Such as CONAPREVI, focused on the prevention of violence against women, and SEPREM, the Presidential Secretary for Women, an advisory and coordinating body for public policy relevant to the promotion of women (SEPREM 2009b).

${ }^{48}$ As footnoted above, because of perceived problems with feminism, especially in its radical or Western forms, not all women's organizations in Guatemala identify as feminist (Cumes Jochola 2010), hence the need for a differentiation between women's and feminist organizations within the broader feminist movement.
} 
importantly, these groups engage in consciousness-raising and capacity building that may contribute to changes in household gender dynamics. After significant repression of an autonomous civil society during the height of the civil war, ${ }^{49}$ the women's movement in Guatemala picked up organizing momentum from 1985 onward - a period of proclaimed liberal democratization in Guatemala - largely in response to how economic crises and political repression were affecting women, fuelled by regional women's organizing, and tied closely to the wider movimiento popular ${ }^{50}$ (Alvarez, Friedman, Beckman et al. 2002, Blacklock 1996).

Indigenous women's involvement in Guatemala's women's and feminist movements has been fraught with difficulty and complexity. Although certainly not absent, they have not held many key leadership roles or had their concerns and views sufficiently heeded (Martínez Salazar 2005). Fractures persist along ethnic lines (i.e., indigenous or Ladina) and according to stances toward feminism and gender inequality (Blacklock 1996, Jeffries 2007). Many indigenous rural women refuse to espouse a feminist label ${ }^{51}$ because they see it as a radical perspective that entails "not want[ing] anything to do with men" and that includes lesbianism (Cumes Jochola 2010). Martínez Salazar notes that because Ladina women predominantly lead it, the movement tends to "prioritize gender as the sole or most relevant reality affecting women" (2005:330), amounting to a racist indifference to indigenous women's experiences.

\footnotetext{
${ }^{49}$ Paradoxically, women became more politically active during this period under repressive military regimes in Latin American because military states tended to ignore women's collective action, mobilized as it largely was around 'apolitical' mothering and care-taking identities that did not seem particularly politically threatening (Chant and Craske 2003)

${ }^{50}$ The movimiento popular is characterized by "an identification with social transformation...the benefits the marginalized", and claims to represent the interests of the poor and working classes in particular (Blacklock 1996:19).

${ }^{51}$ These relate to wider tensions within Latin American feminism over the extent to which equality feminism is anti-family (concerns rooted in the valorization of women's mothering roles), and the divide between 'feminine' and 'feminist' concerns (Chant and Craske 2003).
} 
In response, a Maya women's movement has also grown in the post-war years, (Martínez Salazar 2005), grounding its efforts in both anti-racist and gender equality perspectives, and arguing for the simultaneous redress of material and cultural injustices. In these spaces, indigenous women can be "Mayas first or simultaneously as both" (Martínez Salazar 2005:331). A mainly indigenous women's organization, Nuestra Voz (Our Voice) focuses on strengthening women's organization, consciousness, and political participation through popular education approaches (Asociación de Mujeres Nuestra Voz N.d.). Although some women's groups have oriented themselves toward micro-credit projects to such an extent that activities focused more on consciousness-raising fall to the wayside (Samayoa 2010), groups like Nuestra Voz consider awareness-raising programming important and they try to involve men in order to help them recognize oppression - "they don't see it for what it is, that's what they're taught" (Cumes Jochola 2010). As a result, some men in communities where Nuestra Voz works have come to better understand and respect women's rights.

Despite their successes - including political developments outlined above and inclusion of women's concerns in the Peace Accords - Guatemalan women have had considerable difficulty advancing their claims with the state, as evidenced for instance by the lack of gender electoral quotas and the impunity that plagues the handling of genderbased violence. These challenges owe to divides in the movement, a certain de-centering of women's concerns in the interests of broader struggles (Alvarez et al. 2002), lack of political openings (Yashar 2004), and a history of state repression (Blacklock 1996).

I would like to employ the example of women's and feminist movements to inspire and illustrate the first of three parts of my theoretical framework, specifically by focusing on gender consciousness and its potential to disrupt patriarchal household 
relations. Craske points out that women's participation in social movements in Latin America has been central to building their gender-related awareness by encouraging them to "consider their gender position and the constraints they face in a sexist society" (2003:67). Building on this assertion, the ideological branch of my theoretical framework (corresponding with the ideological 'level' of the gender structure) focuses on gender consciousness. Sullivan describes it as "a continuum, at one end of which a generalized awareness of gender issues may be succeeded by a full consciousness of the rights associated with specific gender locations" (2004:208), and Craske describes it - for women specifically - as becoming "more aware of the gender dimensions of their situation", including how multiple constraints "limit their autonomy and ability to make choices" (2003:69). Drawing attention to women's intersectional situations, Craske includes ethnicity, class, and age among the constraints. In Sullivan's theorization, gender consciousness is key to changing women's perceptions and expectations regarding household gender equality, which are particularly important for stimulating negotiation or conflict about household gender relations. So important is gender consciousness, it "may therefore be utilized as a means of describing the potential for change in the domestic sphere" (2004:208).

Women's and men's development of gender consciousness depends on features of their environments, including discourses about equality in relationships, feminist teachings more generally, and openings in which they can recognize aspects of gender oppression (Chant and Craske 2003, Menjívar 2006, Sullivan 2006). Instances of learning and awareness can develop from such circumstances as direct efforts of women's rights and gender equality advocates (such as Nuestra Voz), and women's participation in paid work. Menjívar (2006) cites research demonstrating that Guatemalan 
women's work in the maquiladoras (export-oriented factories) provides women not only the opportunity to leave the house, but to establish contacts with other women, through which they may develop a feminist consciousness. The question in relation to my project, then, becomes whether migration circumstances create the potential to foster gender consciousness and alternative gender ideologies among Guatemalan women and men. I examine this in my discussion of social remittances in Chapter 9, including the constraints on this potential in the Canadian context. It must be stressed that women can rarely improve their status through strengthened gender consciousness alone, especially because other structural conditions must be taken into account (Chant and Craske 2003). I recognize this point by not hinging my theoretical framework on gender consciousness, but rather including it as one of three avenues of potential change and continuity in gender relations, the other two to be elaborated in the following section and in the next chapter respectively.

\section{Economic Shifts}

The last set of influences, economic shifts - admittedly spanning centuries and not separable from political developments - will illuminate a second major thread of theory regarding change and continuity in household gender relations. I will return to elaborate this shortly, but first outline some of the ways that capitalist penetration, in particular, has conditioned indigenous household gender relations. Traditional Maya life was defined economically by mainly subsistence lifestyles, characterized by the consumption of most goods produced and the sale of surplus to meet other basic needs, and by a sense of complementarity and mutually recognized contributions of men and women. Women's roles in economic production were fairly prominent and valued, even 
if women also held primary responsibility for domestic tasks (Carey 2006). Part of the explanation for the increasingly patriarchal character of their household arrangements lies in the changing nature of types and relations of production, which have induced shifts away from mostly subsistence lifestyles and toward commodification of labour power for survival, where that labour has been disproportionately men's (Bachrach Ehlers 1991, Carter 2004, Fischer and Benson 2006, Little 2005). ${ }^{52}$

There has been no decisive break between subsistence lifestyles and insertion into the cash economy and paid labour markets (Carey 2008b, Carey 2006), and indeed many indigenous households today live a hybrid economic lifestyle (Metz 2001), but particular penetrations of capitalism at historical points in Guatemala have been decisive for household gender relations. For instance, Guatemala's adoption in the late 1880s of plantation export agriculture, in which men were primarily employed, served to reduce many women's income-earning in the informal economy and tie their activities more tightly to the domestic sphere; in short: "sharing responsibilities in a subsistence economy was replaced by dependence on males' income-generating employment" (Carey 2006:92). However, those women who also worked on plantations elevated their status in the household power structure through contributing income (to be theorized below), and sharing the plantation experience with male partners reinforced the idea of complementary positions (Carey 2006).

Despite the proletarianization of some women, the predominant masculinization of waged work considered apace in Guatemala into more recent times. Short-lived

\footnotetext{
${ }^{52}$ Such claims can be traced to Marxist feminism which ties patriarchy to capitalist relations, and to assertions by Friedrich Engels in Origins of the Family, Private Property and the State that the inferior position of women was attributable to the institution of private property and waged labour, from which women have been historically excluded (Hartmann 1981).
} 
import substitution industrialization (ISI) 'development' strategies in the post-World War II era (Blacklock 1996, Fischer and Benson 2006) further shifted productive work from the home and farm to the factory, where it was men who were primarily employed, thus reinforcing a separate world of work for them and the 'housewifization' of women (Chant and Craske 2003, Connell 2002). The late 1970s saw the abandonment of ISI strategies and the shift toward neo-liberal development policies grounded in exportoriented production. This began to reverse gendered patterns of employment ${ }^{53}$ by incorporating women disproportionately into non-traditional agricultural production and maquilas, transnational factories most commonly making textiles (Fischer and Hendrickson 2003, Little 2005). Menjívar (2006) argues that in Guatemala, many in the female economically active population have laboured in the urban informal sector - a disproportionately female domain (UNDP 2010) - whereas if they have formal sector employment, it has tended to be in the maquilas. This is part of wider female-led industrialization and neo-liberal restructuring trends in Latin America, and the resulting rise in women's labour force participation is "one of the most notable changes in gender in Latin America" in recent decades (Chant and Craske 2003:194). The female share of the labour force in Guatemala rose from 22 to 28 per cent between 1980 and 1999 (Chant and Craske 2003:205). ${ }^{54}$

For indigenous, rural women in Guatemala, it has been non-traditional exportoriented agriculture in particular that has affected their economic activity, reflecting

\footnotetext{
${ }^{53}$ In a notable exception, Bachrach Ehlers examines the introduction of an export-oriented commercial weaving industry into a Kaqchiquel community in the late 1970s, which men came to dominate. Women were squeezed out, contributing to a relative decline in women's productive responsibilities; this coupled with their labour no longer being as essential to men's survival, translated "directly into a loss of female status" (1991:12). Because of these trends, "a clear pattern of male dominance is now more evident now than in the past" (1991:7) in that community.

${ }^{54}$ Using a different timeframe, other data indicate that women accounted for 25.5 per cent of the economically active population in 1990, but 35.2 per cent in 1999 (Menjívar 2006:9).
} 
wider trends in Latin America where rising production of agro-exports tends to correlate with the 'feminization' of agricultural employment (Chant and Craske 2003). These shifts may have implications for household gender relations, as illustrated by examples from the area of Tecpán, where my research was centred. Although women's employment at large export-oriented agricultural operations has increased in the region, more applicable to women in my study is the small-scale production of non-traditional crops. Small-scale agriculture is still predominantly oriented toward milpas - small plots of land where maize and beans may be interspersed with other crops - and local diets (Oficina Municipal de Planificación 2008c). However, about 60 per cent of Tecpán-area farmers devote at least a portion of their land to non-traditional crops for export (Fischer and Hamilton 2005, Fischer and Benson 2006). These strategies have generated work opportunities for women - as waged employees in local packing plants, and as productive partners in new forms of household-based farming involved in raising these crops (Fischer and Hamilton 2005). Women are no strangers to small-scale farming in this area, but these new models allow them to directly contribute more to income-earning and despite the ways in which male-dominant gender ideologies and practices continue to apply (Fischer and Hamilton 2005, Fischer and Benson 2006) - may contribute to a rise in their household status. Fischer and Hamilton (2005) found women's participation in decision-making about land use ${ }^{55}$ and division of labour, as well as their control over

\footnotetext{
${ }^{55}$ An intermediating variable here may be who in fact owns the land, and this is a pertinent question given that neoliberal reforms have liberalized land ownership in Latin America (Chant and Craske 2003). As mentioned in Chapter 2, Guatemalan law gives women the right to hold property and land in their own name, but indigenous women's landownership rates are particularly low. For instance, while 13.5 per cent of Guatemalan indigenous men held land in 2000, only 5.1 per cent of indigenous women did (Kachika 2012). I was informed that in my study community, it is generally assumed that women will get access to land through marriage, and this assumption informs the fact that inheritances generally favour male heirs. Migration may contribute to shifting patterns of land ownership, particularly in favour of indigenous people (Taylor, Moran-Taylor and Rodman Ruiz 2006), but also women: some of the single or separated migrant
} 
income generated, more commonplace in non-traditional production households than in households producing only traditional crops.

Outcomes in the household of these economic trends suggest that women's and men's household status may shift in response to their respective roles in productive contributions to the household economy (Stockard 1989). These shifts can be explained through the resource theory of marital or household power (Lindsey 1994, Shortall 2006, Sullivan 2006). Constituting my focus at the institutional level of the gender structure, this is the second of three elements of my theoretical framework. The theory helps to elucidate, from a structuralist-material perspective, the links between money, power, and inequality in marriage and the household (Vogler 1998). It has links to Marxist feminism, which centres the role of class relations in social relations more broadly (Hartmann 1981, Perry 2001), and the attendant emphasis on material shifts over time has been used to understand how aspects of gender relations get reconfigured as a result of men's and women's locations in those shifts. For instance, Stockard's historical work in South China (1989) demonstrates how women's privileged economic location in the mechanized and export-oriented silk industry contributed to a rise in daughters' status in their natal homes and to forms of marriage that afforded women more or prolonged independence from men.

According to the resource theory of household power specifically, economic resources constitute the most important factor in household gender power differentials (Pyke 1996), and contributions to the household economy of men and women constitute resources in the household balance of power between them (Lindsey 1994, Sullivan 2006). From this line of thinking emerges the suggestion that household gender relations 
could change as a result of shifts in income generation among household members, including who earns and how much. For women - who could be either conjugal partners or, as in Stockard's study, daughters in natal homes - income affords them a better bargaining position and they may "expect, and receive, more equitable sharing of decision-making power and family work responsibilities" (Luxton and Fox 2009, Newman 2002, Shortall 2006:303). Their positioning and 'daringness' in the bargaining or negotiation process is bolstered by both a fallback position and by being able to draw on the giving or withdrawal of those resources as bargaining chips (Koch 2001). If men's economic contributions grow relative to women's, household inequality may be further intensified. This may be the case particularly if, as some migration studies suggest, men's work has de-masculinized them through certain forms of treatment and relations of production (Boehm 2008); they may try to regain their masculine sense of self through intensified expressions of patriarchy that emphasize their economic contributions.

A couple of studies out of Guatemala illustrate the implications for household authority of women's and men's income-earning. Women's labour market participation - albeit among other factors - has been found to positively correlate with degrees of their participation in household decision-making (Becker, Fonseca-Becker and SchenckYglesias 2006). And a study by Carter (2004) revealed two related findings: women who earned an independent income were more likely than non-income-earners to yield authority over health care decisions and food purchases, and a household's participation in plantation agriculture (employing primarily men) correlated with the man's sole authority over money.

In my study, drawing on the resource theory of power, I will address whether income and economic remittances have contributed to a balancing of household authority. 
I will use this theory critically, however. The posited correlation between wage-earning and greater equality in household relations has been "overblown and romanticized" in the Latin American context (Chant and Craske 2003:197), subject as it is to a range of intermediating factors. A sampling of these include whether women control their income (Chant and Craske 2003), as well as the possibility of felt slights to men's masculinity and honour (Carey 2008a, Vogler 1998) which could result in heightened control of women in violent ways (Chant and Craske 2003) or women taking authority-negating measures to ease men's emotional or mental well-being (Shortall 2006). Emphasizing different approaches instead of just intermediating factors, Shortall (2006) points out drawing on the paid work of women in farming households - that insights from the Gender Ideology School are just as important to consider as those from the Resource Bargaining School. The former emphasizes that gender ideologies of women and men in a partnership profoundly influence the negotiation of domestic responsibilities, a point that other research supports (e.g., Gazso-Windle and McMullin 2003). Gender in the household cannot be seen in terms of interest-maximizing individual women who strategically use economic gains to alter the domestic division of labour (Menjívar 2006, Shortall 2006). With these critiques in mind, I will attend in Chapter 8 to the simultaneous and intermediating influences of gender ideologies and other understandings in my research community, so as to not treat the impacts of money in isolation from socio-cultural milieus.

The forgoing discussion of 'moments' and processes in Guatemala key to shaping indigenous household gender relations has historicized and contextualized patriarchy in Guatemala and illuminated two elements of my theoretical framework: gender consciousness and the resource theory of household power. This examination also 
focused on how household gender dynamics have been shaped or acted upon by external forces, in some ways portraying Guatemalan women as victims thereof. I therefore close this chapter by critically examining women's agency, enacted in the service of both contesting and effecting continuity in household patriarchy.

\section{Embedded Agency}

Much gender and feminist literature tends to conceptualize women's agency in terms of active, self-interested resistance to forms of patriarchal domination (Korteweg 2008). This is part of a larger call to focus on women as actors (Nash 2001), largely in response to victimizing tendencies in early work on women's engagements with economic globalization. Agency may not always take resistant forms, however, especially when actors have intersecting oppressions or are less than fully cognizant of them (Martínez Salazar 2005). We need to guard against a “"proclivity to overcompensate for formerly passive and victimized images... by characterizing most action and inaction as resistance"” (Behar 1990, cited in Wolf 1992:24). This is not to downplay the ways that Guatemalan women have resisted forms of patriarchy (Carey 2008a, Carey 2006, Taylor, Moran-Taylor and Rodman Ruiz 2006). However, the agency-as-resistance model tends to be based on problematic homogenizing assumptions about women united against gender-based oppression (Korteweg 2008). Furthermore, emphasizing resistance can lead to frustration toward women in the Global South who are not sufficiently inclined to "level assaults on patriarchal domestic ideologies and practices" (Pessar 1999a:66).

For my purposes, a more usable and insightful concept of agency is captured by "“the conscious efforts of social actors to understand and work on their situations...acting 
on, if not always prevailing in the situations"” (Levine 1993: 10, cited in Carey 2006:16). This definition places actors at centre stage, but leaves open what their situations are and how they respond. For instance, as we shall see in gender and migration literature, women may deliberately uphold a certain division of labour or men's household authority, and those practices constitute their agency in their circumstances. We need a conceptualization of agency that acknowledges a "simultaneity of choices and constraints" (Perry 2001:200), intersecting oppressions (Martínez Salazar 2012), and the complexity of acting in response to one oppression to the possible reinforcement of another.

In her examination of indigenous Guatemalan women's "praxis of the marginalized" Martínez Salazar (2005:10) finds them increasingly engaged in critiquing the social order, but also subject to the effects of hundreds of years of discursive and material degradation that have resulted in an internalization of marginalizing ideologies and instilment of a sense of inferiority. Particularly instructive about Martínez Salazar's approach to agency is her emphasis on intersectional oppressions and the importance of small everyday struggles for survival. On intersectionality, Pessar argues that in order to understand why women "have only nibbled at the margins of patriarchy, we must abandon the notion that gender hierarchy is the most determinative structure in their lives" (1999a:66). For Guatemalan women with intertwining social locations and identities (Stern-Petterssen 1997), upholding elements of household gender inequality may in fact constitute efforts to preserve their culture (Jaggar 1998), and provide much-needed material benefits (Pessar 1999a:66).

This dissertation proceeds from the idea of embedded agency, a set of practices informed by social contexts in which oppressions intersect, and that may not aim to undermine oppression but still constitute "active engagement in shaping one's life" 
(Korteweg 2008:437). This will assist with understanding that, just as much as they may struggle to subvert, Guatemalans may "operate on misunderstanding and on improbable hopes in actively defending the status quo even when the status quo acts against him/her/them on an everyday basis“ (Martínez Salazar 2005:119).

\section{Conclusion}

This chapter has laid out this study's conceptual approach to gender, and has contextualized and theorized household gender relations in Guatemala with a focus on indigenous households. By combining conceptual elements with grounded examinations, I have sought to demonstrate how to understand gender in Guatemala and its intersections with other social axes, to recognize non-Western and local perspectives on indigenous households in order to de-construct and counter some of the problematic tendencies of Western feminist research, and to outline the key ideological and institutional impetuses of change and continuity in indigenous household gender dynamics. This chapter has situated my study vis-à-vis gender theory and differing perspectives on Guatemalan household gender relations, and identified two pillars of my theoretical framework gender consciousness and the resource theory of household power. I elaborate the third theoretical element - gender habitus - in the next chapter, where I engage with gender and migration literature, and demonstrate how the critical use of Pierre Bourdieu's work will lend further conceptual power to an analysis of household gender relations in transnational contexts. 


\section{Chapter 3 \\ Gender and Migration, and a Critical Engagement with Bourdieu}

The previous chapter provided a historicized examination of gender in Guatemala and indigenous household gender relations specifically, in order to contextualize my study, substantiate elements of household gender inequality, and understand some of the key impetuses in the trajectories of household gender dynamics in Guatemala. Through examining what has driven changes and continuities, I also identified two of the three pillars of my theoretical framework: gender consciousness, focused on the ideological level of gender, and the resource theory of household power, based in gender's institutional economic instantiations. Building logically on the discussion in Chapter 2 of how household gender relations have been impacted by economic shifts and other processes, this chapter explores the implications of migration for gender in the household, both through a review of key literature and by laying out how I will theorize the potentialities.

This chapter has two main objectives, aligned with its two major sections. First, I locate my project broadly within a feminist gender analysis of migration, one that focuses on the possibilities that may exist in different experiences of migration to effect continuity and change in household gender relations. I adopt a particular focus here on household-based practices, economic remittances, and social remittances, and include research on Guatemalan migration. Examination of remittances will also effectively locate my study within scholarship on transnationalism. The second aim of this chapter is to establish the third pillar of my theoretical framework - the gender habitus - by demonstrating how I will employ Pierre Bourdieu's work on gender and his key concepts of field and capital to understand the social influences of migration. In the concluding 
section, I explain how I integrate the three branches of my theoretical approach.

\section{The Development of Gender and Migration Studies}

Since the 1970s, migration scholarship has increasingly acknowledged and examined women's participation in migration (de los Reyes 2001, Pessar and Mahler 2003), ${ }^{56}$ such that the "mantra-like complaint" that migration research ignores female migrants - and stayers - is no longer sustainable (Harzig 2001:15), even if examinations of women or gender issues may not yet find themselves in the mainstream of migration research (Bjerén 1997). This mounting attention to women in part owes to their increasing presence in international migration flows. Over the last forty years, almost as many women as men have migrated (José Alcalá 2006), and women now account for half of the over 200 million international migrants worldwide (Franck and Spehar 2010). Women outnumber men in some flows, such as those to more developed countries and within Latin America (Sharpe 2001), and certainly within particular occupational sectors, especially nursing, and domestic and sex trade work.

Although the international movement of women is not new, the reasons for and circumstances of their migration have changed notably over the last few decades. It used to be assumed that females moved internationally primarily within refugee movements or as accompaniers or followers of male, principal emigrants (Bjerén 1997, José Alcalá 2006), ${ }^{57}$ but women increasingly decide to move independently (José Alcalá 2006). This is not to deny in the least the multiple types of violence that might impel those 'decisions', nor that many women find themselves in forced migration flows as refugees or trafficked

\footnotetext{
${ }^{56}$ Some authors identify the 1980 s as the defining decade for the emergence of this work, marked, for instance by the 1984 special issue on "Women and Migration" of the International Migration Review (Harzig 2001).

${ }^{57}$ These assumptions may or may not be founded in reality, depending on the type of migration in question (Sharpe 2001).
} 
persons. Nor should one ignore the many undeniably disempowering and even harmful aspects of women's migration (cf Hugo 2000, Malarek 2003, Stasiulis and Bakan 2005) and of staying behind while men migrate (Mahler 2001, Munduate 2008, Tursunzoda 2010). My point here is to draw attention to women's status as independent labour migrants. Many of the factors in countries of origin that motivate this migration are economic (José Alcalá 2006), but these may disguise or be accompanied by social impetuses or personal situations (Piper 2008a) - such as family breakdown (Sharpe 2001), intra-familial violence (Asis 2005), or a desire to broaden their opportunities and be more cosmopolitan (Bryan 2011). Women's movements may also be facilitated by circumstances in countries of destination, including changes in immigration policy and demand for female labour in certain sectors (Preibisch and Encalada Grez 2010). The motivations driving Guatemalan women's migration have become more diverse, including effects of the armed conflict, poverty and lack of work, family problems, and domestic violence (Monzón 2009), although the driving force is undeniably economic necessity (MENAMIG 2006).

Since the 1980s, migration scholarship has moved beyond merely revealing the existence or presence of female migrants to explore related issues - such as wider contexts of their migration, women's agency in migration processes, and migration's impacts - as well as migrant women working in male-dominated occupations, although this aspect is still under-studied (Preibisch and Encalada Grez 2010). These developments mirror the influence of feminism on other fields where an acknowledgement of the neglect of women has developed into more complex analyses of phenomena in question (Silvey 2004). Since the mid-1990s, scholars have acknowledged gender as a central concept for studying migration (Carling 2005, Piper 2005, Preibisch 2005). The 
connections between migration and gender have been examined in several ways, tending to fall into two broad categories framed by cause and effect, and including both male and female migrants: first, how gender contributes to shaping the dynamics of migration, such as reasons, demographic patterns, and experiences; and second, how migration processes may impact gender (Boehm 2008, Carling 2005, Pessar and Mahler 2003, Piper 2005, Ramírez, García Domínguez and Míguez Morais 2005).

As an example of how gender shapes the demographic patterns of migration, the relatively small number of women among Guatemalan agricultural migrants to Canada reflects gender-based assumptions among Canadian farmers about men being more appropriate for agricultural work (Preibisch and Encalada Grez 2010), as well as "cultural factors" in Guatemala (IOM 2008:13), such as the importance assigned to home-based women's roles as mothers and housewives, and the assumption that men are breadwinners. These dynamics result in women having less freedom and inclination than men to leave home, which Pratt and Yeoh describe as "spatial stickiness" (2003:161).

This dissertation primarily focuses on the second approach, examining how migration experiences - of both women and men - impact expressions of gender, including identities, ideologies, and relations of inequality. ${ }^{58}$ Such considerations have been examined in the context of different types and periods of (im)migration, including settler/imperialist colonies in Canada (e.g., Perry 2001, Stasiulis 1997) and colonization processes in the Global South (e.g., Schiwy 2007) ${ }^{59}$ both historical and recent-past labour migration internal to countries of the Global South (e.g., Carey 2006, Resurreccion

\footnotetext{
${ }^{58}$ As will be shown in the analysis, however, gender's shaping of migration experiences is also relevant to understanding the gendered outcomes of Guatemalans' labour migration to Canada.

${ }^{59}$ Although works such as these incorporate considerations of gender, they very adeptly demonstrate that in order to understand gender relations in colonial/settler contexts in particular, an intersectional analysis is necessary.
} 
and Van Khanh 2007, Stockard 1989, Weinstein Bever 2002), forms of forced migration including refugee movements and trafficking (e.g., Doezema 2001, Nolin 2006), and recent waves of economically-motivated (im)migration from South to North (e.g., Boehm 2008, Hondagneu-Sotelo 1994, Menjívar 2006). Specifically, this study examines, and draws primarily on literature on how household gender relations are impacted by modernday South-North temporary labour migration, in which migrants leave behind their conjugal partners or other household members.

From a Western feminist perspective, scholars have seen a lot of potential in both women's and men's migration to disrupt patriarchal household relations, both through what happens during migration, and based on this period, the dynamics afterward. To provide just a few examples: in an oft-cited quote, Resurreccion and Van Khanh argue that migration can be a "radical gender-transformative odyssey" for women whether they migrate or remain behind (2007:212); José Alcalá suggests that "migration can transform the traditional private and public roles of men and women" (2006:30); Salazar Parreñas urges that the migration of women holds "tremendous promise for the transgression of gender boundaries", especially because it brings women out of the domestic sphere and builds their economic power (2005:92); and Weinstein Bever (2002) highlights the possibility for both 'gender-crossing' behaviours and shifts in gender ideologies. However, several studies - indeed some by these very authors - have generated findings that have dampened feminist enthusiasm, noting power struggles between change and tradition (Salazar Parreñas 2005), complexities of conflict, negotiation, strategies and manoeuvers aimed at both maintaining and transgressing the household status quo (Boehm 2008, Taylor, Moran-Taylor and Rodman Ruiz 2006). In the main, the arguments of this dissertation fall into this more skeptical 'camp', and in the pages that 
follow, I will outline some of the reasons provided in the literature on why patriarchal household gender relations in the context of migration might exhibit continuity, or even intensification, as often or more than patriarchy-diminishing change. My own findings bolster this scholarship, but respond to some of its gaps by focusing more on explaining the outcomes through using theoretical tools and attending to influences of local contexts.

To further explain migration's potential impacts on gender in the household, I will outline three sets of processes, which also correspond with the presentation of my analysis in Chapters 6 to 9: localized practices and experiences of both migrants and the partners they leave behind, income and economic remittances, and social remittances. Two of these foci will engage with theoretical perspectives discussed in the previous chapter: income and economic remittances with institutional influences on the household (through the lens of the resource theory of power), and social remittances with ideological impetuses (with a focus on gender consciousness). The third avenue of inquiry requires a foray into a third branch of theory on household gender relations, for which I propose a critical engagement with Pierre Bourdieu and his interlocutors. Not only do his understandings of gender in the household offer explanatory power, but as will be shown, his work also provides other complementary conceptual tools for analyzing the social impacts of migration.

\section{Gendered Selves and the Household: Bourdieu's Habitus}

In Chapter 2, I mentioned that gender is manifested at different levels or in various spheres of social life, akin to a gender structure. Although I have emphasized ideologies and institutions to this point, gender is also lived and expressed at the level of the self. This is not to suggest that gender is rooted in biological necessity, but to 
emphasize that social forces contribute to the internalization of gender in individuals - in their sense of self, their bodily postures, and their practices - especially through ongoing socialization processes. Although scholars have adopted various aspects of the gendered self on which to focus - such as personalities (Risman 1998) and identity (McNay 1999) - what these combined approaches offer is a third way of explaining continuities in household gender relations. In short, it can be so difficult to dislodge gendered thinking and behaviours in the household because gendered selves significantly condition the practices of social actors often in a less than conscious manner (Bourdieu 2001, Lindsey 1994). Gendered selves do not alone explain household gender relations but nor can they be ignored, especially because it is ultimately the actions of individuals that uphold or effect change in social relations (Risman 1998).

Among the gendered selves approaches, I have chosen to engage critically with Bourdieu's gender habitus, particularly because of his application of habitus to household gender relations, the explanatory links between habitus and other elements of social life such as practices, and the enlightening ways his work has been applied to migration studies, which I will outline shortly. Bourdieu's work, and examinations, critiques, and applications thereof, fill volumes. I focus here on the most common understandings of Bourdieu's notion of habitus and will bring in related elements of his theory of practice $e^{60}$ for an application to household gender relations, while also attending to some of the

\footnotetext{
${ }^{60}$ I have chosen not to apply fully Bourdieu's theory of practice (Bourdieu 1990). One could conceive of household gender relations as a set of productive and power-imbued practices, and apply his theory to examine them, and Bourdieu is particularly useful for explaining reproduction of social structures, which would be apt for my analysis of the overall continuity in household gender relations in Guatemala. However, I find the theory of practice too formulaic (e.g., "[(habitus) (capital)] + field = practice" (Mahar, Harker and Wilkes 1990)) and overall too deterministic (Adams 2006). As well, faced with the potential task of explaining practices through an "exposition" (Mahar 1992:297) of the fields, habitus and capitals that characterize the setting, I do not necessarily have fieldwork data to attend adequately to each of the pivot points of this theory and how they work together. I will, however, draw on his concepts of field and capital as they prove to be useful for understanding the dynamics of migration and impacts thereof.
} 
critiques raised by feminist scholars.

Bourdieu developed the concept of habitus as part of an examination of the constitution of subjectivity in late modernity (Adams 2006), and of the interplay of individual agency and structural factors in the generation of social practices. Finding neither an objectivist nor subjectivist understanding of practices adequate (Bourdieu 1990, Bourdieu and Wacquant 1992, Thieme 2008), Bourdieu proposed to combine these perspectives with his theory of practice, which hinges on the concept of habitus. Habitus is "a system of durable, transposable dispositions which functions as the generative basis of structured, objectively unified practices“ (Bourdieu 1979:vii). ${ }^{61}$ Dispositions can be thought of as tendencies, preferences, or strong, normative propensities to perceive and understand the social world and act in certain ways (Bourdieu 2002, Friedmann 2002, Kelly and Lusis 2006). In the generation of practices, habitus provides a sort of 'practical sense' of what to do so that practices are consistently appropriate for a given context or situation (Bourdieu and Wacquant 1992). In contrast to rational actor theory approaches, habitus conditions practices in a largely sub-conscious manner, as if "orchestrated without being the product of the organizing action of a conductor" (Bourdieu 1990:53). Operating in concert with other constraining and enabling conditions, habitus does not determine practices in a mechanical fashion, and Bourdieu does not deny actors' capability for conscious strategizing. However, habitus always has a mediating role in practices (Mahar, Harker and Wilkes 1990). This claim about habitus' involvement in practices is central to including a 'gendered selves' approach in analyzing household

\footnotetext{
${ }^{61}$ Beyond this general description as a set of dispositions, both Bourdieu and his interlocutors emphasize varying aspects, functions, and modes of operation of habitus. It is difficult to state with precision what habitus is (Kelly and Lusis 2006) and considerable debate and disagreement persists as to how it should be understood (Bourdieu and Wacquant 1992).
} 
gender relations.

In addition to structuring practices, habitus is also structured; its consistently patterned and durable dispositions develop through internalizing various external social conditions through processes of socialization and repeated sets of practices, especially in individuals' formative years. Habitus mirrors aspects of the social world such that it becomes "the internalization of externality" (Mahar, Harker and Wilkes 1990:15). Specifically, the features of the external world that constitute habitus are those of fields. Defined by Bourdieu as a "network, or a configuration, of objective relations between positions" (Bourdieu and Wacquant 1992:97), a field is a structured setting in which individual and institutional actors engage with and are positioned in relation to each other in certain ways, based on distribution of various types of capital (Thieme 2008). Each field has its own order, rules, and logic that in part determine which actions and thoughts are allowed or possible, and these elements are internalized into habitus through experience (Crang and Thrift 2000, Mahar, Harker and Wilkes 1990, Thieme 2008, Webb, Schirato and Danaher 2002). Mutually influential but relatively autonomous, fields are delimited or identified by what types of capital are deemed valuable, the predominant activities that take place within them, as well as specific groupings of institutions and actors (Mahar, Harker and Wilkes 1990, Mahar 1992, Webb, Schirato and Danaher 2002).

The various examples of fields suggest that they exist at multiple, overlapping levels of society. Fields constitute a central component to theorizing the gender-related impacts of migration in my project. Scholars contend that Bourdieu is not clear on the spatiality of the concept, but importantly for my study, Bourdieu defines the family and 
home as fields (Bourdieu and Wacquant 1992, Bourdieu 2001). ${ }^{62}$ I proceed by conceptualizing the Guatemalan household as a field, and broader Guatemalan and Canadian settings as locales - defined as "aggregations of social fields" (Thieme 2008:62) - and I work with the idea of a transnational social field, as explained below.

Habitus needs to be thought of as both a collective and individual phenomenon, and the field is central to the former. Habitus is shared among people with some commonality in relation to a field - e.g., they primarily act within a certain field or set of fields, or they receive similar conditioning therein (Bourdieu and Wacquant 1992, Crang and Thrift 2000, Webb, Schirato and Danaher 2002). At the individual level, the habitus is a "structural variant" of the collective habitus (The Friday Morning Group 1990:204). A shared habitus can form according to numerous possible axes or bases of which Bourdieu's overriding focus was class (Adkins 2004a), but among the other major axes for habitus are gender, race, and ethnicity. ${ }^{63}$ Despite some assertions that he situated gender as secondary to class in the formation of habitus (Adkins 2004a, Lovell 2000a), ${ }^{64}$ Bourdieu was not silent on the issue of the gender habitus and gender relations more broadly. In addition to field, the gender habitus is central to my theoretical approach to understanding continuity and change in household gender relations.

The bulk of Bourdieu's attention to gender is found in Masculine Domination (2001), where he seeks to explain the ubiquity and endurance of gender inequality, including in the household. He attributes masculine domination largely to the gender habitus, which amounts to the internalization of the symbolic androcentric ordering of

${ }^{62}$ Other examples of fields include academia, religion, the arts community (Bourdieu and Wacquant 1992), the military, politics, law (Hillier and Rooksby 2002), and labour markets (Thieme 2008), along with more physical places such as workplaces or classrooms (Silva 2005).

${ }^{63}$ Bourdieu was relatively silent, however, about issues of race and ethnicity and their relationships with class and gender, which is problematic (Ashall 2004, Moi 1991).

${ }^{64}$ For an examination of different 'readings' of Bourdieu's approach to gender and class, see McCall 1992. 
society according to "homologous oppositions" (2001:7) of male and female (Latreille 2006). Reflective of the opposition characteristic of objective structures, the gender habitus has two varieties: masculine and feminine. Other axes of social stratification differentiate the gender habitus (McCall 1992), but this acknowledgement does not disrupt Bourdieu's overall point of there being two oppositional versions of the gender habitus. Just below, I outline how I am conceptualizing and inquiring into the gender habitus of my study participants.

As with habitus in general, it develops through socialization and repeated practices within fields, processes to which embodiment is central (Witz 2004). Specifically, it develops early in life through the bodily performance of certain sets of tasks, designated according to the "strict distribution of activities assigned to each sex" (Bourdieu 2001:8) and the "tacit injunctions" (2001:24) of the masculine order. Household life in the early years is crucial to this inscription process; males and females internalize the social order and roles of the household, in which both men's dominance and women's relegation to domestic work are accepted as normal.

The physicality of the spaces occupied by women and men are also central to the development and reinforcement of their gender habitus. Bourdieu calls this the "structure of space", characterized by the "opposition between the place of assembly or market, reserved for men, and the house, reserved for women" (2001:9). Bourdieu emphasizes women's connection to the space of the home and certain places within it, and their relative absence and exclusion from the public spaces that men primarily occupy.

For the purposes of my study, I am positing that the Guatemalan indigenous women as a group and men as a group have fairly differentiated gender habituses from each other, given very gendered socialization processes in early life, and distinctions in 
their daily household-related activities and spaces they occupy, as I will detail further in Chapter 5. In regard to how individual and collective habitus interact, Bourdieu claims that each agent will have his or her own "positions and dispositions" (Bourdieu 2001:57). However, given that my study participants hold a great deal else about their "social position" in common (Bourdieu 2001:57) - e.g., all are indigenous Kaqchiquel ${ }^{65}$, ruraldwellers, and of similar socio-economic status - I would argue that there is limited differentiation in the gender habitus among women or among men. According to Bourdieu, because they are similarly socially positioned, $a$ man or $a$ woman - that is, a person from each gender category in this context - would face similar "expectations" or "potentialities" (Bourdieu 2001:57) in their daily life because of their similarly conditioned gender habitus. ${ }^{66}$ Although pending further elaboration below, the key question for my study is whether shifts to Guatemalan men's and women's gender habitus occur through the experiences of different fields made possible by migration. Attending to intersectionality, however, I will also analyze some aspects of Guatemalan migrants' experiences that activated class- and ethnicity-related elements of their dispositions.

In terms of engendering practices, operating at a largely sub-conscious level because of its inculcated, embodied nature, the gender habitus encourages practices appropriate for females and males in the household and discourages actors from behaving like those of the opposite sex (Bourdieu 2001). This idea has been employed to understand household gender relations (e.g., Doucet 2009a, Doucet 2009b, James 2009,

\footnotetext{
${ }^{65}$ The name of this ethno-linguistic group in Guatemala has different spellings, including Kaqchiquel, Kaqchikel, and Kakchikel. It is pronounced kak-chee-KELL.

${ }^{66}$ However, to the extent that ongoing practices influence habitus, there may be differences according to, for instance, how much remunerated or extra-household work women have done, or how much housework men had to do while they were younger because of particular household circumstances. These types of variation arose among my study participants.
} 
Matsui 2010), where emphasis has been placed on the embodied aspect of gender dispositions that shape differences in care work and other household-related behaviours. Doucet $(2009 a, 2009 b)$ applies the concept of gender habitus to explain differences in 'fathering' and 'mothering' care behaviours, the endurance of women's responsibility for children, and men's perceived responsibility for income-earning, in terms of felt 'correctness' of behaviours. That Bourdieu's work has not been used more in relation to household gender relations may stem in part from the fact that Bourdieu's work has not been a "smooth fit" for feminist analysis (Doucet 2009a:83).

Feminist theorists and researchers, finding various affinities with Bourdieu's work, have engaged with it to a significant extent (Adkins 2004a, Adkins 2004b, Lovell 2000b, McCall 1992, McLeod 2005, McNay 1999, Moi 1991, Silva 2005, Skeggs 2004), and subjected it to a number of critiques, some of which are relevant to the probability of change toward greater gender equality in the household ${ }^{67}$ First, the gender habitus may be largely immutable because, although not a biological foundationalist (Silva 2005), Bourdieu calls gender an "arbitrary construction" (Bourdieu 2001:23) and thus may tie gender too closely to sex (Chodos and Curtis 2002, Lovell 2000b, Witz 2004). Furthermore, intentional change to habitus is precluded by the largely non-conscious, embodied, pre-reflexive character of habitus, as well as the misrecognition and naturalization of masculine domination. Bourdieu terms this symbolic violence - alluded to in Chapter 2 - caused by how "the dominated apply categories constructed from the point of view of the dominant to the relations of domination" (2001:35). As a result of this, women are not likely to behave in non-feminine ways or to agitate for greater equality; the gender habitus, especially when aligned with its corresponding fields, "tends,

\footnotetext{
67 For a summary, see Adkins 2004a.
} 
by discouraging it, to undermine even the inclination to perform acts that are not expected of women - without them even being denied to them" (2001:35). Women's aspirations are products of an "unconscious adjustment to the probabilities associated with an objective structure of domination" (2001:35). Especially if "the domestic unit is one of the sites where masculine domination manifests itself most indisputably and visibly“ (2001:35), the chances of change to household gender relations look particularly slim if understood primarily through the lens of the gender habitus.

Some responses have been provided to such critiques, such as criticisms about the outdated fieldwork in a particular culture in Algeria upon which Bourdieu based these assertions about gender and masculine domination (Witz 2004), warnings against a "straightforward appropriation of the notion of habitus" (Adkins 2004a:16), and recognition that habitus is not all there is to the gendered self but rather a part that is not as "amenable to re-fashioning" as others (McNay 1999:102). Taking up an engagement with Bourdieu, but also his own invitation to think beyond him "and against him whenever required" (Bourdieu and Wacquant 1992:xiv), ${ }^{68}$ I consider gender more differentiated and flexible than Bourdieu's formulation, and I identify more conscious components of gender, such as gender consciousness, as discussed in Chapter 2. At this juncture, I contend that the gender habitus serves as a compelling part of the theoretical grounding for this study, to be combined with ideological and institutional influences. I find habitus valuable theoretically because of the relevant ways that other 'gender and migration' studies have employed it, and because of the way it assists with understanding why continuity tends to characterize household gender relations in the face of other

\footnotetext{
${ }^{68}$ Although I acknowledge that some express concern about stretching Bourdieu's ideas too far such that they are almost completely re-cast (McLeod 2005).
} 
factors encouraging change (Koch 2001, McLeod 2005) due to constraints that habitus imposes on innovative or voluntaristic behaviours (Lovell 2000a). Furthermore, while not easy, and even if he severely underestimates this potential in Masculine Domination (Chodos and Curtis 2002), change to habitus is possible within Bourdieu's framework (Ashall 2004, Bourdieu 1990, Bourdieu and Wacquant 1992), for which we can look for potential in migration.

\section{Bourdieu and Migration}

The question for this study, if we put stock in habitus' strong influence on normative gender behaviour in the household (Salazar Parreñas 2005), is whether and how migration may bring about change or encourage continuity in these staunch sets of dispositions. Migration scholars have had some fruitful engagements with Bourdieu, using his theory in different ways, often focusing on one or two of his key concepts in relation to human mobility. Among a sampling of these works, they attend to cultural capital of (im)migrants (Bauder 2004, Erel 2010), the idea of fields as "gendered moral economies" (Keough 2008: 225) and transnational spaces (Guarnizo 1997, Thieme 2008), the incommensurability of habitus with new environments (Schmidt 2002), changes to migrants' habitus as a result of migration ${ }^{69}$ (Friedmann 2002, Kelly and Lusis 2006, Mahar 1992, Pintor Sandoval 2011), clashes between old and new habitus upon migrants' return (McKay 2005), returning migrants' practices that demonstrate shifts in habitus (McKay 2001), and the accumulation and valuation of capital (Kelly and Lusis 2006).

\footnotetext{
${ }^{69}$ Changes to habitus are sometimes described in terms of its transnationalization (Guarnizo 1997, Kelly and Lusis 2006, McKay 2001, McKay 2005, Pintor Sandoval 2011). The transnational habitus is a set of dualistic dispositions (Guarnizo 1997) or "contrapuntal schema" (McKay 2005:85) that combines elements of the environments that migrants (and non-migrants) encounter, and continues to evolve over time. To provide an example with regard to gender, Guarnizo (1997) argues that the gender habitus of Dominican women in the United States developed a transnational character due to household gender relations being more equal than in their homeland, but that women's Dominican gender habitus remained active by framing return migration decisions according to women's conventional mothering roles.
} 
Although I will re-visit later in this chapter the matter of capitals (indeed, plural), I focus here on changes to the gender habitus.

There are three sources of potential shifts to the gender habitus as a result of migration: movement between fields, transnational social fields, and changes in practices. All three stem from an understanding of habitus as enduring and difficult to change (Lovell 2000a), but ultimately changeable through exposure to new environments and experiences: habitus is "constantly subjected to experiences, and therefore constantly affected by them in a way that either reinforces or modifies its structures" (Bourdieu and Wacquant 1992:133). Either movement between fields (or locales, which are sets of fields) or participation in transnational social fields can contribute to the internalization into habitus of new "values and imperatives" (Webb, Schirato and Danaher 2002:37). I will further explain transnational social fields just below, but the overall argument here is that the exposure to new fields through migration makes habitus' "transformation and adaptation both possible and necessary“ (Thieme 2008:59). Bourdieu (2002) contends that whenever dispositions encounter conditions that differ from those under which habitus was constructed - described as a lack of fit or "fish out of water" situation (Webb, Schirato and Danaher 2002:38) - there is a confrontation between habitus and objective structures in which habitus may be transformed. Habitus can change in itself, but rarely if ever undergoes a wholesale change of itself. The imprints on habitus of early and longterm experiences are difficult to dislodge (Bourdieu 1990), so in the case of migrants, they do not wear different 'hats', so to speak, that they don and doff as they cross borders. Habitus is more cumulative and evolving. As one's experiences and fields of activity change, so does habitus, incorporating new elements, weakening some, and strengthening others (Webb, Schirato and Danaher 2002). 
So in this sense, it is important to explore what is new or different for Guatemalan migrants about gender in Canada, and to which they adapt, and how their habitus might change as a result. Exploring migrants' gendered dispositions, Peláez (2009) found that some male Guatemalan migrants returned from the United States assigning greater value to respect for women than before. In other research on Filipino migration, McKay (2001, 2005) emphasizes changes in gendered aspects of habitus in discussing the return to the Philippines of female overseas domestic workers, identifying changes in how returned migrants dress, present themselves, and make consumer choices. Similarly, in their research on Filipino migrants living and working in Toronto and occasionally visiting the Philippines, Kelly and Lusis identify changes to the habitus of migrants in their styles of speech, appearance, and "sexy outfits, you can see the difference...they make it obvious that they came from Canada“" (2006:844).

In addition to actual migration, which physically brings migrants to new fields and experiences, we can look at exposure to or participation in transnational social fields, which are created from the form of migration that this study examines. Largely gone are the days when immigrants fully integrated into a new country and severed ties with their countries of origin (Glick Schiller, Basch and Blanc 1995). Due to a variety of especially technological and political influences and facilitators, ties to 'home' have increased in extent and intensity among migrants. This has changed approaches to migration scholarship, including calls for new conceptual tools (Goldring and Krishnamurti 2007, Kivisto 2001). In relation to migration ${ }^{70}$, transnationalism generally refers to belonging to or organizing daily life between and among different locales that span borders. It

\footnotetext{
${ }^{70}$ The term has its origins in the 1960s when it was used to refer to transnational corporations (Glick Schiller, Basch and Blanc 1995).
} 
involves networks, practices, organizations, and communities that forge cross-border connections at various scales ${ }^{71}$ (Brickell and Datta 2011b, Goldring and Krishnamurti 2007), and individuals' simultaneous presence in or connection to more than one society (Glick Schiller, Basch and Blanc 1995).

Among the different strands of transnationalism scholarship, I draw on those that emphasize social relations and social spaces. The border-crossing social spaces formed by migrants' social relations and activities (Glick Schiller, Basch and Blanc 1995) have received various names, including transnational social formations (Guarnizo 1997), transnational social fields (Kelly and Lusis 2006), or just transnational spaces (Faist 2004). ${ }^{72}$ They span cross-border territorial locations and are made up of sets of ties and the growing number of people who live within them, which together link areas of origin and destination (Faist 2004, Guarnizo 1997, Kelly and Lusis 2006, Kivisto 2001, Levitt 2001, Portes, Guarnizo and Landolt 1999). Among the ties are forms of exchange and diffusion, for example of ideas, goods, capital, information, influence, and cultural practices (Glick Schiller, Basch and Blanc 1995, Lindstrom and Muñoz-Franco 2005, Ramírez, García Domínguez and Míguez Morais 2005). Among these, I will return later in this chapter to economic and social remittances. While the temptation may be to consider these flows and activities as going from one place or person to another,

\footnotetext{
${ }^{71}$ The scale at which transnationalism has been most often examined is that of the nation-state, with an emphasis on the idea of border-spanning activities. There have been increasing calls recently for consideration of connections at other scales, for instance local-local ones between migrants' home and destination communities, which have little to do with the nation-state per se (Brickell and Datta 2011a).

${ }^{72}$ No one has concluded decisively that migration scholars can unproblematically conceptualize a transnational social space as a field in the Bourdieusian sense. In a forthcoming publication (Hughes Forthcoming), I examine the compatibility of the two concepts according to such considerations of scale, activities within the field, and meaning of space and place. Although my examination is inconclusive, transnational spaces bear resemblance to Bourdieu's fields in a few respects, and in fact Kivisto argues that the "intellectual lineage" of transnational social spaces likely derives from Bourdieu (2001:566). Furthermore, I emphasize that the notion of transnational social fields allows us to incorporate consideration of non-migrants.
} 
examining transnational social spaces involves exploring how something new is formed, how two (or more) geographic areas and the people and activities that constitute them "become a part of a singular new social space" (Kivisto 2001:565). Importantly, among the people that constitute them, integral to forming and maintaining ties, whether affective, economic, or political, are non-migrants, who overall do not receive enough attention in migration scholarship (Kunz 2008, Salgado de Snyder 1993). ${ }^{73}$ Thus, a transnational social field approach is vital if we wish to include in our analysis, as I intend to, non-migrant partners of migrants, and possible changes to their habitus. Kelly and Lusis (2006), for instance, point to this potential by asserting that Filipino nonmigrants' dispositions had changed - evinced by alterations in how they valued certain forms of capital - as a result of their various connections with migrants in transnational social fields.

Tightening up the approach somewhat from rather vague references to 'exposure' to and 'experience' of new fields is the third avenue through which habitus might undergo shifts as a result in migration: through social actors' carrying out of new or different practices, or changing how they do them, or how often. Admittedly this happens in fields - both transnational and local - but lends somewhat more precision to the mechanisms through which dispositions might shift. Bourdieu himself emphasizes that the gender habitus takes shape through repeated practices (2001), and remains responsive to changes in actions so repeated.

There is no shortage of literature about how migration affects the gender household division of labour, mostly for non-migrants, but for migrants as well (e.g.,

\footnotetext{
${ }^{73}$ Several works have begun to attend to the neglect of non-migrants (e.g., Dunn and Gibb 2010, Hadi 1999, Hadi 2001, Hellman 2008, Nguyen, Yeoh and Toyota 2006).
} 
Boehm 2008, Menjívar and Agadjanian 2007, Resurreccion and Van Khanh 2007, Weinstein Bever 2002). In communities of origin during migration periods, households must continue to operate in the absence of one of their members, meaning that other people must adopt at least some the responsibilities that migrants cannot fulfill while away. When men migrate, women in many cases become de facto heads of household (Carling 2005, Datta and McIlwaine 2000). They may take up new, traditionally male roles, as Menjívar and Agadjanian (2007) found in their Guatemala-based research, including waged work in order to guard against the sporadic nature of men's remittances (Weinstein Bever 2002), decision-making (Datta and McIlwaine 2000, Peláez and Ugalde 2006), a more disciplinary approach to parenting (Salazar Parreñas 2005), or avenues of citizen participation, such as attendance at community meetings (Boehm 2008, Munduate 2008). On the other hand, non-migrating women may not take over men's roles to any large extent, as Peláez and Ugalde (2006) found to be the case among some women in Guatemala. They may feel the eyes of other kin and the community upon them (Salazar Parreñas 2005) and male partners may well not want women to take on their work and may exercise influence over the phone or through other family members (Peláez and Ugalde 2006). Women may continue to rely on absent men considerably for decisionmaking (Datta and Mcllwaine 2000). As well, women tend to refrain from engaging in activities that could bring suspicion of infidelity or threaten the image or masculinity of their male partners (Hellman 2008, Menjívar 2006), thereby fighting against assumptions of female household heads' immorality and promiscuity (Datta and McIlwaine 2000).

When women migrate, male non-migrating partners may assume an increased share of some tasks for which women are primarily responsible, such as housework or childcare (Resurreccion and Van Khanh 2007). However, several studies - including 
some involving migration from Guatemala - demonstrate that it is far more likely that other female family members, such as grandmothers and older sisters or non-kin assistants, will step in to assume most of the absent woman's work (Bernhard, Landolt and Goldring 2005, Carey 2006, Hondagneu-Sotelo and Avila 1997, Piper 2008a, Taylor, Moran-Taylor and Rodman Ruiz 2006). Thus, women's migration results in increases in other women's workloads (Carling 2005, Piper 2008a). While women often expand their roles in the course of migration, men left behind tend to "cling to their old roles" (Asis 2005). Carey has demonstrated in Guatemala that men are far less likely than women to engage in gender-crossing activities, possibly in resistance to "choosing subordination" (2006:115). It needs to be stressed that it is not only or always men's resistance shaping these situations; for instance, migrant mothers may prefer to have their children cared for by grandmothers than by their husbands (Hondagneu-Sotelo and Avila 1997). I will explore more of these dynamics among non-migrants in my analysis, including an application of some of Bourdieu's other explanatory tools to demonstrate why nonmigrating women and men may not engage in gender-crossing behaviours.

Migrants in countries of destination may also undergo changes in the practices that they carry out on a daily basis. Certainly, many of these would be in their workplaces, but it must be acknowledged that migrant labour tends to be very gendersegregated (Franck and Spehar 2010), with women and men being concentrated in occupational streams deemed appropriate for them or for which they have been trained along gendered lines in countries of origin. For instance, women predominate among domestic and other care workers, and men dominate flows of construction and agricultural workers (José Alcalá 2006). The minority of women employed as agricultural labour migrants are often assigned tasks deemed appropriate for women, such 
as lighter work or that requiring a 'gentle touch' (Arizpe and Aranda 1993, Preibisch 2005), including floriculture and harvesting strawberries. In addition to gendered waged work, what has also received considerable attention, in relation to male migrants anyway, is their engagement in social reproductive work at destination for which they may not be responsible in their home communities (Hondagneu-Sotelo 1994, Vullnetari and King 2011). The International Organization for Migration - the organization that has facilitated a great deal of Guatemalans' migration to Canada - stressed in one of its evaluations of the migration project (IOM 2006) that men in Canada had to cook and clean for themselves in their group living quarters, tasks that women primarily perform in their Guatemalan households. I will take up this issue in my analysis of migrants' practices in Chapter 6, in addition to the often fundamental shift that immersion into paid work brings to daily 'normal' routines for migrant women. The theoretical point here is that shifts to habitus may occur if migrants and non-migrants engage in new practices.

So, thus far the application of Bourdieu's work to the potential impacts on household gender relations of migration and transnationalism has been rooted in changes to the gender habitus, an aspect of the 'self' level of gender. It is at this point that I can begin to integrate this thread of my theoretical orientation with those discussed in Chapter 2. A focus on fields, as well as other aspects of Bourdieu's theory of practice, help to further incorporate some of the ideological and institutional influences on household gender relations. More precisely, I will be examining economic and social remittances, and connecting those respectively to the resource theory of power, and to gender consciousness and ideologies.

\section{Remittances - Economic and Cultural Capital}


In addition to what is happening to migrants in destination countries and those left behind in communities of origin, it is also important to consider the ongoing flows between people and places during the migration period. These flows - of money, goods, ideas, and affect, among others - that technology and telecommunications make possible, largely characterize transnationalism (Faist 1998, Rivas and González 2011), and may have implications for gender relations. Literature on transnationalism and gender concerns itself not with the effects on gender of staying, or going and returning, with a focus on one or two delimited locations. Instead, the emphasis here turns to the transnational processes during migration, which could be described in terms of how individuals negotiate gender in transnational spaces (Mahler and Pessar 2001, Pessar and Mahler 2003), but we also need to be attentive to how local conditions in both origin and destination countries impinge on those processes, which Brickell and Datta (2011b) highlight in their work on translocality. And importantly, a close examination of remittances allows us to further include non-migrants and understand how migration may impact them in gendered ways (Kunz 2008, Levitt 1996).

\section{Economic Remittances}

Economic remittances are transfers from destination to origin of funds, and sometimes material goods are also included in this definition ${ }^{74}$, either by electronic or personal transfer while sending migrants are abroad and/or in-person by the migrants upon their return home (Ramírez, García Domínguez and Míguez Morais 2005). Although some research has examined how gender-based considerations shape senders'

\footnotetext{
${ }^{74}$ In a more detailed delineation, Kunz (2008), drawing on Durand (1994) provides a typology of economic remittances according to the intended use: wages or salaries to support relatives, investment money to be directed toward the purchase of land or a house, for instance, and capital, to be spent on other productive investments.
} 
remitting behaviour (Vullnetari and King 2011), it is equally important to look at the gendered impacts of remittances. The act of male migrants sending money to their families at home is likely to uphold patriarchal household arrangements because these remittances reinforce men's roles as primary breadwinners (Taylor, Moran-Taylor and Rodman Ruiz 2006). As for women, sending remittances as migrants may result in a gradual erosion of male control coupled with an increase in women's household authority (Kunz 2008, McKay 2001), and those who receive men's remittances may assume more financial responsibilities and greater autonomy over how household income is spent (Ramírez, García Domínguez and Míguez Morais 2005, Vullnetari and King 2011). Frequently conditioning these potential effects, however, is continued control over women's financial autonomy during men's absences (Boehm 2008). I expand on some of this literature to introduce my analysis of women's and men's economic remittances in Chapter 8, and draw on the resource theory of household power, as outlined in Chapter 2, to theorize the gender-related impacts, while being attentive to socio-cultural circumstances that mediate the influences of income.

\section{Social Remittances}

In addition to economic remittances, migration may also present potential for nonmaterial transfers (José Alcalá 2006, Levitt 1998, Peláez 2009, Ramírez, García Domínguez and Míguez Morais 2005). Often over-shadowed and less-developed analytically in current research than economic transnational flows, social remittances are non-tangible transmissions of ideas, behaviours, values and identities (Levitt 1998).$^{75}$ An

\footnotetext{
${ }^{75}$ Most of the literature on social remittances focuses on flows from destination to origin contexts and influences thereof, but the reverse is also true, in that migrants arrive at destination with sets of ideas, behaviours, and values that both influence host societies and shape migrants' experiences therein (Levitt 2010). This has been examined among economic immigrants, for instance, and how their skills and cultural
} 
examination of social remittances from a gender perspective focuses attention on the potential for migrants to learn about new gendered ideologies and practices and transmit them to home communities - through return migration and forms of communication such as telephone - in such a way as to contribute to changes in gender relations in both migrant and non-migrant households through processes of cultural diffusion (Levitt 1996, Levitt 1998, Peláez 2009, UNDP 2009a).

A few authors examining Guatemalan women's migration have explored the "transformative" potential in significant changes of social, political, economic, and cultural settings that migrants experience (Lindstrom and Muñoz-Franco 2005:278). Through migration to the United States, Guatemalan women may learn about contraceptive use (Lindstrom and Muñoz-Franco 2005), how domestic violence is addressed (Taylor, Moran-Taylor and Rodman Ruiz 2006), and that American men participate more in housework than Guatemalan men (Menjívar 1999). As for male Guatemalan migrants in the U.S., Peláez (2009) found that some had adopted attitudes that they should share household tasks more with their wives and that both partners should do income-earning work.

In its analysis of migration's implications for development, the UNDP calls attention to the potential for social remittances to contribute to "far-reaching" effects on social norms (UNDP:71), but it must be said these non-material accumulations and flows are not always 'positive' from a gender equality or wider social change perspective (Levitt 2010). Migrants can learn about and remit socially regressive, harmful, or even hateful ideas as a result of their experiences and exposure. Furthermore, the potential of social remittances to weaken patriarchal gender relations depends, among other

capital suit them for employment success at destination (Erel 2010; Hari 2013). 
considerations, on the features of the contexts where the remitted content is received, notably the value it is assigned and the strength of stakes in the status quo (Levitt 1998). Moreover, social remittances often do not accrue or get transferred (Peláez 2009) - for instance, the possibilities presented in the research on Guatemalan migrants' social remittances above suggest certain qualities of interaction with the host society that would not be the case for all migrants.

With these caveats provided, in my analysis in Chapter 9 of gender-related social remittances, I will focus on gender consciousness as a social remittance, drawing on theory developed in Chapter 2 at the ideological level of gender. And I will draw on Levitt's $(1996,1998)$ three-stage model of the social remittance process - consisting of creation, transfer, and impact - to examine the development of gender-related awareness and its potential shaping of household gender relations. My analysis will include pertinent factors in both Canada and Guatemala that mediate the accumulation and flow of gender-related information.

\section{Bourdieu's Conceptual Tool: Capital}

If we return briefly to look at what Bourdieu's conceptual tools could add to consideration of economic and social remittances, we hone in on capital, which was mentioned above for its role in structuring actors' positions in fields. For Bourdieu, capital includes "all material and symbolic goods that present themselves as rare and worthy of being sought after in a particular social formation" (Thieme 2008:60). In addition to the economic variety - meaning the "ownership of monetary profit" (Thieme 2008:60) - Bourdieu (1986) outlines three other types of capital: cultural, social, and symbolic. Cultural capital, in addition to its objectified forms such as art, includes 
educational and other credentials, language capability, and cultural 'know-how'; social capital includes networks and contacts that can accord advantages; and symbolic capital essentially means honour (Bourdieu 2001), but more specifically, the "recognition and legitimization of other forms of capital that can give a person prestige and reputation" (Thieme 2008:60). All of these forms can be converted from one type to another.

In terms of how capital figures in Bourdieu's theory of practice, I have alluded to capital's relation to field - i.e., fields are oriented toward struggles for these capitals, and the distribution and holdings of these capitals determine people's positions in a field - but as well, habitus contributes to how social actors value certain forms of capital (Kelly and Lusis 2006), and capital combines with habitus and the present and future possibilities presented by the field to shape practices (Mahar, Harker and Wilkes 1990, Mahar 1992, Rahman 1998). Bourdieu (1986) describes the particular role played by capital as amounting to a set of constraints that make everything not equally possible, that determine the chances of success of practices.

Migrants have the potential to accumulate and remit or return with economic, cultural, and social capital. Social capital figures among social remittances (Kunz 2008) and other studies have examined its roles in positioning migrants in destination contexts and encouraging further migration, including the gendered dynamics of these processes (e.g., Pessar 1999a, Piper 2008b). However, I did not incorporate social capital into my study because it did not arise as an issue of much import to the household gendered impacts of Guatemalans' migration. By examining economic and social remittances, I am exploring the accumulation, transfer, and impact of economic and cultural capital. Bourdieu's understanding of the role of capital - as a resource that actors bring to bear on their strategies and to position themselves in relation to others - is consistent with two of 
the pillars of my theoretical framework: the resource theory of power, and gender consciousness. $^{76}$ Both money and cultural 'know-how' about gender roles and practices can be used as resources to effect continuity or change in gender relations (Sullivan 2006). As examples of gender-related cultural capital, some authors have identified certain experiences of female Guatemalan refugees to Mexico, the U.S., and Canada during la violencia as influential in subsequent women's and feminists' organization after their return to Guatemala (Jeffries 2007, Jimeno 2001, Nolin 2006). In other research, McKay saw cultural capital among returned Filipina migrants in the form of dress and knowledge about different lifestyles and inter-personal relations encountered overseas. She sees these influences on local gender practices as "more important than the actual economic contribution of migrant women to local households" (2001:46).

We cannot simply take at face value, and expect impacts from, migrants' return with forms of cultural expression and knowledge. As will be discussed in my analysis chapters, it is crucial to bear in mind two aspects of the interactions between capital and field. First, the value of a particular type of capital is field-specific; that is, each field has its own hierarchy of different species of capital (Bourdieu and Wacquant 1992), and a given form of capital receives value only if it enters a field in which it is valued (Thieme 2008). ${ }^{77}$ For instance, if we consider as cultural capital the knowledge acquired by

\footnotetext{
${ }^{76}$ Some debate continues over whether habitus can be considered cultural capital. For instance, the embodied nature of habitus - e.g., bodily characteristics such as style of dress, comportment, and mannerisms - may be used as cultural capital in settings that bestow value on certain of these aspects (Mahar, Harker and Wilkes 1990). For instance, McKay (2001) argues that certain sexualized postures can constitute resources for women as they try to negotiate discourses of femininity. And Adkins (2002) contends that employees in service sectors can use certain feminine comportments as workplace resources. Lau (2004), however, argues for a tight conceptualization of habitus and against equating it with cultural capital, which involves too much cognitive reflection for it to be part of habitus. Instead, habitus and capital have a relationship of valuation; habitus acts as a framework that predisposes individuals to assign different values to different kinds of capital (Kelly and Lusis 2006).

${ }^{77}$ The rules that govern the value given to different types of capital are alterable, but only by those with sufficient capital (read: power) to do it (Bourdieu and Wacquant 1992).
} 
Guatemalan women that men in the United States contribute more to housework than in Guatemala (Menjívar 1999), this may well clash with what is valued culturally in their indigenous Guatemalan home setting - relatively unchanged ${ }^{78}$ - where being "good wives or husbands" (Rahman 1998:60) entails a gender division of labour that does not include men doing much housework. Second in relation to interaction between capital and field, a migrant's accumulated type of capital might conflict with or threaten the hold of another person's capital in a migrant's community. For example - and this relates to threats to masculinity as discussed in Chapter 2 in reference to the resource theory of power - a female migrant's economic capital ${ }^{79}$ may conflict with her male partner's symbolic capital (honour and prestige) that he derives from being the household head, tied to the norm of the male breadwinner (Latreille 2006). As such, it is enormously important to consider the context to which migrants return and/or send their remittances, for its role in determining how economic and cultural capital can be used to influence household gender relations (Levitt 2001, Peláez 2009). Peláez (2009), based on her study on Guatemalan men's social gender-related remittances, emphasized that their potential for changing gender relations is increased when there is consciousness about gender equality in the return environment, in addition to families' and partners' support.

\section{Conclusion and Integration of the Theoretical Framework}

In this chapter, I have situated my study within three major sets of scholarship gender and migration, transnationalism, and the application of Bourdieu to migration

\footnotetext{
${ }^{78}$ Kelly and Lusis (2006) do point out that participation in transnational social fields can contribute to a transnationalization of the habitus of both migrants and non-migrants, which causes them to change the way they value certain forms of capital, meaning that the way home communities value certain forms of capital can shift.

${ }^{79}$ I categorically reject Bourdieu's contention that women cannot be bearers of capital in their own right because of their positions as objects in the "market of symbolic goods" (Bourdieu 2001:99).
} 
studies. Seeking to explain and not only describe, I have outlined the major ways in which migration may influence household gender relations - by focusing on the gendered self, economic remittances, and social remittances - and have demonstrated how I will critically employ Bourdieu's major concepts of habitus, field, and capital to analyze the processes at play in my study. My framework is founded, first, on conceptualizing gender as a structure - manifesting at the self, institutional, and ideological levels, each of which plays a role in shaping household gender relations - and, second, on approaching Guatemalan household gender relations from both political-economic and cultural perspectives, as emphasized by the literature I reviewed in Chapter 2. Founded on these two premises, I will theorize continuity and change in Guatemalan household gender relations according to the potential influences of migration on the gender habitus, gender consciousness and ideologies, and the distribution of economic resources in the household, according to the resource theory of household power. Put differently, I will investigate the tri-partite influence on household gender dynamics through examining migrants' and non-migrants' local practices (self level), social remittances (ideological level), and economic remittances (institutional level). See Figure 1 for an illustration of my theoretical framework. 
Figure 1: Theoretical Framework - Gender as a Structure and Avenues of Change and Continuity in Household Gender Relations

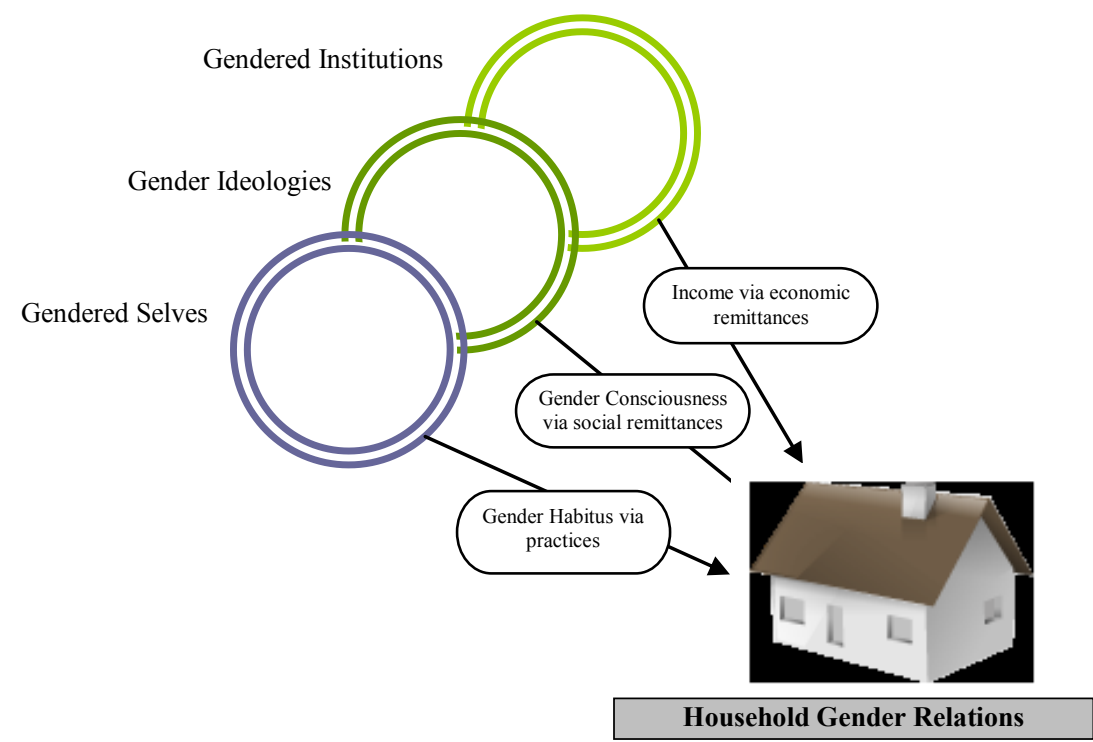

My approach makes a substantial contribution to theorizing gender and migration, as other studies tend to focus on one 'level' of gender's manifestations or one type of influence that migration can generate, such as social or economic remittances. By combining three gender levels and possible avenues of influence, I present a more complete explanation than other studies of the relationships between migration and household gender relations. And while my theory draws on elements of transnationalism, heeding Brickell and Datta's call (2011b) to localize the transnational, my analysis will attend to characteristics of Guatemalans' lives both in Canada and Guatemala.

I turn now to detailing my methodology. 


\section{Chapter 4}

\section{Critical and Reflexive Feminist Research in Highland Guatemala}

This chapter introduces my study region and describes my reflexive process of data collection and analysis. Through so doing, I orient my fieldwork both in its setting in Guatemala and in the literature on feminist, ethnographic, and de-colonizing methodologies. I begin by providing an introduction to the municipality of Tecpán Guatemala and to the village of "Vista Hermosa" ${ }^{80}$ where I conducted the majority of my fieldwork. The subsequent section describes the methods and methodologies that I employed, demonstrating the principles that my research espoused, with an emphasis on critical feminist investigation. The third section provides a detailed examination of my processes of data collection from the initial stages in Canada to participatory and interview-based fieldwork in Vista Hermosa, and importantly, I provide in this section some reflections on challenges in the fieldwork and what those suggested about the implication of my 'self' therein. The final section of the chapter elaborates my process of data analysis, with a focus on a combination of inductive and deductive methods, coding processes, and incorporation of intersectional analysis.

\section{The Study Area: Tecpán Guatemala and Vista Hermosa}

I document later in this chapter the circumstances through which Vista Hermosa became the primary site of my fieldwork, and in the following chapter, I outline household gender relations there. In terms of a brief introduction - drawing on available literature, government documents, and information gleaned through my study - Vista Hermosa is a mostly Kaqchiquel Maya village of approximately 2,500 residents (INE

\footnotetext{
${ }^{80}$ A pseudonym.
} 
2008). It is located in the municipality of Tecpán Guatemala ${ }^{81}$, in the department of Chimaltenango, in the Central Highlands of Guatemala (Oficina Municipal de Planificación 2008a). See Figures 2 and 3 below for maps. The village sits elevated about one kilometre from the Interamerican Highway, about eighty kilometres west of Guatemala City (INE 2008, Oficina Municipal de Planificación 2008c). It is a sprawling place with houses, tienditas (little stores selling basic foodstuffs and supplies) and farmland scattered across a few square kilometres of hills and dales and networks of dirt roads and footpaths. Kaqchiquels today are the predominant ethno-linguistic Maya group in the Tecpán area, making up 70 per cent of the population in the urban area, 95 per cent rurally (with the remainder being Ladino) (Fischer and Hendrickson 2003), and nearly all Vista Hermosa residents. While Kaqchiquel is the first language of many in the village, most are fluent in Spanish.

Tecpán town - population 18,000 - is an important regional trading centre with increasing local-global connections (Fischer and Benson 2006), and is known as fairly "affluent and progressive" (Fischer and Hendrickson 2003:2). However, the region as a whole is still peripheral "to the mainstream of economic prosperity" and services (Fischer and Benson 2006:59), and the rural areas are relatively impoverished. According to the Tecpán municipal office, the majority of the municipality's inhabitants live in economic precariousness (Oficina Municipal de Planificación 2008a), a situation owed to a shortage of non-agricultural employment opportunities, low rates of pay in both urban and rural areas, a relatively high cost of living, and a land system - with a history partly outlined in

\footnotetext{
${ }^{81}$ The municipio (the municipality) of Tecpán Guatemala, like municipalities in Canada, contains an urban centre that I call Tecpán town, which is surrounded by a large rural area made up of villages and hamlets.
} 
Chapter 1 - of latifundio and minifundio ${ }^{82}$ (Oficina Municipal de Planificación 2008a) in which "there are no medium-sized producers, only small ones and big ones" (Fischer and Hamilton 2005:41).

\section{Figure 2: $\quad$ Map of Guatemala}

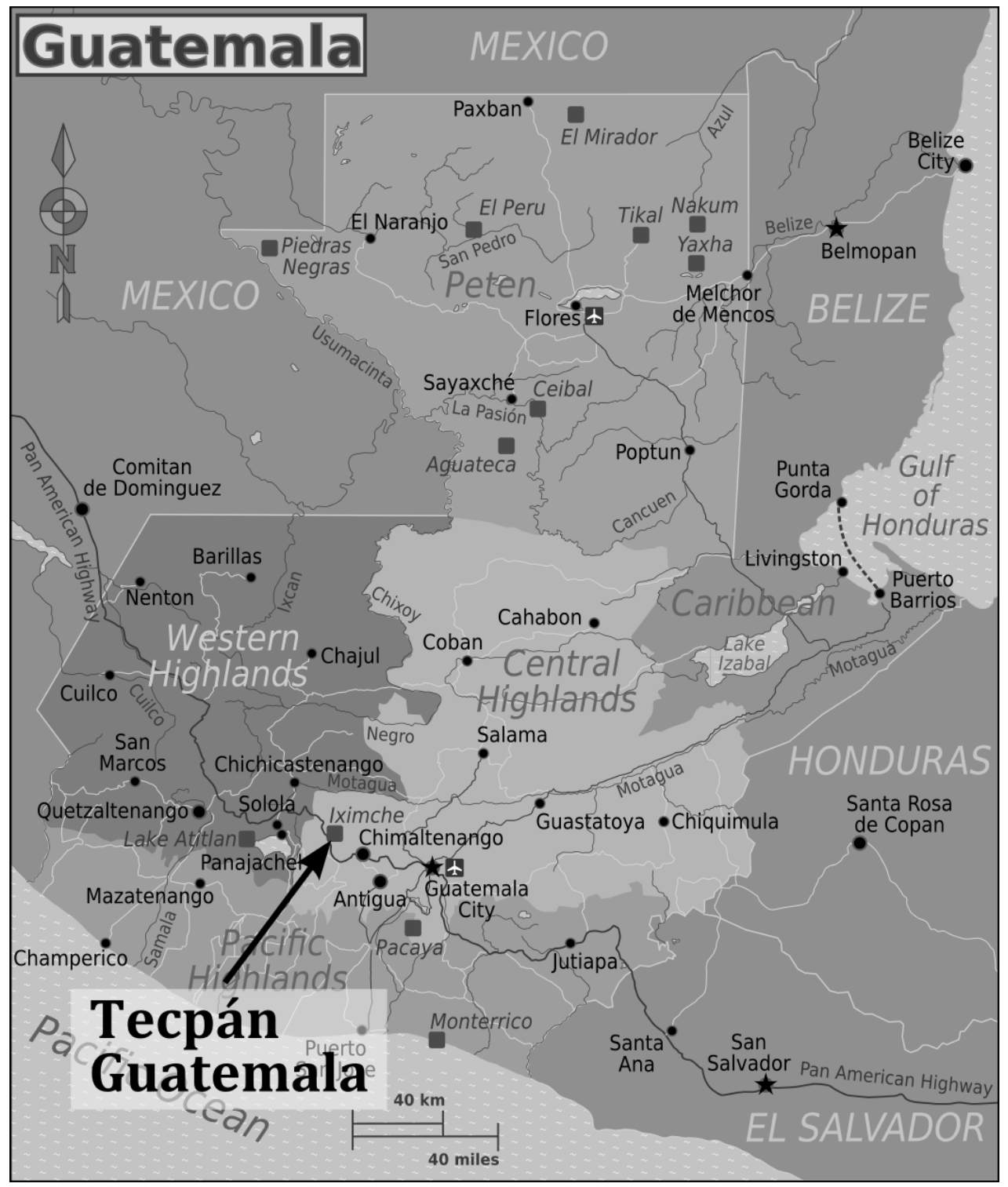

Source: Burmesedays 2010.

\footnotetext{
${ }^{82}$ This land system is characterized by an unequal distribution in which the majority of good land is concentrated on large estates oriented toward agricultural exports, and the poorer land left to small-scale farmers (de los Reyes 2001, PNUD 2008).
} 
Figure 3: $\quad$ Map of the Municipality of Tecpán Guatemala

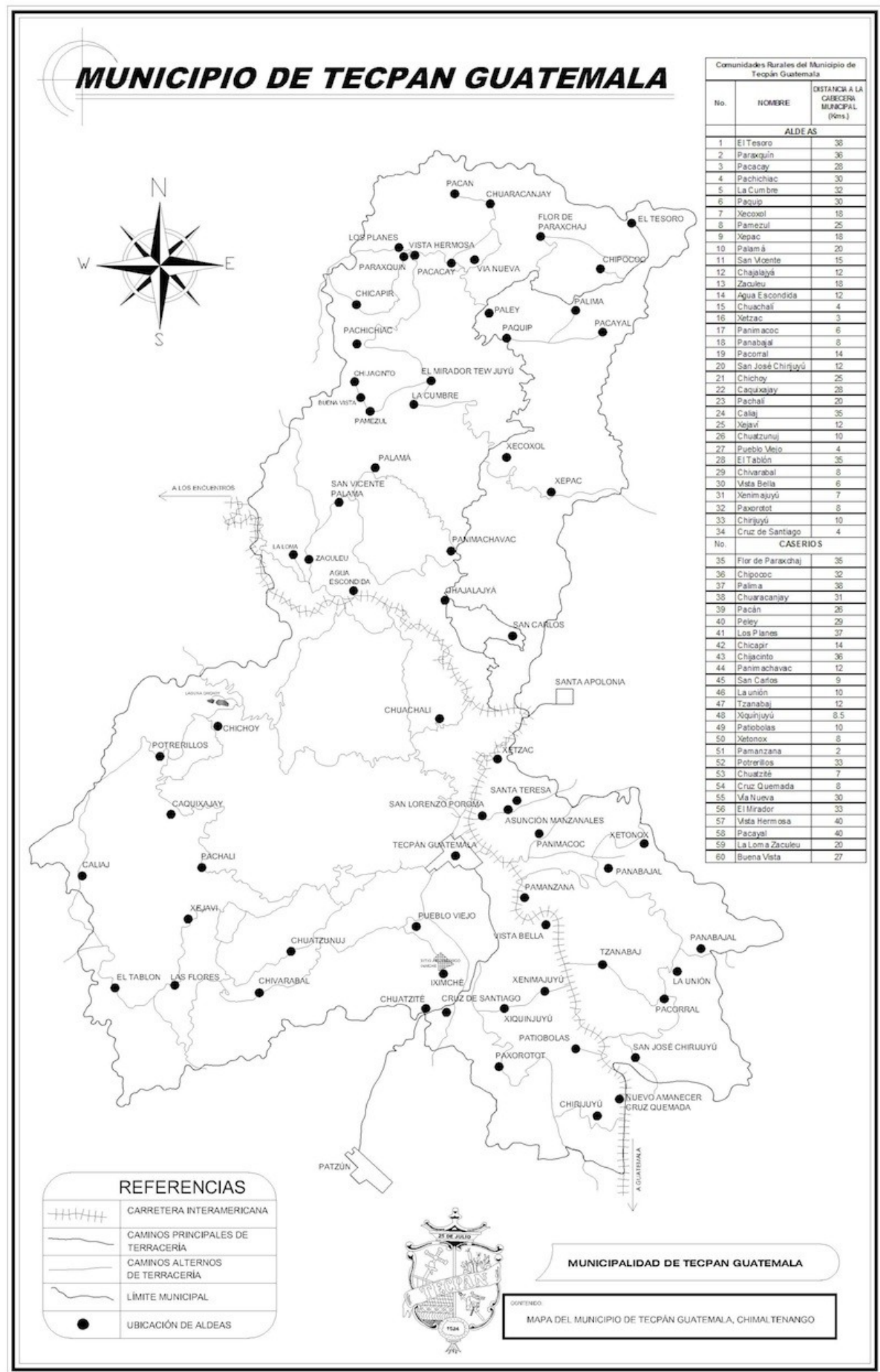

Source: Oficina Municipal de Planificación 2010. 
The vast majority of Tecpán rural area residents - and certainly in Vista Hermosa - earn their livelihoods through agriculture (Fischer and Hamilton 2005), which continues to be predominantly oriented toward production for local diets (Oficina Municipal de Planificación 2008a). Small-scale farming is most often devoted to milpas, small plots of land where maize and beans are often interspersed with complementary crops (Fischer and Hendrickson 2003), for both subsistence and sale. However, trends in the Tecpán area since the 1970s have changed the face of local and household economies through the introduction of non-traditional export-oriented production (Oficina Municipal de Planificación 2008b), as discussed in Chapter 2 for the implications for household gender relations. Many Vista Hermosa farming households are part of this trend, growing such crops as strawberries, lettuce, and snap or snow peas, and the industry as a whole has generated employment on larger plantations, in the transport of produce, and in packing plants, of which there were two in Vista Hermosa. As such, agriculture-related activities of Vista Hermosa households were quite varied, with residents combining production on their own and/or rented land for both subsistence and market, and working for wages in producing, packing, or transporting crops. As an economic spin-off, nontraditional agriculture has contributed to modest reductions in ethnically-biased land concentration as in Tecpán as some indigenous farmers or waged workers have used earnings to buy land from larger landholders (Fischer and Hamilton 2005). However, some ambiguous and negative results have followed as well, including technological divides (Fischer and Benson 2006) and the acceleration of "class differentiation in a way that threatens traditional social cohesion" (Fischer and Hamilton 2005:36).

Vista Hermosa is better off economically than other villages in the Tecpán area, 
with the mayor describing poverty levels as a "nivel medio (medium level), not good, not bad." Certainly the village's prosperity has increased with migration to Canada. The mayor noted sure signs of desarrollo (development) that had arrived fairly recently including a new school, health centre, and better electricity infrastructure - and identified international migration as responsible for these positive changes. ${ }^{83}$ However, research suggests that communities with significant international out-migration are not the poorest of the poor to begin with, given the significant investments and risks that cross-border migratory projects often involve (de Haan and Yaqub 2008). As mentioned in Chapter 1, migrants incurred significant expenses to migrate to Canada, but most Vista Hermosa migrants had borrowed funds to make these payments. Migration to Canada (and to a lesser extent the U.S.) aside, the village's relative advantage owes to its proximity to the highway and Tecpán town (and therefore to employment opportunities), its own two packing plants, and a lot of arable land. However, the mayor claimed that poverty continued to be the most significant problem in the village, due in large part to limited sources of local employment.

Based on my observations from seeing most of the village on foot and being inside many of its homes, there was a mix of socio-economic situations, making a description of a 'typical' house somewhat difficult. Housing materials included concrete block, laminate, and adobe (mud or clay); some houses had dirt floors whereas others had cement or tiles; and many homes had televisions but personal vehicles were more rare. The next chapter details in gender-related terms the key tasks involved in household-

\footnotetext{
${ }^{83}$ It was not entirely clear how these communal sources of development were linked to migration, given that, to my knowledge, there was no hometown association in Vista Hermosa (where migrants pool some of their income for the common betterment of their community (Hellman 2008)). However, residents were taxed by the municipality, and perhaps as a result of rising income levels due to migration, taxation revenues had increased, enabling more investment in the community's infrastructure.
} 
based labour, but in terms of houses' features and amenities related to that labour, almost all homes had dependable electricity while indoor plumbing (toilets, sinks, and showers) were less common, some houses had their own sources of water whereas others depended on communal sources but in neither circumstance was the water purified, and the presence of dirt, dust and animals made cleaning a daily, seemingly constant chore. Related to women's work most directly, every one of the variety of homes I visited had two key features: a large cement partitioned water station called a pila in which clothes and dishes would be washed and non-potable water would be stored, and a wood-fired stove made of clay - often called a plancha for the flat metal cooking surface on which everything from tortillas to coffee would be prepared. ${ }^{84}$ Some households that could afford the use of fuel other than firewood had gas stoves as well but there was always a plancha and - for reasons to do with tradition and the nuisance of keeping the gas tanks filled - it was preferred for food preparation.

Although the experience and effects of the civil war were much less pronounced in Vista Hermosa and the Tecpán area in general than elsewhere, la violencia certainly touched the region, especially in Tecpán town, which the government believed to be the home of guerilla sympathizers (Fischer and Hendrickson 2003). It is a delicate subject to discuss openly, but Vista Hermosa's mayor said, "no fuimos afectados mucho (we were not affected very much)," that the war was responsible for the deaths of three villagers who had been in the guerrilla movement. However, the community certainly felt the government's oppression of indigenous peoples and experienced sadness for the loss of life. And the effects of state terror live on in Tecpán among those not directly affected:

\footnotetext{
${ }^{84}$ Problematically for women's health especially, these planchas are usually located indoors, often with poor ventilation. So-called 'stove projects' have been launched in Guatemala and elsewhere in an effort to improve stoves' efficiency and ventilation systems (e.g., Álvarez, Palma and Tay 2004).
} 
"the years of harsh conditioning to hold one's thoughts and to refrain from any criticism of the state are present in the loaded silences of conversation about the period" (Fischer and Hendrickson 2003:69).”

Stemming in part from the impacts of the war years on religious adherence, as discussed in Chapter 2, religion patterns in Vista Hermosa are largely a mix of Roman Catholic and Evangelical Protestant. These religions account for 95 per cent of affiliations in the Tecpán area (60 and 35 per cent respectively), falling into a diverse range of doctrines and congregations (Fischer and Hendrickson 2003). In Vista Hermosa there was one main church for both Roman Catholics and Evangelicals, as well as smaller congregations of 'Charismatic' Catholics and other Evangelicals. There were occasional politics and 'bad blood' among the churches; for instance, I was told that one of the smaller ones had spread rumours in the community that affiliation with another of the churches would threaten migrants' chances or continued opportunities to migrate to Canada! Although both Catholic and Evangelical churches prohibit contraception, Tecpán area Evangelical denominations prohibit women from engaging in certain practices, including significant cutting of the hair and wearing of jewelry, make-up, or pants (Cumes Jochola 2010).

Having provided an introduction to my research area and village, I move now to a discussion of the conduct of my research.

\section{General Research Orientation and Principles}

This examination of household gender relations in the context of migration is a qualitative study, and in addition to text-based research, I primarily employed semistructured interviews and participant observation (Behar 1996, de Munck and Sobo 1998, 
Mason 2002, McLeod 2003, Rapley 2004). Following interview guides (see Appendices D and E), I conducted 59 interviews (complemented by 13 non-interview encounters) with migrants, their partners, organizational representatives and academics, mostly in Guatemala but in Canada as well (See Table 3 on page 127 of this chapter). By living in Vista Hermosa and staying with a host family for two months in the spring of 2010, I combined participation in everyday activities with the "professional distance" needed to observe and record data (Fife 2005:71), getting closer to social life and building more trust and rapport than would have been the case had I chosen to live outside the community and just go there to conduct interviews (de Munck and Sobo 1998). I provide more information on interviews and participant observation later in this chapter, after outlining my methodologies: ethnographic, feminist, and de-colonizing.

I understand and used ethnography as an approach that entails the acquisition of contextual knowledge and logic through first-hand experience with a given group or culture, and that aims to produce a written representation of their experiences in relation to a certain topic, with an emphasis on contextualizing interpretation and explanation (Behar 1996, Bjerén 1997, Fife 2005, Skeggs 1994). Although my data generally does not lend itself to the 'thick description' characteristic of some ethnography, ${ }^{85}$ it was appropriate and beneficial for the flexible, context-specific research I did with a small group (de Munck and Sobo 1998).

In relation to feminist methodologies, I outline here the primary unifying tenets that I incorporated into my project, and in the following research process section, I

\footnotetext{
${ }^{85}$ In a thick description method, "breadth is sacrificed for depth" (de Munck 1998: 33), and detailed accounts are provided of cultural patterns and meanings (Ezzy 2002) often as a result of in-depth and prolonged participant observation and respondents' narratives. I was not able to do this very much, given the length of time that I was in Guatemala, the breadth of issues I wanted to examine, and the question-andanswer nature of interviews.
} 
provide more details about how I did so. First, at its most basic, feminist research should be conducted with and ideally for women, in order to acknowledge how patriarchy may have subdued their voices, to value their ways of knowing, and to better understand their experiences (Doucet and Mauthner 2006, Field Belenky, McVicker Linchy, Rule Goldberger et al. 1986, Kelly, Burton and Regan 1994).

Secondly, I am concerned with social change and social justice, specifically with challenging patriarchy (Doucet and Mauthner 2006, Fish 2006, Grbich 2007, Kelly, Burton and Regan 1994, Perry 2001, Sprague 2005). I do not set out to liberate or empower women through research, given problems with attendant homogenizing, presumptive, and condescending ways of thinking (Grbich 2007, Kelly, Burton and Regan 1994, Mohanty 2003, Skeggs 1994). For related reasons, as well as practical ones (Millen 1997), I did not use gender equality terminology in my fieldwork in Vista Hermosa. I tried to adhere to what Kelly et al. (1994) call a non-judgmental stance, but in the next section I reflect on problems with this. I see the potential for gender-related social change in attempts to explain (not just describe) social phenomena so as to better identify where local leaders can target transformative efforts (Kelly, Burton and Regan 1994), and in sharing my research findings with participants and women's groups in Guatemala (Skeggs 1994).

Third, I have concerned myself with issues of power and inequality in the research process (Coffey 1999, Doucet and Mauthner 2006, Fish 2006, Grbich 2007, Skeggs 1994, Sprague 2005), during much of which I occupied an advantaged position relative to participants (Millen 1997, Wolf 1993). In relation to Vista Hermosa residents, my privilege stemmed from my socio-economic status, high level of education, North 
American-ness, and Whiteness (Fish 2006, Perry 2001). ${ }^{86}$ Imbalances of power cannot be completely overcome, despite our best efforts (Doucet and Mauthner 2006, Fish 2006, Millen 1997). However, participants are not powerless and may get more out of interviews than we think (Phoenix 1994, Skeggs 1994, Sprague 2005, Thapar-Bjorkert and Henry 2004), and we can 'give back' in small but meaningful ways (Fish 2006).

Fourth in terms of feminist research principles, I have engaged in my own reflexivity (Doucet and Mauthner 2006, Fish 2006, Grbich 2007, Mauthner and Doucet 2003, Tuhiwai Smith 1999). ${ }^{87}$ This involves open reflection on my 'self', biography, and social location in relation to the research context and participants, and how those may have shaped the research process, my experiences of it, and the final products (Coffey 1999, Doucet and Mauthner 2006, Fife 2005, Jasper 2005). The call for reflexivity is based in acknowledgement that research is never objective, and that knowledge is partial, perspectival, and co-created (Fish 2006, Mauthner and Doucet 2003, Millen 1997). ${ }^{88}$ Researchers are urged to be reflexive about a great deal (cf Fawcett and Hearn 2004, Mauthner and Doucet 2003, Rapley 2004, Roberts and Sanders 2005, Sanford 2006), and it is sometimes unclear how to discern how the 'self' has influenced our processes (Mauthner and Doucet 2003), and what to do after "we make ourselves the object of reflective inquiry" (Atkinson, Coffey and Delamont 2003:38). However, we are encouraged to integrate reflexive processes into our writing so others can better understand our representations of what we observed (Behar 1996, Coffey 1999, Jasper 2005). I have done so in parts of the writing that follow, including an examination of

\footnotetext{
${ }^{86}$ Perry urges us to remember that to be White is to "have a race like any other", which "challenges the assumption that whiteness is normal and brownness, blackness, and redness are problematic "others"” (2001:5).

${ }^{87}$ Although for critiques of the 'reflexive turn' in social science, see Atkinson et al. 2003.

${ }^{88}$ Reflexivity is particularly important when a given topic of research - such as gender relations - poses the risk of reproducing polarizing discourses, or essentializing the parties involved (Tuhiwai Smith 1999).
} 
some challenges in the fieldwork process.

Given that early stages of research implicate the self, I would disclose in a biographical sense (Roberts and Sanders 2005, Sprague 2005) that this project and its questions have been influenced by a trajectory that includes a Master's degree in International Development Studies - a discipline where, although not uncritically, gender equality is considered a desirable form of 'development', an internship in 2003-2004 with a women's anti-violence organization in Guatemala where I saw gender inequality in some of its worst forms, and a longstanding sympathy toward social justice causes. While I can be explicit about this particular conditioning, it is quite possible that the biographical researcher self suffuses the whole research text (Coffey 1999), and sometimes not in ways we can perceive (Doucet and Mauthner 2006), including a "scholastic point of view" (Schirato and Webb 2003:549). However, we can approach these exercises in terms of "degrees of reflexivity" (Mauthner and Doucet 2003:425).

Combined with feminist orientations, this study also incorporates elements of decolonizing or anti-imperial approaches to research, in recognition that "the pursuit of knowledge is deeply embedded in the multiple layers of imperial and colonial practices" (Tuhiwai Smith 1999:2) that continue today in new forms (Martínez Salazar 2012). Seeking to redress or at least not repeat harmful practices of research against people in the Global South, de-colonizing or anti-imperial approaches share in common with feminist research a concern with power relations and calls for reflexive practices (Shih 2002, Tuhiwai Smith 1999).

Combining feminist and de-colonizing/anti-imperial approaches forces new realizations and ways of conducting research. Feminist research, undertaken by women in the Global North with or on women or gender relations in the Global South is potentially 
fraught with Western cultural imperialism (Mohanty 2003, Pratt 2004). By undertaking research with ideas and goals flowing from feminist teachings and worldviews, it is argued that Western feminist scholars risk imposing supposedly superior ideas without acknowledging or valuing research participants' knowledge, perspectives, and complexities of oppression, or recognizing their agency (Mohanty 1991, Shih 2002). Martínez Salazar likens telling Guatemalan Mayan women how to be, to the past destruction of their culture, which happened "not only with guns, but with the power of the word" (2012:10). And particularly by applying gender equality approaches to nonWestern contexts, we are problematically suggesting that gender relations are sufficiently egalitarian in the West and a model to which the Global South can and should 'catch up' (Mohanty 1991, Shih 2002).

The 'de-colonization' of my feminist methodologies involved the following critical moves. First, I have reflected upon and sought ways to avoid the imposition of Eurocentric assumptions and biases, and will highlight participants' voices and perspectives. This does not necessarily require rejecting Western theory, knowledge, or a critical perspective, but an incorporation of participants' concerns into our projects, and their worldviews in our understandings (Cervone 2007, Fife 2005, Tuhiwai Smith 1999). Second, I reject the homogenizing label of the 'Third World Woman' (Kaplan 1994, Mohanty 1991), and show attentiveness to historical and cultural specificity in my study. Third, although I acknowledge many structural constraints on Guatemalan women's lives, I try to avoid victimizing them, instead illustrating their different practices of agency (Mohanty 2003, Shih 2002, Tuhiwai Smith 1999). Fourth, and also reflecting a concern with intersectionality, I try to recognize ways in which gender may not be the most dominant or felt axis of social differentiation or oppression for study participants 
(Mohanty 2003). Finally, I will share the results of my research with study participants using formats and ideas that they might use to the benefit of community members (Tuhiwai Smith 1999).

Having laid out the key methodologies, principles, and intentions in my research, I turn in the following section to discuss my primary data collection, derived primarily from interviews and participant observation conducted in Canada and Guatemala over a 10-month period. In doing so, I also take the opportunity to share some reflections about how my subject position influenced undertaking and experiencing my fieldwork, and reinterpret certain challenges by drawing on anti-imperial and intersectional insights. This exercise follows some 'best practices' of critical feminist research, including attentiveness to the emotional components of research (Denzin 1998), and a willingness to expose the complexities and dilemmas of research experiences in order to improve our approaches (Fish 2006, Sprague 2005, Wolf 1993). Through a few examples, I will show how difficult it can be to shed our subject positions (Fish 2006) as much as we try to consciously follow the guidelines of ethical and anti-imperial or de-colonizing research.

\section{The Research Process: Primary Data Collection}

I began the process of data collection in the summer of 2009 in Canada by volunteering at the Agricultural Workers Alliance migrant worker support centre in StRémi, Quebec. Funded by the United Food and Commercial Workers (UFCW) Canada, it provides information and services to labour migrants and supports unionization of agricultural workers. I initially intended to recruit and possibly interview study

participants and discern where to do my fieldwork in Guatemala, but due to a combination of time constraints, trust issues, and no female migrants (because they 
worked too far away) that precluded recruitment and interviews, I volunteered my time, chatted with workers and staff, and walked around the town to get a sense of workers' experiences. That I was not able to kick-start my study in St-Rémi may have been to my advantage because of the cautiousness I would encounter in Vista Hermosa of involvement with "the union". However, this initial affiliation sowed the seed for an activist side project that I document at the end of this section.

In the intervening months before going to Guatemala in February 2010, I contacted organizations in Canada related to my project for information and interviews, most notably Human Resources and Skills Development Canada (HRSDC), ${ }^{89}$ the Guatemalan consulate in Montreal, and the Commission des droits de la personne et des droits de la jeunesse (CDPDJ), Quebec's human rights body. I also began concretizing fieldwork plans by deciding on Tecpán Guatemala as the general area for my research, through information gleaned from IOM reports, American ethnographers, and a list of migrant workers obtained from an unidentifiable source. I would further narrow my focus to the village level at a later point.

I arrived in Guatemala City on February $2^{\text {nd }} 2010$. With a women's co-operative and rooming house as my home base, I planned my next steps and conducted five formal and five non-formal organizational interviews ${ }^{90}$ with twelve respondents at seven civil society and research organizations ${ }^{91}$ (others would follow, including the IOM), and had a

\footnotetext{
${ }^{89}$ Now called Employment and Social Development Canada.

${ }^{90} \mathrm{~A}$ few of these research encounters would be better classified as conversations, focused to a greater or lesser extent on issues related to my study.

${ }^{91}$ 1) INCEDES, the Central American Institute for Social Studies and Development, a developmentfocused NGO with an interest in migration; 2) Asociación de Mujeres Nuestra Voz, (Our Voice Women's Association); 3) MENAMIG, the National Roundtable on Migration, a migration-oriented NGO; 4) AVANCSO, the Association for the Advancement of Social Sciences in Guatemala; 5) FLACSO, the Latin American Faculty of Social Sciences; 6) the Institute of Economic and Social Research at Universidad Rafael Landívar; and 7) Sector de Mujeres (Women's Sector).
} 
few casual, informative conversations with Guatemalan feminist academics and women's movement representatives. I relocated to Tecpán town on February $24^{\text {th }}$, where I met with one IOM project migrant and his wife, and chose the main village for my research with migrant households. That determination followed from fortuitous circumstances including my encounters with American PeaceCorps volunteers with knowledge about surrounding villages, and an American woman, Jane ${ }^{92}$, who had married a Guatemalan and lived in a village that had many labour migrants to Canada. That village was Vista Hermosa, where I relocated on March $8^{\text {th }}$.

A settling in period before starting interviews with migrant households entailed several activities. With the help of Jane and her husband Miguel ${ }^{93}$, I identified a migrantsending host family with whom I would soon move in, as well as two research assistants, Clara and Fiona, who were IOM project ${ }^{94}$ participants. I sought research assistants in order to locate study participants, ease communication and translate between Spanish and Kaqchiquel as necessary, facilitate conversation in interviews - given that they could relate to what would be discussed - and give the study greater legitimacy locally by virtue of their involvement. With Fiona and Clara, I discussed the project and what their roles would be (to which I will return), reviewed good interviewing practices, sought their advice on how to proceed, went over my proposed interview questions, and asked about household gender relations in Vista Hermosa. We also discussed issues of payment, confidentiality, and anonymity, and they agreed to confidentiality measures (see Appendix C).

\footnotetext{
${ }^{92}$ A pseudonym.

${ }^{93}$ A pseudonym.

${ }^{94}$ In relaying study participants' comments and views, I refer more to the IOM Temporary Agricultural Workers to Canada (TAWC) project than to Canada's Low-Skill Pilot Project because it was really only the IOM project that workers had any knowledge of; for them, that was what they participated in and how they got to work in Canada.
} 
Also during this time, I sought demographic and statistical information from the Tecpán municipal office and met with local government leaders to introduce my project, one of several occasions when I would have to clarify with locals my reasons for being in the village and be asked to help send more migrants to Canada. In response I would emphasize that I lamentably had no influence over participation in the IOM project. I also walked around Vista Hermosa, familiarizing villagers with my presence and my study, and myself with the dynamics of daily life. I also conducted semi-structured interviews with the leaders of two women's groups in the village, and with the director of a women's organization in the nearby city of Chimaltenango.

In one of my disappointments that occurred during the research process, I was not able to engage significantly with a women's group for the execution of my study, or seriously incorporate their concerns through focus groups (Fish 2006), these being components of engaged research (Cervone 2007). This state of affairs resulted from few if any women from migrant households being part of these groups, time constraints, and not much congruity between my research interests and their primary focus on small productive projects. Their concerns reflected a distinction made by Molyneux (via Jaggar 1998) between practical and strategic gender interests, ${ }^{95}$ and issues to do with migration to Canada were really not among their concerns (even though it was a livelihood strategy for many in the community). These circumstances reinforced the fact that in Guatemala, "the struggle for equality and fair treatment takes second place to providing food and shelter" (Taylor, Moran-Taylor and Rodman Ruiz 2006:58). This

\footnotetext{
${ }^{95}$ While strategic interests aim to disrupt women's subordination, the groups in Vista Hermosa very much pursued practical interests, those that do not tend to challenge prevailing gender norms and focused on basic perceived necessities, including food, shelter, and income. Jaggar (1998) points out that the pursuit of practical interests may reinforce women's subordination by supporting actions that fall within women's perceived responsibility for caring for the family, but that work on practical gender interests may develop into greater consciousness of and attention to strategic interests over time.
} 
moved me to think about changing my project to align more with their concerns, given that prioritizing my research interests was potentially problematic from a de-colonizing perspective (Mohanty 2003, Tuhiwai Smith 1999). However, reflecting the challenges of engaged research for graduate students (Cervone 2007, Fish 2006), fearful of changing track with less than two months to finish my fieldwork, I decided to continue with my planned topic. I enhanced the economic considerations thereof, however, and would share my findings with women's groups. As I document at the end of this section, although not related to women's concerns specifically, an occasion subsequently arose to advance the interests of those in my research community as they related directly to migration to Canada.

In the first week of April, I moved in with my host family - Rafael (a migrant to Canada) and Miranda, and their two children, a girl (8) and boy (6). Rafael had been to Canada twice on long contracts in British Columbia and had returned just prior to my arrival in the village. They provided me my own room and treated me as a guest in many respects, but I ate meals with the family and helped Miranda with cooking and household chores. I made she and Rafael aware that, with discretion, I would use aspects of my experiences with them for study purposes. Participant observation entailed both casual and semi-directed conversations and intermittent note-taking about aspects of household gender relations that I noticed while living with them. Most conversations occurred between Miranda and I while Rafael was out of the house working, and other opportunities to talk with Miranda and Rafael together arose over meals or late-afternoon coffee time. I present parts of these conversations in my analysis.

Soon after moving in with Miranda and Rafael, I began interviewing migrants and their partners based on a working list of names I had obtained in Canada, and with the 
help of research assistants Clara and Fiona who identified other migrants, and the interviewees themselves who would suggest others. As such, participants were incorporated into the study in a semi-directed manner (partly chosen, partly snowballed), so I cannot make any claims to representativeness. Migrants had worked in British Columbia, Alberta, and Quebec. I had set out to focus on conjugal couples, because gender relations between partners constituted both my primary interest and the focus of the 'gender and migration' literature in which I was versed. All male migrant study participants were married, but it was a challenge to find enough migrant women who were married or in a "unión libre" (common-law union), as many were single or separated mothers. This could be because these women were freer to migrate - not being partnered with men who in most instances, would have been the ones to work abroad but also because of economic necessity in the case of separated women with children. ${ }^{96}$ Wanting to have as many female migrant participants as male, I adjusted my interview questions to integrate unpartnered women into the study. It was a limitation on the study that I was unable to gain as much insight into partnered migrant women's experiences as I had hoped, but I have included considerable insightful analysis of unpartnered women's household gender dynamics in relation to migration.

A formal interview usually followed a day or two after an initial visit during which I introduced myself and shared information about the study in general terms, as aiming to learn about how households and families were impacted by migration to Canada (see Appendix A). As per Clara and Fiona's suggestion, I called the potential

\footnotetext{
${ }^{96}$ In recruiting migrants, the IOM seemed to welcome single mothers in particular, provided that there were job openings for women. A couple of separated mothers in my study said that the IOM asked into their marital status, and approved their participation in the program in part based on the economic necessity that they had because they were unwed mothers.
} 
interview a "plática" (chat) because participants may have felt put off about having an "entrevista" (interview), and resorted a couple of times to referring to my study as "tarea" (homework). These simplifications reflected attempts to downplay differences between myself and potential participants (Fish 2006), most of whom had not completed primary school and were largely unfamiliar with the sort of study I was undertaking. It was also important to clarify my identity and purposes at these visits, because, as mentioned above and as I had been warned, several people thought I was affiliated with the IOM, the Canadian government, or employers. I emphasized that I held no sway over migration to Canada, but suggested that participation might benefit them through the chance to talk about their experiences, and improve them through information they provided anonymously. To improve the chances of an interview, I also clarified that I was not with "el sindicato" (the union) in Canada because many workers had been warned by the IOM against such involvement.

Despite laying all of this groundwork, about one third of planned interviews did not materialize. I found rejections somewhat frustrating but understandable as ways that villagers negotiated their participation in their immediate circumstances (Phoenix 1994, Sprague 2005). Likely reasons included concern about employment security (despite my assurances), shortage of time, worries about how I would use what they said (Phoenix 1994), and lack of husbands' consent for wives to be interviewed alone. Some men were in Canada while I was there, but mostly it was that, for safety reasons, I could not conduct interviews after 6 p.m., and most men were out of the house working during the day from Monday to Friday and often Saturdays. These time constraints in large part explain why I interviewed more female partners than male migrants, and was not able to interview any of the male partners of the four married migrant women participants. 
Nevertheless, I conducted many successful interviews over a 6-week period. All in all, 33 migrant households in Vista Hermosa were represented. A total of 45 migrant household participants included 29 migrants (15 women and $14 \mathrm{men}$ ) and 16 partners (all women). Of the 45 participants, 41 were interviewed, whereas with the remaining four Rafael and Miranda, and Fiona and Clara - I engaged in casual intermittent conversations that touched on issues related to the study, and they agreed that with some discretion, I could use such conversations as study material. All of the 14 migrant men were married or partnered, and among the migrant women, 4 were married or partnered, 6 were separated or widowed with children, and 5 were single and childless. ${ }^{97}$ All participants were indigenous Kaqchiquels. I also count among Vista Hermosa respondents two women's group leaders, the village mayor, a female leader in the main Evangelical church, and my American friend Jane and her husband Miguel. See Tables 1 and 2 for summary information.

\footnotetext{
${ }^{97}$ A couple of the migrant women had marital statuses that changed over their migration periods, or that were not easily classified. I categorized them as seemed most appropriate, and given what we had focused the interview on.
} 
Table 1: $\quad$ Female Migrants and their Households

\begin{tabular}{|c|c|c|c|c|c|}
\hline \multirow{2}{*}{ Pseudonym } & \multicolumn{2}{|c|}{ Marital Status } & \multirow{2}{*}{$\begin{array}{c}\text { (Approx.) } \\
\text { Age }\end{array}$} & \multicolumn{2}{|r|}{ Children } \\
\hline & As a migrant & At time of the study & & \# & Age(s) \\
\hline Manuela & Married & Married & 43 & 6 & $5-21$ \\
\hline Gloria & Married & Married & 45 & 3 & -- \\
\hline Gabriela & Married & Married & Early $30 \mathrm{~s}$ & 4 & $4-11$ \\
\hline Brenda & Single, Married* & Married & 35 & 0 & \\
\hline Laura & Separated & Separated & 36 & 1 & 16 \\
\hline Isabela & Separated & Separated & 36 & 5 & $7-17$ \\
\hline Flor & Separated & Common-law & 33 & 3 & 2 mos., 14,18 \\
\hline Luz & Separated & Separated & 26 & 1 & 6 \\
\hline Eva & Separated & Separated & -- & $1 * *$ & 1 \\
\hline Sofia & Separated & Separated & $30 \mathrm{~s}$ & 1 & 6 \\
\hline Esperanza & Single & Single & Late $20 \mathrm{~s}$ & 0 & \\
\hline Delia & Single*** & Married & Late $20 \mathrm{~s}$ & 0 & \\
\hline Emilia & Single & Single & 29 & 0 & \\
\hline Fiona & Single & Single & 25 & 0 & \\
\hline Clara & Single & Single & 25 & 0 & \\
\hline \multicolumn{2}{|c|}{ TOTAL HOUSEHOLDS } & \multicolumn{4}{|l|}{15} \\
\hline \multicolumn{2}{|c|}{ TOTAL RESPONDENTS } & \multicolumn{4}{|l|}{15} \\
\hline \multicolumn{6}{|c|}{$\begin{array}{l}\text { Note: All female migrants were interviewed individually; no male partners were interviewed. } \\
\text {-- designates no information available. } \\
* \text { Brenda had migrated once while single and once while married. } \\
* * \text { Eva did not have children at the time of her migration. } \\
* * * \text { Delia and her husband had both been to Canada before getting married. }\end{array}$} \\
\hline
\end{tabular}


Table 2: $\quad$ Male Migrants and their Households

\begin{tabular}{|c|c|c|c|c|c|c|c|}
\hline \multirow{2}{*}{$\begin{array}{c}\text { Man's } \\
\text { Pseudonym }\end{array}$} & \multirow{2}{*}{$\begin{array}{c}\text { Female } \\
\text { Partner's } \\
\text { Pseudonym }\end{array}$} & \multirow{2}{*}{ Interviewed } & \multicolumn{2}{|c|}{ Marital status } & \multirow{2}{*}{$\begin{array}{c}\text { (Approx.) } \\
\text { Age }\end{array}$} & \multicolumn{2}{|r|}{ Children } \\
\hline & & & $\underset{\text { migrant }}{\text { As }}$ & $\begin{array}{l}\text { At time } \\
\text { of study }\end{array}$ & & $\#$ & Ages \\
\hline Rafael & Miranda & $\mathrm{n} / \mathrm{a}^{*}$ & Married & Married & 28 & 2 & 6,8 \\
\hline Alberto & Delia** & Together & Single & Married & Late $20 \mathrm{~s}$ & 0 & \\
\hline Ramón & Amparo & Together & Married & Married & 29 & 2 & 4,7 \\
\hline Rolando & Graciela & Together & Married & Married & Early $30 \mathrm{~s}$ & 4 & Under 5 \\
\hline Cristóbal & Alicia & Together & Married & Married & Late $30 \mathrm{~s}$ & 3 & -- \\
\hline Lucas & Yaneth & Individually & Married & Married & -- & 4 & $1-9$ \\
\hline Eduardo & Yolanda & Together & Married & Married & - & 5 & $1-16$ \\
\hline Franco & Adelina & Together & Married & Married & - & 3 & Under 5 \\
\hline Felipe & Mónica & Individually & Married & Married & -- & 3 & Under 3 \\
\hline Elías & Beatriz & Her only & Married & Married & 42 & 7 & $5-12$ \\
\hline Marco & Lourdes & Her only & Married & Married & Mid 40s & 8 & $5-24$ \\
\hline Guillermo & Dominga & Together & Married & Married & -- & 4 & $2-11$ \\
\hline Donardo & Alba & Him only & Married & Married & 28 & 2 & 7 mos., 2 yrs. \\
\hline Gustavo & Eloísa & Together & Married & Married & Mid 40s & 6 & $10-22$ \\
\hline Simón & Lucinda & Together & Married & Married & -- & 5 & 4-12 \\
\hline Jacobo & Paola & Her only & Married & Married & 20 & 2 & 2 mos., 2 yrs. \\
\hline Vicente & Jimena & Her only & Married & Married & -- & 6 & $4-9$ \\
\hline Mario & Dolores & Together & Married & Married & $40 \mathrm{~s}$ & 7 & $5-17$ \\
\hline \multicolumn{2}{|c|}{ TOTAL HOUSEHOLDS } & \multicolumn{6}{|l|}{18} \\
\hline $\begin{array}{l}\text { TOTAL } \\
\text { RESPONDENI }\end{array}$ & $T S^{* * *}$ & 30 & MaLe & 14 & FeMALE & 16 & \\
\hline \multicolumn{8}{|c|}{$\begin{array}{l}\text {-- designates no information available. } \\
\text { * Rafael and Miranda were in my host family. I did not interview them formally but engaged them in } \\
\text { conversation, both individually and together. } \\
\text { **Alberto and Delia had both been to Canada before getting married so were counted as both female and } \\
\text { male migrants. } \\
\text { ***Delia was not considered Alberto's partner for this study because neither had migrated while they had } \\
\text { been married. She was not counted as a respondent here because she was counted among the female } \\
\text { migrant respondents in the previous table. }\end{array}$} \\
\hline
\end{tabular}

Before beginning a given interview, I (re)iterated information regarding the study, how I would use the information participants provided, how their anonymity would be maintained, and what the roles of Clara and/or Fiona would be, and I outlined the general lines of questioning I had (see Appendices D for interview guides). Both adhering to 
ethical requirements ${ }^{98}$ and trying to address power imbalances, I advised participants that they could decline to answer any question, discontinue their participation, and ask questions of me at any time. I gained their oral consent to participate either explicitly or tacitly (see Appendix B for a script that guided the informed consent process), often feeling that it was too indicative of power dynamics to seek formal written consent. Participants consented to audio-recording in approximately two thirds of the interviews, and I took notes for the remainder.

Interviews were between 30 and 60 minutes in length. I based all interviews on a guide, and adapted questions to time available and participants' particular circumstances. As mentioned above, I did not frame my questions along the lines of gender equality, nor did I use 'gender' terminology at all with villagers because it would not have been familiar to them, and although a general theoretical orientation guided my questioning (Bernard and Ryan 2010), I kept my inquiries in plain Spanish language, occasionally translated by Fiona into Kaqchiquel for clarification (the Spanish fluency of myself and that of study participants was generally adequate). In general, I asked about who did what in the household, if and how those arrangements changed during migration periods, migrants' experiences in Canada (including gender-related work), and elements of change and continuity upon return in both the migrant him/herself and household divisions of labour and authority. I tried to ask as well how migrants and partners felt about any shifts they cited.

Although these interview techniques were aimed at adopting a non-judgmental stance (Kelly, Burton and Regan 1994) and being a 'good' feminist researcher who does

\footnotetext{
${ }^{98}$ This project received clearance by the Carleton Research Ethics Board, and adhered to the ethical requirements I indicated in my application regarding such issues as consent, anonymity, remuneration, and audio-recording.
} 
not impose her viewpoints, I cannot help but feel that I may have missed some opportunities for insightful exchanges by not very often taking opportunities to share impressions of gender dynamics in the community, or even to just discuss differences between their household gender relations and those I knew in Canada. I largely withheld my views, trying to be neutral in response to interview comments as well as gender practices in my host family, as challenging as those sometimes were to observe. Nor did I often ask what they would think if household gender dynamics were been different because I thought this would insinuate that they should be different. Such situations are fairly well documented in critical feminist methodology scholarship. Feeling that certain displays of honesty will compromise relationships and the ability to gather data so desperately needed (Millen 1997, Sprague 2005), researchers may try to downplay or misrepresent aspects of themselves in order to lessen differences (Fish 2006), and guard against the unpredictability of what honesty would bring (Atkinson, Coffey and Delamont 2003). I am frustrated that I let these concerns get the better of me because I missed opportunities for exchange, and tended to problematically see participants as unable to 'handle' or interpret what I might have said. I likely overestimated the influence of my position, and underestimated their ability to interpret and respond in reasoned ways (Kelly, Burton and Regan 1994, Skeggs 2004). It is naïve to think sharing has no influence, but nor do we do cross-cultural feminist research any favours by seeing those with whom we share as passive recipients of information, incapable of reflecting on perspectives or ways of living different from their own (Skeggs 2004).

Interviewees generally seemed willing and interested - if a little shy and awkward - during our encounters, but they varied in their 'chattiness' and length of answers. They had likely not talked before about some of the issues I inquired into, may have limited 
their criticisms about work in my country (Phoenix 1994), and were not sure what or how much to say. In most cases, commentaries did not fall into the narrative category of interview data (Bernard and Ryan 2010, Ezzy 2002), instead best described as questions and relatively short answers despite my efforts to follow up and elicit more information. Some of the richest responses came in stories about migrants' negative experiences. This sometimes detracted focus from my interview questions, but it was a good practice in ethical research to allow participants to express their concerns, through which I would become a sort of "mouthpiece against injustices" (Skeggs 1994:81) by means of a side project (see below) and subsequent publications (Hughes 2012, Valarezo and Hughes 2013). At the end of each interview, I provided my contact information and material about migrants' rights and support services in Canada, and helped as I could with questions about Canadian regulations and correspondence they had received. I expressed my thanks liberally and offered a few pounds of sugar, suggested by the research assistants as an appropriate token of appreciation, given that I did not want to incentivize participation through payment.

Some of the most difficult and frustrating interviews were with women in the absence of their husbands and less educated women, who would say things like "I don't know anything about that." I took greater pleasure in the few more conversational interviews with more articulate women - usually those who had pursued secondary education or worked outside the home - who could answer certain questions to which I had found, or suspected, that differently socially located women could not. Corroborating these circumstances, scholarship on feminist research stresses the importance of felt differences between interviewees and researchers. Largely eschewing any "cosiness" based on shared gender - perhaps exacerbated by the fact that I was 
neither married nor a mother - experiences of and attitudes toward interviews with women depend in part on "relative positions... in the social formation" (Phoenix 1994:50), and my preference for articulateness implicated my biases (Millen 1997, Sprague 2005). Contextualizing circumstances further, women's reserve may have reflected war-time self-silencing tactics (Martínez Salazar 2012), uncertainty regarding my intentions (Martínez Salazar 2005), feelings that certain lines of questioning were irrelevant (Phoenix 1994), and from a material perspective (Skeggs 1994), economic dependence on men's migration that they did not want to jeopardize. All in all, these interview dynamics indicated their exercise of power over the process (Phoenix 1994).

Another gender-related dynamic arose occasionally in interviews with couples also discussed in literature (e.g., Phoenix 1994) - in which men would do most of the talking and women would actually be absent from the room at times, despite my attempts to increase their involvement. In one instance, a female partner stayed on the porch shucking peas, well within hearing distance, while I interviewed her migrant husband. I felt annoyed by what seemed to be an expression of patriarchy - men limiting women's participation - and that I was not doing enough to manage interviews more inclusively. Re-framing these occurrences calls attention to the possibility that both men and women saw interview encounters as occasions for men, acceptably, to be the public face of their households.

The roles of Clara and Fiona were both minimal and significant at the same time. Before visits or interviews, they would tell me what they knew about participants' marital status and history of work in Canada. In interviews, they provided me a certain buffer against the strangeness that participants and I felt in our encounters. I envisioned that they would participate to some extent in interviews, but they held their involvement to 
sharing an occasional laugh and clarifying my questions. They explained that it was not appropriate to ask questions as if it was their study, because they were locals with only primary education, and participants would not respond as well. In the sense of reactivity (Behar 1996, de Munck and Sobo 1998), I do need to acknowledge that the simple presence of Clara and/or Fiona likely influenced respondents' comments. I said that they had agreed to not disclose participants' identities or comments, but I cannot guarantee that they complied, and in a place where gossip figured prominently, it is understandable that participants would exercise some discretion with Clara and/or Fiona present.

The research assistants also helped to illuminate interview dynamics afterward. For instance - this time implicating my reactivity, as well as power imbalances - Clara said after a challenging interview that participants were often not sure what I wanted them to say; she thought they had been, to some extent, shaping comments according to answers they thought I desired. This also comes up in literature on interviewing, that participants may be inhibited by a fear that there is a 'correct' answer of which they are unaware (Phoenix 1994). So in the early stages, I quite possibly received responses that were less than honest and thorough. I emphasized with Clara and Fiona and in subsequent interviews that I did not want any particular responses, and that participants should express themselves freely.

Toward the end of this six-week period from April to mid-May, I conducted further organizational interviews in Guatemala City, Chimaltenango, and Tecpán town. For more information about the IOM project, I carried out interviews at IOM-Guatemala, the Canadian Embassy, and the Ministerio de Relaciones Exteriores (Ministry of Foreign Affairs). To better understand religious dynamics and their role in the household, I spoke with a female leader in Vista Hermosa's main Evangelical church (I was unable to 
interview a counterpart in the main Catholic church), and the director of the Presbiterio Kaqchikel of the National Presbyterian Church of Guatemala, with whom I had connections through my networks in Canada. And, wanting more views on local gender relations, I interviewed two representatives at the Oficina Municipal de la Mujer (Municipal Women's Office) in Tecpán town.

The interview process was often tiring due to having to maintain focused attention for long periods, communicate in a second language, and exercise empathy in response to some troubling aspects of participants' commentary, but I made a concerted effort after interviews had wrapped up each day to type up interview notes. I also wrote occasional memos about new issues that participants raised, and adjusted my interview guide. Occasionally these memos - as well as emails home - voiced frustrations with my emerging study findings regarding patriarchal gender relations. Partly a result of naïveté and condescension, at the time these reactions reflected the optimistic potential in the gender and migration research I had read and my biases toward Western feminist orientations. In my analysis chapters, I contextualize the reasons for the findings that motivated my frustrations.

In order to minimize the risk of negative repercussions related to migrants' work in Canada, I safeguarded the identities of study participants and the actual name of the village. With the exception of some organizational representatives who did not require anonymity, I used a coding system for participants' names and did not write names in my notes, keeping them and my interviewing schedule in a password-protected file, and generated pseudonyms for nearly all participants. I have disclosed the village's real name to only a few people, and did not give it to any organizational representatives interviewed.

A final aspect of the fieldwork experience was the opportunity to be involved in a 
project in support of migrant workers' rights and access to work in Canada. Giselle Valarezo, a PhD candidate in Geography at Queen's University, was also doing fieldwork in Guatemala with IOM project participants at the time. In the department of Sacatepéquez, she witnessed and assisted with the formation of a group called AGUND (Asociación de Guatemaltecos Unidos por Nuestros Derechos - Association of Guatemalans United for our Rights), made up of migrant workers to Canada who were seeking redress for having been allegedly unfairly treated, including being dismissed or 'blacklisted' from the IOM project. Giselle and I discuss in greater detail the formation and activities of AGUND in a recent publication (Valarezo and Hughes 2013). I happily lent my support given that I had limited opportunities to 'give back' to participants in my research. I recorded testimonies from workers about their problems - that would be used in a United Food and Commercial Workers (UFCW) Canada information campaign in the fall of 2010 - and assisted with the first meeting of the Tecpán area branch of AGUND.

I left Guatemala on May $20^{\text {th }} 2010$. In a period of almost sixteen weeks there, I spoke with approximately 74 people for the purposes of my study, including 51 in Vista Hermosa, 22 organizational representatives, and a few miscellaneous contacts ${ }^{99}$, and gathered further data from participant observation. Counting the Canadian phase of the research, my study draws on 49 interviews and a further 13 non-interview encounters. All of this is summarized in Table 3.

\footnotetext{
${ }^{99}$ I do not count among the respondents the workers from whom I received testimonies for the purposes of the AGUND group and UFCW campaign because I did not obtain permission from the workers to use their testimonies for my own study.
} 
Table 3: $\quad$ Full List of Respondents and Research Encounters

\begin{tabular}{|c|c|c|c|c|}
\hline Migrant Households & Households & Respondents & Interviews & $\begin{array}{l}\text { Non- } \\
\text { interviews }\end{array}$ \\
\hline Vista Hermosa & 33 & 45 & 41 & 4 \\
\hline Tecpán Town & 1 & 1 & 0 & 1 \\
\hline $\begin{array}{l}\text { VISTA HERMOSA - OTHER } \\
\text { - Women's group - Mujeres en Acción } \\
\text { - Women's group - Partido Patriota } \\
\text { - Iglesia ELIM (main Evangelical church) } \\
\text { - Jane and Miguel } \\
\text { - Mayor }\end{array}$ & $\mathrm{n} / \mathrm{a}$ & 6 & 4 & 1 \\
\hline $\begin{array}{r}\text { TOTALS - MigRANT HOUSEHOLDS AND } \\
\text { VISTA HERMOSA }\end{array}$ & 34 & 52 & 45 & 6 \\
\hline Organizational Research Encounters & Organizations & Respondents & Interviews & $\begin{array}{l}\text { Non- } \\
\text { interviews }\end{array}$ \\
\hline $\begin{array}{l}\text { GUATEMALA } \\
\text { - Asociación de Mujeres Nuestra Voz } \\
\text { - Asociación para el Avance de las Ciencias } \\
\text { Sociales en Guatemala (AVANCSO) } \\
\text { - Embassy of Canada to Guatemala } \\
\text { - Facultad Latinoamericana de Ciencias } \\
\text { Sociales (FLACSO) Guatemala } \\
\text { - Instituto Centroamericano de Estudios } \\
\text { Sociales y Desarrollo (INCEDES) } \\
\text { - IOM-Guatemala } \\
\text { - Mesa Nacional para las Migraciones en } \\
\text { - Guatemala (MENAMIG) } \\
\text { - Ministerio de Relaciones Exteriores } \\
\text { - Oficina Municipal de la Mujer (Tecpán) } \\
\text { - Presbiterio Kaqchikel } \\
\text { - Sector de Mujeres } \\
\text { - Universidad Rafael Landívar }\end{array}$ & 13 & 22 & 11 & $5^{*}$ \\
\hline \multicolumn{5}{|c|}{$\begin{array}{l}\text { *I had } 4 \text { non-interviews at FLACSO-Guatemala, accounting for the difference between } 13 \text { organizations and } 16 \text { research } \\
\text { encounters. }\end{array}$} \\
\hline $\begin{array}{l}\text { CANADA } \\
\text { - Consulado General de Guatemala en } \\
\text { Montréal } \\
\text { - Commission des droits de la personne et les } \\
\text { droits de la jeunesse (CDPDJ) } \\
\text { - United Food and Commercial Workers } \\
\text { (UFCW) Canada } \\
\text { - Agricultural Workers Alliance } \\
\text { - Human Resources and Skills Development } \\
\text { Canada (HRSDC) }\end{array}$ & 5 & 6 & 3 & 2 \\
\hline TOTALS - ORGANIZATIONS & 18 & 28 & 14 & 7 \\
\hline
\end{tabular}

\section{Theory and Analysis}

I understand analysis in qualitative research as the interpretation of empirical data in order to suggest the meaning of events and experiences, through deconstructing data 
and applying analytic categories that reveal patterns, relationships, and factors (Coffey and Atkinson 1996, Denzin 1998). Analysis occurs both during and after data collection in an on-going continuum of reflexive activity (Coffey and Atkinson 1996, Huberman and Miles 1998). While in the field, I did some preliminary analysis (Grbich 2007) through occasional memos about initial findings and certain factors that may have been influencing gender relations during and after migration periods. This is indicative of my combination of inductive and deductive approaches (Bernard and Ryan 2010, Ezzy 2002), which would continue into later analysis stages. I had designed my study's questions and interview questions with a theoretical framework in mind, and as such, did not follow an inductive or grounded theory approach (Bernard and Ryan 2010, Huberman and Miles 1998), but nor did I adopt a deductive approach characterized by hypotheses (Ezzy 2002). Over time in the field, I gradually increased inductive reasoning as conditioning factors and processes emerged - such as the influences of in-laws and gossip - that my understandings of gender and migration relationships had not yet included, and to which I would be more attentive.

Also in the vein of general approaches, my study seemingly has cause-and-effect components to it, i.e., how labour migration impacts household gender relations. In reality, however, the social processes at work are far too complex and non-linear to be understood as such, as alluded to in Chapter 1 among the study's limitations. I did not attempt to establish law-like relationships between variables (Ezzy 2002) or generalizable causal explanations (Grbich 2007). ${ }^{100}$ I did strive to identify what the most significant constraining and enabling circumstances are that may contribute to or facilitate or make

\footnotetext{
${ }^{100}$ Although see Huberman and Miles (1998) for why, from a transcendental realist perspective, exploring causality is quite possible in a qualitative study.
} 
likely, but not cause the outcomes that I discerned (Huberman and Miles 1998).

Although analysis occurred during data collection, the bulk of "systemic analysis" 101 (Bernhard, Landolt and Goldring 2005) came afterward, informed by my data, research questions, and theoretical orientations, among other factors (Bernhard, Landolt and Goldring 2005, Coffey and Atkinson 1996, Ezzy 2002). After transcribing all the audio-recorded interviews, I carried out thematic analysis of transcripts and notes from unrecorded interviews using a combination of deduction and induction, having determined beforehand what the general issues of interest would be, but allowing themes or categories to emerge (Ezzy 2002). To generate and later organize these themes, I employed coding (Coffey and Atkinson 1996) using computer-assisted qualitative analysis software. Specifically, I used Atlas.ti, not to do the intellectual work of identifying analytical categories and discerning patterns and relationships, but to more efficiently store, handle, retrieve, and interrogate interview transcripts and notes ${ }^{102}$ (Atkinson, Coffey and Delamont 2003, Bernhard, Landolt and Goldring 2005, Coffey and Atkinson 1996, Ezzy 2002).

In the early stages, my thematic codes ${ }^{103}$ reflected my overall research questions, specific interview questions, the gender and migration literature I had read, preliminary analysis, and various theoretical concepts (Skeggs 1994); these 'lenses' influenced what data I considered important (de Munck and Sobo 1998). However, the code list soon

\footnotetext{
${ }^{101}$ Also called thematic analysis by Grbich 2007.

${ }^{102}$ In most cases, each Primary Document in Atlas.ti corresponded with a single interview, but in a few cases, they corresponded with sets of encounters, such as where I had engaged in participant observation with my host family, or ongoing conversations with my research assistants.

${ }^{103}$ I employed different types of codes (Bernhard, Landolt and Goldring 2005, Bryman and Burgess 1994, Huberman and Miles 1998), e.g., 'structural' to capture aspects of a given research encounter, 'thematic' (both descriptive and explanatory) to identify topical categories related to the research questions, and what I would call 'process or reactive' codes that classified, for instance, interviewees' discomfort or awkwardness about a given topic that I had noticed.
} 
grew as data suggested new themes, ideas, and connections to apply (Bernhard, Landolt and Goldring 2005:63, Coffey and Atkinson 1996). A sampling included respondents' ethnicity-related experiences in Canada, the cultural importance of 'helping', and meanings of 'pride'. It was not straightforward to balance the "emergent nature" of codes with the influences of pre-existing theory and issue knowledge, but my aim was to move the analysis beyond those pre-existing frames (Ezzy 2002:93). I let my codes proliferate, but later reined in and re-organized the list as the foci of my analysis became clearer (Bernard and Ryan 2010, Coffey and Atkinson 1996). I also employed memos in Alas.ti to capture 'aha!' moments and hunches, theoretical linkages, and particular comments and interview dynamics (Bernhard, Landolt and Goldring 2005, Ezzy 2002).

I undertook three key measures to maximize accuracy and consistency in coding. First, I did the vast majority of coding manually and conscientiously, and minimized the use of auto-coding in Atlas.ti. ${ }^{104}$ Second, as my code list proliferated, I started giving many of the codes a mnemonic (Bernard and Ryan 2010), a description of what the code referred to, in order to apply the most appropriate code to a given piece of text. And third, as often as possible, I employed manifest coding, in which a code is applied only when particular words or phrases appear or when a respondent explicitly refers to a certain topic. This contrasts with latent coding where I would 'read between the lines' and interpret what was said so as to find themes even if certain words did not appear (Bernhard, Landolt and Goldring 2005).

Related to manifest codes, and reflected in the references above to 'helping' and 'pride', I also combined emic codes and etic codes. Emic codes captured understandings

\footnotetext{
${ }^{104}$ Near the completion of my coding process, I did perform this function in order to code for themes that had developed later in the process and that I therefore needed to apply retroactively to the texts I had already read through. However, I confirmed whether to apply the code to each instance.
} 
held by cultural insiders or research participants themselves. These provided alternative, contextualized explanations that ethnographic work should seek (Skeggs 1994), tempered my application of Western feminist viewpoints, and were part of reflexivity and 'decolonizing' my approaches. By contrast, etic themes - common in politically-oriented and theoretically-informed research (Huberman and Miles 1998) - encompassed my interpretations (Bernard and Ryan 2010, Denzin 1998). ${ }^{105}$

Later stages of coding and analysis entailed further organization of codes around broader themes that emerged, and conducting queries in which I investigated particular themes' relationships and patterns, both commonalities and irregularities or one-off instances that might have illuminated broader trends that the rest of my data had not captured (Coffey and Atkinson 1996). The appropriate time to stop coding is not always clear, but I did so when all interview texts were saturated with codes, and when I was confident that my analysis was going to yield sufficient insight into the issues under investigation (Ezzy 2002). Gradually, in stops and starts, my reliance on Atlas.ti shifted into writing, but I referred regularly to my computer-based analysis while writing the following chapters.

\section{Addressing Intersectionality}

As mentioned in Chapter 2, intersectionality is both an aspect of lived experience and conceptual orientation or tool of analysis that aids in investigating and understanding relative oppression and/or privilege situated in multiple axes of social differentiation (Cook 2007, McCall 2005). I address aspects of Guatemalan women's and men's intersectional locations in my analysis, but not specific interactions or 'weight' among

\footnotetext{
${ }^{105}$ I tended toward etic codes because of my theoretical and ideological biases (Ezzy 2002), and because I regrettably did not ask enough questions about how or why respondents understood things in certain ways.
} 
the "analytical categories" that make up their intersectional lives (McCall 2005:1773). This choice owes itself to three related factors: my analytical frame from the outset has been gender, I did not combine indigenous and non-indigenous households in my sample so as to be able to compare them with respect to gender relations, ${ }^{106}$ and I do not have the data to incorporate intersectionality in my analysis in a systematic fashion.

I am not naïve about the implications of how I conceptualized and designed this project. With gender as my frame, or put differently, when I isolate gender through “abstract individuation" (Sprague 2005:16), I may be blind to other important aspects of social actors' experiences (Grbich 2007), create biases in knowledge, misconstrue outcomes that result from how a complex system of social relations is organized, and not be able to see the blind spots so created (Sprague 2005). And I am conscious of Martínez Salazar's point - raised in Chapter 2 - that to focus on gender relations alone in Guatemala, to conduct an "orthodox feminist analysis" (2005:110) results in seeing indigenous women as oppressed by their culture, in seeing indigenous men as their main 'enemies'. She qualifies her remarks by adding that there is nothing inherently wrong about a focus on gender (or race or class), but individually it is "insufficient to analyze the multiple entanglements of social relations of ruling" (2005:112).

I cannot investigate the "multiple entanglements" of the experiences of indigenous Guatemalan women and men in my study in a systematic or detailed fashion. However, I paid attention in my analysis (through coding and memoing) and incorporated

\footnotetext{
${ }^{106}$ At earlier stages of the research design, I included intentions to do this. However, the demographics of Guatemalans' participation in the IOM project and the circumstances in which I found myself in Guatemala imposed limitations in these regards. The majority of Guatemalan participants in the IOM project are indigenous, and the Tecpán area where I did my research is also mostly indigenous, especially in rural areas from which migrants primarily come. The particular village of Vista Hermosa had only a few nonindigenous families, and neighbouring villages were also indigenous. I considered interviewing a few Ladino migrant households in Tecpán town, but did not have sufficient time to do so.
} 
into my writing in subsequent chapters, significant aspects of social relations other than gender, and in a couple of instances, how ethnicity and gender might interact. I attend to comments - especially among migrants - that point, first, to the poignant activation or presence of ethnic and class relations in their experiences, and second, how social relations other than gender shape the gender-related aspects of migration. What I mean by these two considerations will become clearer in the following chapters, but by way of a few examples, race or ethnicity sometimes emerged as determinative elements of migrants' experiences in Canada, I discerned shifts in migrants' class habitus, and culture (i.e., being Maya-Kaqchiquel) as well as religion were central to the social locations (Menjívar 1999, Sprague 2005) that contributed to considerable continuity in migrants' selves and household gender relations. In attending to these considerations, I try to illustrate participants' 'frames' (Grbich 2007) or 'standpoints' (Sprague 2005), and illuminate experiences from which I can "extrapolate illustratively to the broader social location embodied by the individual" (McCall 2005:1781). And it is often in considering other contexts (e.g., Canada) that different configurations of inequality will be revealed (McCall 2005). Although I incorporate intersectional analysis in these ways, my frame is gender relations, and I follow Cockburn in that my attention to intersectionality does not “invalidate our perception of a gender hierarchy and gender oppression" (2001:16).

\section{Conclusion}

This chapter has outlined the methodologies, processes, and challenges involved in the data collection and analysis phases of my project. Through an application of ethnographic, feminist, de-colonizing, and (qualified) intersectional approaches, I emerged with a rich data set, although one not without its limitations. In highlighting my 
fieldwork challenges in particular, I have sought to highlight some of the 'nitty-gritty' of this process, and ways that certain experiences could be re-examined through processes of reflection on how the self unavoidably affects our research. Before elucidating in Chapters 6 to 9 my findings in relation to how migration is contributing to continuity and change in Vista Hermosa households, I provide in the following chapter an analysis of general household gender dynamics in the village and further details about its residents' migration to Canada. 


\section{Chapter 5 \\ Vista Hermosa: Gender Relations and Migration to Canada}

In order to discuss in the following chapters the gender-related changes and continuities that migration has encouraged in Vista Hermosa households, it is vital to provide a picture of 'conventional ${ }^{107}$ gender dynamics that characterized those homes before migrants went to Canada. In this chapter I outline the main contours of household gender relations in the village, along the productive and power dimensions outlined conceptually in Chapter 2 (Connell 2002, Connell 1987, Risman 1998). As such, I also identify the focus points for my analysis of change and continuity, both during and following migration. The concluding section of the chapter sets the final piece in place for my analysis by detailing Vista Hermosa residents' migration to Canada.

In interviews with villagers, I sought a characterization of their household gender dynamics by asking: who lived in their household, what a typical day entailed for the interview respondent and her or his partner as applicable, what types of non-remunerated and income-generating work women and men did, how they spent their free time, and how they divided specific household labour, decision-making, and financial responsibilities among household members. ${ }^{108}$ Comments from representatives from women's and faith-based organizations supplemented villagers' responses, and I also base some of the following portrait on participant observation of my host family. Overall, I emerged with a good picture of both what the respondents themselves did, and what men and women in general did, the latter illuminating broader socio-cultural ideologies

\footnotetext{
${ }^{107}$ I acknowledge that gender relations are dynamic due to a variety of influences, including migration, and that any 'snapshot' approach to describing them may be problematic. That said, this analysis requires a 'benchmark' of sorts from which to begin.

${ }^{108}$ Whom in the household I focused on was determined by who the migrant was in relation to other household members. Primarily, I focused on relations between conjugal partners, and in the case of single or separated women living at home, between them and their parents, especially their fathers.
} 
and understandings, and I draw here on both sets of responses. I begin with a brief explanation of household composition and then focus on three themes: typical days, the household division of labour, and household authority. In discussing these three themes, I focus more on 'partnered households' (those with a migrant-partner conjugal couple) than on single or separated women living with their parents, ${ }^{109}$ but do draw out illuminating aspects of single women's gendered lives as well. These findings make clear that some general patterns in household gender relations did hold across many of the households represented by my interviews, but some areas of differentiation and nuance also emerged.

With respect to household arrangements and membership, Vista Hermosa is a village characterized by patrilocality - which is quite common in Guatemala, especially in rural areas (Bachrach Ehlers 1991, Menjívar and Agadjanian 2007) - meaning that adult men upon marriage usually remain in their parents' home and bring their wives to live there. In Vista Hermosa, it is not uncommon for a couple to live close to or on the same property as the husband's parents, either in the same house or in a separate small one. ${ }^{110}$ A given couple's ability to live in their own home, off their parents' property, depends largely on their economic circumstances. In most cases, when I asked married or partnered respondents who made up their household, participants referred to themselves and their children (if applicable), but in some cases, they included one or both of the husband's parents, and less commonly, siblings. As I will discuss in Chapter 7, the

\footnotetext{
${ }^{109}$ I do this because I have more interview data on these topics from couples than from single women.

${ }^{110}$ Although not a focus of my study, inheritance patterns in Vista Hermosa stemmed partly from these patrilocal arrangements. Miguel, husband to Jane, the American in the village, said as a rule, women always receive less than men. For example, if a parent has 3 children - two sons and one daughter - the sons will collectively receive 80 per cent of the inheritance and the daughter will receive 20 per cent. The logic is that the woman will be/is married, and she will share the inheritance her husband receives from his family. If the woman does not marry, she receives the house from her deceased parents.
} 
immediate or nearby presence of husbands' parents - wives' in-laws - was important as a conditioning influence on gender dynamics, especially during migration periods, as other research has confirmed (Hellman 2008, Menjívar and Agadjanian 2007). Single women, whether not yet married or separated with children, lived in their parents' home or on their parents' property and other siblings were often present.

\section{Typical Days}

Participants' descriptions of their typical days - assumed to be Monday to Friday, and often Saturday ${ }^{111}$ - provided considerable insight into the differences between women and men in the productive dimension of household gender relations. It is somewhat easier to describe a man's typical day in Vista Hermosa than a woman's because men's activities admitted of greater predictability, less variation, and less multitasking than women's. All men who had work on a given day would rise early - often by 5 a.m. - have breakfast (prepared by women), tend to animals or other household chores as necessary, and leave the house for agricultural work, which could be labouring directly on their land or that of others, or other related activities like transporting produce from the village. They would sometimes return home for lunch, and retire for the day in late afternoon or early evening. They would eat dinner, visit with the family, perhaps play with children or help with their homework, and attend to other matters as necessary, such as garbage disposal, chopping firewood, and securing cattle in their corrals. Some men tended the family store in the evening or attended activities at church. As an example, Ramón described his day like so: "A normal day for me is getting up, having breakfast, getting ready for work, and seeing what work there is to do in the campo (fields). At 4

\footnotetext{
${ }^{111}$ Sundays were different, often a day off from income-earning work, and consisting of other activities such as going to church and visiting family.
} 
p.m., I return... and a bit of rest, see what there is here, deal with the garbage a bit, then dinner and rest." And Flor described her husband's typical day this way: "He leaves at 5 a.m. for work. Or sometimes he doesn't go until 7 , and he'll get water for laundry because we don't have water. He leaves it there in the túnel (water barrel) so I can wash. He arrives sometimes at 6 p.m., he bathes, has dinner, and goes to bed."

With respect to women's typical days, I discerned through interviews and observations with my host family that most women have similar routines in the morning, after which their days would take different paths depending in large part on whether they engaged in income-earning activities. Women would often rise before men in order to prepare men's breakfast and pack their lunches if necessary. They would start their woodstove fires, then go to the mill to grind their nixtamal (corn kernels soaked with lime and water) into masa (dough) for making tortillas, which they would shape by hand and cook on a woodstove with other breakfast items. After seeing their husbands off to work, if they were mothers, they would wake, feed, and dress young children and send them off to primary school. ${ }^{112}$ After attending to school-age children, women would do their housekeeping work: wash dishes, tidy up, sweep, mop, and perhaps wash or iron clothing and tend to small animals. Single women would have similar routines, but women's tasks would often be divided among the females in the home as applicable; for instance, one woman would go to the mill while others prepared the woodstove, or one would be

\footnotetext{
${ }^{112}$ Meanwhile, older children who attended secondary school would do so in the afternoon, so in the morning, they would help their mothers or fathers, as per gendered expectations. As for children who no longer attended school, boys would often accompany their fathers to the fields or other locations of agricultural work, and girls would remain at home to help their mothers, although some young women had paid work in the community, such as at a store or local packing plant. Despite high enrolment of girls in both primary and secondary school in Vista Hermosa, cultural beliefs persist in Guatemala that it is more important for boys than for girls to continue their education (Martínez Salazar 2005). In an interesting conversation with Miranda in my host family regarding their thoughts on sending their daughter to secondary school, she told me that both she and Rafael understood the value of continued schooling, but were also nervous about the nefarious influences and possible pregnancy that sometimes resulted from relationships formed at secondary school, especially if it is located outside their home community.
} 
responsible for the cooking activities while others focused on cleaning and washing.

After the home-based morning routines, women's days would vary, including several other possible forms of income-earning and unremunerated work. The primary consideration was whether they had young school-aged children to tend to. The primary school day would finish at 1 p.m., after which time women would need to be home to prepare lunch and care for children in the afternoon if there was no one else to do so. All but four of the 31 women of migrant households represented ${ }^{113}$ in the study had some form of income-generating work (not including migration to Canada) at the time of the study, and the remaining four had had such work recently.

Women's primary income-earning activities included agricultural work, weaving or embroidery, domestic work, and sales. Of the 26 women with income-generating work, 19 were occupied in some form of farming - either as jornaleras (day-labourers) with their husbands or in household-based market-oriented farming. Three more had been involved in family farming recently but could no longer do so because of childcare responsibilities. In family-based farming, women's tasks included some work in the fields as well as hand-processing crops at home, such as shucking peas or de-cobbing corn. Reflecting a traditional skill among indigenous Guatemalan women, over half the women interviewed (17) engaged in weaving or embroidering huipiles (shirts or blouses that indigenous women wear) and would sell them. Among other income-generating work, a few women provided domestic labour for other households, such as washing clothes, and some women tended their small family stores or did door-to-door sales. It was relatively rare that women had waged paid work, the exceptions being jornaleras and

\footnotetext{
${ }^{113}$ By saying "represented", I include both women who participated in interviews, and those who did not. There was one case - Donardo and Alba - in which I spoke only with the husband.
} 
the one single mother who held a job in one of the village's agricultural packing plants. Almost half the women represented took part in more than one income-earning activity; for instance, many combined farming and weaving.

It was discernible from interviews and conversations with women's group representatives that women contributed to the family economy because of situations of economic necessity, but also because they attached cultural value to the act of working, which is consistent with other assertions about indigenous Guatemalan women's work (e.g., Carey 2008a). In an interview that I found quite compelling, a single mother, Luz explained her attitude toward the paid work she did to sustain her daughter: "You have to work, because if I'm going to just sit [around] like that, or sleep, how am I going to find money? There's no money. So you have to kick a little of that laziness to work and earn money." Not only did her words touch on financial motivations for work, but also the cultural value of work for her, including its demonstration of industriousness and shunning of laziness. Other cultural sentiments of attachment to work came through in the comments of Brenda, a married migrant woman, who said of her contributions to family farming: "One does it with real will if one wants to get ahead...and while I'm healthy, I'll be there working."

Among forms of unpaid and provisioning work - a term that usefully encompasses "all the work that women do to provide for themselves and others" (Neysmith, Reitsma-Street, Baker-Collins et al. 2010:152) - women were more likely than men to be responsible for volunteer work in schools and churches, and for food purchases. Women with children in the primary school, for instance, might be responsible once or twice a month for making the children's snack at school. Women with church affiliations would often visit the sick in the community and clean or otherwise prepare the 
church space for services.

No matter what women's varied activities entailed during the day, they would usually be at home to prepare dinner for their families, which included making tortillas for the second or third time on a given day. Evenings would give them the chance to visit with their partners and children, see other family members nearby, help children with homework, do some weaving or embroidery, prepare the nixtamal to bring to the mill the following morning, and perhaps prepare men's breakfast in advance for early departures. In households with televisions, women would maybe spend a little while watching a program before bed. It was not uncommon for women to retire later in the evening than men, and to be up before them in the morning.

Summed up, this is how Jimena described her home-based day after waking up:

"I start my fire, I wash the nixtamal and go to the mill. Upon return, I make tortillas, eat breakfast, and get the girls ready for school. They leave, and he leaves, and I get to tidying my house, my kitchen, my room, then I wash clothes, and I take care of my animals. We're talking about 10:30 or 11. At 11:30, to the kitchen again to make lunch and tortillar (make tortillas). After lunch, the same work - wash dishes and clean again. Now we're talking 2 p.m. and later, and again with the animals, and after the animals, that's a time to rest, to do a little weaving. At 4 p.m., light the fire again, do the nixtamal again, and make dinner. At 7:30 or 8 , I rest. That's the norm, the routine."

Other women would intersperse other types of work into this daily schedule, but women emphasized that they were often in the kitchen three times a day, performing a similar routine of lighting a fire, making tortillas and other foods, serving their household members, and cleaning up. It perhaps comes as little surprise that women said they did not have very much free time, and when they did, fairly rarely would they turn to leisure activities. One exception was a more educated woman without children - Esperanza who would read or watch a lot of television. Instead, most women said they would do some variety of domestic work, such as collecting firewood, weaving, or general clean-up, 
or occasionally visit family members. Men were more likely to spend their free time relaxing, watching television or walking about (paseando) the village, perhaps talking with friends. It was not clear to me that there were meeting places for men aside from the churches, although I did hear of an informal tavern on the outskirts of the village, but drinking or gaming were off-limits for Evangelicals. In their non-work time, most women and men would go out at least once a week to regular church services and related gatherings, such as Bible study, choir practice, or women-only services.

\section{Divisions of Labour}

In relating how they would typically spend their days, participants illuminated elements of gendered divisions of labour with respect to housework, child-rearing, breadwinning, and within certain task areas, such as agriculture. The most obvious and rigid aspects of such divisions concerned home-based unpaid work - what feminist political economy often captures as social reproduction (Luxton 2006) ${ }^{114}$ - particularly meal preparation and housework, and to somewhat lesser extent, child-rearing. Both women and men considered cooking, cleaning, and related tasks - locally called oficios, which roughly means 'housework' - as women's areas of responsibility, and men would do some of them only if women could not do so. One man, Donardo, put it this way, framing the division of labour in terms of the time available to him and his partner, and the spaces they primarily occupied: “The oficios domésticos (housework), I don’t really help her, because I leave early for work and return late, so she mostly stays here in the house taking care of the household tasks and the kids. She's in charge of the majority of that work." Meanwhile, Cristóbal, illuminating broader cultural consistencies, remarked:

\footnotetext{
${ }^{114}$ See (Luxton 2006) for feminist political economy discussions of the terms used over the years to describe these types of activities. I draw on a few of those terms here, including domestic work, housework, social reproductive work, and provisioning.
} 
"Here the one who maintains the husband is the woman, the kids and the husband, take care of them... I come back from work, and [there's] nothing more to do... Work here in the home, it's not a lot that man or husband does." Aside from supplying firewood and tending to large animals such as cows, which many men did, women generally agreed that they themselves were primarily responsible for the oficios. Jimena, for instance, stated "the housework, [it's] almost nothing [that he does], only me. " Men would do certain household tasks from time to time, but only if women were unable to fulfill their normative responsibilities for reasons of illness, being out of the house, or being overburdened. Rolando illuminated this well: "When she's not here, I do nixtamal, I put on the nixtamal. If she doesn't have enough time, I wash dishes...[but] When I see that she can do it, she does it."

Participants indicated that child-rearing, too, fell mostly within women's area of responsibility, but I also discerned a fair amount of involvement on the part of men in caring for children at home, more so than in cooking and cleaning tasks. Men tended to see their main contributions to child-rearing as providing economically for their children's needs and education, and teaching their sons how to farm. In my host family, I also discerned that the father, Rafael, was the primary disciplinarian. However, interviews suggested some degree of men's involvement in active caring for children, especially if women were over-burdened or out of the house. I saw this first hand when I interviewed a migrant man, Felipe, at his family's store while his wife was out, where he was talking with me at the same time as taking care of two young children. His wife Mónica, who I interviewed separately, confirmed the active child-rearing participation of her husband: "If one was crying and I have my oficios to do, he would go get her [the baby] while she calmed down a bit. If he sees to one, I see to the other." For his part, 
Donardo made it clear that his presence gives his wife at least a short time of rest or time to herself in the evenings after he returns from work: "in the evenings, the 2-year-old wants to play, so I spend 15 or 20 minutes playing, so that she can rest a bit." In yet another household, Yaneth said her husband would help her a fair amount with caring for their three children, especially the baby: "I don't have to ask him, 'please can you take care [of her].' Yes, in the afternoon or evening he takes care of the nena (baby girl)."

These findings regarding men's assistance with 'women's work' are reflected in some literature; Menjívar (2006) says this reflects the value attributed to incomegenerating work that women do that may take them out of the house, as well as a focus in Kaqchiquel culture on respect and consideration for other household members. However, further confirming mothers' lead parenting roles, Yaneth added that it is almost always the mother who takes care of the children; children come to their mother, not the father, if they want or need something, such as when they are sick or hungry. As well, Yaneth had heard there was an opportunity to go to Canada as a migrant but her husband said it was better that he go instead because "the kids would die without their mom." So while I do not wish to minimize fathers' parenting contributions, it became clear through interviews that women are primarily responsible for the home-based, nurturing aspects of caring for children, which is consistent with other research emphasizing the centrality of motherhood to Guatemalan women's identities (Menjívar and Agadjanian 2007).

If women were primarily responsible for broadly taking care of their homes and families, men were primarily responsible for sustaining the family financially. The normative rigidity of men's breadwinning roles was not as pronounced as that of women's home-based responsibilities; that is, as discussed above, it was relatively common that women would contribute to the household economy in some fashion, 
whereas it was proportionally uncommon that men would do social reproductive work, especially oficios. Substantiating such findings, Carey's research confirms Kaqchiquel women's active roles in 'productive' work especially in local markets, and describes these transfers into men's primary sphere of responsibility as "rational" (2008a) because economic necessity impels such engagements. Men, however, were comparatively very reluctant to engage in gender-crossing behaviours, e.g., domestic work, because of the social pressure they felt to maintain their masculinity, honour, and household status, points to which I will return in my analysis.

So although women often contributed to the household economy in Vista Hermosa, both women and men expressed beliefs that men were primarily responsible for the bulk of income-earning. For instance, in conversations with Miranda in my host family, she said that she thought it was proper that the man earns money to give the woman what she needs, while the woman takes care of the household. Men's normative responsibility in this area often emerged in discussions about why men had migrated to Canada. In regard to his migration, for instance, Rolando said: "I have to luchar por mi familia (fight for my family) and do it for them." Another man, Franco, explained why he had migrated instead of his wife: "We made the decision that she would stay, to look after the family, and I went there to fight, and to help the family get ahead."

For their part, women tended to frame their income-generating work as 'helping' their partners or fathers. For instance, Jimena said: "I plant, and when there's no need to work in the field, I weave. I do whatever to make a few cents, to help him." The director of the women's organization Mujeres en Acción (Women in Action) in Chimaltenango also spoke to this 'helping' theme by claiming that women who took part in micro-credit projects that the organization facilitated would give most or all of their earnings to their 
male partners. I return to this theme of 'helping' in Chapter 8 in my discussion of the gendered impacts of economic remittances.

Gendered divisions also arose within sets of activities, most notably householdbased tasks and farm work, in which women and men demonstrated proclivity toward performing some tasks but not others. For instance, it was relatively common that men would assist with aspects of childcare and child-rearing while at home, and on occasion they would prepare food, but it was explained to me that men would almost never go to the mill, make tortillas, or wash or iron clothes. With respect to family-based farming, men would focus on preparing the land and fertilizing, while women would plant seeds or occasionally partake in weeding; and it was more common that women would do afterharvest hand-processing of crops at home than men. One woman explained these genderbased differentiations in farming tasks in terms of the tools men and women were allowed to use; explaining why she would only weed and harvest, Brenda said: "because to work with an asadón (hoe), more than anything, he doesn't want [me to]. I can do it, but he doesn't want me to, because here in Guatemala, the ones who work like that are the men; the women do other things in the field that aren't as hard." Literature confirms that hoes are more commonly - but not exclusively - used by men in Guatemala (Carey 2008a, Carey 2006). ${ }^{115}$

These explorations of gendered divisions of labour illuminate a sense of cooperation and complementarity between women and men in the activities they did to sustain their households, as confirmed by research on household gender relations in Guatemala discussed in Chapter 2. For instance, in describing the cooperative practices of

\footnotetext{
${ }^{115}$ Carey also describes a related gendered division of tools: men use a tumpline (in Kaqchiquel a tapäl) - a leather strap across the forehead that supports a load (usually of firewood) across the back - whereas women bundle firewood and carry it on their heads.
} 
herself and her husband, Manuela said: “Sometimes when my kids aren't here, when they're off studying and I'm alone here, I go to the campo, and my husband helps me. We help each other." Among organizational representatives, the director of the Kaqchikel Presbytery contributed to this understanding, referring to women and men having different natures, meaning they could not equal but that they were "complementarios", they complemented each other in what they did. Households varied, however, in the extent to which women and men assisted each other in ways that transgressed normative boundaries of gendered behaviour.

In men's and women's remarks about what they did there also emerged a spatial differentiation with respect to where women and men spent the majority of their time. I hesitate to call this a public-private divide because women would clearly leave the house regularly to shop, farm, and serve the community, and men carried out some home-based responsibilities. However, there was a proportionality to the 'where' of the activities that women and men did, and to which they thought they should devote most of their time in a given day. Summing up what her parents did, for instance, separated single mother Luz said, "my dad in the campo (field) and my mom in the house, in the kitchen and [doing] a little weaving." Adding a normative dimension to this spatial division, Gloria, a married woman explained: "What I dedicate myself most to is my house, my home, taking care of my husband and my kids. Sometimes I go out with my husband to help him in the field, but I almost never go with him because I abandon my house.” Thus, one gets a sense of women's normative spatial sphere of activity being the home. If women engaged in income-earning activities or other pursuits that required them to leave the house, they could not neglect their daily maintenance of the household. Some women also stressed that they left the house only when they had need to. They would not "go out just to 
pasear (walk around)," as Amparo put it, whereas as mentioned above, men more often spent their free or after-work time doing so. Other research in Guatemala suggests that these mobility differentiations stem from concerns about fidelity and men's honour being tied to control over women in their household (Carey 2008a).

In summary, then, participants' remarks revealed several aspects of the gendered division of labour - discernible in housework, child-rearing, income-earning, and within sets of tasks - as well as complementary and spatial dimensions of those divisions.

\section{Household Authority}

In addition to which activities women and men typically did on a daily basis, and the various gendered divisions of labour, the third major theme that I investigated concerned household authority in decision-making and financial management, or what I characterized in Chapter 2 as the power or control dimensions of household gender relations. Overall, men had greater control than women in these matters, but in comparison to the discernible daily gendered division of labour, I found the issue of household authority somewhat more difficult to ascertain because it was more nuanced and complex (with differences between separated and married women, for instance), and because there seemed to be a continuum among households in terms of whether authority was relatively equally shared or primarily men's prerogative.

Other research confirms the variations and difficulty in assessing these dynamics in Guatemalan households, even within a given community. Variations owe to factors such as marriage or life-cycle stage - for instance, older women in longer-standing established marriages may be able to claim more authority over household affairs than newlyweds (Weinstein Bever 2002) - and type of religion, with Evangelical Protestants 
arguably exemplifying more rigid patriarchal patterns than Catholic households (Whiteford 2002). As well, even if men tend to wield more control overall, decisionmaking and financial authority tend to be divvied up according to men's and women's spheres of responsibility, with women having more power than men over certain issue domains, such as food or children (Carter 2004). Research by Becker and colleagues demonstrates further complications in these assessments: the vagaries of reporting behaviours and interview encounters themselves, conditioned by who is present, how partners have handled the decision area being inquired about, and "different cognitive understandings of the questions" (2006:2315). ${ }^{116}$

To get at decision-making and household authority generally in my study, I phrased interview questions as variations on "¿quién manda?" (who is in charge?), and responses illuminated a spectrum of circumstances. Responses and characterizations depended, first, on the demographics of the household and participants' places in them, and second, the particular subject matter over which authority was exercised. There were no discernible patterns in my study according to households' religion. Demographic variations - centred on who the migrant was - included young single childless women living with their parents, separated mothers also living with their parents, and conjugal couples. Young single women living with their parents said that the exercise of authority depended on the issue at hand, but overall identified their fathers as having more household authority than their mothers. Separated mothers cited considerable clout over their own affairs and those of their children, but also felt their fathers' overall control;

\footnotetext{
${ }^{116}$ For instance, Becker (2006) noted that if women and men had disagreed in their handling of a given issue asked about in an interview, women tended to under-report their decision-making influence. And with respect to interpretation of interview or survey questions, respondents may have different thresholds for the answers 'yes' or 'no', or incongruent understandings of the meaning of who takes the final decision.
} 
Luz, for instance, explained: "my dad is the one that orders around here. Second, my mom, because my dad has more valor (courage or validity) to scold us and explain how things are, and my mom, le da pena (it makes her feel bad) to do that... Yes, more my dad... And we can't boss him (laughs a bit)." However, household authority for separated women living in their natal home also depended on the parents' age and condition; for example, 36-year-old Laura lived with parents who were fairly aged and often ill, resulting in a largely female-headed household in which she was in charge of most affairs, and Isabela, also in her mid-30s, claimed to have equal household authority with her parents who were in their 60s.

Among conjugal partners, I discerned considerable variation between relatively egalitarian arrangements and disproportionate male control, with nearly equal representation within each characterization among the eight households for which I have information, with a slight proclivity toward men's authority. On the former end of the spectrum, partners said they discussed matters and tried to come to an agreement. Ramón described it this way: "Here, in our home, nadie manda (no one commands or bosses). We share ideas, so that there isn't any problem. Because if someone gets to commanding, there are lots of problems. So better that we share the needs and see [about] everything [together]." In her household, Yaneth explained that authority was:

"Igual. Él no manda, yo no mando (Equal. He doesn't command, I don't command).

$\mathrm{CH}$ : And when there are decisions to take?

Yaneth: The two of us, he always asks me if I'm in agreement. If not, then no. Or to buy some land, if they're offering some, he asks me if I agree, because to buy that, one has to reduce the other expenses more in order to buy that. So I tell him, it's fine, and we do it."

Representing a third household with relatively egalitarian decision-making, Brenda 
explained:

"With us, it's always shared. Sometimes I'll say something, and he says, "but why?' I understand that it doesn't have to be that way [that I decide] or the contrary, better that we do it this way. It's always between the two of us; no one takes a decision alone. The same with going to Canada, we always think about it the two of us, to be in agreement about him staying or me staying, or who's going, or who's going to be far away. One doesn't say, 'you have to be here.' We have to decide it."

Tipped more toward his authority but involving his wife significantly, Franco explained: "There are times when I have to share with Adelina to see and make just one decision. In the global, I pretty much do it, because here we've gotten used to [where] one sees, and reports to the other. But there are situations that are more delicate where you have to put it on the table and chat. That's how we do it."

In regard to households with disproportionate male authority, the director of Mujeres en Acción said unequivocally: "normally, it's the man who manda (is in charge), it's the man that makes the decisions. That is to say, the woman is just like an... objeto (object). 'Here I am at your órdenes (service)' and everything.” I did not discern in my study patriarchal dynamics as one-sided as this organizational leader suggested, but certainly there were instances where men had more say than women. Exemplifying these circumstances, participants in four households - both women and men - said that men often consulted women on important issues, but did what they thought best or made the final decisions. In this vein, Eduardo explained that he sought the support of his wife and family, but he made the decisions because "as a man [he] expresses what he wants done." His wife Yolanda concurred: "It's my husband, it's always him que manda aqui (that's in charge here). I always ask him what we'll do." Rolando said each home has its own character in these regards, and "for my part, I can mandar more. If I can't do it, she tells me, too, but mostly we work together, we talk together, and the one who tiene lo más que 
ver (has the most to see about or decide on) is me." Representing a third household where the man had the disproportionate say was a relatable exchange with Mónica that resulted in laughter:

"It's more him that makes the decisions. He says, 'we're going to do this, are you in agreement - yes or no?' If I say no, sometimes he does it (laughs a bit). So yes, more him.

$\mathrm{CH}$ : But at least he consults you.

Mónica: Yes, he consults me but sometimes doesn’t obey me (laughs). I say to him, 'don't bother asking me because you know what you're going to do.'”

Finally in line with a male-authority characterization, although somewhat contradictory, Flor claimed: "the one who is in charge is the man (laughs a bit). It's them that mandan (command). The two of us, we chat, we both have to be in agreement." The apparent contradictoriness in Flor's comments likely in part reflected her uncertainty about which types of decision-making on which to focus in her response - mirroring Becker's (2006) contentions about different understandings of an interview question - but relatedly, her response also likely signaled the fact that decision-making dynamics depended on the issue in question. Along with demographic variations, this was the second major dimension that served to add nuance and complexity to household authority.

Decision-making often fell within gendered spheres of activity, sometimes spatial in character. When asked about who was in charge in her house with her parents, Emilia said: "More my dad, yes, more my dad. He tells us how to do things. Now, in the kitchen, it's my mom (my emphasis)." She elaborated to say that depending on the issue, she and her siblings would also share their opinion. Yaneth explained the spatial decisionmaking domains of she and her husband Lucas: "When he's here, if it's about the siembra (crops), he makes the decisions because it's about the campo (farm field). If it's 
about the house, I tell him, 'we have to do this and this and that.' 'Ah okay,' [he says]."

What emerged quite clearly - in six of eight households for which I have information - was men's authority over financial decisions and management. Cristóbal, for instance explained that "here we're united, but maybe sometimes no, because only me, only the husband administers the money." Lourdes said her husband was in charge when it came to money; he would spend a lot of it on luz (utility bills) and leña (firewood), and she did not have to worry much about the expenses: "yo como y me duermo (I eat and I sleep) (laughs)." In my host family, Miranda explained to me that Rafael held overall control over the household's income, that when he got paid, he would give her what she needed for her expenses, but her comments - together with those of Lourdes - also illuminated gendered patterns to spending. Although Rafael controlled earnings, he would give most of his pay to her for food purchases, for which she was responsible, and over which he did not exert any further influence generally. Once or twice a week, many women would take a bus into Tecpán town, or sometimes further to the city of Chimaltenango, to shop in the market and grocery stores. On the other hand, representing one of few households where finances were managed more equally between partners, Luz said, "My mom and my dad, the two of them together agree on how to do it, or where to get something. When there are expenses, it's between the two of them."

Interestingly, the director of the women's organization Mujeres en Acción (Women in Action) in Chimaltenango stressed that women were better household financial managers than men, especially when women got money through the microcredit projects that her organization facilitated. However, she commented that women commonly gave or shared their project-derived earnings with their husbands because women are respetuosas and consideradas (respectful and considerate) of their husbands' 
financial authority.

So, as I attested above, it was not straightforward to discern gendered household decision-making and financial management dynamics in Vista Hermosa. However, overall, despite some egalitarian arrangements, study participants suggested that household authority tended to fall disproportionately toward men.

In summary, then, these three themes - a typical day, the gendered divisions of labour, and household authority - reveal a considerable gendered dimension to women's and men's practices and relations between them in respect of the household. Men's daily routines were fairly predictable and consisted of less variety of activities than women's, and women's extra-household undertakings needed to be fit around or adapted to their primary sphere of household responsibility. Gendered divisions of labour applied, in which women assumed the majority of responsibility for housework and parenting, while men were seen as the main or proper breadwinners even though most women contributed to the household economy. The spatial dimension of these divisions showed that men spent more time out of the house than women. Finally, although the third theme admitted of more nuance and variation than the previous two, the discussion of household authority in financial management and decision-making illuminated an understanding on the part of both women and men that men held disproportionate control in these matters.

By providing a benchmark of sorts of household gender relations in Vista Hermosa, this discussion has set the stage for the following three chapters that examine change and continuity in these dynamics in the context of migration. However, by way of one last set of context-setting information, I close this chapter by providing details about migration to Canada among my study participant households. 


\section{Migration to Canada}

Although Chapter 1 provided an overview of the IOM project, situating it in Canada's immigration policies and trends, I offer here a more specific account of migration patterns among my study participants, including why they went, how they became participants, and some general outcomes and challenges. Tying the two sections of this chapter together, women's limited participation in the IOM project will illuminate some of the household gender relations that have been discussed.

Reasons for wanting to migrate to Canada focused almost exclusively on economic circumstances. With occasional mention of "wanting to see what it was like there," the vast majority of responses emphasized having gone "por necesidad (out of necessity)." Economic need stemmed in general from a combination of not making enough money, and having expenses and debts that they had trouble managing, especially if there were kids, or household members with health needs. Respondents often cited agricultural projects with low yields, or getting low prices for their harvests. Manuela, for instance, explained: "We plant a bit of snow peas, cabbage, a little potato. But sometimes it doesn't get a good price. All the money we invest there, and sometimes no sale nada (nothing comes of it). That's when the failures come. Sometimes our food isn't even enough." It was not clear how many households were participating in nontraditional export-oriented agriculture initiatives noted in Chapter 4, but Fischer (2005) notes that these are risky ventures, with success requiring significant knowledge and investment for inputs, and often the risks do not pay off. As well, inequalities in the very access to the means to diversify their crops as well as little in the way of 'trickle-down' effects may indicate growing economic inequalities in the Tecpán region, which may have been contributing to migrant households' economic need. 
In terms of what migrants in my study sought to do with their earnings, recently married migrants cited desires for their own houses and land, and parents wanted to provide better care, education, and land for their children. Rolando explained: "I don't want to leave them [the kids] like they [my parents] left me. So I tell my kids, they have what I never used. I never put on a pair of shoes when I was a little boy. They have studies, that's what I want most for them, that they aprovechan (take advantage)." Separated mothers, in the absence of fathers' financial help, emphasized going for their kids, to "sacar adelante a mis hijos (to help my kids get ahead)." Isabela, a separated mother, described her reasons this way: "I want to just make a house for them [my kids]. That's what I've said there in the IOM office, I say that one goes there out of necessity... Because if one here has stuff to eat, well then, but if we don't have that, well then...”

For the most part, migrants and their partners expressed happiness and gratitude for their participation in the IOM project, which had not always come easily. Recruitment of migrants from Vista Hermosa involved three principal sets of actors: IOM staff, recruiters that the IOM had contracted, and Canadian employers. Migration to Canada from the village began in 2003, through the 'help' of a man, who I will call Don Hector. He owned a local export-oriented packing plant and had contacts in the government through which he "brought the program" to Vista Hermosa. The IOM had contracted him to recruit people from the community. It seems he sought out or invited certain people he knew, including his own jornaleros (day-labourers), both men and women. Isabela explained: "he sees that I work here, and my husband isn't here with me, and seeing that, he came to tell me. And he gave me the opportunity." For three female migrants, it was the female owner/employer of a large Alberta farm who made direct visits to Vista Hermosa to recruit workers. And a number of other migrants had sought 
ways to sign themselves up, often with the help of social networks, which research suggests are often key to migration projects (e.g., Pessar 1999a). Many were skeptical about the legitimacy of the opportunity at first. Simón, for instance, said, "at first, people didn't want to go, because here in Guatemala, as we know, there's a lot of lying people. They take your money and in the end, there's nothing" and likewise Eduardo attested: "I didn't believe it, that they would give a campesino (peasant) that opportunity." However, word about good experiences soon spread through friends, family, neighbours, and coworkers, who often recommended potential migrants to the IOM or their employers.

After pursuing one of the above avenues, migrants' names arrived on a list at the IOM office in Guatemala City. After that, if and when opportunities arose, the IOM administered certain exams - either in the village or at the IOM office - which migrants generally passed with ease. Sometimes the time between clearance to participate and leaving for Canada was a matter of a few short months, whereas in others, it was one or two years; everything seemed to depend on matching them to appropriate jobs in Canada. Overall, relatively few of those jobs were for women, although it seemed in some cases that employers or the IOM had specifically recruited women (asking for their word that they were not pregnant, and sometimes, that they had dependent children), whereas in others, women had had to fight and convince their way onto the IOM list because they had found recruitment male-selective. In Brenda's case, "Don Mariano was saying it was only for men. But I heard that there were [opportunities] for women, but women hadn't gone from here... And then those from the IOM came and said that there were opportunities for women."

For some women wanting to go, issues of male household authority became evident, in that daughters and wives sometimes needed the permission of fathers and 
husbands, although sometimes this came after women had already signed up. Luz explained that she had already done her paperwork and paid her deposit and "then, I asked my dad if he'd give me permission to go to Canada, because what are we going to do with the nena (little girl)?" Also related to normative gender roles, for three of the four married migrant women, they had migrated because their husbands could not: Manuela's husband had gone one year but could no longer because of health problems; Gloria's husband was too old for the IOM project; and Gabriela's husband was blind, so most of the household's income-earning fell on her shoulders. In Manuela's case, when her husband failed his health tests, "I told him, 'if you give me permission, I'll go [to Canada]. When your boss comes... I'm going to talk with her and ask her to do me the favour to help me.' 'That's fine,' [he said]."

Among the women who had not gone to Canada - female partners - considerable evidence arose of the "spatial stickiness" (Pratt and Yeoh 2003:161) mentioned in Chapter 3, i.e., their home-oriented gendered responsibilities, especially motherhood, had held them back from migrating. Asked if she had thought of migrating instead of her husband, Amparo replied yes, but "no [I can't go], because of the kids, they'd be here alone... Like when I go out for a bit, they're looking for me right away, and they get sick." In another household, Franco explained: "We made the decision that she would stay, to look after the family, and I went there to fight, to help the family get ahead." In a third case, Mónica claimed, “if I didn't have kids, I would go. I've thought about that, I tell him [my husband], 'if only I could go and know what it's like there.' But then I think about my kids, they're what make me not do it." Pointing out that older daughters could step in for other mothers but not for her, Lucinda said "me, because the five [kids] are boys, I can't leave.” I comment further on migration decisions in Chapter 7. 
There were considerable expenses involved in migrating to Canada. Until late 2010 , the IOM charged the deposit of 4000 quetzales (approximately $\$ 500.00$ ). It was common that potential migrants had to sell animals or other possessions or go into debt to come up with these funds. Organizational representatives explained that banks would generally not lend this money for lack of collateral, so 'neighbours' would lend, sometimes at up to 40 per cent monthly interest. And there were illegal charges as well: the IOM found out that Don Hector had been charging Q1000 to each migrant for the favour of enlisting him/her, and duly dispensed with his services. I heard some disheartening stories in these regards. In particular, Isabela, a separated mother, claimed that for her first season, she had had to deposit almost Q7000 "and after that, they told me the farm had closed! They told me that I had to bring the Q4000 again [the following year]!... I didn't have the money, I had no money. I sold my bed, I sold my things, what I had." Once there, as mentioned in Chapter 1, migrants had deductions from their pay, on top of personal and food expenses.

For the most part, migration to Canada had been economically worthwhile, although the extent of success in meeting financial goals depended on how many times migrants had gone and for how long. Contracts in my study ranged from three to twelve months, and with one exception, no consistent differences emerged between women's and men's contract lengths. Women, however, had gone to Canada fewer times averaging two trips to men's three trips - likely owing to the facts that extremely few women from Vista Hermosa went initially and that there are fewer opportunities in Canada for women overall, due to the highly masculinized nature of Canadian agricultural work. Table 4 provides a summary of information about migrants' seasons in Canada and their destinations. 
Table 4: $\quad$ Participants' Migration to Canada

\begin{tabular}{|c|c|c|c|c|}
\hline Pseudonym & $\begin{array}{l}\text { \# of migrations } \\
\text { to Canada }\end{array}$ & $\begin{array}{l}\text { Trip year most } \\
\text { recent to study }\end{array}$ & Province(s) & $\begin{array}{l}\text { Average migration } \\
\text { length in months }\end{array}$ \\
\hline \multicolumn{5}{|l|}{ WOMEN (n=15) } \\
\hline Manuela & 2 & 2009 & QC & 5 \\
\hline Gloria & 1 & 2008 & QC & 4.5 \\
\hline Gabriela & 3 & 2009 & $\mathrm{AB}$ & 4 \\
\hline Brenda & 2 & 2009 & $\mathrm{AB}$ & 5 \\
\hline Laura & 2 & 2009 & $\mathrm{QC}$ & 6 \\
\hline Isabela & 2 & 2009 & $\mathrm{QC}$ & -- \\
\hline Flor & 3 & 2008 & $\mathrm{AB}, \mathrm{QC}$ & -- \\
\hline Luz & 1 & 2006 & $\mathrm{AB}$ & -- \\
\hline Eva & 1 & 2007 & $\mathrm{AB}$ & 7 \\
\hline Sofia & 1 & 2007 & QC & 4 \\
\hline Esperanza & 3 & 2009 & $\mathrm{AB}$ & 5 \\
\hline Delia & 3 & 2009 & $\mathrm{AB}$ & -- \\
\hline Emilia & 2 & 2008 & $\mathrm{AB}$ & 7 \\
\hline Fiona & 2 & 2008 & $\mathrm{AB}, \mathrm{QC}$ & -- \\
\hline Clara & 2 & 2008 & $\mathrm{AB}, \mathrm{QC}$ & -- \\
\hline \multicolumn{5}{|l|}{ MEN (n=18) } \\
\hline Rafael & 3 & $2010^{*}$ & $\mathrm{BC}$ & $10-12$ \\
\hline Alberto & 3 & 2009 & $\mathrm{AB}$ & -- \\
\hline Ramón & 3 & 2009 & QC & 4 \\
\hline Rolando & 2 & 2008 & $\mathrm{QC}$ & 4 \\
\hline Cristóbal & 4 & 2009 & QC & 5 \\
\hline Lucas & 6 & 2009 & $\mathrm{QC}$ & 5 \\
\hline Eduardo & 4 & 2009 & $\mathrm{QC}$ & $7-8$ \\
\hline Franco & 1 & 2009 & QC & 3 \\
\hline Felipe & 1 & 2008 & $\mathrm{BC}$ & 6 \\
\hline Elías & 6 & $2010 *$ & QC & 6 \\
\hline Marco & 5 & 2009 & $\mathrm{QC}$ & $4-5$ \\
\hline Guillermo & 4 & 2009 & QC & 6 \\
\hline Donardo & 1 & 2007 & $\mathrm{BC}$ & 5.5 \\
\hline Gustavo & 2 & 2008 & $\mathrm{AB}$ & 7 \\
\hline Simón & 4 & 2009 & $\mathrm{AB}, \mathrm{QC}$ & $4-5$ \\
\hline Jacobo & 2 & 2009 & $\mathrm{QC}$ & $5-6$ \\
\hline Vicente & 3 & 2009 & $\mathrm{QC}$ & -- \\
\hline Mario & 5 & 2009 & QC & -- \\
\hline
\end{tabular}


It did not seem appropriate to ask how much money migrants had made, but I provide more information in Chapter 8 - focused on income and economic remittances of how households used migration earnings. Here, I would mention that there were a few cases where migrants described their IOM project experiences as less than economically successful, because of insufficient work, unexpected expenses, early repatriation, or not being called back for subsequent seasons. Giselle Valarezo and I document some of these difficulties in our publication mentioned in Chapter 4 (Valarezo and Hughes 2013), but key to these situations and to the general uncertainty among migrants about their prospects was the significant control that employers had over their fortunes. Employers could send workers back to Guatemala at any time for virtually any reason (and because of employer-tied work permits, Guatemalans could not easily switch employers) and choose whether or not to re-call given workers by name for subsequent seasons, and sent migrants home with sealed work evaluations for the IOM that in large part determined whether or not they stayed on the IOM's list of workers. To ensure that they maximized their chances of receiving positive evaluations and being re-called, migrants sometimes had to, in their words, aguantar (put up with) some strict and difficult circumstances in Canada, both on the job and in cramped living quarters. Rolando, for instance, explained: "We go there for necesidad, it's not to just go there... for gusto (fun). We have to aguantar a bit of maltrato (mistreatment)." In my exploration in Chapter 9 of circumstances shaping social remittances processes, I return to elaborate on some of migrants' challenges in Canada.

At this point, having presented an analysis of 'normal' household gender relations in Vista Hermosa, and a sketch of migration to Canada among my study participants, I launch my analysis of how the latter has influenced change and continuity in the former. 


\section{Chapter 6 \\ Investigating Habitus: Migrants in Canada}

Leading off my analysis, this chapter examines the potential for migration experiences to contribute to changes and continuities in the gender habitus, with a focus on migrants. As such, the following discussion centres on the 'self' level of the gender structure and of my theoretical framework. This chapter draws on other research on habitus in relation to migration, as highlighted in Chapter 3, including its gender components. Those works identified particular markers of changes in migrants' habitus. In the main, authors have identified shifts in the way that individuals act, dress, carry themselves, think, and value particular forms of capital (Friedmann 2002, Guarnizo 1997, Kelly and Lusis 2006, Mahar 1992, McKay 2001). Such clues to habitus change may be evident during a given migration period and/or upon migrants' return. Mahar (1992), for instance, examined changes in Mexican internal migrants' economic dispositions conditioned by the requirements of the squatter settlement fields to which they moved. Focusing more on return, Kelly and Lusis (2006) and McKay (2001) found differences in returned Filipina domestic workers' styles of dress, speech, consumer choices, and in the symbolic worth they assigned to particular assets. Highlighting both migration and return, Guarnizo noted the dual frame of reference that constitutes the transnational habitus, which operates "regardless of the shores they are on," including standards of both where they are and the society they have left behind (1997:310).

In relation to migrants' experiences in Canada, I outlined in Chapter 3 that I could investigate three principal avenues through which the gender habitus could shift: movement between fields, transnational fields, and practices. I focus in this chapter on the first and third. Migrants' movement to new locales (groups of fields in Canada) 
involves encountering and adapting to certain prerogatives, 'rules', and social relations that differ from those familiar to them, and as a result of the discord between migrants' habitus and the demands of these fields, habitus might shift to better agree with and suit the actors for life there. More so, however, I look at gender-related practices in Canada that social actors carry out on a regular basis, contending that an examination of practices lends more analytical feasibility and precision to possible shifts and continuities in habitus than the rather ambiguous 'exposure to' or 'experience of' new fields (in Chapter 9, I explore this angle more by focusing on migrants' gender consciousness).

Four temporal and substantive themes structure the following discussion: what happened in Canada that may have affected habitus, evidence of habitus change and continuity while in Canada, evidence of habitus shifts and stability upon return to Guatemala, and elements of the return context that may have encouraged those modifications or re-adaptation of dispositions to the home environment. I demonstrate that for both women and men, new or intensified gender-related practices in Canada held significant potential to shift their gender dispositions, yet I argue - based on migrants' practices after their return - that there was only limited enduring shifts of the gender habitus in ways that had consequences for household gender relations.

This chapter begins with an exploration of general differences between Canada and Guatemala to which migrants adapted, and of changes and continuities in migrants' selves - including their behaviours, thoughts, and personality. I then focus on the gender habitus specifically by examining men's reproductive labour and women's waged work, and the consequences for gendered dispositions relevant to the household. Drawing on intersectionality-related insights, the last parts of the chapter draw out contentions about the 'activation' of other elements of migrants' habitus integral to their social locations. 


\section{General Differences, and Changes and Continuities in Migrants}

A great deal was different for migrants in Canada compared to the lives and settings to which they were accustomed in Guatemala: their work, including its pace, rigour, tasks, and implements; living in groups - often with strangers - and organizing how to care for themselves; their accommodations and related amenities of convenience; the language of the surrounding society, if not their workplace ${ }^{117}$; the farmland, scenery, infrastructure, and climate; food (although they replicated Guatemalan fare as much as access to ingredients and products allowed); and elements of being income-earners and consumers. Drawing on contentions by Friedmann (2002) and Mahar (1992) that migrants have to adapt to the differences in their new environments in order to survive and succeed there, and that such adaptations amount to or signal habitus shifts, I was attentive to migrants' frequent comments about 'getting used to' Canada. This was sometimes expressed as hallarse, literally meaning to find oneself, but more like getting accustomed or settling into somewhere or something. Migrants expressed this adaptation sentiment a lot, in relation to work, food, and their group living conditions and attendant issues. The women commented on their discomfort with wearing pants, ${ }^{118}$ and the men to doing housework (a topic that I re-visit in more detail below). A few comments

\footnotetext{
${ }^{117}$ I inquired regularly into language issues in Canada for migrants. Fairly often, their workplace language was Spanish (and sometimes Kaqchiquel among the women), both among co-workers and with supervisors or bosses, many of whom spoke Spanish. In earlier stages of formulating my project, I considered the possible acquisition of English or French skills as important to consider for habitus change and as a marker of new cultural capital. However, none of the migrants in my study became proficient at all in either of Canada's official languages, limited to "a few words", usually geared toward the workplace, such as names of plants or tools. With these findings in mind, I have not included discussion of language acquisition in this chapter.

${ }^{118}$ All the migrant women with whom I spoke about their clothing at work emphasized that they had had to put on pants, and sometimes hats and hairnets; in most cases, this was a requirement of the work, whereas in others, it seemed to be more that their traje - attire consisting of blouse (blusa) or woven shirt (huipil), skirt (corte) and belt (faja) - would have been uncomfortable or risked getting damaged. In response to being in pants, some women felt "horrible" or "embarrassed" whereas others had definitely felt "uncomfortable", even though they eventually got used to the unfamiliar attire.
} 
represented this getting used to life in Canada, sometimes tied to the experience of returning: Emilia said, "when one is there, little by little, one se halla with the work"; Luz asserted that "you get used to it. Right away, no, little by little, with experience" and that "when you come back here to Guatemala, you have to be sad because [there] se halla sus modos (one finds one's way)"; and Franco called his return "50 per cent happy and 50 per cent sad because one gets comfortable there." So, there was considerable potential for shifts to their habitus. I begin exploring this potential by examining whether migrants themselves had changed much personally.

Working from the research cited above that identifies markers of habitus change, I straightforwardly asked migrants whether they felt different somehow or thought they had changed personally while in Canada or upon return, and I asked the female partners how they perceived their returning husbands. Many of the migrant women cited feeling different because they had had to wear pants for work in Canada ${ }^{119}$ but more generally, migrants' and partners' remarks suggested that it was more often the case that migrants stayed pretty much the same in their personality, thought, and behaviour than that they changed in these respects. As a sampling of those migrants who did not think they had changed much while in Canada $(\mathrm{n}=8)$, Alberto said he was the same: "no puedo ser otra persona allá que aquí (I can’t be a different person there than here)"; Simón claimed, "I don't feel different, the same, because I know that I'm going to go back to my family

\footnotetext{
${ }^{119}$ An earlier draft of this chapter explored the implications for women's gender habitus of their non-traje work clothing or uniforms in Canada, taking cues from studies on the gender habitus of Filipina migrants that highlighted changes to returning migrants' clothing and sense of style (Kelly and Lusis 2006, McKay 2001). Women in my study generally wore their traje outside of work, and did not wear North American clothing after their return to Guatemala. While interesting, I realized that this discussion had little to do with household gender relations per se, so have not included it in any more detail here in relation to the gender habitus, but later in this chapter I explore women's traje for its reinforcement of their ethnic habitus (not unrelated to gender, given the intertwinings between the two, especially for indigenous women, as mentioned in Chapter 2).
} 
again"; and Brenda, when I asked her if she felt a little Canadian or less Guatemalan there, said no: "I always feel chapina (Guatemalan) there and here (laughs a bit)."

Some migrants provided insight into why they had not changed much while in Canada - including points about the purpose of being there, language, temporariness, and worries about how others would perceive them when they returned home - the latter explanation exhibiting some active effort to stay the same. Alberto claimed they were "just there to work," and Donardo said he was not able to be much different in Canada partly because "with our vocabulary [language], communication is difficult; if one had the same language, it would be easier." Emphasizing temporariness and efforts to remain as before, Luz explained:

"No, we didn't feel different, because we said, 'it's a few months, no more.' Because after, what if here we feel different, arriving there to Guatemala we're going to change character with people, we're not going to talk to them. The people would start talking about us - 'ah with that short time there, you feel proud [in a negative sense].' Better that we stayed the same. [...] because just a few months, and [we] are going to change, now we're Canadians? No."

Although fewer in number $(n=6)$, some migrants noted changes in themselves while in Canada (that did not relate to clothing). Eva said she became more independentminded in Canada and able to defend herself, because her familiar care networks all but vanished. Cristóbal noted a decrease in his tolerance for noise, and his appreciation for all things tranquilo (calm or quiet): "I've liked the silence, one is encerrado (isolated/alone), cooking or chatting with the company, not making a lot of noise." Guillermo claimed he came to feel somewhat different and "gringo" (North American) because of the food he ate and where and how he lived. Donardo cited changes in his thinking along lines that I return to below in regard to class-related aspects of habitus:

"Being there, it's like the mente (mind), it despeja (clears up a bit), and one thinks about a bunch of things about getting ahead economically. Because one realizes 
there, almost everyone is like empresarios (businesspeople or entrepreneurs), and here, no. Only a few are empresarios, and most are agricultores (agricultural workers). And that comes to one's mind there, why don't I do that there [in Guatemala]?"

With respect to the return home, migrants' and partners' comments indicated that twice as many migrants had not changed at all $(\mathrm{n}=20)$ as ones who had $(\mathrm{n}=9)-$ not counting the fairly often mentioned physical changes, including weight loss or gain and becoming fairer-skinned because "the sun there doesn't burn," contended Emilia. Among the changed cohort, some of their differences mirrored how they felt in Canada, with Eva being more independent from her mother after she returned, and Cristóbal not liking bulla (noise), about which he offered a lot of comments, including references to his wife not liking the changes she saw in her returned husband every year:

"what I missed is the bulla there [in Guatemala] because there [in Canada] it's really silent. I don't know, that's how people live. They don't make noise, it's very slow. The kids' shouting, I missed that, the scoldings, I missed that. Those things that I learn there [in Canada], I get used to them... When I arrive back here, I don't want noise anymore."

He shared some comments from his wife:

““¿qué pasa? (what’s happening), why did you change?’ [she would say]... There are things that for her, aren't okay - you're not going to learn anything good,' she says. But according to me, yes. As I say, they're things that maybe-- I think they affect the family here, because ni modo (what are you gonna do?), we're used to [that]. [...] She said to me one time, 'you don't even want to talk anymore. Like that, it wouldn't be life anymore for me,' she says."

Among other situations, Lourdes noted that her husband took better care of his hygiene and insisted on bathing daily, and three of the female partners noted that their husbands seemed more cariñoso (caring), less angry, happier, and more loving and attentive toward their kids. Jimena described it this way: "When he comes back, he's more amoroso (loving) (laughs)... Because when he's here [before], he just scolds, but when he comes back, no (laughs). He doesn't regaña (scold or yell) anymore." Another 
of these men was in fact Rafael in my host family; although I noted and at times found myself frustrated with some of the gender practices I saw while living with them, Rafael was clearly a loving and involved father, and Miranda claimed that he was different - in a positive way - from the angrier, abusive, and more demanding man he had been before, rooted in gaining a greater appreciation of his wife and family while he was away.

It was far more common $(n=20)$, however, that migrants did not exhibit much change in their person upon their return home. Among the women, Flor denied any change: "Me, no. I came back the same as when I left... I can't change from how I went, because people say when you have money, you change. But me, the same, here with my family" and Laura insisted, "sigo normal (I'm still normal)," that she was the same, herself - “¿qué cosa puedo cambiar? (what thing can I change?).” Representing the men, Eduardo explained: "Being here again, I'm the same because I think one isn't a different person in another country" and Donardo commented, "I started with my same work and my same behaviour. I didn't really have any change. People just told me that I'd whitened a bit."

It was the tendency of the majority of female partners to attest to the 'sameness' of their husbands, sometimes counter to worries to the contrary. Yaneth explained: "No, he's the same when he goes and when he comes back. He's the same because he says that when he's there, he misses here a lot.... His character is the same. I see a lot of others that yes, when he goes there and comes back, [he says] I don't like this or that. Him, no. He stays the same." Similarly, Yolanda compared her husband to the worries she had about him: "I felt as if, me daba pena (I was worried), could it be that he'll be the same when he comes back, or more scolding or demanding of his things here, the food. Or what if he doesn't eat our food anymore because he has better food there. But thankfully, 
no, it's not like that."

In addition to the female partners' perspectives, I indirectly sought those of other friends and family members by asking some of the migrants what those people had said to or about them when they returned home. In the main, others had sometimes commented on migrants' physical changes, but mostly the relationships had resumed their normal character. In a couple of exceptions - and opinions with which they disagreed - Gabriela and Esperanza said that others might have said or thought that they had returned more orgullosa (conceited or vain). I return to this prominent cultural theme in Chapter 8 in relation to income and economic remittances.

I consider it important to share these comments in that they constituted migrants' and partners' direct opinions and assessments of changes - or not - in migrants that could signal habitus shifts and continuities. Although their remarks were illuminating in some ways, they did not reveal much about the gender habitus, with the exceptions perhaps of Eva's more independent nature, and the couple of men whose wives said returned as more caring and attendant husbands and fathers. I now attempt to acercar (get at, get closer to) migrants' gender habitus by considering migrants' rather intensive and frequent gender-related work practices that differed from what was 'normal' for them at home in Guatemala, and that may have impelled shifts in their gendered dispositions.

\section{Men's Reproductive Labour}

Key among the practices I investigated in Canada among migrants was men's performance of housework and cooking, which they generally would not do in Guatemala, at least not nearly to the same extent. As discussed in Chapter 5, men may well have contributed to reproductive labour in their Vista Hermosa households, especially food 
preparation, but generally only when their wives (or older daughters) were not present or able to do so. And it was asserted that men would never, if given any option at all, do certain tasks like sweeping or clothes washing. In Canada, they had to do all activities necessary to reproduce their daily labour power, including food shopping, food preparation, laundry, and cleaning of their living quarters. As mentioned in Chapter 3, the International Organization of Migration (IOM) noted this set of activities in their first evaluation of the outcomes of its migration program, for its potential to improve the situation of women in Guatemala, to the extent that men would return to their home communities and contribute more to this household work, and that men would appreciate more the value and difficulty of unremunerated housework (IOM 2006). I will explore shortly whether these outcomes proved to be the case in my study.

Migrant men described their performance of these activities in Canada in matterof-fact ways, but also suggested the difficulty with which they executed them. They lived in groups and would clean their shared accommodations by alternating turns individually or in small groups, and they prepared meals either communally or individually. A few of the men were very vocal about how these circumstances differed from at home in Guatemala. Felipe, for instance, explained: "The food, each person prepares his own, what he eats. Each person has to make his food because when you're here with your mujer (wife), you just wait for your food that she serves you well, but there, if you're hungry, you have to eat. If not, you bear it [the hunger] until you see the other ones eating." Similarly, Eduardo commented, "it's different here because here the one who maintains the husband is the woman, the kids and the husband, take care of them. Whereas in Canada, it's very different because I have to take care of myself." The men mentioned having to get up early to prepare their breakfast and lunch, and to stay up late 
enough to do their laundry and make the necessary preparations for the next day. Men's wives were well aware that their husbands had done this reproductive labour. Paola said her husband would say, “'Here, I don't do anything because tengo mujer (I have a woman/wife), whereas there, it's me that has to do it. I come back tired and I have to make my food and do the cleaning.",

Depending on their upbringing and household circumstances in Guatemala, some of the men had cleaned or cooked before - "he knew how to burn things," Eloísa retorted jokingly about her husband's pre-migration abilities - but others had to completely learn some or all of these activities in Canada. The food preparation seemed to have posed particular challenges. ${ }^{120}$ Ramón said, "We have to prepare them [the meals] and sometimes one doesn't know what to put in, the ingredients. So a bit difficult. For me, all the seasons are hard with the food. The cleaning, no, one learns it quickly." Indicating the importance of telephone communication - a topic that will emerge in each of these analysis chapters - a couple of the men said that they would talk to their wives about how make given meals.

What influence, if any, did men's performance in Canada of tasks gendered as women's have upon their behaviour when they returned home? There were certainly enough comments in my interviews about 'getting used to' this self-care work in Canada, accepting it as part-and-parcel of working there; they emphasized a certain adaptation to and embodied competence in those activities. Was there evidence of changes to their gender habitus as a result of doing so much reproductive labour in Canada? In a handful

\footnotetext{
${ }^{120}$ Tortillas - a necessary accompaniment to most Guatemalan meals - posed particular difficulties given that men would probably never have made them. Thanks to the stores popping up in Canada catering to Latin American migrant workers, they were fairly easily able to acquire ready-made tortillas that they would simply heat up; this was an acceptable substitute, even though they did not taste the same.
} 
of male migrant households $(\mathrm{n}=6)$, men helped their wives more with housework or parenting upon return. Eduardo, when asked whether doing the oficios (housework) in Canada had influenced him to help his wife more, said, "I come to help my wife when she's really busy, I help her in the little that I can. [...] I can help a bit more.” Five female partners commented that their husbands contributed more to parenting - such as going to children's activities and helping with homework - or did more meal preparation. As an example, Jimena, laughing a bit at first, commented, "Lately he's been doing that [helping more around the house]. As I say, he comes back a bit more cariñoso (loving or caring). So if I get called to some errand...he says, 'go and I'll stay and see what I'm going to do.' And when I come back, he's made something [for lunch].”

The men in these six households, I would argue, exhibited signs of shifts to their gender habitus, tied to doing those reproductive labour tasks in Canada; they had learned those tasks and seemed more disposed to do them upon their return. However, drawing into question the 'habitus conditions practice' relationship that is somewhat automatic or unconscious in nature, in one and possibly two instances, there also surfaced a more conscious, thoughtful reasoning that suggested - in line with assertions by the IOM (2006) - an enhanced appreciation among men for how difficult it can be to do and juggle these tasks. Jimena, when asked how she felt about her husband's increased help, said, "I feel happy seeing him like that, it's un aprecio para mi (an appreciation of me). ${ }^{121}$ Much more elaborately, here is how Yaneth described the change in her husband and why she thought it had occurred:

“[I]n the beginning, when he hadn't gone, he always helped me, but it was less.

\footnotetext{
${ }^{121}$ It was not entirely clear how to interpret the word aprecio here. It can literally mean either 'appreciation' - in which sense, I would argue that it suggested a better appreciation of Jimena's work - or 'regard', as in a nicety, in which case it would be less clear that he appreciated her work more.
} 
Because he would say that 'uno casi no hace nada (we women don't really do anything).' Because if someone always does the same thing, one doesn't see the work of someone else. But when he went there, and comes back from work, and has to do the oficios (housework) that one does, is when he saw the difference, that yes, one works. So that's when he started to help more.

$\mathrm{CH}$ : And why do you think that happened?

Yaneth: Because he saw there that one gets tired, and one works here. He said 'dan ustedes más vueltas que uno (you women do more work than us), one gets more tired.' So because of that, he helps more. [...]. They see that it's hard for someone [a woman here], because to wash clothes, and then make tortillas, and clean, one gets tired. So he says, 'you [women] get tired out,' because he hadn't seen that."

Although these comments indicate conscious reflection that would not generally be characteristic of how habitus conditions practices (Bourdieu 1990), from a capitalfocused take on habitus, we could understand such shifts in thinking as re-evaluations of certain forms of capital (Kelly and Lusis 2006), in this case cultural capital embodied and practiced as 'know-how' and gendered as women's. Using this lens, changes to a couple of the men's gender habitus manifested not only in their practices upon return with respect to housework, but also modifications to their valuation of that set of competencies.

Outnumbering those households where men did more reproductive labour upon return, however, were those where they did not; it was more common that returning male migrants did not help their wives more with household-oriented tasks. In ten of the male migrant households, after a brief re-adjustment or rest period, the household gender division of labour slipped back into its 'normal' routine, not only with respect to chores and parenting but also migrant men's income-generating work; they usually quickly resumed their subsistence and/or waged agricultural activities.

Male migrants and their partners explained this with a few different reasons. ${ }^{122}$

\footnotetext{
${ }^{122}$ There is a methodological note worth mentioning here in relation to investigating reasons for behaviour.
} 
Pragmatically, some men described the situation as one of time, i.e., they had their own work to do when they returned home. Óscar explained that, "when one comes back here, it continues the same [as before] because I have to go to work here." A second line of reasoning centred on men deserving to rest. For example, Amparo in an interview conducted jointly with her husband Ramón, explained, “he doesn't really do that [the oficios], and he takes advantage of the time that he's here - he doesn't do anything (laughter)," suggesting that he had the right to rest a bit between his migrations. I return to such rest-deserving examples in Chapter 8 , in relation to men's migration-derived income and potential connections to the intensification of women's carework in the home.

Other explanations suggested that men wanted to divorce themselves, in a sense, from being in Canada and the difficulty and feelings associated with doing housework there. Rolando said, “No, I don't do the oficios more here because if I do them here, I'd feel like I'm there." His other remarks suggested that he felt somewhat emasculated by having done 'women's work' in Canada. When asked if friends or family thought he had changed as a person when he came back, he said that the daily reproductive work he had done in Canada in part prevented him from returning 'bigger-chested': "Why am I going to believe [that I'm something more]? Like, if one comes back dirty, and one has to wash one's clothes and make one's food [there], why is one going to come back more creido (arrogant/conceited)?" This remark ties in to research mentioned in Chapter 2 (e.g.,

Bourdieu (1990) suggests that it is difficult to 'get at' habitus by directly asking about reasons for practices that it may be in engendering, due to the largely unconscious and unreflexive nature of the dispositions at work. For Bourdieu, the logic of practice is that people are generally "unaware of the principles that govern it" (1990:92); "the very nature of practice is that it excludes this question" of reasons for actions (1990:91). Bourdieu briefly touches here on the implications for "academic interrogation", i.e., that by asking an agent to reflect on or explain behaviour "the agent loses any chance of expressing the truth of his practice" (1990:91). I accept the limitations this point implies for interviewing, but I present here the reasons that respondents provided, and try shortly, with the information I have, to discern what may have been going on from a Bourdieusian theoretical perspective. 
Boehm 2008) contending that migrant men's experiences may be emasculating. I explore this tendency more in Chapter 8 in relation to men's income and economic remittances. Also drawing a cultural and geographical separation between Canada and Guatemala, Cristóbal voiced his objections to doing more 'women's work' upon return, saying, "I come here, I'm with my family, I live how I live here, and I go there, and I also have to adapt to how it is there." Notably, his wife had said: "'so you have to do everything here with me that you do there, do the work that I have to do because you did it there'... She's partly right, but one can't do everything... it would affect my family because they're used to [things a certain way]." He got used to doing that work in Canada, but kept temporariness in mind: "one never forgets, because I say, 'I'm going back to Guatemala."” One gets a sense that returning migrant men re-adjusted to follow certain customs in Guatemala that were resistant to change.

In theoretical terms, I think we see here the clash between, on the one hand, the dispositions and embodied know-how with which men returned, and on the other, the requirements and conditions of their home fields. As emphasized in Chapter 3 in regard to the return context and the connections between habitus, field, and capital, we can attend to the possibilities that, first, men's performance of housework (as mis-gendered cultural capital) may not have been valued in Vista Hermosa, and second, that it may have conflicted with the symbolic capital that women derived from their primary responsibility for that household labour (Mahar 1992). I consider each briefly in turn, in addition to habitus' fit with field more generally.

The negative evaluation of men doing housework may have manifested not only in their resistance to doing it, but in community gossip and shaming. Vista Hermosa seemed to embody a shame culture "in which people - for better or for worse - mind 
each other's business" (Hellman 2008:199). Hellman's research on migration has characterized Mexican communities this way, and I saw many parallels in Vista Hermosa. It became discernible to me over the course of my time in the community - through interviews, chats with Jane, and with Miranda in my host family - that gossip was rampant and sometimes hurtful; residents there frequently talked about and criticized others. People sometimes found fodder for gossip in hearsay that women or men were acting outside of their expected household roles. In chatting with Miranda one day, I asked her whether sometimes women wanted men to help more with the housework or if women would ask men to do so. She replied by saying that sometimes men did help, but people talked negatively about behaviours that were out of the ordinary; in essence there was social pressure to conform, reinforced by the threat of 'word getting out.' I will return to these elements of shame and gossip later in my analysis as they apply to other findings about shifts and continuities in behaviour.

The second conditioning influence - of women's symbolic capital being threatened by men's performance of housework - would likely have emerged in women's resistance to them doing it. I do not have a lot of data on this, but Cristóbal's remarks above suggested his wife in fact wanted him to 'do what he did there,' and three women Jimena, Miranda, and Dominga - indicated that they liked or appreciated their husbands' extra help. However, Jimena did say that it felt "a little strange," and Dominga said "it's different," comments in which I sensed a certain resistance or ambivalence, but I have no evidence to suggest that women turned down men's assistance.

A third influential factor in the return context is habitus' fit with its original fields. Bourdieu stresses that there is a strong tendency for a shifted habitus to revert back to its original state when actors re-enter the field(s) that have been so pivotal in the formation 
of their habitus throughout their lifetimes. McLeod reminds us, quoting Bourdieu, that "when habitus encounters a social world of which it is the product, it finds itself 'as a fish in water"' (2005:14). We cannot lose sight of the strong propensity for field to condition habitus, and for habitus to be 'at home' in the fields that structured it; it is as if a changed habitus wages a tug-of-war with the field of its provenance and with older versions of itself. How this plays out depends on how much and in which ways habitus has changed, the related endurance and strength of the pre-migration aspects of habitus, and migrants' aspirations and ability to change the conditions of the fields to which they return. Related to pre-migration aspects, it is reasonable to posit that men's income generation in Canada - intensified both in hours worked and money earned - would have reinforced and strengthened their breadwinning dispositions, and thereby, in most cases, the corresponding household division of labour as well, in which men would do much less of the care and domestic work. In a handful of cases, there was evidence to support assertions of an expanded gender habitus among men that was strong enough - perhaps backed up by men's re-valuation of 'women's work' - to survive the re-adjustment of habitus that home fields typically impel, and that 'made room for' both breadwinner and caring aspects of men's self.

\section{Women's Waged Work}

A corollary to migrant men's performance of housework in Canada was migrant women's immersion in waged, extra-household work. I draw here on research into habitus and field in relation to work - for instance by Friedmann (2002) and McNay (1999) - that highlights the discord that new work environments can spur between actors' habitus and the demands or social relations inherent in those spheres, and the possible re- 
adjustments of habitus as a result. Women's agricultural work in Canada amounted to a massive re-structuring of their daily life compared to a typical day in Guatemala, the majority of which would be spent at home, as described in Chapter 5. Accounts were common among the women of 12- to 14-hour working days in Canada, usually six days of the week. Isabela described her day-to-day routine as such: "We get back at 6 p.m. from work, we shower, we make dinner, we prepare food for the next day for work, and we do laundry. At 11 p.m., we sleep. And at 4 a.m., up. [CH: Only 5 hours of sleep.] Yes, 5 hours, nothing more. The work is really hard." Gloria said her work routine was really different than in Guatemala: "It's different than here - the schedule, the style of life, everything. We got up at 4 in the morning, it was still dark. We prepared food, and at 5 a.m., we left. We would get back at 8 or 9 at night." A related change to married women's typical days was that, as pointed out by Brenda, "because we're only women there, we don't have to serve our husbands (laughs), only ourselves."

In addition, the women did different sorts of tasks and in different types of crops than in Guatemala; that is, they came to embody new agricultural skills and movements that could have impelled a change in habitus. Their duties in Canada including picking or cutting, weeding, bunching (e.g., radishes), washing, and especially packing produce; and crops included carrots, broccoli, melon, cauliflower, radishes, cabbage, peas, strawberries, and onions, many of which they had never worked with before. Luz, for instance, explained that she worked "in carrots, radishes, and cutting arveja (peas), raspando repollo (removing outer layers from cabbage) (laughs).... Things that we had never done here, we did there to make a little money."

What impacts, if any, did their paid work in Canada - and not having to care for men, as Brenda pointed out - have on the women's gender habitus, evident both in 
Canada and upon return to Guatemala? Did it incline them to dedicate more time to paid or income-generating work in Guatemala, or disrupt their primary dedication to reproductive household-based labour and carework? Few such impacts were discernible. To begin, among female migrants with children, their mothering dispositions remained very strong in Canada, as expected and in line with other research on transnational motherhood (e.g., Bernhard, Landolt and Goldring 2005, Hondagneu-Sotelo and Avila 1997), but came to incorporate more material aspects of care for children (Montes 2009). Their mothering dispositions came through in interview comments about what they would think about while in Canada and the topics and frequency of their phone communication with home - which I argue helped to reinforce these aspects of their gender habitus - and even their interactions with co-workers. On this last point, Manuela spoke of her relations with co-workers in Canada as akin to those among mothers and daughters: "Because I'm the oldest of them, I talk to them and yo les mando (I tell them what to do) and tell them, 'you have to obey.' 'Because you're our mom,' they say to me. .... [CH: So you're mom here and mom there.] Yes."

Migrant mothers' thoughts, worries, and phone conversations often centred on their children. When asked what she thought about when she had some free time in Canada, Gloria exclaimed, “'Ay Dios! Mi mente solo estaba aqui (Oh God! My mind was just here [in Guatemala]!) Just with my kids, what are they doing, are they fine or not - on my kids, and my husband, [but] more my kids.” For her part, Luz claimed that having a daughter to worry about distinguished her experience in Canada from that of single or childless women: "it's harder because, what if my daughter gets sick, or who knows how she is, or if she hurts herself or falls, or is sad for me. I think about all of that. But when one is single, all they think about is their boyfriend (laughter)." She would ask 
her parents over the phone to buy her daughter what she needed "and [ask] if she's not sick, and if they're giving her things, and they'd say yes. And if my mom was buying her things, and if my daughter was eating well." Although I will return to this element in the next chapter - in relation to the parenting roles of non-migrating men - Gloria highlighted her ongoing role in decision-making regarding her daughters: "In one case, my two daughters wanted to go on a paseo (field trip), but my husband waited for my authorization. So, we chatted, and I told them no, because they were even younger than they are now. And I called him, and we decided things, the two of us made the decisions."

A handful of the women emphasized aspects of material care for children that they would carry out transnationally. Luz would say on the phone to her daughter:

"I'm going to do such and such work to make money, so later I can buy your things. So she [my daughter] would get happy, I would talk to her so she wouldn't get sad, and tell her I'm going to do this now, I'm going to send money this day, and you're going to ask your grandfather to buy you your cositas (little things)."

Similarly, Isabela, recounted what her phone conversations with her kids would consist of: "I tell them, 'I'm going to bring you DVDs - I brought that DVD player - for my kids, and 'I'm going to buy you a cellphone here,' I told them. Ah good. 'Now I'm going to buy you shoes and bring them there for you, and clothes.' That's how we talk, so that they're happy here. And I brought them a ball as well (laughs)."

For migrant mothers in Canada, then, their mothering habitus remained very strong, maintained in large part through frequent telephone communication with their children and caretakers. The frequent references to 'material mothering' may indicate that they had incorporated to a greater extent than before into their mothering dispositions an emphasis on providing materially for their children, as other research has suggested (e.g. Hondagneu-Sotelo and Avila 1997, Montes 2009), including among female migrants 
to Canada (Preibisch 2005). This was evident before among Vista Hermosa mothers for instance in comments about migrating to Canada "for their kids," to provide them education, to make better futures for them - but this economic provision emphasis may have been amplified during migration both by greater financial means and the need for 'replacement' parenting practices because they could not be there in person to care for their children (Montes 2009). Montes calls this love commodification, in which overseas mothers try to make up for the lack of direct care by emphasizing the material elements. The overall point here is that the combination of geographical distance and massive restructuring of their 'everyday' geared toward the exigencies of work in Canadian fields (both literally and conceptually) did little to weaken the mothering elements of their gender habitus, but seemed to increase an emphasis on material care.

Women's return further exemplified the endurance of their mothering dispositions. Mirroring their attachment to their children shown while they were in Canada was migrants mothers' joy in re-uniting with their children and in resuming their in-person mothering roles. Most exemplary of this, asked how she felt when she came back, Gloria exclaimed: "I felt as if I was born again (laughs), because I came home to find my daughters. That's what most filled me with emotion, because I came back to find them here. [...] when I came home to find my daughters, it was like I returned to see la luz de dia (the light of day)." And when asked whether she fully resumed her mothering responsibilities when she came back, Isabela joked, “¡Ya no los quiero! (I don’t love them anymore!). I don't love them anymore, I tell you. Yes, of course, I have to see to them again." I asked whether she felt the same as a mother, and she noted that other mothers from a different village who had been to Canada several times no longer tolerated their kids' noise and rowdiness but this had not happened to her: 
“'When I get there [back to Guatemala], I don't want to hear bulla (noise),' [they say]... But you get used to it [there in Canada], and they have 6 or 7 years of having gone, and me only two. But that's what they say - 'Ay, I don't want to hear my kids anymore!' Me, happy here with my kids."

In relation to women's other reproductive and income-generating work upon their return, women gave the impression that after a short rest period, they fell into the same work routines they had before leaving. I will reserve a few of the women's comments for the next chapter for the discussion of whether temporary caretakers continued in their roles after migrants returned, but highlight a few others here from childless women. Emilia, affirming a return to the 'normal' routine in her home with her parents: "Yes, one know one's tarea here, what le falta (is needed or needs to be done)." Brenda explained that the return was "a little strange, because sometimes there, one gets used to how the house and work is there... one feels strange for the first few days, but from there, it's the same - back to work again and everything. It's all fine."

In relation to whether their work in Canada may have shifted their habitus such that they would be more disposed toward income-generating work in Guatemala, I do not have much data on this. However, Sofia had been intensively "just packing broccoli for four months" in Canada, and I asked her whether she went to one of the packing plants in Vista Hermosa to work there packing broccoli, and she said no, instead to the "la siembra (planting) because it was the time in May when I returned to plant... Here I went to work in the campo (fields)." And Eva, a week after returning, went back to Guatemala City to resume her job as a doméstica (domestic worker). Certainly, the relative lack of waged work opportunities for women in the immediate Vista Hermosa area likely played a role in women not jumping more into paid work.

In terms of theorizing the outcomes upon return from a Bourdieu-inspired 
perspective, among the explanations offered in relation to the outcomes of men performing reproductive labour in Canada, the conditioning influence of 'home' fields applied here as well. That is, women's gender habitus - orienting them in particular toward mothering and other household carework - would have been reinforced when they returned to Vista Hermosa, where, as well, such responsibilities continued to be strongly gendered as women's and sources of symbolic power. This raises the question of whether any re-gendering of this work occurred because of involvement of men as 'replacement' caretakers, but I visit this in the following chapter.

\section{Intersectional Habitus}

We recall from Chapter 3 that habitus can form according to various social axes, and that its elements intersect. I have focused here on the gender habitus and migrants' experiences in Canada - especially work-related practices - that had implications for their gendered dispositions. However, migrants' comments highlighted that their insertion in particular social relations in Canada - reflecting their intersecting social locations - had activated, accentuated or shifted other aspects of their habitus as well.

\section{Interactions with Others: Ethnicity}

Ethnicity- and race-centred experiences of migrants emerged fairly often in their comments, mostly notably about their interactions with and treatment by co-workers and supervisors on the job, and, among women especially, local residents when they would go to town. I contend that these experiences would have reinforced the ethnic (indigenous) elements of their habitus. As I discuss in more detail in Chapter 9, migrants would be transported to town by their employers once every week or two, and the locals in the towns and cities that anchor the regions in Canada where migrant workers cluster 
are increasingly accustomed to seeing migrants in their midst. However, there was a sense that the Guatemalan women were treated as spectacles when they were in town, largely because of their traje (traditional outfit) and language, especially when they would speak Kaqchiquel. Gloria described that people would come up to them in the supermarkets, and they could not chat because of language differences (and being surveilled, which I explore in Chapter 9) but "when you go around with your Guatemalan traje, they love to see that. They wanted to talk to us." Having had similar experiences, Brenda explained:

"They come up to us and take pictures. [...] Yes, 'where are you from and where do you work?' [they say]. But they're nice. I felt good there, because nadie nos hacía de menos (nobody treated us like less). The first year, I thought they were going to see us like strange things because we're not from there, but no, the opposite. Most people greet us and everything."

Recounting experiences tied to her traje specifically, Brenda continued: "They looked at us differently, but in a good way, like, 'your clothes are so pretty, where are you from?' ...Same in the airport, when we met people, they'd always tell us how pretty our clothes were." Isabela, too, had attracted a lot of attention for her traje, and in fact because she would embroider clothing there: “when I start to embroider, they ask, 'how much is it?' They want it. [...] Yes, there in Santa Ana (Spanish version of the town name). There they ask for it, when we go to do our shopping...they say, 'you're blusa (blouse) is so pretty, how much is it?' They want it for themselves, they say." Manuela explained the draw and friendliness that speaking Kaqchiquel would bring:

"Sometimes we talk how we talk here, our language, Kaqchiquel. When we talk, the people look at us and wonder what language we're talking. [...] 'It's Kaqchiquel,' we tell them. 'Ah, we don't understand,' they say. But that's bonito (nice) too because they look at us and talk to us and ask us where we come from."

While women's ethnicity-centred experiences with locals in town were generally 
positive - respectful, friendly, and Delia even said less discriminatory than in Guatemala - women's and men's ethnicity- and race-related interactions and treatment on the job were decidedly more negative. Being Guatemalan - tied up with being indigenous brought discriminatory dealings in the workplace. Franco stated matter-of-factly: "there are farms where it's a bit hard. There's discrimination because of the difference in countries." Esperanza said she had been treated differently from Canadian workers - paid less, less respected, and forced to work harder. A few of the workers had discerned that workers had different pay rates, seemingly depending on where they were from. In cases involving Mexicans, this could have been due to differences in pay at the time between the Seasonal Agricultural Worker Program (SAWP) and the Low-Skill Pilot Project (LSPP), ${ }^{123}$ but on one farm where Guatemalans worked alongside Hondurans (who would have also been in Canada through the LSPP), Delia and Clara said Honduran workers were given more favourable treatment by the originally-Honduran patrona (boss), for instance being paid by the hour whereas the Guatemalans had been paid by destajo (piece or quantity). And Gabriela said her traje specifically drew discrimination and hateful words from Honduran workers, who would say mean things in reference to her indigeneity. Not referring to nationality or ethnicity specifically but likely related, Cristóbal said, "So there's problems, sometimes one can't put up with that many things...But it would be among ourselves, things that I don't like. The discrimination, but that's among us. There are a lot of differences; there's a bit of jealousy among us." This sentiment is explored in research by Preibisch and colleagues (e.g., Preibisch and Binford 2007, Preibisch 2010), pointing to the inter-country competitiveness of migrant

\footnotetext{
${ }^{123}$ Wage scales according to specific commodities and provinces have since been aligned between the Seasonal Agricultural Worker Program and the new Agricultural Stream of the Temporary Foreign Worker Program. See: http://www.esdc.gc.ca/eng/jobs/foreign_workers/agriculture/commodities.shtml.
} 
farm labour in Canada. ${ }^{124}$

I contend that these ethnicity- and nationality-focused town and workplace interactions - involving on the one hand residents' fascination with the visible and auditory differences that Guatemalan women brought to their towns, and on the other, discriminatory and hurtful treatment in the workplace, sometimes based not only in nationality but also indigeneity - would have reinforced the ethnicity-related elements of these migrants' habitus, rooted in being indigenous Guatemalans, and also intricately related to being women and men.

\section{Attached to Canada: Class and Lifestyle}

As mentioned earlier in this chapter, I examined a theme of 'getting used to Canada' as containing possible impetuses and/or evidence of shifts in habitus. Relatedly, I made note of frequent mentions of types of attachments to Canada, and what migrants missed about Canada after returning to Guatemala. Several participants had comments on these issues, and they touched on general things like relationships with co-workers and friends, the longer days, the "beautiful fields" (Franco) and the "things that one sees there" (Cristóbal). Alberto claimed to have fallen in love with Canada because "life there is really bonito (nice)." I also discerned, however, a particular focus on income-earning, consumerism, and other aspects of their lifestyle in Canada. It is perfectly reasonable that migrants would miss these elements of the bonito life in Canada, and I suggest that this also reflected shifts in the class-related elements of their dispositions.

\footnotetext{
${ }^{124}$ Some employers combine workers from different countries - often based on race-based stereotypes and somewhat pit them against each other, sometimes threatening to replace whole groups with workers from another country. This threat, combined with employers' ability to follow through and workers' often desperate desire to keep their jobs, can result in workers over-extending themselves or engaging in unsafe practices, not complaining about mistreatment or rights violations, and surveiling themselves and other workers, sometimes to the point of 'tattling' or reporting dishonestly about co-workers (this in particular figured among the accusations leveled in testimonios (testimonies or accounts) that I gathered for the purposes of the UFCW campaign, mentioned in Chapter 4).
} 
Such an assertion is based in a Bourdieu-inspired (rather than a Marxist) understanding of class (Allen and Anderson 1994, Bourdieu 1984, Weininger 2002). Here, class fractions are determined by relative possession of different types of capital, but one's class position is expressed or most discernible through markers of cultural capital - such as consumption patterns and "taste", "an acquired disposition to differentiate and appreciate" (Bourdieu 1984:468) - themselves made possible by economic and social capital. Although closely linked to the social standing into which social actors are born, markers of class can change as life circumstances do.

Among aspects of their life in Canada that they missed, migrants - both women and men equally - often emphasized the work and the income; for a couple of migrants, the work and paycheque were all they missed about Canada. Among the women's comments, Flor said, "when I come back here, I missed there, because at least there, there's work. Here one only spends money, there's hardly any work for women," while Gloria claimed, "the body gets used to working. After, on a day of rest [here], el mente está allá (one's mind is there). That day, I would go and withdraw my money and do my shopping. And here, it's not like that," and Brenda pined, "If only I was there, I'd be working and making money." Among the men, about his return to Guatemala, Ramón said, "I have two problems there (laughs). On one hand, happy to be back, but back here, sad, because one gets used to working and working [there]," and Simón added: "when I'm here in the months of January and February, when the crisis comes and there's no money, one wants to be there again, because one knows that one makes something there." Elements of migrants' enhanced consumer lifestyle also came through in what they missed. Because they sent so much of their income home, they did not really 'live it up' in Canada with a luxurious lifestyle, but their consumer capabilities were markedly 
different. Ramón commented, "I like the stores there, the food there, because there are restaurants with nice food where one eats what one wants. That's what we miss," and Delia missed the forma de vivir (lifestyle) including being able to work, go out, and buy what she needed. Donardo provided another example:

"What I miss most is going to the almacenes (department stores) and supermarkets (laughter). That's what I always tell my wife, because imagine, when one comes back from work there, sometimes the day is like so, and it doesn't get dark until 9 or 10 at night, so one comes back at 8 p.m. and you have three hours to be resting. So we'd sometimes go to the supermarket, we'd go in, buy some fruit, eat them on the street, all tranquilos (calm-like). We know that we've made money. ... That's something that I always remember. Sometimes when I go to the Despensa (supermarket) here in Tecpán, I'm reminded of there.”

Relatedly, I made specific note about two migrant men with whom I spoke - Rafael in my host family and Yaneth's husband Lucas - because they struck me as more 'worldly' and North American in the way they dressed and interacted with me than other male migrants. I cannot compare them to their pre-migration selves, but their differences from other men seemed quite pronounced - what Bourdieu might describe as "distinction" (1984) - and likely signalled class-related habitus shifts.

Finally, elements of migrants' domestic lifestyle - their houses and amenities also figured in their comments. Among the men, Rolando commented, "there [in Canada] one lives with just a stove, and a bathroom to have a shower, hot water. So that's what one misses [here]... to make food it's easy because [one needs] just a stove." Remarks in this regard were prominent among women, understandably because they would bear the brunt of the difficulty and extra effort that domestic work at Guatemala entailed compared to Canada. Emilia, for instance, spoke at length about this:

"What one misses is... One is always clean, the house is different, one can put on the kettle (laughs a bit)... the oficio (housework) is different here. Well, it's the same, but it's a bit different. One gets used to bathing every day there, and right there, you just have to heat up the shower, whereas here we don't have that 
possibility, or we haven't been able to make a bathroom like that to bathe in. Here, we have to light a fire and heat up water, and that takes a lot of time. That's what one misses... It's easier there."

So, the migrant women and men got used to - and enjoyed - elements of their enhanced socio-economic status in Canada, and this was reflected in what they missed about Canada, and I argue indicate shifted elements of their class-related habitus. Although it is not my focus, a traditional Marxist class analysis would spur more critical discussion here. In terms of class position being determined by one's relation to the means of production and position within relations of economic exploitation (Wright 2006), the migrants in my study went from a variety of occupations in Guatemala (often in control of their labour power, although they were poor) to being waged labourers in Canada in structurally disempowering positions. My reference to Guatemalans' enhanced class status in Canada - in terms of income, consumption, and lifestyle - is made on the basis of comparison to their lives in Guatemala, and I do not deny in the least that Guatemalan migrants in Canada were often 'unfree,' degraded, and poorly remunerated by Canadian standards.

Nor am I asserting that they had significantly improved class positions after returning to Guatemala. Certainly their experiences in Canada had incited thinking about how they could be better off at home, and not unimportantly, many migrants had invested their earnings in land and a few in family-run stores. However, they faced significant constraints on putting their dreams - and shifts in class habitus - into action in Guatemala, illustrated by many only barely making their way out of debt by going to Canada coupled with the amount of investment needed to do more. This was illustrated by Donardo whose thinking had "cleared up" in Canada, prompting ideas about being an empresario (business owner) in Guatemala: 
"But being here, the economic situation doesn't permit it. Because I would like to make a greenhouse, and I've worked in one, but they're expensive. So being there changes one's mente (thoughts), but being here, it's better that one leave it at that (thoughts only), and continue as it was before because one can't do it, because of the economic situation."

Furthermore, to put the discussion back in Bourdieu terms, class-related shifts in their habitus that I discerned from their expressions of attachment to Canada may be short-lived, especially among those who no longer migrate. A combination of not being in Canada where those dispositions would be reinforced, and being in largely the same economic and lifestyle situation in Guatemala as they left, may well have propelled a dispositional re-adjustment to the "objective potentialities" (Bourdieu and Wacquant 1992:128) of their home setting, as per Donardo's thoughts above. Future research would do well to investigate class-related habitus shifts of Guatemalan migrants who have spent more time in Canada and have markedly improved their economic situations.

To close out this section, I could provide a few speculations about how ethnicityand class-related aspects of habitus intersected or engaged with gender components. Among women in particular, because of their traje and its being integral to indigenous womanhood, their gender habitus may have been reinforced by ethnicity-centred treatment - both positive and negative - related to their clothing. And migrants' enhanced class status in Canada may have reinforced the centrality of household economic provision in men's gender habitus and may have further incorporated income generation into women's gendered dispositions, even if those dispositions continued to primarily orient women toward home-based carework.

\section{Conclusion}

I have investigated here the consequences for migrants' habitus of their gender- 
related practices in Canada by examining their thinking and behaviour in relation to household gender relations upon return. I focused on potential for the shifts and expansion of habitus' gender components, but demonstrated how intersecting elements inherent to their social locations were also implicated. Men's self-care work was central to their existence in Canada, and indicating shifts to their gender habitus, a minority of returning male migrants engaged more in reproductive labour than before. The fact that the majority did not likely owed to dispositional re-adjustments, reinforced by gendering of that work as women's, and related symbolic capital and cultural shaming. Women's immersion in paid work in Canada resulted in little if any weakening of the care components of their gender habitus, especially their mothering dispositions, but may have broadened those to include material aspects of care. In exploring these themes, I developed theoretical ideas about fields' influence on habitus - specifically practices and particular social relations in fields, and the re-adjustment of habitus that return fields tend to impel - as well as the discernment of habitus shifts in behavioural changes, and the accumulation and re-valuation of cultural capital in relation to its gendered symbolic value. Finally, drawing out a couple of intersectional angles, I argued that migrants' experiences in Canada reinforced their ethnic habitus (especially among women), and shifted their class-related habitus, at least in the short term. Having examined migrants' experiences in Canada with implications for their dispositions, I turn in the next chapter to a second exploration of gender habitus, in relation to whether and how much nonmigrating partners assumed migrants' at-home responsibilities and their attendant participation in transnational social fields. 


\section{Chapter 7 \\ Investigating Habitus: Non-migrants in Transnational Households}

In this chapter, the second of two attending to gender habitus, I discuss the dynamics of daily life for non-migrating partners and other household members. This chapter addresses two main points in its engagement with the increasing body of literature focused on or at least considerate of 'those left behind'. First, I call attention to the pivotal roles they - especially women - play in supporting and enabling loved ones' migration, and maintaining family unity and the well-being of other household members (Hellman 2008, Peláez and Ugalde 2006, Pessar 1999b). Second, we can and need to consider non-migrants in any examination of possible gender-related changes from migration, as these are expressed in those "who stay in the country of origin (as heads of families, daughters, caretakers, etc.) as well as those who decide to migrate" (Monzón 2009:226, Carling 2005, Resurreccion and Van Khanh 2007).

The particular approach I take in this latter respect focuses on changes in the daily practices - located in both local and transnational social fields - and spaces of activity of non-migrants. While migrants were in Canada, they could not perform their gendered household responsibilities to the same extent or in the same ways. In short, this chapter examines whether and how those tasks were otherwise accomplished by non-migrants in the transnational maintenance of the household. This chapter draws on two main theoretical insights from Bourdieu: first, that the gender habitus contributes to men's and women's inclination to act in certain ways and relatedly tends to "exclude from the universe of the feasible and thinkable everything that marks membership of the other gender" (Bourdieu 2001:23, Doucet 2009b), and second, gender-crossing and genderaffirming practices and spaces of activity may impel modifications to gendered 
dispositions. In relation to these premises, this chapter examines the ways in which nonmigrating women and men engaged in practices contrary to what they were used to, and in ways that could have shifted their gender habitus, as well as - keeping in mind that habitus is not all that explains practices - the reasons and factors at play.

For both female and male non-migrants, I address the gender division of household labour, and particularly for female non-migrants, issues of mobility, given that spatial dimensions of household gender relations are integral to the gender habitus, particularly women's (Bourdieu 2001). Again contending that research on migration's impacts needs to attend to why changes and continuities occur in social relations instead of just describing the posited effects (Kunz 2008), within these topic areas, I discuss possible contributing factors, drawing on reasons stated by study participants themselves and my participant observation, and engaging those findings with other research.

The following analysis demonstrates some change in household gendered practices and dynamics, but also considerable continuity - despite migrants' absence and distance from home - and sometimes intensification of the gendered nature of certain practices, such as women's parenting. Practical situations often demanded that nonmigrating partners assume some of their migrant partners' responsibilities, but time, ability, and influences from the community shaped what tasks were assumed and how. As well, migrants continued to assert considerable control, especially through telephone communication, over their normative gendered responsibilities. As such, my findings demonstrate the influential operation of gender norms and ideologies at both local and transnational scales.

I begin by briefly recapping the literature on during-migration configurations of household gender relations, and then turn to my analysis, devoting most of the chapter to 
discussing non-migrating female partners before turning to a briefer examination of female-migrant households. This imbalance owes primarily to data availability and the demographics of my respondents, some of which I discussed in Chapter $4 .{ }^{125}$ For both male and female non-migrants, I discuss patterns of gender-crossing and -affirming behaviours, reasons and factors shaping these outcomes, and how non-migrants responded to their circumstances. I close by offering a few points of comparison between the outcomes for non-migrating women versus men.

My focus in this chapter is not on whether non-migrants' gender habitus changed during migration as I do not have the same quality of evidence to draw upon as in my discussion of migrants in the previous chapter; instead, my analysis concentrates on the during-migration circumstances that could have contributed to habitus change and continuity as well as clues to relatively unchanged dispositions.

\section{Gender in the Household during Migration: The Literature}

In developing in Chapter 3 the idea that non-migrants' gender habitus might shift due to the practices impelled by maintaining the transnational family, I discussed the possible ways in which migration can affect the daily gendered lives of non-migrants, especially conjugal partners. There is considerable potential for gender-transgressing practices because other people often have to adopt the responsibilities that migrants cannot fulfill while away. With respect to men's migration, I cited research that highlights both the enabling and constraining implications for non-migrating women. Men's absence, and the attendant decrease in men's direct patriarchal control, may open

\footnotetext{
${ }^{125}$ As a reminder, whereas all male migrants were married, conjugal relationships characterized only four female-migrant households (this is not to minimize the possibility of changes to gender practices in the households of separated mothers and single women, but in general, I only have information related to childcare), and I was not able to interview as many men as women because they were not generally available during daytime hours.
} 
up new possibilities for women as de facto household heads to assume some of men's household responsibilities (IOM 2006, Menjívar and Agadjanian 2007, Piper 2008a, Weinstein Bever 2002), to exert more autonomy in their decisions concerning themselves and their mobility (Loza Torres, Vizcarra Bordi and Lutz Bachère 2007), and to participate more in community life (Boehm 2008, Munduate 2008). On the other hand, non-migrating women may not take over men's roles to any large extent (Peláez and Ugalde 2006), and men's migration can often induce very constraining and burdensome circumstances. These are created by increases in women's workloads (Kunz 2008, Peláez and Ugalde 2006, Piper 2008b), as well as firmly entrenched ideologies suggesting that men are better household leaders than women (Datta and McIlwaine 2000). These manifest in men's continued influence over household affairs and over women themselves (Peláez and Ugalde 2006) and familial and social pressure to abide by the household gendered status quo and not tarnish husbands' reputations (Hellman 2008, Menjívar 2006).

Women's migration can also present opportunities for non-migrant men's gendercrossing behaviours (Piper 2008a, Resurreccion and Van Khanh 2007), but studies indicate that men are less likely to assume women's normative responsibilities than vice versa (Asis 2005, Carey 2006). One of the principal contentions has been that it is quite likely that other female family members will step in to assume most of absent women's work (Bernhard, Landolt and Goldring 2005, Carey 2006, Hondagneu-Sotelo and Avila 1997, Piper 2008a, Taylor, Moran-Taylor and Rodman Ruiz 2006), sometimes because migrant women want it this way (Hondagneu-Sotelo and Avila 1997), thus resulting in increases in women's workloads and loss of opportunities for them (Carling 2005, Munduate 2008). Overall, women's migration - perhaps more so than men's - tends to 
leave largely unquestioned gender relations in countries of origin, especially women's responsibility for domestic and care work (Carling 2005). On the whole, although migration can create opportunities for changes in household gender practices - at least temporarily - it can often bring "ambivalence, emotional upheavals, and generally difficult circumstances" (Carling 2005:13). I will re-visit some of this and other research below as I engage my findings with those of other studies.

\section{Male-Migrant Households}

For non-migrating female partners $(\mathrm{n}=16)$, I investigated how elements of gendered productive and reproductive work, finances, decision-making, and parenting were handled while their husbands were in Canada, as well as women's mobility outside the home. In interviews, I asked general questions of how daily life was different while their partners were in Canada, and what they liked, disliked, and found difficult about being without their partners. And I posed more specific questions about increases or decreases in their work, the handling of migrant men's responsibilities, decision-making procedures, and money management. Men's migration brought varying degrees and types of change to a 'normal' day's activities for their female partners in Vista Hermosa. There were no women for whom their daily or regular tasks and responsibilities did not change qualitatively (what they did) or quantitatively (how much they did).

\section{Men's Farm and Household Work}

The majority of the non-migrating women (12 of 15 households for which I have information) had taken on at least one type of task that would normally fall to men in the gendered division of labour. These included certain aspects of farmwork, caring for large 
animals, acquiring firewood, tending to the nixtamal (tortilla dough) mill, ${ }^{126}$ and spending in men's expense areas. Performing these tasks in their husbands' absence involved crossing gender boundaries, meaning their husbands would normally do these things.

It was more likely that women would take on certain of men's tasks compared to others. Here I differentiate firewood from farmwork as an example. Men typically took responsibility for gathering, cutting or buying firewood. I found that it was equally common that migrant men would leave it purchased for their wives or that fathers-in-law would provide it, as it was for women to search for or buy it themselves. Contrasting the two situations, Graciela explained: "here, the work that they [the men] normally do, one has to do it. Something like that, like thinking, there's no firewood, so one has to go buy it, whereas when they're here, they cut it," whereas Yolanda said, "about the firewood, he leaves enough purchased, so maybe only once I have to ask the favour of a relative." Contrasting these mixed results, women tended not to take on men's farmwork. Among the 11 male-migrant households for which I have information on this, only four women had done so; it was more common that other arrangements were made. Seven of the male-migrant households employed male mozos (day-labourers), and three of the four households where women took on some extra farmwork also employed mozos. Brenda, for instance, explained: "He leaves the land, the corn, and another man comes to help, because I can't do it alone... I only have to weed and harvest, only that." In a few other households, instead of employing mozos, the migrant's farmwork fell to eldest sons, or rented land was left to be rented to other people, or certain crops were not planted. Other research on non-migrating women in Guatemala has also found that they pay mozos to do

\footnotetext{
${ }^{126}$ I found it very interesting that the vast majority of aspects and stages of tortilla-making are 'women's work', but in this case it was the man instead of the woman who ran the mechanized molino (mill).
} 
men's farm work; in one case study, this caused extra stress for women because others would come asking for work (Peláez and Ugalde 2006).

The explanations offered as to why, in the majority of cases, women would not take on their husbands' farmwork centred on the gendered nature of farmwork (discussed in Chapter 5), as well as limitations on women's time, and women's knowledge and physical abilities, although these as well derive from gendered arrangements and divisions of labour. In a sampling of comments from women about why they did not do their husbands' farmwork, Paola claimed that "a woman doesn't know much about what to do with vegetables, and that's what's missing [when he's away]," Jimena explained “we pay mozos because the work of a man, the woman can't do it. She can do some parts but not others," and echoing this, Dominga said, "if one [I] can do it, one goes, but sometimes it has to be a man, like for the picada (chopping)." Donardo lent further support to the knowledge factor: "The wife doesn't see what the siembra (crops) need; the husband, when he's here, sees what it needs - whether it's fumigation or fertilizer and he goes, but the wife has to look for someone to do that work."

Among typically men's tasks, it could be that there was a greater tendency for women to acquire firewood than to do men's farmwork because the former is a less rigidly gendered practice but also one that requires less technical knowledge, physical ability, and time (if purchased). Sometimes it was simply easier on non-migrating women that men arranged for their supply. Moreover, men's very migration financially enabled both the use of mozos and the purchase of firewood.

\section{Spending}

In addition to men's farmwork and firewood acquisition, a third major type of 
migrant men's household-related responsibilities to which many women tended was certain spending practices. With all male-migrant households, I inquired about how remittances and household finances in general were managed during the husbands' absence. In comparison to men's farmwork, where relatively few women had treaded, several women experienced shifts in their financial responsibilities, especially toward spending on expenses that would typically be men's purview. In all but one case, nonmigrating female partners received their husbands' remittances directly through a financial institution. In the outlying case, Paola's father-in-law went to the bank instead of her to receive the money, and then gave her an allowance of sorts. She was happy with this arrangement because of the challenges posed by bringing her children with her to town and the worry that plagued her and other women regarding their safety: ${ }^{127}$

"It's more my father-in-law that has it [the money] because it scares me to keep money in the house... If I know there isn't anything [to worry about] it doesn't me da pena (make me feel bad or worried). That's the way we're working it, that I don't keep that money here in the house."

Although there was only one such case in my study, such circumstances have come up more often in other research, including in Mexico and Guatemala (e.g., Hellman 2008, Peláez and Ugalde 2006). Although Paola did not raise any complaint about this arrangement, other research suggests that struggles may arise and a woman's situation of dependency on her in-laws for funds may curtail her decision-making and behavioural autonomy (Hellman 2008).

In all other cases besides Paola's, non-migrant women would always use some of the money for regular expenses of food and children's needs, and save what they could in the bank, but they also spent in areas that women normally would not. These included

\footnotetext{
${ }^{127}$ Miranda in my host family mentioned that there were concerns about women's safety in and near the banks in town where they would receive remittances, and deposit and/or withdraw funds.
} 
debts, utility bills, fertilizer, loan payments, and building materials for home improvements. Miranda in my host family related to me how she purchased building supplies including concrete block, cement, and paint while her husband was in Canada. He came back to find the materials purchased and some work done, presumably by male relatives, on building a new two-room building on their property. Women's payment of debts arose often, and reflecting other research (Loza Torres, Vizcarra Bordi and Lutz Bachère 2007, Peláez and Ugalde 2006), they were often debts incurred to finance the migration itself, as well as other longer-standing debts for which migration earnings were thought to be the remedy.

To clearly appreciate how and for whom these financial responsibilities were different than when their husbands were home, I compared these during-migration findings to comments about how household spending was arranged when husbands were present. I have comparable data for six of the sixteen households, indicating that women's spending differed during and outside of husbands' migration periods. Jimena, for instance, explained: "I have to make a list, pay electricity, pay water, pay for school things, pay for work [day-labourers], and the household expenses," and Brenda described the situation this way:

"So the first few remittances are to pay that off, those debts. And from there, when the third remittance comes, I start saving. Now that he's been going, I've been buying blocks and hierro (steel) for the house, so there's a part that's used for the house, we invest that. Or we buy fertilizer for the siembra (crops) as well, if it's needed... And [we use] a bit for food as well, because one has to eat."

As indicated in Chapter 5 on gender relations in Vista Hermosa households, receiving an income and spending money would not have been new to these women. However, in receiving, spending, and saving husbands' remittances, non-migrating wives were handling hitherto unknown quantities of money: "He'd send a lot of money, we'd 
never seen that kind of money," Yolanda claimed. Furthermore, by expanding their spending outside 'their' realm of food and children's needs, they had more expenses to handle. This increased the knowledge and skill required to purchase those items (Peláez and Ugalde 2006), and increased their presence as the 'public' face of their households.

These findings align to a considerable extent with other research on non-migrant women's spending (e.g., Kunz 2008, Loza Torres, Vizcarra Bordi and Lutz Bachère 2007, Weinstein Bever 2002), but the extent to which women decide about and manage expenses - as opposed to being told by men how to handle or spend the money (Weinstein Bever 2002) - is another matter. I address issues of financial management instead in Chapter 8, because of theoretical links I wish to make to the resource theory of household power.

To summarize to this point, then, the majority of the women had taken on some aspect of their husbands' work or responsibilities in men's absences. Relatively few women performed men's farmwork or tended to large animals, but it was fairly common for them to acquire firewood and carry out spending activities that were normally men's. These changes to their everyday tasks could contribute to shifts in their gender habitus.

\section{Decisions \& Parenting}

In relation to decisions not involving finances, although women could decide about "small needs" - however those were defined - the limited data I have on this suggests that absent men continued to have a significant say over many decision areas, and that in-laws were also influential. Female partners' decision-making constitutes one of the most weighty topics in the literature, admitting of a spectrum of outcomes. Research suggests that some women end up with more decision-making power during 
their partners' migration because of the absence of men's direct dominance (Hadi 1999, Loza Torres, Vizcarra Bordi and Lutz Bachère 2007, Peláez and Ugalde 2006, Weinstein Bever 2002). Other studies - sometimes the same ones with divergent findings among households (e.g., Peláez and Ugalde 2006) ${ }^{128}$ - document the extent to which women's authority is controlled both from a distance by their partners, and locally by family members (Monzón 2009, Peláez and Ugalde 2006).

In my study, telephone communication was the primary means through which husbands provided input on how household-related decisions were negotiated and made. Miranda, in my host family, relayed somewhat mixed messages about decision-making in in Rafael's absence. She said she had to "do everything around there" so would have had some control over daily decisions, but Rafael would "manda de allá (command from there)." Rafael would call every day and ask or instruct her; she said she would not make decisions or do anything without consulting him and getting his permission, although what "anything" means was subject to interpretation. Yolanda, when asked what she would discuss with her husband over the phone, echoed Miranda: "I start to talk to him about the needs, the big needs, here in the house. If there are small needs, I see to them. If there are big needs [to tend to] I ask him [what to do]. If I don't ask him, I think that because of that [indecipherable $]^{129}$ la gente (people). So it's better that I ask him."

Transnational decision-making often involved children, as indicated in Chapter 6

\footnotetext{
${ }^{128}$ Among the factors or circumstances that explain the differences, Peláez found women's age or length of marriage to be particularly influential, in that younger or newly married women in Guatemala are more beholden to their husbands' authority - and to their in-laws' control - than older women. Drawing on similar research in Mexico by Weinstein Bever (2002), I explore this possible influence in Chapter 8 in an exploration of divergent findings with respect to non-migrant women's financial management. I do not have appropriate or sufficient data to offer such a comparative examination in relation to non-financial decisions.

${ }^{129}$ This part of the recording was unfortunately indecipherable, but I am confident that Yolanda indicated that people would talk about or judge her negatively.
} 
in my discussion of mothering. Despite childcare and parenting being primarily women's normative responsibility, men were sometimes actively involved in this domain of decisions. Although to lesser extent than the migrant mothers discussed in Chapter 6, half of the fathers (9 of 17) provided some parenting support and direction over the phone. Men would ask their wives about the children's well-being, schooling, and behaviour, they would talk with children directly over the phone, provide direction to the nonmigrating mothers about parenting decisions, or tell those mothers what to buy with men's remittance money in order to soothe children who missed their fathers. In Mónica's case, she received advice or direction about her daughter's medical care from both her husband and in-laws, and it caused her some stress when those opinions contradicted each other:

"Here by myself, I would say, we'll go there, then I go to my parents-in-laws' place, and they say, 'no, let's go to this place.'...That's what was a bit hard for me. ... He [father-in-law] would bring me where they considered it to be better, but I felt that it wasn't. [CH: Was [your husband] saying from there where to take her?] Yes, he would tell me to take her where we'd always taken her. But I arrive at my in-laws and they say, 'let's go there,' and I'd go with them."

These phone interactions suggested, positively, that both migrants and their wives made efforts to keep fathers involved in and knowledgeable about their children's lives, and it was particularly helpful for children to be able to speak with their fathers. However, it is also clear from these comments that women faced limits - imposed by both their husbands and other relatives - in their decision-making regarding children or other household affairs in their husbands' absence. The role of telephone communication reflects research by Mahler (2001) demonstrating that this way of staying in touch tends to reinforce inequality in gender relations between migrant men and non-migrating women. I re-visit in-law involvement again shortly in relation to women's mobility, 
I have addressed some of the reasons that informed the dynamics around men's farmwork and firewood tasks, but what of the reasons that women were not given or did not try to claim more decision-making authority? Did women try to negotiate for more authority? I do not have much information on this directly from the women I interviewed, largely because I did not ask such questions. This relates to my points in Chapter 4 about taking a 'non-judgemental stance' and fearing that if I had asked such questions, I would have been insinuating that this aspect of household gender dynamics should have changed during migration. In retrospect, I regret not pursuing this line of questioning, but Beatriz's remark in this regard - "respeto a él" (I respect him [my husband]) - offers a clue to women's normative adherence to patriarchal authority, and more is provided in the literature to substantiate the possible reasons.

From men's perspective, we are looking at issues of their household headship and all that that materially and symbolically involves. Men would likely be resistant to giving up the disproportionate household authority they are used to, and from which they garner so much of their symbolic capital, to frame it in Bourdieu's terms (Bourdieu 2001). What about women's perspectives? There is a tendency in some of the literature documenting women's assumption of migrant men's responsibilities to see this as 'empowering', because it means women are breaking out of patriarchal molds to some extent and asserting more power in their households and autonomy (e.g., Loza Torres, Vizcarra Bordi and Lutz Bachère 2007, Munduate 2008). This largely reflected my stance going into the research. However, women may not want to take on new gendered practices, or like them if they have to assume them out of necessity; Salgado de Snyder found in her study of Mexican gender-crossing non-migrating wives that "contrary to the way many may think, most women were not happy with their empowerment" (398). 
Other research reveals that, instead of reveling in their increased household authority, non-migrant wives really missed the decision-making contributions or steering of their husbands (Peláez and Ugalde 2006).

Why would non-migrating women not want to assume some of men's responsibilities, or why would they be relatively content with not being allowed to do so? Aside from just being 'accustomed' to dependence on men's decision-making (Loza Torres, Vizcarra Bordi and Lutz Bachère 2007), other reasons implicate women's identity, their present and future well-being, and their workload. On the first point, Pyke documents that women may not want household power relations to change in a more egalitarian direction because this may threaten their female identity, which they may emphasize in order to "wield considerable power from behind a smokescreen of female subservience" (1996:546). Carey (2006) makes a related point regarding indigenous Guatemalan women, namely that the power they exercise domestically primarily derives from their 'feminine' responsibilities.

Second, other research emphasizes the possible immediate and eventual negative consequences for their well-being that women consider in relation to 'overstepping their bounds'. Men could withhold remittances (Mahler 2001) - "everyone is living on the edge, in extreme insecurity and totally dependent on remittances," says Hellman (2008:62) - or see reasons to be unfaithful to or abandon their wives, so women try to avoid generating such marital discord (Weinstein Bever 2002).

The withholding of remittances is a particularly consequential risk if nonmigrating women have no other source of income, and the migration of men can sometimes result in women's income generation being discontinued (Hellman 2008, Menjívar 2006, Peláez and Ugalde 2006). This happens because of concerns of fidelity 
that come with women's extra-household mobility (an issue to be visited shortly), the links between men's honour and economic provision (Carey 2008a), and relatedly, "because it will suggest that her husband doesn't send enough money and is a failure" (Hellman 2008:52). Although as noted in Chapter 5, a majority of the women in my study earned some sort of income locally, there did arise a couple of cases in which men's migration seem to have impelled a cease or reduction to women's productive activities. In my host family, Miranda used to enjoy doing some sort of door-to-door sales but when Rafael's migration started, he had instructed her to discontinue her money-making activities, using the rationale that she would be better off staying at home so she did not become too tired. At some point, she also discontinued her involvement in a loan-oriented women's group. This is not to say that women always obeyed these directives. Miranda confided in me that she had taken paid work in Rafael's absence without telling him, and Yaneth recounted how women in her women's group would keep their participation secret from their husbands: "I know of some that their husbands call them [the women], and they go out [of the meeting or wherever] so that others won't hear, and say, 'I'm at home.'”

This brief discussion illustrates two types of agency, both embedded and resistant. In the former vein, by limiting their usurping of husbands' decision-making authority, non-migrant women to a considerable extent acted in their immediate and longer-term interests "under particular conditions of economic and social contingency" (Resurreccion and Van Khanh 2007:214). Other research documents "transgressive actions" on the part of non-migrating women in response to "exploitative" relations (Pessar 1999b:583) and as a way of contesting their immobility, signaling that we should not assume that they completely support their husbands' migration or acquiesce to demands placed upon them. 
Resistant agency seemed very limited in my study, with the only other example - which I document in Chapter 9 - being occasional objection to answering husbands' phone calls.

In addition to issues of feminine identity and power, and immediate and future well-being, increased workloads and associated stresses constitute the third set of reasons that likely influenced the limited assumption among women of much decision-making autonomy. That brings into consideration not only the qualitative (gender-crossing or affirming) aspects of non-migrating women's practices but also the quantitative element. Other research suggests that non-migrant partners' workload can increase perceptibly or significantly (Peláez and Ugalde 2006, Piper 2008b), to the point that it is "simply overwhelming" (Weinstein Bever 2002:213).

In my study, despite the fact that men's absence typically resulted in less work of certain types for women - fewer clothes to wash and less food to prepare - they often faced an increase in the daily or regular responsibilities they had to accomplish, as the preceding discussion of farmwork (both doing it or managing mozos), firewood acquisition, and spending would suggest. Dolores, for instance, related that the most difficult part about her husband's absence was the farmwork she had to do because she then had to come back to the house to do the oficios (housework). And Jimena poignantly explained: "It doubles my work [when he's gone]... because of that, I'd have to be father and mother for my daughters. So, the place that he occupies, and the work in the campo (field), that becomes my responsibility, his work in the campo and mine. So it's double responsibility."

In terms of women's responses to these circumstances - involving both qualitative and quantitative aspects of what they did regularly - they felt ambivalent at best, with Dolores for instance describing her feelings about her new money-related 
responsibilities this way: "no más feliz, hay que luchar, me siento normal (not any happier, one has to fight, I feel normal/as usual)." More often, women explicitly suggested that they felt burdened or stressed by their increased obligations. I asked Lourdes what she liked least about her husband being away, to which she replied, "so much, looking after all the needs." She felt sad while her husband was away because: "Me ha costado (it has been hard for me) to be here with the kids and all the needs, no está el hombre para estar frente a todo (the man isn't here to head up everything). Sí, cuesta (Yes, it's hard)."

Perhaps more than any other area of activity, it was single-handed parenting that added to non-migrant women's workloads, and with which they had the greatest difficulty. As I discussed above, many migrant fathers remained involved in parenting decisions, but their absence meant they could not be involved in day-to-day care or direct discipline, which was often their domain. Lourdes said that she had been left to be both mother and father to her children, to which Jimena added: "Me daba pena (it was hard for me) to be here alone with the girls. It's really different because when he's here, one feels a bit supported, one doesn't feel alone. Rather-- I can't explain it, but it's complete, it's complete. But when they're not here, for my part, by my own criteria, I only feel half." In particular, the women missed the fathers' contributions to general child-minding, caring for sick children, making decisions about the children's medical care, helping with homework, and fathers' availability to attend meetings at the children's school and be home at lunchtime when women had obligations in the community. Lucinda explained:

"Now, it's hard [juggling everything I do], and even worse now that he's going to go [again]. Because sometimes I go to the school [to help with the snack], and we don't finish at 12, and the little ones want to eat, and because he's here, I don't worry much, but now that he's going, I'm going to worry more. [...] He doesn't really cook, but if I leave it [lunch] ready, he just has to heat it up." 
Single parenting was made even more difficult by the emotional and health toll that separation from fathers seemed to exact on children, or in a couple of cases, women giving birth while their husbands were away. Mónica struck me with her story of feeling desesperada (desperate or exasperated):

"My daughter felt it a lot when he left, and I was pregnant when he went. When he was there, I told him to come back because I felt I couldn't manage with her [the nena]. She got really sick... and she was sad. [...] When I was 7 or 8 months along, I told him to come back because I couldn't do it anymore. He said 'no, be strong there, keep trying because if not, we're not going to succeed in anything.' And 20 days later [after the baby's birth], he came back... But yes, it was hard (emphatically) for me."

Related to Mónica's story, a representative with the Guatemalan Ministerio de Relaciones Exteriores (Ministry of Foreign Affairs) stated that one of the most prominent reasons that male migrants want to return home prematurely is that their wives want them to. She stressed the importance of involving male migrants' wives in migration decisions and pre-departure information sessions so they realize what the absence of their partners is going to entail. I sensed that information provision was or would be of little consequence for facing the actualities of men's migration, particularly their first season, made even more challenging in the absence of any kind of support services for them. And it is well enough documented that women often lack influence over their husbands' migration decisions (Boyd and Grieco 2003, Jolly and Reeves 2005, Loza Torres, Vizcarra Bordi and Lutz Bachère 2007). This was backed up by remarks in my interview with representatives from the women's organization Nuestra Voz, but in only one instance in my study, ${ }^{130}$ however, did a woman really not approve of her husband going to Canada - Jimena explained:

\footnotetext{
${ }^{130}$ There admittedly may have been more disapproval from wives but they may not have wanted to disclose this, especially if husbands were present in the interview.
} 
"He told them that he would like to go. He told me, but I wasn't in agreement because that me da pena (that worries me) that the ones that go suffer a lot. But me daba lástima (I was feeling sorry) that he was suffering here. So, we came to an agreement. I wasn't really in agreement, but he went to sign up and just told me that we had to go to a meeting... I couldn't do anything because he had passed his test... so I had to be in agreement."

In other scenarios, it had been a joint decision, or men at least had consulted their wives and gained their approval before taking action. ${ }^{131}$

My aim in the preceding section was to identify - by drawing on both women's comments and available literature - the reasons that they may not have been given or wanted to assume more decision-making authority in their husbands' absence. I have expanded on this third point, in particular - women's daily workloads and stresses - in order to demonstrate the considerable social reproductive labour they lend to enabling their husbands' migration. This continues in the vein of studies that show that these women are not passive (e.g., Kunz 2008) and do not always "cloak" their experiences in discourses of unity and female sacrifice for the common good (Pessar 1999b:587) women in my study were quite vocal about the toil demanded and tolls exacted by their husbands' migration.

This discussion of women's decision-making suggests two principal theoretical points as well to do with the gender habitus and its relation to practices. First, considerable limits on decision-making practices would have minimized shifts to women's dispositions related to those practices. And second, one of the likely reasons for not assuming more authority - the intensification of parenting by virtue of doing it almost single-handedly - may have reinforced or even intensified women's gendered dispositions toward the responsibility for this part of the household division of labour.

\footnotetext{
${ }^{131}$ Admittedly, I did not interview representatives from households without experiences of migration where perhaps the husbands had chosen not to go because of wives' objections.
} 
I turn now to women's spatial mobility, another set of realities that could have reinforced or accentuated their gender habitus, especially its relation to 'domestic' space.

\section{Women's Spatial and Social Experiences}

In exploring possible impetuses of habitus continuity and shifts among nonmigrating partners, it is important to consider not only what they do, but also where they spend their time. I noted in Chapter 5 - on household gender relations in Vista Hermosa - that to some extent, these are characterized by a spatial dimension; although I did not describe this as a rigid private/public divide, women did spend less time out of the house than men, and women considered the home their normative sphere of activity. Bourdieu's Masculine Domination describes how central this division between home and public spheres (associated with women and men respectively) is for the gender habitus. As such, I investigated whether women's experience of mobility and association (e.g., socializing with other women or participation in women's groups ${ }^{132}$ ) changed while their husbands were away. Some research illuminates the potential for increases in non-migrant women's control over their own movements, the physical spaces they occupy, and more generally how they spend their time (Loza Torres, Vizcarra Bordi and Lutz Bachère 2007, Peláez and Ugalde 2006).

Despite some women presumably leaving the house to do farmwork or make purchases that men would normally make, the circumstances created by men's migration imposed significant limitations on spatial mobility. In only one case did a husband's absence provide more opportunity for the woman's independent mobility, in certain

\footnotetext{
${ }^{132}$ At the outset of my research, I looked at this possible increase in independence in terms of potential gender consciousness-raising, in that non-migrant women might talk with each other about their shared circumstances or participate more in women's group workshops, for instance. However, I have chosen to instead frame non-migrant women's mobility in relation to the spatial element of the gender habitus because of how very limited their freedom of movement was.
} 
respects - Mónica took pleasure in being able to visit her own mother in another village more often than while her husband was home because he was not there to say she should not do so. Female partners in eight male-migrant households ${ }^{133}$ were less spatially mobile outside the home compared to when their husbands were present. Women did not seem to have socialized more with other women, or participated more in women's groups while their husbands were away. When I asked women if they talked with other wives with migrant husbands in Canada, Yaneth replied simply, "No, I hardly ever go out" and Yolanda explained further: "No, because sometimes one chats with other wives, [and] sometimes they desaniman (discourage or dishearten) you because of things that don't actually happen, and they assure you of this or that [happening]. And I don't like that, so I don't chat with anyone when he goes. I dedicate myself more to my work." There were fairly active women's groups in Vista Hermosa, but of the 15 non-migrating women I asked, only two were participating in groups at that time - Yaneth had been involved since before her husband started going to Canada, and Alicia's involvement seemed to have started with her husband's migration to Canada because she needed a loan when he was not able to send as much money as necessary or frequently enough. ${ }^{134}$

The primary reasons for women's limited mobility and association included practical ones, namely childcare responsibilities and other general constraints on their time - well documented above - but some women also faced other, more serious considerations, including suspicion of infidelity and forms of control over their behaviour, such as community gossip and in-law involvement. Some women cited beliefs or gossip

\footnotetext{
${ }^{133}$ It is not the case that the remaining wives had the same or more mobility, but rather that I do not have mobility-related information for them.

${ }^{134}$ Although it did not come up very often in my study, a couple of women faced situations where their husbands were not able to send money for quite some time after arriving in Canad a, or did not send as much as expected.
} 
about there being "problems" between partners or even separation because of suspected infidelity on the part of one partner or the other, and this seemed particularly acute for non-migrating women, as documented in other research on Latin American men's migration (Hellman 2008, Mahler 2001, Peláez and Ugalde 2006). Mahler argues that "infidelity becomes central to the reconstituting of gender divisions and hierarchies" in circumstances of men's migration (2001:606). In Vista Hermosa, Beatriz said that she would go out only when she had to run errands and tried to minimize going out alone in order to "avoid problems." Jimena explained the relationship between suspicion and her mobility this way:

"When he's not here...there isn't freedom for me to go or leave freely. How would I say it, it's like, I'm more private. That's the whole difference, because when he's here, I can come and go from my house when I want to. But it's not because of him, but rather to avoid problems... They [the men] go to work, and one knows that people here don't think about the fact they're suffering there, but rather about what they [women] are doing here. And, for my part, it causes me pena (to feel bad) to cause him problems because he's working, and he's there for the same necessities. So to avoid that, as I say, better to avoid it [going out]. That's what changes with me when he goes."

In a third case, Miranda in my host family said that she was in daily phone communication with Rafael in Canada, in part so that he knew where she was and when. She said some women would go out alone more when their husbands were away and "who knows what they're doing." She believed that some non-migrating wives took up with other men while their husbands are gone. To avoid potential negative consequences of community members' suspicion of what she might be doing while out alone, and to keep her husband's trust in her, it was her initiative to regularly tell Rafael by phone where she was.

Possible "problems" likely affected women's group participation specifically. The representatives from the municipal women's office explained: "Women are going to be in 
the groups less while their husbands are away, because if they go out to a meeting, it's the same, there can be problems." Of the two women involved in groups, Yaneth emphasized that she would tell her husband when she went to group meetings: "When I'm in those groups, [I'm] always chatting with him to see if he's okay with it. So when the time comes that I have to go [to a meeting], he knows that I have to go out. So there's no problem with that." And as mentioned above, Miranda had discontinued her women's group involvement during Rafael's migration.

Acting in the interests of maintaining men's household honour and authority, the involvement of in-laws also seemed to play a role in the lack of participation in women's groups and conditioning mobility more generally. Miranda explained that her husband's mother was sometimes involved in her affairs in a meddling way while her husband was in Canada, and took issue with Miranda's participation in the loan-oriented women's group, which resulted in her withdrawal. And Mónica, who was able to visit her own mother more during her husband's absence, always reported those visits to her mother-inlaw before going: "when he's not here, I just tell my mother-in-law, 'I'm going to visit my mom,' and I would go." In response to my emerging concern with this relationship among in-laws, mobility, and fidelity, my American friend Jane's husband Miguel said about the situation of non-migrating women, "yes, the suegra (mother-in-law) keeps tabs on her nuera (daughter-in-law)." The representative from the municipal women's office explained the suegra interference as a demonstration of mothers 'watching out' for their sons, preventing sons' wives from usurping too much of the men's household power (Samayoa 2010). It is reasonable to posit that it is not only the son's household power generally that is potentially threatened, but also specifically their honour (Carey 2008a). Carey contends that among indigenous Guatemalans, men's honour - and relatedly a 
family's or household's reputation - hinges on those men not only adequately supporting the household economically, but also controlling its members, especially women. ${ }^{135}$

Although I had not anticipated the in-law involvement before beginning my fieldwork, I subsequently came to realize that it is fairly well documented in gender and migration literature (e.g., Carter 2004, Hellman 2008, Menjívar and Agadjanian 2007, Monzón 2009, Peláez and Ugalde 2006). Emphasizing how restricting and sometimes pernicious husbands' families can be, Hellman, based on research in Mexico, describes the situation as the "tyranny of the in-laws" (2008:247). She found that mothers-in-law can be particularly influential in curtailing the mobility of male migrants' wives, based in the threat that mobility is seen to pose to women's faithfulness, and backed up by the risk of spreading rumours or conveying accusatory information to their sons abroad. Such measures could also be veiled attempts to 'get at' men's remittances by painting women as unworthy recipients (Menjívar and Agadjanian 2007). One woman in Hellman's research put it this way: "every time you left the house, the family was at risk of scandal because you might stop to talk to a man... Sometimes your suegra would accuse you directly of plotting an affair." (2008:48). It becomes easy to see here how gossip, a characteristic of Hellman's depiction of a 'shame culture' - as discussed in Chapter 6 in relation to Vista Hermosa - would fuel these fidelity concerns and the subsequent surveillance of women. Other research on men's migration from Guatemala specifically (Menjívar and Agadjanian 2007, Peláez and Ugalde 2006) found that women may be moved out of their conjugal homes and into husbands' parents' homes while the men are

\footnotetext{
${ }^{135}$ The double standard in relation to fidelity during men's migration also needs to be acknowledged (Mahler 2001). Menjívar and Agadjanian document that Guatemalan men in the U.S. are virtually expected to be unfaithful if given the opportunity, but for women at home "the expectations are very different" (2007:1252). Furthermore, women's infidelity brings the very real possibility than migrant men may abandon them, whereas the reverse is fair less likely.
} 
abroad, for reasons including to "keep gossip under control" (Menjívar and Agadjanian 2007:1254). Hellman goes on to say that this "remarkable residue of the past" (2008:48), i.e., women's submission to their in-in-laws, has been transformed for the worse by migration in that husbands are not there to intervene to protect their wives. This discussion is not to deny that in-laws can be important sources of practical and emotional support (Mahler 2001, Salgado de Snyder 1993), but to illustrate that their efforts to safeguard their sons' honour ${ }^{136}$ may constrain women's activities and mobility.

Back in Vista Hermosa, likely related to fidelity concerns, women's mobility and socializing was also limited in some cases by being accompanied during their husbands' absences, especially at night. Jane, my American friend, informed me that, "every 'good' wife, when left alone by a migrant husband, does not sleep alone" and she cited examples in the village, including Miranda in my host family who, indeed, said that one of her brothers would stay with she and the kids overnight. Another woman, Paola, whose father-in-law received her remittances, explained that her sister-in-law lived with her the second time her husband went to Canada. Granted, there were likely motivations at play here not directly related to fidelity. Paola said her sister-in-law helped her with the children and with tending their store, and that she felt very desperate when she had no company. Non-migrating women may also face safety risks. Women's organization representatives from Nuestra Voz asserted that non-migrating women were at risk of sexual harassment or sexual assault on the part of unwanted male visitors trying to take

\footnotetext{
${ }^{136}$ Mothers may also be protecting their longer-term economic security, which often depends upon their sons' economic situation, especially in settings where property and land flow through paternal family lines (Mahler 2001). Mahler explains that mothers-in-law, particularly if they have more than one married son, "intervene in the relationships pursued by their sons, favoring the hardworking wives, who through their labors and the children they bear will contribute to the support of their mother-in-laws" (2001:597). Possibly mirroring this, Miranda in my host family noted that she was treated much more poorly by her mother-in-law than another cucuña (brother-in-law's wife).
} 
advantage of women's husbands being away, and the IOM Director of Mission confirmed that some migrant households had been victims of extortionists (Field 2010).

I would argue that collectively, these circumstances discouraged women's mobility and association, and encouraged women's 'homebodiness' - reinforcing the idea that women's primary sphere of activity was the home. As such, these circumstances also likely fortified their gender habitus, tied as it is, suggests Bourdieu, to the house and its surrounds being their primary domains of activity. Related to the connection between practices and habitus, the preceding discussion has argued that women's household decision-making did not take on a remarkably different character, but that they often did take on certain of men's everyday tasks in the household division of labour. I move now to consider the during-migration circumstances for a group of female-migrant households.

\section{Female-Migrant Households}

Just as the absence of men affected daily life in their households in several ways, so too did the migration of women. Of concern here is how women's 'normal' responsibilities for housework, child-rearing, and caring for husbands, were carried out during their time in Canada. Relative to the rich data and stories I have from partners in male-migrant households, I have comparatively little information about experiences in female-migrant households because I did not speak directly to any non-migrating male partners, as explained previously, or other household members of single and separated women. The discussion that follows is based heavily on interviews with the four married migrant women (Manuela, Gloria, Gabriela, and Brenda ${ }^{137}$ - the first three of whom were

\footnotetext{
${ }^{137}$ Note that I discussed Brenda's experiences in the previous section as being the wife of a male migrant, but she had also worked in Canada twice herself, once while married, but she did not yet have children.
} 
mothers), complemented by comments on childcare from separated migrant mothers. ${ }^{138}$

Overall, the four non-migrating husbands did not assume a great deal of the women's housework or child-rearing responsibilities, although more of the latter than the former. The women's eldest daughters, mothers-in-law, sisters-in-law, or non-kin domestic help generally assumed these tasks. In Manuela's household, her daughters took on much of the work, as indicted by this exchange:

"Two years ago, my oldest daughter stayed [to help]. She was working, but she dropped that. And last year, the other menor (young one) was studying as well [as taking care of the younger siblings]... And this year, the other young one will stay here again to take care of her younger siblings.

$\mathrm{CH}$ : Does your husband take on some of your responsibilities when you're gone, or just your older daughters?

Manuela: Sometimes, yes he helps. Sometimes when my daughter hasn't finished her work, he helps her."

In Gloria's household - where their three young children were not old enough to take on much of their mother's responsibilities - she and her husband had hired help:

"I left a person here in charge of the kids [...].

$\mathrm{CH}$ : And when you were there, did your husband help this person take care of the kids, or did he do the same thing [as usual]?

Gloria: At night, he was in charge of them. During the day, the other person was.

$\mathrm{CH}$ : And your housework, like the cleaning and dishes?

Gloria: She did them. The person that I left, she did them."

Gabriela also said that she had a señora (female domestic helper) who was there day and night to take care of the kids and the house. Given that her husband was blind, Gabriela was normally responsible for most of the farmwork that sustained the household; while

\footnotetext{
${ }^{138}$ My analysis here of single or separated migrant women's households is all but limited to childcare, as I do not have much data on the performance of migrant women's other tasks (such as cleaning or cooking), but strongly suspect that mothers and sisters, or sometimes hired female domestic helpers, assumed them.
} 
she was gone, her kids worked more in this area, and they had a mozo work for them as well. In the fourth scenario, Brenda and her husband were living with her in-laws, and it was the women in the household who took care of her husband: "He took advantage of [my] sisters-in-law and his mother being here, they took on the carga (workload), they made his food. Now I imagine that he helped them once in a while, but my sisters-in-law said to not worry about him, because he's our brother and we'll look out for him."

The remarks of the three women with children suggested that their husbands were more likely to increase their contributions to childcare and parenting than to women's varied housework. Although a comparison to childcare is not possible because she did not yet have children, one of Brenda's comments was indicative of problems with men cooking; she essentially said that she would not have been able to migrate if it were not for her sisters-in-law:

"If maybe we were in a house apart [from the family], I wouldn't have gone because he's a man, and the men here work less in the kitchen than there [in Canada]. Because here, we eat a lot of tortillas, and you to go the mill, and they [the men] don't do that. While there's a wife [here], they don't do it. I imagine that if they're alone [not living with other family members], they might do it, but maybe not."

This aligns with other research documenting that if women are present, men will not generally take on these tasks necessary to care for themselves (Menjívar 2006). One of Manuela's comments indicated that, although it seemed that primary responsibility for the children rested with her two eldest daughters, her husband's fathering role had expanded, or she had at least encouraged him to expand it:

"I [would] tell him [on the phone], 'you have to see to things there because you're padre (father), you're madre (mother), you have to see to my kids there and not only regañar (scold) them,' I tell him. Because a dad is stricter than a mom. When I come back, I say, 'I want to have all my kids there, I hope that [it's not the case that] one of them isn't there!' (laughs)" 
Manuela's comment harkens back to my discussion in Chapter 6 of how migrants and their non-migrating partners would communicate regularly over the phone, and often about parenting issues. Migrant women would always talk about how their children were doing health-wise, in their behaviour, and with their studies, and where applicable, how the señora was getting along with them. Gabriela said she would provide her husband with a lot of guidance when she talked with him - she would tell him what to buy for the children, what they needed for school, and why - and said her husband would thank her for keeping him on track. And Gloria - as discussed in the previous chapter - cited the example of her involvement in decisions about her daughter's school field trip. These instances provide further evidence of the strong continuation of women's mothering roles and of their transnational motherhood (Hondagneu-Sotelo and Avila 1997). However, they also suggest, in a sense, that migrant women themselves - by having trouble letting go of "an intrinsic part of their obligation as women" (Resurreccion and Van Khanh 2007:219) - somewhat limited men's more extensive self-directed involvement in parenting. This is just one of several possible reasons and factors at play in limiting men's assumption of 'women's work', more of which I visit just below.

Other research echoes this overall tendency for other women to take on the work of absent female migrants instead of men assuming any great responsibility for these tasks (Asis 2005, Piper 2008a, Resurreccion and Van Khanh 2007), including in Guatemalan contexts (Bernhard, Landolt and Goldring 2005, Carey 2006, Taylor, MoranTaylor and Rodman Ruiz 2006). Piper describes the situation as one of two types of nonmigrant men: "those who try to adapt and make the best of the situation and those who cannot cope and burden other (usually female) members of the family with responsibilities previously taken care of by their now absent wives" (2008a:1290). My 
study demonstrates that circumstances are more complex and nuanced than this, however. Furthermore, it is unfair and inaccurate to lay the 'blame' only on men in these cases. Although it was not clear in my study how these decisions had been made, other research suggests that migrant women may prefer that childcare and -rearing are assumed by other women instead of their husbands (Hondagneu-Sotelo and Avila 1997), thus reflecting the idea that men can parent or provide care but cannot 'mother' (Doucet 2006, Piper 2008a). Regardless of the reasoning, of particular concern and certainly an area for further research (Piper 2008a) are both the immediate- and longer-term impacts on those female relatives - 'other mothers' (Hondagneu-Sotelo and Avila 1997) or replacement caretakers - of the additional responsibilities placed upon them. It certainly struck me in Manuela's example that two of her daughters had disrupted their schooling in order to fill in for their mother during her absence.

On the theme of other women taking on absent women's work, here I can include discussion of the five separated migrant mothers of young children. Although they did not have husbands to care for their children, it was also clear - with the exception of one case - that it was other women and not other men who stepped in. Usually those women were the migrants' mothers and sometimes their sisters. Luz's case really indicated the importance of replacement caretakers - usually women - in making women's migration possible. When she told her father she wanted to go to Canada, he did not at first agree, but she explained, "we came to an agreement with him, that if my daughter was left with my mom, and if I sent money for them to save a bit and use a bit [then I could go]" (my emphasis). It was not without difficulty that Luz's mother took on this extra responsibility: “my mom doesn't trust herself with her [Luz's daughter] because she's worried about my dad, his food, washing his clothes... so that's more work for her." 
As the case of Brenda and the provision of her husband's food illustrated, the separated women's living circumstances largely dictated who cared for the kids. Flor lived with her mother "so they [the kids] stayed here," and her mother spent some of Flor's remittances on care for her daughter. In Laura's case - the exception to the female caretakers finding - the facts that her parents were aged and unwell, and she was the only other woman in the household largely dictated the fact that her brother had played an active role in overseeing her son, although the family had hired domestic help for Laura's housework.

Admittedly, my analytical interest here lies in partnered migrant women's households, so as I did with non-migrating female partners, I can provide an outline of the reasons as well as facilitating factors that explain men's limited assumption of their migrant wives' responsibilities. I have already illustrated that women's active transnational mothering by phone and patrilocal living arrangements facilitated these outcomes. In terms of other considerations, this is where I found the limited literature lacking and where my study makes a needed contribution. Other research resorts considerably to gender ideologies and blaming of 'resistant' men (e.g., Asis 2005, Piper 2008a, Taylor, Moran-Taylor and Rodman Ruiz 2006). Although my study echoed some of those findings, it illustrated practical concerns as well, and how those intersected with gender ideologies. Coinciding with situations of non-migrating women, key among these practicalities were time availability, and questions of knowledge and ability, as well as gossip, although not related to fidelity.

First, in relation to time, there was no indication that husbands of migrant women had discontinued their day-long work in farming, which meant that they would not have had time to devote themselves to assuming absent women's work to any considerable 
extent. This certainly touches on their spatial mobility, an issue that I have treated in detail only for female non-migrants. This is partly because I do not have comparable information for male non-migrants, except to say they probably spent more time during the evenings at home to take care of children (after the señora or doméstica had left, or to ease other siblings' obligations), instead of being out with friends or other family members as they often did in their free time. However, the fact that they continued to engage in daytime waged or subsistence work, accompanied by having other people care for children who might otherwise encumber their mobility, suggests that their daily spatial routines were not much disrupted. On the topic of their continued productive work, because of the possible uncertainty of migrants' work or irregularity of remittances, it is in part unreasonable to expect non-migrating men to discontinue their incomeearning at home. However, there are certainly powerful gender ideologies at play here as well. As I will discuss in Chapter 8 in relation to migrant women's income, the belief may continue that non-migrating men are the principal or dominant income-earners in their households, despite the fact that women's migration-derived income often vastly outweighed that of household men.

Second among the reasons, men would not know how to do many of normatively women's tasks, especially cooking and washing clothes, because they would have rarely if ever done them. Brenda suggested this issue of inability by saying that other women cooked for her husband because men simply do not make tortillas, which I can confirm first-hand is an activity that demands skills that women develop over the course of years from a young age. Certainly, gender ideologies and division of labour intersect with men's and women's abilities and knowledge here - i.e., the former largely explain the latter - but we should not trivialize the impact on non-migrants' practices of the fact that 
women and men in Vista Hermosa knew how to do some tasks and not others.

A third possible contributing factor to men's limited take-up of migrant women's household work is gossip, which I discussed in the preceding chapter in relation to migrant men's performance of housework after their return. This issue did not arise in my interviews with married migrant women, but those interviews occurred early in my research period, when I did not yet know to investigate the extent and influence of the community's propensity to 'talk'. As I mentioned in the preceding chapter, Miranda in my host family helped to illustrate this for me. In relation to men's gender-crossing work, specifically - which seemed to be more of a problem than women doing 'men's work' she said "people talk badly about that sort of thing." And demonstrating both judgment and the act of gossiping, she came back from her father's house one morning and reported, somewhat distressed, that she had found him serving himself breakfast and coffee, contrary to the conventional custom of wives serving meals to their husbands. In Chapter 6, I located this issue of gossip in Hellman's studies in Mexico, but influential social pressure more generally has certainly been an issue in North American contexts, as demonstrated by Doucet's research with fathers who felt a negative "social gaze" (2009b) and Luxton's study revealing men who tried to keep their housework hidden from onlookers (1990).

To sum up the situations of the female-migrant households that I have examined here, men assumed some additional parenting responsibilities, but generally did not take on cooking or housework. Instead, other women took on the bulk of these tasks, as they also did in the cases of most separated migrant mothers. Reasons and factors that explain the outcomes among non-migrant husbands stem from both local and transnational influences that are at once practical, cultural, and ideological. 


\section{Non-Migrants' Responses and the Return Home}

To the extent that I want to be able to offer a few comments on whether nonmigrants' gender habitus changed in the absence of their partners, I turn now to clues in the responses to and characterizations of these duration-migration circumstances, and what happened upon the migrants' return. I have documented that women especially but also men felt challenged, burdened, or stressed by the demands put upon them, and responded actively in various agentic and strategic ways to their circumstances, thus further supporting the contention that non-migrants are not passive recipients of circumstances handed to them (Pessar 1999b). I would like to briefly probe in more depth their responses to the realities of their partners' migration, specifically how they conceptualized those time periods, and in the case of one female-migrant household, a non-migrant man's exercise of authority over his wife's further migration. I do so because I feel these thoughts and behaviours could provide clues to whether gendered dispositions shifted as a result of the change in gender practices many of them did take on, and how enduring those shifts might be. Was there a sense in which non-migrating women and men got used to doing some gender-crossing work, akin to migrant men's adaptation to doing reproductive labour in Canada as discussed in the preceding chapter? Did they see the modifications to their practices as 'normal', and if so, for what timeframe? Overall, I would characterize their actions and responses as active resignation to temporary circumstances. Mirroring the imbalance above, most of the information I present here relates to male-migrant households.

As mentioned above, non-migrating women were at best ambivalent but more often stressed out by their situations, but their comments suggested that they resigned or accustomed themselves to the extra responsibilities they had, and that migration periods 
were temporary time spans to 'get through'. The verbs conformarse (intransitive) and pasar (transitive) came up fairly often in remarks about their experiences. The former means to accept, get over, or resign oneself to a situation, and the latter, in this context, suggests getting through a situation. Asked about the experiences of his struggling wife, Donardo said her in-laws "had to convince her that she had to conformarse" to the difficult situation of giving birth to the couple's first child while he was away. Brenda, when asked how she felt about staying home while her husband went to Canada (whereas she had gone the year before), responded: “Fine, because at least there's an opportunity for one of us, and nos conformamos (we accepted that). He's there, and I take care of things here.... one knows as well why one does it [goes to Canada], and se conforma (one accepts it) because one is doing something good, not something bad." Yolanda, who had handled hitherto unseen amounts of money and chosen not to chat with other women, said, "I was really sad for a month, but then I resigned myself to it." So there was a sense here that women adjusted to what was required of them - the increased workload and some attendant gender-crossing practices. On one hand, this aligns with what Carey (2006) has asserted about indigenous Guatemalan women's often accepting and stoic attitudes toward the difficulties of their work. One the other, more theoretically, these resignations and adjustments may encourage or reflect shifts to their gender habitus.

This was offset, however, but references to temporariness, evident in both sets of households. In relation to 'getting through' the time, Graciela, who had had to acquire her own firewood and single-parent their four young children, commented, "as I say, it [his migration] has its advantages and disadvantages (laughs a bit). We get through it," and Adelina, who had been particularly challenged by the void left by an absent father, attested that "it was a bit hard, but we got through that time, and he came back again.... 
A little sadness, a little happiness, but we got through it." Other non-migrant partners emphasized the relatively short timeframes of migrants' absences, and of the changes in their practices, sometimes framed as worthwhile because of the economic gains. For instance, Amparo said she had a lot of time to think and worry while her husband was away "but the days and months go by. Four months isn't that much time, it goes by quickly" and Paola explained that she was "a bit sad, but we knew that he would be back within a short time... we know that it's just for a time." Likewise, female migrants also emphasized their absences - averaging five months in length - and their non-migrant husbands' circumstances as temporary. Manuela said, "It's just a short time that one's there," while Brenda said in relation to care for her husband, "his mom and sisters are here to do it [look after him], and it was only 4 months."

This emphasis on temporariness falls in line with other research on labour or seasonal migration, where it is considered a temporary situation in the pursuit of economic footholds (Peláez and Ugalde 2006), changes to gender practices are explained as "practical and necessary" (Weinstein Bever 2002:224), and migrant women as much as their non-migrating husbands look toward the future when 'proper' gender responsibilities would be restored (Resurreccion and Van Khanh 2007:220). In Resurreccion and Van Khanh's study, migrant women regularly assured and reminded left-behind husbands of the short-term nature of their absence in order to enable men to perform the domestic work required of them and to reinforce their masculine identities. The authors describe such behaviours as acts of agency that allow women to continue to make important claims on non-migrant husbands' time and labour, thus identifying another example of embedded agency.

Resurreccion and Van Khanh along with Weinstein Bever demonstrate that this 
emphasis on temporariness, necessity, and practicality figured in the fact that conventional gender roles or ideologies remained relatively untouched by migration in their studies, despite the fact that gender practices changed while migrants were away; non-migrating women, for instance, did what they had to do for a short time and were not intending to challenge existing gender ideologies (Weinstein Bever 2002). The point I wish to advance here is a related but different one: that shifted gender practices among non-migrants, to which many resigned themselves or became accustomed, likely did not result in shifts to their gender habitus, both reflected in and in part because of their emphasis on the temporary nature of these arrangements.

On a last note related to possible changes in gender habitus, what happened upon migrants' return that indicated whether or not gender dispositions shifted? Relatively speaking, literature abounds on what happens during migration compared to what happens afterward, and my study will make needed contributions in this regard. Some available research suggests that male non-migrants tend to drop their 'women's' tasks when female migrants return (Resurreccion and Van Khanh 2007), whereas return situations in male-migrant households can be ones of conflict where women have gotten used to managing households on their own (Hellman 2008, Loza Torres, Vizcarra Bordi and Lutz Bachère 2007:54-55). On the whole, says Boehm, men's migration and return can lead to a "complex negotiation involving both the erosion and the reconstitution of male power" (2008:25). In Vista Hermosa, I did not detect any conflicts in the renegotiation of the household division of labour or decision-making, but neither was I party to them and respondents may have been hesitant to disclose those details. I am continuing to keep particular details of return situations to the specific topics addressed by each of my analysis chapters, but here, as will become a common refrain of sorts, 
household gender relations returned to 'normal'. According to the limited data I have, non-migrants discontinued the gender-crossing practices they may have taken on. These were re-assumed by returned migrants, sometimes after a few days for rest and readjustment. In Gloria's case, asked whether her husband still did some of her work that he had done while she was gone, Gloria responded:

"Ya no (not anymore), I tell you. Ya no. Because my daughters are here, and because he also has work in the fields. As I'm here and my daughters are here, he goes to work there. [CH: So things went back to normal when you came back with respect to who does what in the house?] Yes, that's it."

Migrant Rolando said about his return, "I rest for only one or two days, and I start working here [in farming]." And Mónica had to get firewood during her husband's absence, "but when he came back, I don't worry about it anymore. I was happy."

Finally in regard to responses and return, I want to highlight the case of Manuela for not only a 'return to normal', but other post-return responses of her husband indicative of his efforts to preserve the status quo - faced with the possibility that she could return to Canada - as well as limited changes to his gender habitus. Because of the perceived impacts of Manuela's absence, the decision was taken that she would not migrate again. Manuela's normative responsibility for the children and how that responsibility had been handled in her absence figured prominently in the decision that she not return to Canada after the one season she spent there:

"It went well for me there but last year I couldn't go because of my kids. My husband, he didn't want me to support me in going anymore. [...] It was because of my kids. They were younger, but for him, it was hard as a man that he is-- A woman who's here with her kids - come what may - she's there with her kids, but a husband, no. So he said - they [recruiters] came by, they called - and he said, 'ni una papelería vas a mover (you're not going to do even a bit of the paperwork) because the kids are there. If you didn't have kids, go, but while they're here, better that no' [he said]."

It was not entirely clear how much her husband's response to the situation had influenced 
her viewpoints on returning, but she voiced the opinion that

"leaving another person [in charge] here, it's not the same as when the mother is there with them. Even though the kids maybe... how would I say that... would put up with staying, but the way of life that they have with the other person, it's not possible...the kids were a little abandoned but that's done."

In response to going to Canada again, she said: "If I could, I would go again. But it's hard for a woman with kids, it's not easy."

\section{Comparisons and Conclusions}

To conclude this chapter, I offer a brief comparison of the situations in femaleversus male-migrant households in terms of changes and continuities in gender practices. In both male- and female-migrant households, there was considerable continuity to the status quo of gendered household responsibilities. To the extent that gender practices did change for non-migrants - potentially fostering a change in gender dispositions - men were less likely than women to undergo, or accept, those shifts. Although women did not take on all the responsibilities of their absent husbands, on balance, they certainly assumed more of 'men's work' than men did 'women's work'. Even though I have identified practical concerns that influenced behaviours of both sets of non-migrants, I think gender ideologies and expectations may have been more powerful for men, dissuading them more than women from engaging in gender-crossing behaviours. Although certainly not always without negative consequences, it is well-established that it is more acceptable for women to transgress into men's terrain than vice versa, in large part because work gendered as women's is less valued than men's (Bourdieu 2001) and as such, men's transgressions pose considerable threats to masculinity (Carey 2006). Women encounter limits as well, however, reflected in the fact that non-migrant wives in my study were more likely to assume men's tasks than to take the lead in household 
decision-making, thus threatening men's authority and masculinity less (Carey 2008a).

Other points of comparison include mobility and local income-generating work. In large part owing to single-handed childcare, in-laws' involvement and related concerns about women's fidelity - in a context of a double standard regarding sexual activity (Mahler 2001) - non-migrant women's mobility and freedom of association was significantly restricted. Non-migrant men, on the other hand, worked freely outside the home during the day. On the issue of paid work, illustrating the strength of male-asbreadwinner ideologies, it was interesting that, although I can only document it with Miranda's case, men's migration may contribute to the cessation of women's incomegenerating activities whereas those of non-migrating men generally go ahead unquestioned. Despite these differences, non-migrant men and women did share some circumstances in common, including the influence of gossip and social pressure more generally, issues of ability and time, the role of telephone communication, and emphasis on the temporary nature of migration periods and attendant re-arrangements.

Overall, this chapter has drawn attention to the realities of those who are just not 'left behind' but who strategize and struggle in order to play roles that enable their partners' migration. I have illustrated examples of embedded agency, both local and cross-border influences on gender-crossing and -affirming practices in transnational households, the particular burdens of women including extended kin, and the overall persistence of gender relations following migration periods that fostered considerable upheavals in day-to-day life, a continuity that likely reflects limited changes to the gender habitus. I turn now to the first of two chapters focused more on transnational aspects of circumstances created by migration: the impacts of economic remittances on gender in Vista Hermosa households. 


\section{Chapter 8}

\section{Income and Economic Remittances: Whither Household Authority?}

This chapter explores the potential impacts on gender relations in Vista Hermosa households of both sending and receiving economic remittances. As highlighted in Chapter 3, male migrants' income-remitting is likely to uphold patriarchal household arrangements (Taylor, Moran-Taylor and Rodman Ruiz 2006), whereas a diminution of male household authority may follow from women either sending money as migrants (Kunz 2008, McKay 2001), or receiving and managing men's remittances (Ramírez, García Domínguez and Míguez Morais 2005, Vullnetari and King 2011), but a host of socio-cultural factors mediate these relationships by tending to preclude men's loss of authority (Boehm 2008). I expand further on this literature below to introduce my analysis. This chapter draws theoretically on the resource theory of household power outlined in Chapter 2, and rests soundly within a broader framework of transnationalism, given the focus on economic flows (Kunz 2008), but also emphasizes the specifics of localities (Brickell and Datta 2011b) that shape the outcomes that I will discuss.

I make four main arguments in this chapter. First, although migrant women often guided decisions about the use of their remittances, their significantly enhanced contributions to the household economy did not increase their household authority postmigration. Second, a couple of cases, based on male-dominant decisions about women's subsequent migrations, suggest that women's income threatened men's masculinities. Third, Chapter 6 indicated that female receivers of remittances often spent funds in men's areas, but here I show that their wider financial management responsibilities were less pronounced in comparison. And fourth, men's emasculation in their experiences of migration may have contributed to the intensification of women's care-taking roles. 
This chapter privileges the economic; that is, using the resource theory of household power, it investigates whether and how flows of money have contributed to shifts in household status and authority. However, tempering the focus on economic shifts in isolation, I conclude the chapter by exploring key inter-related cultural imperatives that shaped the potential effects of economic remittances. Before my analysis, I briefly review the literature on the potential gender-related impacts of economic remittances. My analysis opens with a sketch of how remittances were used, and then examines female-migrant households and male-migrant households respectively for possible shifts in household gendered authority.

\section{Income, Remittances and Gendered Household Authority}

The act of male migrants sending money to their families at home is likely to uphold patriarchal household arrangements because these remittances reinforce men's roles as primary breadwinners (Taylor, Moran-Taylor and Rodman Ruiz 2006). The asserted link between male migrants' earnings and their household authority may be made even more pertinent by the possibility that men's migration, especially for low-skill work, may emasculate them (Boehm 2008, Pessar 1999b) - or more generally threaten aspects of the social standing that they enjoy in home communities (Fouron and Glick Schiller 2001). To offset perceived threats to their masculinity, they may emphasize the importance of their remittances in order to "regain the status and privileges that migration itself has challenged" (Pessar 1999a:65). In short, economic remittances often reinforce and possibly help men regain their breadwinner identities and household authority.

With respect to women and remittance scenarios, some research suggests that the economic and social roles that women take on through sending and/or managing of 
remittances can "catalyze transformations in gender relations" (Ramírez, García Domínguez and Míguez Morais 2005:27). Women often receive men’s remittances, and some literature has examined the impacts on household gender dynamics of women's receipt and potential management of those funds. Women may assume more financial responsibilities and greater autonomy over how household income is spent (Kunz 2008, Ramírez, García Domínguez and Míguez Morais 2005). Conditioning these potential effects, however, the literature also highlights the frequency with and extent to which husbands from abroad and other relatives locally control women's financial activities (Boehm 2008, Kunz 2008, Ramírez, García Domínguez and Míguez Morais 2005), as well as women's feelings of burden in relation to these new and extra responsibilities (Munduate 2008, Salgado de Snyder 1993), as Chapter 7 highlighted.

In regard to female migrants, some research has examined the potential link between women's economic remittances and gender equality (José Alcalá 2006, Kunz 2008, Pessar 1999b, Ramírez, García Domínguez and Míguez Morais 2005), specifically a gradual erosion of male control coupled with an increase in women's authority. While there are ideological 'flows' here as well - such as new definitions of femininity (José Alcalá 2006) - a focus squarely on earnings in these scenarios invokes the resource theory of household power (Lindsey 1994, Sullivan 2006), wherein contributions to the household economy of men and women constitute resources in the household balance of power between them. Illustrating the implications of men's income in Guatemalan households characteristic of the ones in my study, a representative from the municipal women's office in Tecpán explained: "What happens is that, because it's him that brings the money into the house, it's him that gives them food to eat, so it's him that's in charge. So, it's something that people traen entendidos (just understand)" (Samayoa 2010). In 
terms of women's migration, some studies suggest that "men lose ground" (Pessar 1999b:585) when migrant women increase their contributions to the household economy, in that women's control over budgeting and decision-making increases and they have more leverage for appeals to men to assist with domestic tasks.

I anchor much of the following discussion in this economic resource-focused way of conceptualizing household gender relations, while also engaging critically with it, given the other factors and considerations at play. With respect to remittances specifically, the belief in a correlation between women's income-generation and enhancement of household status fails to delve into "the complex and varied human, social, political and economic realities in which remittances are embedded" (Kunz 2008:1398), such as ideologically-imbued household power dynamics that influence control and use of

remittances (Ramírez, García Domínguez and Míguez Morais 2005:25, Vullnetari and King 2011). In short, the relationships between gender and remittances often play themselves out in "complex and contradictory ways" (Kunz 2008:1400), demonstrating in large part that the impacts of economic flows cannot be considered in isolation from socio-cultural prescriptions, which are both locally and transnationally enacted (Brickell and Datta 2011b, Vogler 1998).

\section{Remittances - General Findings}

All migrants in my study sent remittances on a regular basis. The vast majority of men remitted funds biweekly, while women's frequency varied between weekly and monthly. Migrants generally sent money through formal banking systems and/or money transfer outlets such as Western Union. How remittances were handled - spent or saved, for instance - varied greatly according to the financial circumstances of the household in 
question, which itself fluctuated from one migration period to the next, or one envio (transfer) to the next. Echoing other research (e.g., Ramírez, García Domínguez and Míguez Morais 2005:25), expenses in the immediate or short-term for which remittances were used included food, medicine and health care, school supplies and clothing for children, utilities, loan payments, agricultural inputs such as seed or fertilizer, and other productive inputs such as thread for women's embroidery or weaving. Funds that were saved would in the medium to long term go toward school fees, building or renovation materials, other agricultural inputs, husbandry animals, small businesses such as homebased stores, houses, and land. Some research looks at women's migration in terms of their independent economic empowerment (e.g., Hugo 2000, Menjívar 2006), and in this vein, it was common among the younger or single women that they saved a good portion of their income for future plans and/or had capitalized on opportunities for long-term investments such as land. However, all women committed a sizeable portion of their earnings to household daily expenses, investments, and/or debts.

\section{Female Migrants and Household Authority}

In female-migrant households, I particularly investigated the extent to which the women assumed more household authority by virtue of their enhanced economic contributions. Although the bulk of the following discussion focuses on this main question, I highlight at the end of the section, drawing on examples of men's influence over women's subsequent migrations, that men may have felt their breadwinning masculinities threatened by women's earnings.

Contributions to the Household Economy - ¿Más Voz?

To inquire into whether women's enhanced contributions to the household 
economy had contributed to a strengthening of their authority, in Spanish, I framed this as whether they had más voz (more say) upon their return. The women made clear the importance of their income to the household and their families' appreciation. For instance, Manuela, whose husband had been quite ill, said, "Thank God I worked there, because with that little money, we've been able to get him better, bring him to the hospital...If I didn't work, we'd have a big debt because where would the money come from [to do that]?" Gabriela's husband had told her that she had really helped them by working in Canada, improved their living situation. And when asked how her parents felt about her payment of the family's debts, Emilia asserted, "Yes, I've helped a lot... They feel happy because, as I say, they know that one has a little [money], and to help them with one has, one feels happy." Women were often humble about their influence, but they seemed content about facilitating opportunities for their families.

Women seemed to have a say in how their remittances were handled by the generally male family members who received them, and later in how those funds would be spent. In Manuela's case, her husband felt as though he needed her permission to use the remittances: "What he does or says most is, 'I have to save the money.' He says to me, 'me da pena agarrar el dinero (I feel bad grabbing the money) because it's not mine.' But I say, 'that's why I'm here. It's not only mine. If there are necessities, use it. The kids need the money." Gloria's husband saved as much of it as he could, and they decided upon her return what to do with it:

"I would send, but my husband would save it. He would take what he needed for household expenses. When I returned, when I came, he told me, 'here it is, what could I do [save it], and now, what are we going to do?' This and this and this. So we did it, and some things didn't turn out well, but he gathered it, and when I returned, there it was, and between the two of us, we handled it."

As for separated women living with their parents, Isabela also authorized a mix of 
saving and spending by her father: "[He uses it] for expenses here, and he leaves a bit in the bank. For example, if he says we don't have corn or something here, 'go buy it' [I say]. Or other things, 'go buy them, and manage the money well, and leave [the rest] in the bank." And Luz explained that she would instruct her mother over the phone on how to spend the money on her daughter's needs, and that after she returned, she and her father came to an agreement about investing her savings into la siembra (crops). Among single women without children, it may have been more likely that more of the funds were saved than used for immediate family use. Although some of her money went toward the family's debts, this was the case with Emilia: "I sent the money, and they deposited in the bank... and when I arrived back here, I bought a piece of land." In Esperanza's case, she managed two bank accounts - one in which she would deposit money for herself, and one for her family's use - and her family would tell her how that money had been spent. For those women who had a say in how their migration earnings were used, it was not clear how much this differed from how their locally-earned income - if applicable - was handled within the household prior to their migration. Notably, however, in no case did other household members dominate decisions about the use of women's remittances or try to appropriate them.

Aside from decisions about how their money was spent, however, these undeniably important contributions to the household economy generally did not translate into more say or authority in their households about other decisions or the division of labour. In one exception, Luz, when asked if she thought she had more say over household matters when she returned, said, "Ah yes, because he [my father] would say, 'now [let's do it] like this,' and I can say, 'no, better that we do it like this.' Why did I mandar (have the say)? Because I had a bit of money." But this behaviour soon fell out 
of favour with her father and she felt obliged to defer to his authority. She said that four years later she no longer had that sort of voice in household affairs:

"No, not anymore. Like my dad says, "now that the nena (your daughter) is growing, you have to humillarse (humble yourself) more, because you have to educate her more. It's not like when she was younger, you'd say more selfinterested things.' Now, it's different because she's growing up, I have to take care of her and educate her. I can't mandar (command) because I have that patojita (little girl) here, I can't mandar here, because they've given me a place to live. That's the way we are."

For other women, there was no shift in their household authority at all. Gloria said in relation to asserting more voice in the home: "No, you could do that, but no me convenia hacerlo (it would be better for me not to). Because of the fact that I left my house, and I come back to be encima de todo (above everything)? No, it's not like that." Brenda emphasized her father's authority: "When I was with my parents, my dad was in charge of household expenses... I don't feel good doing that [being authoritative], being bad because I had been in another country, I don't feel good [about that]." Gabriela denied having more power at home as a result of her economic contributions - things were the same as before, when she and her husband would do and decide things together.

We can see here that the women were not inclined to, or were dissuaded from, asserting greater authority in the home despite their economic contributions. Menjívar, drawing on research with Guatemalan women, characterizes these circumstances as a mix of empowerment and disempowerment: earning a wage and being in a better financial position empowers women personally and potentially relationally, but they are disempowered by what she calls deliberate attempts to recreate gender inequality in the home. Among the Ladina women in her research, these attempts were aimed at maintaining “an idealized (class-specific) union" (2006:93); the women were convinced of their duty to follow prescribed household gender relations, even if men - the proper 
breadwinners - did not have paid work. This reasoning illuminates the intersections between gender, class, and ethnicity in Guatemalan households. Although not comparable in class-related terms to women in Menjívar's work, the indigenous women in my study expressed a general sense that asserting more authority in the home was not appropriate or something that the migrant women would have felt comfortable doing. In the concluding section of this chapter, I highlight some socio-cultural and ideological considerations that may have influenced women's limited inclinations in this regard.

\section{Threats to Masculinity}

Some literature on women's paid work - both in the context of migration and more generally - suggests that increases in women's income-earning, especially when their husbands are out of work or earn considerably less than women, may be perceived by men as threats to their masculinity and/or household authority, given that they are not fulfilling their prescribed breadwinner roles (Chant and Craske 2003, Montes 2009). Women's transnational labour migration may reconfigure male gender identities in an "uncomfortable fashion" (Montes 2013:474), including loss of self-esteem, self-respect, and dignity. In such situations, men may try to re-assert household authority in other ways (Chant and Craske 2003), and I want to draw attention briefly to this possibility.

In my study, in most situations of migrant wives, the income they were generating and sending from Canada far exceeded their husbands' local earnings, so I would argue that potential existed for threats to men's prescribed status. I contend that one way in which men may have sought to re-assert themselves in such situations was to deny their wives a return to Canada. In Manuela's case - highlighted in Chapter 7 - her husband had explicitly disallowed her subsequent migration to Canada. In that chapter, I 
connected this to the pressure on non-migrating men to gender-cross into women's areas of work, and in Manuela's case, it had been care for children - who had been "abandoned," she said - that in particular seemed to have motivated her husband's prohibition, but breadwinning-related motivations may have informed those reasons. Two other cases that I did not profile in the previous chapter highlight those rationales. Brenda had been to Canada once while married, but the subsequent year, she and her husband decided that her husband would go instead of her. Part of this may seemed related to the disruptions to household life in Guatemala - "this year we decided that it would be better that he go because it would be more difficult if he stayed than if I stayed" (my emphasis) - and she was emphatic that her husband had not forbidden her from going. However, when I probed this a bit more to better discern the reasons, her response was: "He said, 'I'm going to go because I'm a man and I'm the one who has to work more'," smiling a bit, as if she might have disagreed. In the second case of both male and female migrants - Delia and her husband Alberto - the decision had been his. Delia said Alberto had told her not to go back to Canada this year, that he would go instead, because work in Canada is hard for women, and being in Canada poses risks to women in particular, contentions with which Delia agreed. Although not couched in male-asbreadwinner reasons, I suspect those informed his rationale, especially seeing as they were newlyweds and he likely wanted to establish 'proper' gender roles, including economic provision as a husband. So, through these three examples, I have sought to suggest that women's income threatened their husbands' desired or prescribed status.

Having examined the consequences of women's migration earnings and remittances on household gender relations - in large part, continuity - I turn now to men's migration. 


\section{Male Migrants and Household Authority}

In relation to male migrants and their earnings and remittances, my analysis focuses on two main points: women's responsibilities as receivers of remittances, and the reinforcement of women's reproductive roles upon men's return.

\section{Male Remitters and Female "Administrators" and "Informants"}

As highlighted above, some gender and migration literature posits that shifts in household gendered balances of power can come about not only through migrant women remitting money, but also through non-migrant women's management of remittances sent by their family members, but that certain influences limit this potential. In my study, female partners certainly carried out new financial responsibilities related to remittances, but with important variations in the extent to which they managed financial affairs.

I discussed in Chapter 7 regarding non-migrants' practices in Vista Hermosa during migration that female partners would often take on spending in typically men's areas of responsibility, usually having received men's remittance money directly, and this was not unimportant. I alluded briefly to broader financial management, but reserved that part of the analysis for this chapter because I wanted to engage those findings with the resource theory of power. Drawing on differentiations made by Volger $(1998)^{139}$ between certain aspects of financial responsibilities, I wish to distinguish between spending money and managing finances, the latter referring to figuring out or deciding what expenses to pay, when, and in what amounts. Drawing on studies into the idea of marriage as an agency relationship, Vogler explains that couples may have separate

\footnotetext{
${ }^{139}$ Vogler differentiates strategic control over money from being responsible for managing money on an everyday basis. In the latter circumstance, the person responsible for managing daily affairs and implementing decisions "may not necessarily be able to exercise any real power or control over broader strategic decisions" (1998:691).
} 
financial spheres; in such circumstances, women, "acting on the basis of assigned or delegated power rather than holding power in their own right" (1998:696), act as men's agents instead of controlling finances. Financial management relates to household authority, and in this respect, there was considerable continuity in my study in men's responsibility and control. It was less likely for women to be financial managers than to spend in men's expenditure areas. For the majority of male-migrant households, the men provided significant instruction and guidance - both before they left and over the phone from Canada - about how their wives at home should manage the finances. This finding echoes other research, both on men's financial control from away and women's consultation with them on most spending issues (Menjívar and Agadjanian 2007), and, again, the important role that communication technologies play in upholding gender inequality (Mahler 2001).

In discussions with partnered women and/or their husbands, variations arose on the idea that women were "informants" who spent or "administered" the money. They would inform men in Canada about the financial needs that the men may not have known about, and men would then provide some degree of instruction about how to spend the money, in some cases how much women could spend on daily expenses. Some women would also report to men how they had spent the remittance money. It was Cristóbal who really alerted me to the administrator-informant role among women:

"It [the money] is administered here. A better explanation would be the husband... Here we're united, but maybe sometimes no, because only me, only the husband administers the money. So she is like an informant - I need this, I need this - and I tell her, [and she says] 'I've spent this,' [so] I know. So she only, as I say, [says what] she needs. And where [she] took it out, he [the husband] also needs to know that."

Jimena described it this way: "It's him that guides me. He's like my guide. He tells me, 
'this is what to do, and I'm sending you this much, pay for this, pay for that.' And it's like administering it, nothing more." Rolando explained what he and his wife would do:

"What I've told her is that she has to spend [the equivalent to] what I make here she has to eat, she has to spend it as we do when I'm here.... I ask [from] there, 'what are the kids missing?' If she tells me a kid needs shoes, [I tell her], you have to buy them. The next week, she takes out a bit more [money]. So I tell her what she spends. So when I send it, she knows how to use it."

Indicating a little more consensus and women's input, Simón commented, "we come to an agreement. She tells me by phone that I have this need, and I need this much for the [women's] group and all that. The little that's left, she deposits in the bank."

In Chapter 5, I highlighted the assertion from the director of the women's organization Nuestra Voz that women often manage funds better than men, and such contentions underlie the focus in many developing countries on women as targets of micro-finance and conditional cash transfer initiatives (Gitter and Barham 2008, Mayoux and Hartl 2009). An obvious difference in this particular examination is that the women have not earned the money to be managed, but what else explains men's predominant control over remittances? It may be explained by both quantity of income, and a concern about women mismanaging the funds, despite experts' opinions to the contrary. First, as household income levels rise, men may take more ownership over financial management, citing the importance of the decisions that need to be made with higher sums (Vogler 1998). Secondly and relatedly, comments by migrating men and their non-migrating partners also revealed, both implicitly and explicitly, a concern about women misspending or wasting remittance money, fuelled by stories about women who had allegedly squandered funds. Miranda, in my host family, felt that some women spent remittances on whatever they pleased, and when the husbands came back, all the money would be gone. About such accounts Dominga said: "There's nothing [when they come 
back] (laughter)... I'm not in agreement with that... He's suffering there, it needs to be said... [and] here, maybe one wastes the money. I don't want to do that." This concern seemed to be a key impetus for women reporting their spending to their husbands, saving what they did not need for immediate expenses, and waiting until their husbands returned for decisions to be made on how large sums would be used. Cristóbal explained: "After [returning], one oneself has to administer it, what am I going to buy, what am I going to do, because one has plans." Indicating both doubt about his wife and more mutuality in decision-making, Ramón said that after his return, "We get together what we have...[because] sometimes she makes the decision, 'I'll buy this,' and maybe when I come, I don't like this thing so better when I'm here, between the two of us, we buy such and such a colour."

Comments from a few women - Yaneth, Dominga, and Eloísa - suggested that they had more control than other women over financial management in their husbands' absence. Yaneth made clear that while her husband did request that she use the money in certain ways, he did not monitor her spending or expect detailed reports from her about it:

"Sometimes when he sends money, he tells me that he sent it, and can I do him the favour of paying this for me or that, or do this. But when he sends it, he never says I sent this much, and you pay this, and save what's left. No. He tells me, 'I sent it,' and [then] one has to pay for lots of things. And when it's gone, I tell him, and then [he says], 'give me time and I'll send some more.' There are other people that when he sends it, he says it's this much, and how much is left over? Why did[n't] you spend it? No, he's not like that. He sends it, and if it's used up, it's used up. [...] As he says, 'what's mine is yours. When it arrives to your hands, it's yours because you know the necessities there and you know what you have to spend [it on].' [...] When he comes, he never asks what I did with the money."

Dominga said, instead of just spending money, she managed it - "When he sends money, I manage it. When there are needs, I use it. When there aren't, it stays saved in the bank" - and in Eloísa's case, she "llevaba la responsibilidad" (held the responsibility) to 
manage the finances while her husband was in Canada. This was a definite change for Eloísa, who said that her husband would normally manage those financial responsibilities. Both women said they held this responsibility because they knew what needed to be done and paid for.

My study does not benefit from a sample size or data adequate to consider in detail the factors that could explain the differences in gendered patterns of financial management among these households, but by engaging available literature ${ }^{140}$ with what Yaneth, Dominga, and Eloísa have in common, I would suggest that marriage stage played a role for these women. Weinstein Bever (2002), based on her study of men's migration from Mexico, argues that in contrast to younger or newly married women who feel considerable pressure to obey and please their husbands, older women have gained enough status and respect in both the home and community to 'push back' against norms of appropriate behaviour to some extent. All three women with more control over financial management had been married ten years or more. On the other hand, Lourdes, married twenty-five years, was one of the women who was very explicit about her husband controlling the finances from Canada: "no es yo que manda... Él lleva su control de allá (it's not me who's in charge...he controls things from there)," thus also implicating other factors. From the information I have about Lourdes, religion may have played a role. She was Evangelical Protestant, and based on some of the literature (see Chapter 2) as well as observations of my Evangelical host family, male authority can be quite pronounced among adherents. These considerations are informed conjecture on my

\footnotetext{
${ }^{140}$ Although I do not have the data to investigate these in any depth, other research suggests differences among households in relationships between migration and gender relations may be explained by: marriage stage (Weinstein Bever 2002), the number of times migrants have been away, household gender relations more generally (Kunz 2008, Ramírez, García Domínguez and Míguez Morais 2005), income distribution (i.e., pooled or not) (Vogler 1998), and religion (Carter 2004, Mahler 2001).
} 
part, but do highlight the need for research that can "situate remittances within their underlying contexts" (Kunz 2008:1398).

From a Western feminist perspective, we may 'approve' of Yaneth, Dominga, and Eloísa having more authoritative positions in relation to managing remittances, but - as discussed in Chapter 7 - non-migrant women tended to feel burdened or challenged by these extra responsibilities. Such sentiments came out in particular in Yaneth's comments. Asked whether she felt she had more control over household affairs while her husband was away, she said:

"Yes I have a bit more control over everything, and I have more to take care of as well. And if it's not enough [the money], I have to figure out what to do (laughs). So one has to think more as well [when they're not here]. [...] When he's there, it's me that thinks more than him, because he only has to think about sending and sending. I have to think about how to do everything."

When male migrants returned from Canada, consistent with the findings presented in Chapter 7, they tended to re-assume their direct responsibility for household financial management. Women often referred to things as going back to 'normal', to what their costumbres (customs) are like there. Women assessed this positively because of sometimes feeling burdened by having had to take on men's money-related tasks. For instance, although she had not done a lot of financial management during her husband's absence, it made Lourdes feel recargada (overloaded). She said her husband retook full control of the finances when he returned and she did not have to worry much anymore about the expenses: "Yo como y me duermo (laughs) (I eat and go to sleep)."

In the concluding section of the chapter, I touch on a few of the local sociocultural circumstances that may have contributed to women's limited financial authority, but through conceptual and theoretical lens, we see here gender's operation transnationally, as well as correlations between men's economic and symbolic capital. 
Mahler and Pessar describe the former as "gendered geographies of power" (2001:441), in which gender relations are enacted, and often reinforced, within transnational social spaces. From a Bourdieu-inspired perspective, women's household authority would have been limited by men's aspirations to maintain symbolic power (i.e., honour and household control), tied as it is to economic capital, which was considerably enhanced in the households under study here.

\section{Reinforcement of Productive and Reproductive Roles}

The second issue I wish to investigate in relation to men's migration relates to the consequences for women's roles that followed from men's ability to uphold and in some cases regain their prescribed roles as principal economic providers, defining features of masculinity in the Americas (Broughton 2008). Both male migrants and their partners expressed satisfaction in men's enhanced abilities to provide for the family, and especially to facilitate better present and future circumstances for their children. Women underscored the sacrifices men were making in Canada, their long hours of arduous work for the economic betterment of the family, and asked who knows where they would be without the money their husbands were making and sending from Canada.

In a few cases in Vista Hermosa, I perceived an intensification or deepening of patriarchal household dynamics upon men's return, indicated by women being more subservient to their husbands, treating them in extra-special ways, either by their own initiative or in response to men's demands. Hellman describes the situation of returning men this way: "he's very overbearing in his behaviour. He keeps talking about his sacrifices, but doesn't appreciate hers, and he expects to be waited on like a king to make up for all he's done without" (2008:60). Indeed, in my study, Rafael literally claimed to 
be treated like a king when he returned, and Miranda said that she would really cater to him when he was at home because it would often be only a few months before he would set off again, so it was best to treat him "a su gusto (as he likes it)." Lourdes claimed that she serves her husband more when he returns because he does not have a wife there in Canada, so has to work doubly hard and comes back to Guatemala tired, knowing his wife is there to serve him. Graciela cited a more demanding husband: "When they're there, they do it all. So when they come back, they ask [for things] so one has to do it.... When they come back, one has to take care of them."

I assert that these cases of intensification of women's 'normal' care-taking responsibilities may stem from men's enhanced economic provision. It stands to reason, given the theoretical connection between economic contributions and household authority status, and the complementarity between productive and reproductive roles that tend to characterize conceptualizations of household gender relations in this community, that an enhancement of men's income generation might be matched by an increased emphasis on women's care-taking roles. In Bourdieu terms, we might describe this as women's assertion of their cultural capital (read: cultural 'know-how' in the domestic sphere) in the face of men's increased economic capital.

The effect of men's economic provision on the intensification of women's normative reproductive behaviour may also have been heightened in situations where men's experiences in Canada had 'de-masculinized' them in some ways. I introduced this possibility in Chapter 6 in relation to migrant men's performance of housework in Canada. Migration both potentially (re)constitutes and compromises masculinity (Boehm 2008); although it may shore up their breadwinner identities, male migrants may "have their masculinity stripped from them" (Boehm 2008:20) by enduring "material and 
symbolic indignities" abroad (Broughton 2008:585). Efforts to reclaim their sense of masculinity may take the form of intensified displays of machismo (Pessar 1999b).

There are a few possibly emasculating aspects of men's labour migration, the first relating to their working conditions: they leave behind their work as farmers who control their own labour and manage their farms - even if small-scale, family plots - to work in low-wage, low-prestige jobs abroad (Boehm 2008). In Canada, migrant farmworkers take the "triple-D" - dirty, difficult, and dangerous (Preibisch 2005) - and often minimum-wage jobs that Canadians do not want badly enough to work as reliably and productively as employers need. In my study, migrant men's labour, hours, working conditions, and mobility were all largely out of their control in Canada. Hours were long, and they often felt under pressure. "No es cosa facil (it's nothing easy)," said Mario, "es sudar duro (it's sweating a lot)." Rolando lamented that he would prefer to work in Guatemala than go to Canada "because uno es matado (one is killed) [by the work there]." These work challenges were accentuated by instances where employers violated labour violations or terms of their contracts. Eduardo, for instance, said:

"they demand a lot of work and they don't honour the rights of the person who's working. As I say, for me, work is work, and one has to do it, but when they cumplen con los reglamentos, uno se siente mas cómodo (follow the rules, one feels more comfortable). Because here in the $[\mathrm{IOM}]$ office, we signed a lot of forms where if one is in agreement, one can do it. But, practically when one arrives there [CH: it's different], it's different; one doesn't cumple (fulfill it) and we say, what did we sign, those documents, and here you don't cumplen. But they say, we're not working with that, you've done that [signed those papers] there, and here no...One doesn't have any ampara (support or protection) or anything."

Discrimination and preferential treatment on the job may have also contributed to men's feelings of degradation. I explored aspects of nationality-based and ethnicity-implicating treatment in Chapter 6, in relation to migrants' intersectional habitus. To the extent that 
Guatemalan men's masculine sense of self is tied up with Guatemalan and indigenous identities, these types of treatment may have harmed their sense of masculinity.

In addition to working conditions, two other potentially emasculating experiences can be considered. One is men's performance of housework in Canada, which I discussed in Chapter 6, and I found evidence in Rolando's remarks in particular a potential felt loss of manliness from when "one comes back dirty, and one has to wash one's clothes and make one's food [there]." The other is the emotional dimension of migration. Experiences of migration and work were often very emotional, including feelings of sadness, loneliness, fear, worry, and missing their families and other aspects of their lives at home. Rolando described going to Canada in this way: "When I go [there], it's sad, because Guatemala se quedó (stayed behind). One has to forget one's family because one is far away, and one doesn't know what one is getting to." For Simón, "there are days when one gets sad for the kids, the family, the wife." Emerging research on the emotionality of men's migration (e.g., Montes 2013) investigates men's emotional dilemmas and costs that while difficult, may call into question the traits normally associated with hegemonic masculinity, such as being unemotional or dispassionate. Montes suggests that these emotional experiences may lead men to embrace less hegemonically masculine models, thus making migration "a factor of change within the construction of masculinities" (2013:487). However, perhaps in the meantime, such 'unmanly' emotions may have felt threatening to Guatemalans' masculinity.

So for some men, migration-derived income and economic remittances served to buttress their breadwinner roles and household authority. Where aspects of experiences in Canada compromised their masculine selves, their economic contributions may have served to reinforce and in some cases intensify patriarchal household arrangements. This 
seems to be the case for Rolando - he had comments in relation to all three elements of possible emasculation mentioned, and his wife, Graciela, was one of the wives who cited a more demanding husband. Not all male migrants returned more demanding. In most cases, the household division of labour just returned to "normal", and as elucidated in Chapter 6, a few husbands returned more appreciative, loving, and helping toward their wives. And below, I identify a cultural factor - prescriptions regarding orgullo (pride) that may have limited the extent to which men asserted themselves in more demanding ways. However, the few cases where women intensified their carework after men's return signal an important finding about the possible impacts of male migrants' income.

\section{Socio-Cultural Factors Shaping the Impacts of Remittances}

This chapter's analysis has been significantly informed by the resource theory of household power, but among the weaknesses of that theoretical approach is that the prioritization of the economic in relation to household gender relations tends to isolate households from wider socio-cultural systems (Menjívar 2006), and overlooks the importance of ideological, cultural, and emotional factors that may either reinforce or offset differences in economic resources and their impacts (Gazso-Windle and McMullin 2003, Vogler 1998). I conclude this chapter by examining a set of prominent sociocultural phenomena that I discerned in Vista Hermosa and that conditioned the influence on household gender relations of the economic circumstances fostered by remittances. Specifically, I will apply these cultural imperatives to understand the lack of shifts in women's household authority by virtue of their economic contributions, and the fact that most men did not return more demanding of their wives. This examination also reflects an important attentiveness to socio-cultural specificities and emic perspectives. 


\section{Male-as-Breadwinner Ideology and 'Helping'}

In relation to female migrants and the relative lack of más voz in the household upon their return, the ideology of male breadwinning is significant, and as an outcome of that, I also discerned a prominent theme among women of 'helping'. Vogler contends that "differentials in economic power may be reinforced or offset by ideological power, particularly by the ideology of breadwinning" (1998:695). In the Guatemalan context, Menjívar argues that "gender ideologies rooted in social and cultural prescriptions in each place qualify the link between women's employment and a potential increase in their status within the family" (2006:102). My interviews suggested, in keeping with literature on household gender relations in rural indigenous Guatemala, that men are primarily tasked with maintaining the family economically. And indeed, this kind of reasoning influenced decisions regarding who would migrate, if the potential existed for both partners to go, as indicated above in Brenda's husband's assertion that he should go to Canada because he should work more than her. The point here is that when migrant women in particular continue to accept that men are the 'proper' breadwinners, even if their income vastly outstrips that of men in their households, they are unlikely to disrupt - or if they do, not for long - much of the household authority that breadwinning normally bestows on men. This came through in remarks from Luz and Brenda above, both migrant daughters for whom their father's household authority was key to limiting the potential for más voz.

The role of the male-as-breadwinner ideology in shaping household gender relations is well-established, both in my study and elsewhere, but I highlight it again in order to tie into and introduce a dominant cultural theme that emerged in women's

remarks: that they were 'helping' their household members, especially the 'proper' male 
income-earners, by migrating to work in Canada. I would like to draw on the contention that gender-related outcomes of migration are shaped in part by the reasons that people migrate (Monzón 2009). For female migrants, I argue that the particular socio-cultural way they conceptualized the economic reasons for their migration - as 'helping' - had a conditioning effect on the outcomes of their migration in terms of household authority.

A few married women expressed the sentiment of helping their husbands. Manuela explained: "I went por necesidad... My husband went one year, he could only go one year. Because of health problems, he hasn't gone again. Because of that, I decided to go." She said she went for the kids and "for my husband as well, I did it" because "one can't do anything here anymore [to earn an income]." Similarly, Gabriela's husband could no longer work because he had lost his sight, so she was interested in going, and Gloria's husband would have gone, but he exceeded the IOM's age limit. Even more so than married women, young migrant women's remarks about their migration indicated this focus on desarrollar la familia (helping their families' wellbeing). Luz described it this way:

"Our dad suffered a lot to bring us up, and now we have to do it, mantenerlo (provide for him) a little bit, so even if it's just a little [money], I'll give it to my dad, because I see that there isn't a way to make money here. So now that they've given me this opportunity to go to Canada, I have to help my dad, even a little."

When she went to Canada the first time as a single woman, Brenda used some of her earnings to finance a new building on their property for her father, and as mentioned above regarding her economic contributions to the household, Emilia had helped her parents pay off their debts. For her part, Esperanza said that she went to support the family economically and her younger siblings' education because her father had not been able to work for several years due to a disability. 
This 'helping' discourse in part owed to a cultural imperative that all household members contribute to the well-being of the group. One of the research assistants, Fiona - a migrant daughter living at home - explained to me that, as a costumbre (custom), sons and daughters commonly contributed part of their income to the household economy specifically to their parents - whether or not they still lived at home. She elaborated to explain that family members helped each other in other activities, such as farm work. Other respondents confirmed these costumbres in how they talked about collaboration among household members to meet their collective needs. Literature on indigenous Guatemalan culture and lifeways reinforces this point. To varying extents, present-day Maya continue to organize their social practices, including gender relations, in ways premised on ideas of the Mayan Cosmovision (Martínez Salazar 2005, Martínez Salazar 2012, Pu Tzunux 2007). Among these, Martínez Salazar emphasizes that "life belongs not only to the individual. Life is articulated within a collectivity" (2012:15).

However, coming through perhaps more implicitly in women's comments was the idea that their income earned through migration was supplementary or complementary to the earnings of men or elders in their households who were supposed to be the primary income-earners. Other research has established this inclination in regard to women's income-earning, both in general and in migration contexts (Pessar 1999a, Resurreccion and Van Khanh 2007, Vogler 1998, Vullnetari and King 2011). I assert here that the tendency for household members - both men and women - to see migrant women's earnings in these ways contributed to minimizing the extent to which women may have wanted to or been able to claim más voz in the household.

Menjívar's research on the migration of married Guatemalan women contrasts the 'helping out of necessity' reason with more independently-minded motivations. She 
argues that "entry into paid work is not a liberalizing act on the part of the women, but more so, an indication of men's economic vulnerability" (2006:93). Women in her study provided substitutions for men's income in order to ensure the survival of their families; they were often not "seeking personal fulfillment outside the home propelled by feminist conscientization" (93). Her point is supported by other research on gender dynamics in rural farming households (Shortall 2006), in which survival strategies and "a desire to maintain the farm family household" underpinned women's off-farm work, not "efforts to maximize their position" in the household (313). My point here is that when circumstances motivate women to have to engage (more) in income-generating work, those activities may carry a different meaning - and may bring different outcomes in terms of household dynamics - than if they were to engage in it for more personal, independence-oriented reasons, as other research has suggested that younger single women in particular may do (Broughton 2008, Wolf 1990).

Western feminists may be inclined to fault women in my study for minimizing their paid work, or failing to use economic resources to their advantage in the household distribution of power. In a strong statement in this vein, Pessar argues that by calling their paid work 'helping' and minimizing their time and effort, "these women manage to keep the fires of patriarchy burning" (1999a:67). However, these behaviours may be quite consistent with cultural norms in a setting like Vista Hermosa, where both the norm of men's breadwinning and the importance of contributions to collective well-being over personal gains have been engrained.

\section{Orgullo}

In addition to men's breadwinning, women's 'helping', and emphasis on the 
collectivity, a fourth theme emerged in my study that potentially tempered the inclinations of both women and men to claim greater household authority as a result of their earnings. This was the cultural imperative of not being orgulloso (proud). Migrants presented two different meanings of orgullo (pride): feeling good about themselves for their accomplishments and sacrifices, and being big-chested, conceited, and boastful. The former was culturally acceptable, whereas the latter was frowned upon and migrants sought to avoid personifying this negative sense of the word. Mention of orgullo arose in interviews with about eight migrants, equally male and female. Among the women, Brenda distinguished the two senses of pride: "I feel happy that they give us that opportunity there, but not to-- I feel proud to have traveled to another country that accepts us, but not to get proud like that, like, 'look at how you are!' No, nothing like that. [...] I'm serious but not proud... I try not to become something else or to get proud. I don't like that." She went on to explain this aversion to expressions of orgullo ran in her family: "My husband is like that [not orgulloso], and my family - both this one and my parents' family. That's what we're like. My dad says we can't be orgullosos. Why? Because it doesn't bring anything good. You have to be nice to people and not do bad things and try to help others when you can."

Often respondents paired mention of orgullo with reference to the tendency among others - friends, neighbours, and family members - to judge and talk about them. One of the research assistants, Fiona, explained that sometimes people in the community think that when one works hard and earns good money, that person becomes orgulloso. There was a sense that returning migrants wanted to avoid having others think poorly of them, so they were conscious of how they acted, both in Canada and in Guatemala. Luz thought about it this way: "After, what if here we feel different, [as if] arriving there to 
Guatemala [and] we change character with people, we're not going to talk to them. The people would start talking about us [and say], 'ah with a short time there you feel proud.' Better that we stay the same." And in a couple of cases, returning women thought that others had criticized them for being proud in this negative sense. Gabriela explained that she did not feel she had returned with any differences in her character, but some of her friends had said that she had become orgullosa and had talked badly about her: "it's always that way, it's never good things they say. Probably it's because of jealousy that they're like that."

Male migrants as well expressed resistance to being - or being seen as orgullosos, remarks in which they tended to contrast themselves with how people might see them, and with other migrants who allegedly had returned more big-chested. Donardo noted orgullo in other returnees but denied that it happened to him: "What happens is that many times, what affects some people here, and I've noticed this in a few, is the orgullo. When one returns from there, they have money here and they have the things they want, and it's like they look at other people as lesser. But in my case, it wasn't like that." Eduardo also suggested that others might think that returning migrants feel superior, but not him: "Maybe they imagine that coming back from there, one is different, that one feels more superior. Sometimes they think that in the family, but one actually feels the same because each person [just] fights for their life and their family." Perhaps referring to the moral dangers of big-chested pride, Ramón expressed his feelings like this way: “I don't like to be orgulloso. Pride doesn't get you anywhere." Rolando also denied coming back with a chip on his shoulder but sometimes people would think otherwise: "when one returns here, one sometimes gets bothered, one gets told, 'let's see if he se crezca (gets bigger-chested or vain) there in Canada or what.' But 
when one comes back from there, it's not to be proud. For work [is why one goes there]." In terms of where this aversion to orgullo comes from, both Mayan values and Christian religious teachings likely play roles. Roncal and Ajquijay (2004) point out that avoidance of arrogance or haughtiness figures among the norms of Maya spirituality. In regards to religion, reference to God permeated my interviews in general, and remarks like Ramón's tied religion to resisting orgullo: "If one gets money from working in Canada, it's because of God's will, it's not my will, everything is owed to God. When I return with health, it's because of God. Who would I be to be proud? I can't do that." Religious teachings in the community also warn against being orgulloso. This came to light in conversations I had with the research assistants and with a female church leader. Sara, a deaconisa (Deacon) in the Evangelical church explained: "the Bible says that people like that [who achieve things] need to be humillado (humble), and those that are humble, Dios los exalta (God praises them)." She said that people should not exaltarse, meaning 'toot their own horn,' so to speak.

It seems reasonable that this aversion to orgullo played a role in limiting the extent to which migrant women claimed más voz in the household upon their return, and in tempering returning migrant men's demands (and concomitant intensification of women's subservience). If we look at who made comments about not being orgulloso, we indeed see Gabriela who claimed she had no more household authority upon her return, and Luz, who fairly quickly ceded her increased say to her father. However, problematizing this connection, Rolando and Ramón had made anti-orgullo statements, but both their wives claimed they treated their husbands in extra-special ways or that the men had returned more demanding. 


\section{Conclusion}

Migration to Canada has significantly altered the economic landscape of Vista Hermosa households receiving remittances, both the quantity of income, and in the case of many female-migrant households, who has earned it. This chapter has examined whether and how these dynamics have contributed to shifts in gender relations in those households, especially men's and women's authority. With a few exceptions, the 'normal' arrangements remained largely intact, and in a few cases, intensified. Female migrants had input over how their remittances would be used, but with one short-lived exception, were not given or did not claim más voz upon their return. And instances where it was decided that women would not migrate again indicate possible threats to men's breadwinning identities and attendant household authority. When male migrants sent money, the extent to which women managed financial affairs was circumscribed, notably by men's continued control from afar. Men's earnings reinforced their breadwinning roles, and - particularly if coupled with men's emasculation in Canada may have contributed to an intensification of women's caretaking roles. Finally, I argued that the cultural imperatives of 'helping', the male breadwinner, an emphasis on the collectivity over the individual, and aversion to orgullo may have shaped the outcomes, thus illustrating the importance of considering how cultural factors condition the impacts of economic shifts. I turn now to the last of my analysis chapters, focused on remittances of the social variety. 


\section{Chapter 9 \\ Gender-related Knowledge and Social Remittances}

This chapter explores the potential for impacts on household gender relations in Vista Hermosa as a result of gender-related social remittances. We will recall from Chapter 3 that social remittances are key among transnational processes that characterize much of migration's dynamics today, and refer to non-tangible flows of ideas, behaviours, values, beliefs or identities flowing - for the present purposes - from receiving- to sending-country communities in the context of migration (Levitt 1996). I cited other research in that chapter on gender-related social remittances among Guatemalans in U.S. contexts, such as information about birth control (Lindstrom and Muñoz-Franco 2005), how authorities handle domestic violence (Taylor, Moran-Taylor and Rodman Ruiz 2006), and the division of labour in American households (Menjívar 1999), as well as greater respect for women (Peláez 2009). These types of learning and realizations among migrants are not forgone conclusions, nor if occurring do they necessarily impact household gender relations in communities of origin. The outcomes of social remittances and the possibility of gathering and transmitting the content in the first place ${ }^{141}$ depend on factors that I will examine here by drawing on Levitt's $(1996,1998)$ three-step model of social remittances. Within my theoretical framework, the following discussion engages with the ideological level of the gender structure as new information about gender could condition household relations through gender consciousness (Sullivan 2006).

\footnotetext{
${ }^{141}$ Admitting of some exactitude, I reserve the term "remittances" - based in the word "remit", or to send for ideas, practices, etc. that actually get sent or transferred or that flow from one place to another, or the process of such sending. I differentiate content - ideas, practices, etc. - from social remittances in order to maintain the possibility that migrants may learn about, gather, or acquire this content, but not remit it. Put differently, social remittances have a spatio-temporal aspect that differentiates them from their substance, which, until such a time as it actually flows, remains the stuff of a would-be or potential remittance only.
} 
I start by summarizing and adding to Levitt's model, and then examine each step in the social remittance process as experienced by study participants, outlining the main findings and just as importantly, elucidating the salient factors contributing to them. These features illuminate significant aspects of migrants' experiences in Canada, primary concerns of migrants and their family members, and socio-cultural contexts in Guatemala, and I draw on theory from Pierre Bourdieu and Margaret Archer to further explain some of these dynamics. Overall, I found relatively little in the way of imapctful genderrelated social remittances, but the few cases I do highlight suggest preliminary steps toward greater gender awareness among those few migrants and their partners.

\section{Critical Use of Levitt's Model of Social Remittances}

Levitt developed her three-stage model of social remittances - including creation, transmission, and impact - from case studies of migration and transnationalism between the Dominican Republic and the United States. She explains that migrants need to create social remittances in their destination contexts and transmit them to their home communities via telephone communication and return migration, and a focus on impacteffectual dissemination or putting into practice - highlights the fact that "social remittances are separable from their effect" (1996:24). As for my study participants, Guatemalan migrants would need to be aware of or learn about the gender-related messages or differences between Canada and their home communities. This also draws on Sullivan's assertions (2004) regarding gender consciousness, i.e., that its development requires exposure to or learning about gender issues. Second, they would need to remit that knowledge to Vista Hermosa, either through communication channels or return migration, and third, we would examine whether and how those social remittances 
influenced household gender relations. Sets of conditioning factors ${ }^{142}$ impact each stage.

There are two main critical engagements that I would propose in order to work with Levitt's model and with the social remittances literature more generally, relating to the quality and interpretation of the content of potential social remittances. First, as mentioned in Chapter 3's introduction to gender remittances, we must not assume that by virtue of migration being from less-developed to more-developed countries that the gender-related practices or ideologies that migrants encounter in their specific destination contexts are going to be more 'progressive' or expressive of gender equality than those in their communities or countries of origin. Much of the literature that I have consulted seems to make this assumption. Certainly, on a macro level - according to various indicators that I discussed in Chapter 2 - Canada does much better at gender equality than Guatemala, but is still far from an exemplar (e.g., McInturff 2013b). To focus on the environments in which Guatemalans in Canada primarily find themselves, research on gender relations in the rural Global North points to an "agrarian patriarchal culture" (Preibisch and Encalada Grez 2010:292). The continued association between masculinity and farming contributes to fairly rigid gendered divisions of both farming and household labour (Bock 2006, Brandth 2006); women's farming contributions tend to be side-lined and under-valued, and their primary responsibilities are to support male farmers through household labour (Machum 2006). Certainly some of the Guatemalans in my research found women in leadership roles in farming in Canada, but my point here is that in examining gender-related social remittances processes, we should not assume from the outset that particular destination contexts will be characterized by greater gender equality

\footnotetext{
${ }^{142}$ Although I do not investigate all of them, Levitt includes patterns of interaction with the host society, how ideas or practices are transmitted, the fit between social remittances and other socio-cultural messages, and the balance of power between those who stand to gain and those who stand to lose from social change.
} 
than settings that migrants come from.

Nor should we assume that migrants - especially women - will automatically want for their own lives what they see or learn about gender relations in the contexts to which they migrate, if those relations do evince greater equality than those to which migrants are accustomed. This is my second critical engagement, with Levitt's model specifically. Levitt does point out that "migrants do not absorb all aspects of their new lives unselectively" (1998:943), but she does not adequately follow the implications of this for the 'take-up' of the potential content of social remittances. I do this by examining the creation stage more closely, focusing not only on exposure to genderrelated ideas and practices but also whether migrants aspire after or adopt them, or at least assign the differences they observe some importance or relevance to their lives. For the gender-related social remittance process to reach the full creation stage, this intermediary step needs to happen, and we cannot assume that it will.

\section{Creation: Awareness and Learning}

For migrant women and men to remit social knowledge about gender, they first have to acquire it. This requires that they find themselves in personal and social circumstances that permit them to notice or learn about gender-related differences between origin and destination society contexts. The degree to which they will do so depends a great deal on the extent and nature of contact with the host society (Hadi 1999, Levitt 1998), as well as, I argue, the reasons for their migration (Monzón 2009). I queried this stage of the process by asking both women and men what differences they had noticed between Canada and Guatemala, and, if necessary, asking directly about gender-related differences. Some had indeed made observations about women or gender 
relations in Canada. Female migrants $(\mathrm{n}=5)$ tended to note things they had observed during their trips to town: Canadian women dressed differently, seemed more friendly and sociable as strangers than women in Guatemala, were more free or independent both in their own affairs and in relations with men, and seemed well-educated and had their own businesses, and couples in Canada had fewer children than in Guatemala. To expand briefly, Esperanza said Canadian women seemed "más libres" (more free) with their "propio criterio" (own opinions or judgement); they seemed less likely than young women in Guatemala to mind what their parents said or thought; they would go out and walk around, "como si nada" (as if it was nothing). About family size, Brenda said, "the families are fewer [have fewer people]. There, sometimes they have only one child. Here, no, the majority of families are a lot [big]. We have six siblings... or there are families that have eight. That's a big difference." Although on the surface, Brenda's remarks relate to fertility, I see them as pertinent to the authority component of household gender relations in a context where patriarchal dynamics often include men's influence over women's sexuality and couples' child-bearing decisions (Bachrach Ehlers 1991, Metz 2001, Taylor, Moran-Taylor and Rodman Ruiz 2006).

Migrant men $(\mathrm{n}=3)$ had made a few observations regarding gender and work, both inside and outside the home, among whom Cristóbal had the most extensive comments:

"I notice that not everyone lives in families there like we do here. That's another difference. Yes, they respect [each other], but the woman works a lot. Cada quien, cada quien (each person) sees how to maintain [themselves, the family], I realize that the majority are like that. Once in a while, one sees the family united, sharing something to eat, or whatever. On the contrary, one goes up and down [alone] seeing to their work, both woman and man; they work equally. That's the difference in Canada."

A friend from Nicaragua had invited him and a couple of co-workers to dinner:

"When we arrived, he was making our dinner and everything. So even though 
he's from another country and has lived liked this [like we do here], there, no, and he has his wife and family. But we asked him about his wife and kids. [He says] 'My kids, who knows what they're doing. I'm here alone in the house, I just wait for my wife.' So cada quien (each to his/her own), she does her own work."

Cristóbal also remarked about women in supervisory roles in agricultural work, which generally would not be the case in Guatemala:

"La patrona - the daughter of the boss - she goes with us [to work], and she doesn't just stay there driving; she sometimes get bothered - quickly, quickly she does it. And she can do it, too. So, as I say, it's not just that she commands, she works a lot, too. That's why I say a woman there works the same as a man."

A second migrant, Eduardo, had been struck by both women and men working: "sometimes here women, in our environment, say that the man is the more responsable (responsible for the family), so only the man should work more, but I've realized that there in Canada, almost everyone works. They [the women] can work, too. We all have the same capacidad (ability)." Thirdly, Lucas' wife Yaneth, although she may have some of the details incorrect, described what her husband had learned:

"Sometimes he says that one learns a lot there, because here, one works here in the house, but doesn't have a salary, whereas there, he says his patrona (female boss) doesn't have any servant. She does everything, and the [male] boss pays her. So he learns a lot, and because of that, he says 'they've superado (gotten ahead) and us no because if you [the women] work, they don't pay you. And if another person comes to work a domestic worker), then yes. Because of that, they've gotten ahead and us no."”

Although Lucas' and Cristóbal's observations are significant, remarks about gender relations particular to the household were rare, for reasons that I will address just below. In interviews, I found I had to ask directly about these gender-related observations; much more freely offered and often cited were other types of differences migrants had noted between their home and Canadian society. Among these, they emphasized safety and security - such as vehicles' respect for pedestrians, being able to walk around without fear, and residents being more law-abiding - that infrastructure and 
housing looked dissimilar and everything was more orderly, and that housework or farm work was performed differently. A couple of the women, for instance, emphasized that they liked the appliances they had in their accommodations, and about the machinery on the job one man remarked "nunca se cansa" (it never gets tired).

Overall, the migrants did not or were not able to comment on gender-related differences between Canada and Guatemala to a significant extent. The reasons for this, I argue, stem from factors that influenced what they saw and what they noticed in Canada. Key among these were, first, their limited contact with Canadian society - a common circumstance among temporary foreign workers in Canada, especially those working in agriculture or in rural areas (e.g., Becerril 2007, Preibisch 2004b), second, the reasons for their migration, and third, their temporary and transnational existence in Canada.

On the first point, Levitt maintains that "more contact with the host society means greater exposure to its different features, more reflection on existing practices, and a greater potential for incorporating new routines" (1998:930-1). This contact depends on the social organization of their working and living conditions in countries of destination. Who do they work and live with? Who do they talk to? What "structures of opportunity" (Menjívar 1999:602) do their daily social interactions provide for learning about sociocultural differences between home and host societies? Menjívar (1999) cites the example of a Guatemalan woman in domestic employment in the urban United States, who, by working and living in the home of an American family, comes to realize that the man of the house contributes more to housework than men in Guatemala. Such a realization would generally not occur for migrant Guatemalans in my study, whose working and private lives provided relatively little contact with their host society in general, let alone inside Canadian households, with the exception of Cristóbal. 
A few sets of circumstances produce this reality. First, if we examine the idea suggested by Sullivan and supported by women's movement literature (Chant and Craske 2003 ) - that gender consciousness may develop from direct feminist-inspired teaching or awareness-raising, we run headlong into language barriers. None of the migrants in my study had much proficiency in English or French (this is not a requirement for their participation in the IOM project), commonly telling me that they had learned "a few words", including simple greetings and work-related terminology, such as crop names. They certainly were not capable of receiving information in English or French about gender-related issues, for instance. A few of the migrants in my study had accessed the services of migrant worker support centres, but none of them mentioned having participated in Spanish-language workshops that those centres offer. Given these language limitations, the avenues that I investigated for gender consciousness related more to observation of gender in their surroundings.

This line of investigation revealed significant limitations. Guatemalan labour migrants in Canada faced considerable social exclusion and mobility restrictions, findings consistent with other research demonstrating how migrant agricultural workers in Canada are 'unfree' and encounter significant limits on their interaction with Canadian society (e.g., Basok 1999, Hennebry 2012, Preibisch 2004a). First, the Guatemalans in my study lived in accommodations provided by their employers, on farm property, which tended to be quite far from towns or urban areas, a finding again consistent with other research (e.g., Fairey, Hanson, MacInnes et al. 2008, Trumper and Wong 2010). Second, the migrants' working conditions and demands largely precluded meaningful contact with Canadians. By and large, they worked predominantly alongside other Guatemalans and often Mexicans; rarely did they labour alongside Canadian workers, and if they did, their 
limited command of English or French made conversation virtually impossible. Furthermore, working 12-(or more) hour days six days of the week was common, leaving workers very little time for non-work activities (over and above what they needed to do daily just to reproduce their own labour power (Luxton 2006)), such as language lessons or participation in community inclusion efforts that other research has occasionally highlighted (Díaz Mendíburo 2011, Preibisch 2004a). Third, related to geographical isolation, restrictions on mobility and freedom of association further limited migrants' interaction with Canadians outside working hours, again in line with other research (e.g., Fairey et al. 2008); the use of bicycles did not arise in my study, and faced with high-cost private taxis as their only independent options, they were largely at the mercy of the farmers' provision of transportation once every week or two to a nearby town to do their shopping and banking. A couple of male workers - such as Cristóbal - had developed friendships (usually with other Latin Americans established in Canada) or participated in church outreach activities through which they had accessed private transportation and taken recreational trips from time to time, but these opportunities were exceptions.

Although these mobility limitations affected all workers, less prominent in the research (although cf Becerril 2007, Preibisch 2005, Preibisch and Encalada Grez 2010) is my contention that women faced more constraints than men on their mobility and freedom of association. ${ }^{143}$ I argue that this has contributed to there being no remarks from the women of the type that Cristóbal offered regarding household gender relations. To demonstrate the heightened restrictions on women, I profile here a farm in Quebec where four women from Vista Hermosa had worked: Manuela, Gloria, Laura, and Isabela.

\footnotetext{
${ }^{143}$ I further address issues of employers' direct restrictions on women's freedom of mobility and association in Canada in a recent publication (Hughes 2012).
} 
They offered similar accounts of restrictive working and living conditions. To begin, they were not allowed to receive visitors to the farm property. "The señora doesn't allow anyone to enter there with us," said Manuela. Laura explained that her brother worked on another farm and had come to visit her, but they had had to visit in the farm office. She said that if a car came onto the property, the bosses would be on it right away with some suspicion: "who is it?". Nor were the women allowed to freely leave the farm premises, for instance, to go to church or for a walk. Asked if she had gone to church in Canada, Gloria responded, "among the compañeras (co-workers), it was prohibited, along with having some kind of gathering inside the farm." Isabela described life as being "bien encerradas (really shut in)," and explained that her only contact with Canadians had really been with the boss and the capataces (supervisors) because "they don't let us go out to pasear (walk around). Here, we go to Chimaltenango or Tecpán, but there no...From the kitchen to the rooms, from the rooms to the kitchen." Manuela furthermore lamented: "one time someone visited us from the Guatemalan embassy and said we were invited to a mass in Montreal, but we never go, we never went, because the señora doesn't want [us to]. She laughed when the consulado (consular official) said that. They hardly let us leave."

Their only off-farm time was a half-day once a week when they would be transported to a nearby town to shop and bank: "they take us in a bus to do our shopping. Only to shop, nothing else, and then we come back," said Manuela. During that time, the women cited being closely monitored by an accompanying supervisor, and told not to speak with locals. They could exchange smiles or little greetings, but interaction was sometimes actively discouraged by farm staff, as Manuela explained:

"One time, a gentleman was talking with us, and he said, 'I'm from Venezuela, 
where are you from?' 'From Guatemala,' we said. 'Ah Guatemala, that's really far away! [he said]' When the señora (boss-lady) showed up, nos regañó la señora (she scolded us). 'Ay muchachas (oh girls),' she said, 'here one can't talk with the people.'...It scares us to talk to them because la señora nos regaña (the missus scolds us)."

Isabela concurred: "When we're there, we meet people like you, and they talk to us, but we can't talk with them [CH: Because of the language?]. No, because of the bosses, they don't want us to talk. They don't let us."

If a supervisor was not with the women during their time in town, an indirect surveillance prevailed, claimed Manuela:

"Even if she doesn't go [to town with us], it's very strict that farm. There, where the supertienda (supermarket) was, she says there are cameras if we talk, or I don't know. That's what she said. I don't see them, but she says, I know [what you're doing]. The next day, you're not going to work [if you talk]; that's what she said."

Not only possibly denied a day of work, but what the women conceived of as "bad behaviour' - both on the job and in town - were possible grounds for not being 'named' for subsequent seasons. As has been mentioned, migrants' return trips to Canada largely depended on positive work evaluations and employers requesting them by name for the following seasons. Manuela, Laura, and Isabela claimed that supervisors discouraged talking while working; Isabela said: "We can't talk, we only work, because those who talk, ya nunca se van (they never go anymore), ya nunca se van." As such, claimed Manuela, "it's better, no matter what one does, that we aguantamos (put up with it). If we don't listen to the señora, she tells us we won't have the opportunity next year." Overall, Laura said they felt very controlled.

A couple of the women considered some of their circumstances to amount to mistreatment, with Manuela claiming, "what they do to us isn't just." To some extent, though, the women spoke matter-of-factly about restrictive conditions, accepting them as 
rules that went along with working in Canada. Although she did not work on the farm in question, Brenda said, "there are rules everywhere one goes, and you have to respect that." The women also tended to apply a discourse of caring to these circumstances, interpreting their supervisor as a mother caring for them, in line with what Rollins (1987) describes as maternalism toward domestic workers. ${ }^{144}$ Isabela said that while treatment was strict and she felt controlled, she also felt well cared for: "Sometimes we say that we're a little mistreated, and sometimes we say, they're taking care of us like that." The no-visitors rule in particular was interpreted as protecting vulnerable women from unwanted intruders, and from 'problems' that arise when women and men inter-mingle while working in Canada.

This perspective had been foreshadowed by the representative from Quebec's human rights commission that I interviewed before leaving for Guatemala. She was aware of the alleged mobility, communication, and association issues at that particular farm. She acknowledged that some of the treatment might amount to violations of Quebec's Charter of Human Rights and Freedoms, and potentially important for consciousness-raising, during her visit to the farm, she had provided Spanish-language information about their rights in Quebec. However, she emphasized that the women were more concerned with what an employer would do in the case of pregnancy than with the restrictions on the farm. She also cited allegedly nefarious visitors to the farm that neither workers nor employers had welcomed - such as abusive boyfriends and or people involved in prostitution - although my study did not provide any corroborating evidence of such. She explained that particular employer's protection of female workers this way:

\footnotetext{
${ }^{144}$ Judith Rollins refers to maternalism, relating to women's supportive family roles, as "the motivation for and the belief system behind such apparently benevolent gestures that make them [workers] highly beneficial to the employer at the psychological expense of the domestic" - see Rollins (1987:157).
} 
"[Farm name] wants to protect the women, because they think that women are more easily abused than men, because of language, because of lack of knowledge about the customs in Quebec" (Fiset 2010).

I have mentioned the possibility for 'negative' social remittances and in some respects these circumstances would qualify. Instead of receiving messages that they have rights and can be automonous and in charge of their lives, some Guatemalan women have learned in Canada that they need to be protected in ways that restrict their freedoms. The representatives at the Guatemalan consulate in Montreal were particularly critical of employer practices of 'protecting' these workers. Although they had a number of concerns about how workers were being treated in Quebec, they emphasized the issues of mobility and communication among women: "they've been prohibited from leaving the farm outside working hours. They're reprimanded if they talk with anybody who isn't a worker on the farm... Here they live in a system of slavery" (Consular official 12010 ).

By highlighting restrictions on workers' mobility and association, especially women's, I do not intend to demonize the employers, nor suggest that generalizations can be extended to all farms that employ Guatemalan labour. Study participants who cited negative experiences were as numerous as those who claimed that their time in Canada had generally been problem-free, although it must be pointed out that respondents may have filtered what they said in the interests of keeping or re-gaining their employment in Canada. What this examination has demonstrated are the disempowering structural conditions of employment that Guatemalans encounter in Canada as Temporary Foreign Workers, which I further trace in a related publication that demonstrates key elements of employer control and the vulnerability under which Guatemalans work (Valarezo and Hughes 2013), and the particularly gendered character of those conditions, echoed to 
some extent elsewhere (Becerril 2007, Preibisch 2005, Preibisch and Encalada Grez 2010). ${ }^{145}$ More to the point with respect to this chapter, though, Guatemalan migrants have relatively little meaningful contact with Canadian society at large. To the extent that this limits the potential for gender-related social remittances, women's particular restrictions also serve to demonstrate that the gendered experiences of migration impact the gender-related outcomes of migration (Carling 2005), thus adding an extra layer to the 'gender and migration' relationship.

In Levitt's typology of patterns of interaction with the host society, Guatemalan migrants are "recipient observers" who cannot "actively explore their world because the structure of their lives [does] not bring them close enough to it" (1998:931). And consistent with my research, she argues that women are more likely than men to fall into this recipient observer category (Levitt 1998), in line with more general remarks that "migrant women are more likely to have their personal development thwarted" than men (Piper 2008a:1290). A comparative look at Levitt's research and my study demonstrates the importance of the conditions of migrants' lives and work in countries of destination when considering the potential for social remittances. Levitt (1996) documented changes in gender identity among some female emigrants from the Dominican Republic to the United States, but these emigrants lived fuller, less isolated lives and enjoyed more social citizenship opportunities than migrants in my study who faced significant linguistic, geographic, and restrictive circumstances while in Canada.

Although their isolation from broader Canadian life is the dominant factor in their limited gender-related observations at the first stage of the process, I contend that these

\footnotetext{
${ }^{145}$ Becerril notes that female labour migrants tend to be more isolated than men, and punished more harshly for certain sexual and social behaviours, e.g., if women get pregnant or have affairs with employers, they are laid off from the migrant labour program.
} 
shortages also stem from two further considerations: their transnational and temporary existence in Canada, and their reasons for migrating. Although I have established that migrants faced many restrictions on their interaction with the wider society, the transnational and temporary nature of their stay in Canada may have played a role in limiting their aspirations for such engagements. Although not often very integrated into their host communities, migrants did not lack social interactions of other types, especially with their co-workers, but also with their families at home, with whom, as I have outlined in previous chapters, they kept in close and regular contact. Their existence in Canada was a profoundly transnational one in which they maintained very close connections with their home communities and were under no presumption of staying in Canada permanently. Furthermore, migrants and their partners emphasized the migration period as a temporary phenomenon - as discussed in Chapter 7 in particular in relation to changes in non-migrating partners' lives - at the end of which migrants would return to Guatemala. Reflecting on both her affective transnational and temporary existence in Canada, Manuela commented: “It's just for a time. It's just a short time that one's there, but one never forgets one's family, one remembers them everyday."

Finally, I argue that individual motivations for migration constitute the third main factor putting limits on gender-related learning and awareness, and this point also brings in consideration of intersectionality, given that these reasons, seated in structural imperatives, are primarily economic. As mentioned in Chapter 7 in relation to economic remittances, Monzón (2009) maintains that the gender-related impacts of migration will depend, in part, on why people migrate. While migrants' circumstances in Canada limited what they were able to observe, I argue that the reasons for migration influenced what migrants noticed or focused on about their experiences. It is important to consider 
not only exposure to gender-related differences and learning opportunities, but also migrants' propensity to be aware of or take note of those aspects of their experiences.

Although other research suggests that motivations impelling the migration of Guatemalans - especially women - have diversified (MENAMIG 2006), the driving factor that emerged in my study, among both women and men, was economic need. Over and over again I heard that they had migrated "por necesidad" (out of necessity), in line word for word - with other studies on migrant agricultural workers in Canada (e.g., Becerril 2007). Reflecting that reason and exemplifying their primary focus on socioeconomic concerns at home, migrants emphasized paying most attention to the dynamics of their work in Canada, and underscored the money-earning aspects of their experiences. One of the more highly-educated women in the study - Brenda - said she would have been interested to know more about Canadian politics and society, but she felt that she had to maintain her focus on her work in Canada: "What interests us is the work, and what they pay us." She was among those respondents who justified their long working days because of the money: "For me at least, it's fine to work 12 or 14 hours because I earn more." Among the men, Mario emphasized that one does not go to Canada to pasear (walk around or have fun) but to work. Because of this focus on work and financial achievements, aside from the reproductive work required to sustain themselves and keeping in regular contact with family at home, most other concerns while in Canada had been secondary, if not distant or non-existent.

Certainly, particular aspects of their employment relations and the precariousness of their employment work in Canada accentuated a focus on their work (see Fudge and MacPhail 2009, Nakache and Kinoshita 2010, Valarezo and Hughes 2013). My main point here is that the economic reasons for migrating, and concomitant focus on earning 
money, influenced their goals as migrants and largely precluded consideration of nonmonetary ways in which their experiences in Canada influenced them. Although not framed in quite the same way, this assertion reflects Menjívar's point (1999b) that the potential for migration to facilitate the development of a gender or feminist consciousness (drawing on Shukla, 1997) is limited by the fact that migrant women in particular may feel injustices more related to class and race than gender. Certainly some of the discussion around nationality and ethnicity-based discrimination in Canada - as discussed in Chapter 6 - may apply here as well in limiting gender-related realizations. Migrants' conscious economic orientation, combined with and not analytically separable from, limited contact with Canadian society, contributed to restricted gender-related learning. The first step, then, toward realizing social remittances - that migrants learned about or took note of gender-related differences - was met only to a limited degree.

\section{Creation: Aspirations and Adoption}

Despite limited opportunities and other demands on their attention, it is certainly not the case that the migrants I spoke with had noticed nothing about gender or women in Canada. Drawing on some of the gendered differences they did take note of, I explore here a second requirement in the creation stage of social remittances process, one that I think Levitt acknowledges but under-examines: that migrants take up or aspire to the gender-related differences they notice, or at least consider them important or relevant to their lives. Taylor et al. argue that through Guatemalan women's employment in the United States and exposure to American culture, "their views about traditional gender roles, relations, and ideologies at home inevitably change" (2006:55). I question this inevitability. Compared to women in my study, those in the research by Taylor and 
colleagues had more exposure to host country culture, but I argue that there are more than issues of exposure at play. Countering assertions about inevitable change, and highlighting issues of reflexivity and desire, other research suggests that Guatemalan women do not necessarily aspire after or wish to emulate what they see or learn. Menjívar (1999), for instance, suggests that Guatemalan indigenous domestic workers did not want to incorporate into their lives the performance of housework by men that they saw in their American employers' homes.

There were mixed results about whether migrants in my study identified with or wished to see emulated in Guatemala the limited different gender-related ideas or behaviours they encountered in Canada. Yaneth suggested that her husband Lucas approved of women more often doing income-generating work in Canada because it had helped Canada "get ahead" and they could give a better life to their kids, while Eduardo spoke positively of women and men having the same capacidad (capacity or ability) to work. For her part, Brenda saw relevance to her own life of the smaller family sizes she had seen:

"there are more opportunities because the family is more... I don't know... we've thought about having just one child because there's more opportunity for just one. Me and my husband, we think about that. Here, we're seven siblings, but one passed away. If we were only three, we would have had more opportunities."

On the other hand, Cristóbal came across as judgmental and disapproving of both women and men being so independent and working in Canada because of negative effects on family unity: "Maybe for them, there's no time to share a big moment with their wife or kids, but here, we do that. Anyway, that's the way that they live there." And when I asked Esperanza how she felt about her observation that Canadian women were more libres (free), she said that it was just different, and she respected those women, but did 
not necessarily want things to be different for her in Guatemala, "ningún pensamiento asi (no thoughts like that)."

Trying to get at evidence of 'take-up' of gender-related differences from a different angle, I often asked whether migrants had returned any different in their thought or behaviour, a line of questioning that I reviewed in Chapter 6. As noted there, Eva said she returned feeling more independent from her mother's guidance, but this was an exception to responses overall, which focused on physical changes, like returning paler or having lost or gained weight. From yet another angle, I asked in many of the interviews what they liked about Canada, and occasionally followed up by asking which of those features they wished could be replicated in Guatemala, and no issues related to gender or women arose in response to these questions. Instead, again implicating concerns other than gender, they emphasized the money or the work and the purchasing power this afforded them. And bringing race- or ethnicity-based experiences to the fore, Delia said she liked the impression she got in Canada that everyone was treated equally there, which was not the case in Guatemala where she felt discrimination against Mayas and their traje (dress); Mayas are different from Ladinos, she said, but there, "todos somos iguales (we're all the same)."

Although I have noted a few exceptions, there was relatively little 'take-up' or aspirations toward gender-related differences that migrants may have noted in Canada. This limits the potential for gender-related social remittances because these largely rely on personal changes involving shifts in migrants' aspirations or positive incorporation of new elements into their thinking (Levitt 1998). The social remittances literature as well as certain theoretical insights illuminate what may have shaped migrants' propensities to accept or approve of less familiar ideas and practices. Migrants are not sponges who 
undergo changes in their selves through mere exposure to influences in their surroundings. In a continued thread of Menjívar's study of domestic workers, she explains that they did not aspire to the household gender relations they witnessed because they "may perceive their social worlds as too distant from those of their employers" (1999:620).

To explore this further, I draw on concepts of reflexivity from Margaret Archer and Bourdieu's habitus. Social actors engage in reflexivity, defined by Archer as "the regular exercise of the mental ability, shared by all normal people, to consider themselves in relation to their (social) context and vice versa" (2007:4). Archer describes this process as an "internal conversation" (2007: 2) that involves actors thinking about and strategizing in their lives, in response to changing experiences. Based on these reflexive activities in response to what they know or find out, social actors may or may not develop certain concerns or aspirations - in Archer's terms, the 'what do I want' - for their lives. If new "desiderata" (2007: 20) do emerge, not discounting potential constraints and obstructions on achieving them, actors may try to develop strategies or projects for how to go about getting what they want.

Along Archer's lines of thinking, if through their experiences in Canada, migrants learn and reflective positively about different ways to structure their household relations with their partners, they might make this a concern of theirs and in part through remitting these new ideas and aspirations, pursue a strategy to re-structure those household dynamics. Brenda seems to fit this model, in that she had reflected on the benefits of having fewer children and had made this a concern or project of sorts for her own future family. On the other hand, migrants may ignore or discount the gender-related differences they encounter or learn about, especially if these do not align with what they consider important or relevant to their lives. Certainly Cristóbal comes to mind here, 
having considered the negative repercussions for family unity and harmony of household gender models in Canada.

Considerations of reflexivity provide an important counter-weight to determinist accounts of practice for which Bourdieu has been criticized (Archer 2007). However, Bourdieu's habitus provides certain explanatory power here as well. In the quote above from Menjívar about domestic workers' social distance from their employers, the use of the word 'perceive' is key to illustrating the role habitus plays in actors' responses to new social influences, and indeed in reflexive processes themselves. As has been discussed, habitus as a set of dispositions endures with social actors as they cross into new social terrains, and shapes actors' perceptions of new or different phenomena they encounter there. In particular, habitus disposes individuals to "shape their aspirations according to concrete indices of the accessible and inaccessible, of what is and is not "for us"" (Bourdieu 1990:64). In a similar vein, Levitt brings in consideration of migrants' "interpretive frames", which largely stem from "how things are done at home" (1998:930). As a result of the influence of those frames, says Levitt, migrants' ideas or practices may continue unchallenged, or be blended with new ones, or be largely discarded in favour of new social relations and cultural patterns. Whether habitus or interpretive frames, these lenses on perception may shift in the context of migration (Levitt 1998), but habitus tends to endure, rooted as it is in home contexts - or fields where migrants have spent most of their lives.

Characteristic of those home contexts are certain patterns of household gender relations to which migrants are accustomed and that have become subjectified and embodied through processes of socialization. Reflecting this habitus-field relationship, Stolcke contends that the cultural values informing gender hierarchies affect "“subjective 
responses"" to other options for how to live (1991:98, quoted in Carey 2006:63), and Menjívar argues that the "local expression" of certain ideologies at home highly influence migrant women's perceptions (Menjívar 2006:89). Key among these ideologies for indigenous Guatemalan women are not only those related to gender but their intersections with ethnicity in particular, given the real and perceived differences between indigenous and Ladina women. Emilia shared an interesting remark when I asked her about the differences she had noted between Canada and Guatemala: "it's different because here, we're indigenous, and there, it's mostly Ladinas. That's the difference." This suggests that she mapped onto Canadian society the ethno-cultural relations pertinent in Guatemala. As a result, she likely would not identify with the Canadian women she saw, given that she conceptualized them as Ladina and she was an indigenous woman familiar with the repression and discrimination faced by Guatemala's indigenous population.

As for gender ideologies and relations in Vista Hermosa that would be reflected in the migrants' habitus or interpretive frames, we have seen the gender roles at play that largely prescribe caretaking responsibilities to women and economic provision and household authority responsibilities to men. And if we look at women's roles in particular from a perspective of complementarity, as Guatemala scholars have pointed out, Kaqchiquel women may approach their work with a sense of esteem, pride, and competence, with "dignified stoicism" (Fischer and Hendrickson 2003:11), partly due to the adverse conditions under which they do it, but also due to the sense of contribution to household and community well-being that they derive from it. As for young single women, such as Esperanza who had noted that Canadian women seemed more libres, it is expected in Vista Hermosa that they be under greater influence of or maintain a closer connection with their parents until an older age than might be the case in Canada. 
Esperanza explained that she did not have aspirations to be more independent like Canadian women because she felt and appreciated her parents' continued involvement in her life. Clara and Fiona, my research assistants, made similar comments. They highlighted a couple of instances in which they had seen a Guatemalan co-worker acting more 'liberally' than would be acceptable at home, but did not feel at all inclined to act similarly because of the continued, transnationally-felt influence of their parents on their behaviour. Clara said it was like she expected to be reprimanded for 'bad' conduct.

These gender practices and ideologies, subjectified in habitus and resistant to being dislodged, surely coloured migrant women's (and men's) perceptions of gender practices in Canada. In short, simply being in Canada, where people were different and behaved in some unfamiliar gendered ways, did not tend to lead Guatemalan migrant women and men to aspire after or emulate what they saw or learned about. Clearly, they were capable of reflecting on social differences and of imagining how their lives could be

different with respect to gender - thus demonstrating the utility of Archer's ideas - yet the transnational weight of socio-cultural influences conditioned such reflections and imagining, largely precluding them - exceptions like Brenda not withstanding - from assigning value or relevance to the potential content of gender-related social remittances.

\section{Transmission}

To this point, with the exception of my discussion of Brenda, I have not discussed findings regarding the actual remittance or transmission of gender-related learning; at the present juncture, the limited observations that migrants had made about gender in Canada constitute potential social remittances only. To what extent was the third step transmission - of the social remittances model met? If we focus first on the migrants that 
had accumulated gender-related knowledge in Canada, it was not always clear whether or how they had remitted that information to those in their household or community. In interviews, however, Brenda explicitly said she had spoken with her husband about smaller family sizes, Eduardo said he had talked with his kids about women and men having the same capacidad for paid work, and Lucas had obviously told his wife about women getting paid for work in Canada because she relayed this information to me. In the case of Cristóbal, if he had not previously spoken with his wife about his visit to his Nicaraguan friend's house or other experiences that his comments illuminated, his wife found out in the interview as she was present at the time!

Granted, gender-related learning emerged relatively infrequently in the interviews, and even less often, as we have seen, did migrants aspire to change their gendered behaviour after what they encountered. However, to the extent that there may have been more potential gender-related social remittances than my interviews captured, and that it is arguably as analytically useful to explain why a given process did not happen as it is to explicate why it did, I examine here the study findings in relation to two key avenues through which social remittances occur (Levitt 1998): telephone communication and return migration.

I asked in almost all interviews what migrants and their at-home partners, parents, and children's care-takers talked about in frequent phone conversations, and to a lesser extent about migrants' communication with others upon their return. As discussed in Chapter 6, all migrants talked regularly by phone with their family members in Guatemala - sometimes as often as daily - but generally were not remitting knowledge about gender-related differences between Canada and Guatemala. Instead their conversations, as recounted to me, centred on topics related to personal well-being, 
migrants' workdays in Canada, and family or household affairs - often financial, and with migrant mothers especially devoting a considerable portion of their time talking about children's welfare and parenting issues. Among topics related to Canada, migrants would talk about their work, the food, and, less frequently, their outings, and when I asked specifically about what differences between Canada and Guatemala they would discuss, they mentioned the weather, the land, and sunset times. The topics and trajectories of the conversations - specifically the absence of gender-related issues certainly in part reflect the findings discussed in the previous two sections about awareness and take-up of gender-related differences. However, the content of their conversations also reflects other factors. First, they had limited time - often a maximum of fifteen minutes - to talk to multiple family members. Second, also pragmatically, they often had to work out important matters, like how much money migrants should send or how to handle remittances. Third, important aspects of transnationalism and continued attachment to family and home emerged in that their conversations focused on topics easiest to relate to the person on the other end of the line or that provided connection across distance.

Although I do not have direct information from female-migrant households, the overall impression I received from wives of male migrants was that they had learned relatively little about Canada through conversations with the men. In a couple of exemplary quotes, when I asked Dominga what she had learned about Canada through her husband, she replied, "Nothing much. When we talk, when he calls, we just talk about our necesidades (needs). I'm not going to learn anything," and when asked if she had learned a bit about what Canada is like, Jimena responded: "No, not really because he doesn't tell me mayor cosa (anything major or much of anything), just stories about 
what he does for the work. That's all. He tells me, but I don't understand because who knows what he's talking about, I can't see what he's talking about." Hellman found this state of affairs among Mexican non-migrating women. Due to limited time to talk, and the phone often being passed to children to speak with migrant fathers, the women "had only a very approximate idea" of husbands' working and living conditions (2008:59).

I picked up on a lack of interest bordering on annoyance in Jimena's remarks, in "who knows what he's talking about." The attitudes expressed by a couple of at-home women toward their phone conversations suggested that, given their immobility and busy lives, at home, they may not have much cared to hear what Canada was like. Feelings of resentment came through strongly in Mónica's recounting of her husband's phone calls:

"He would mostly tell me that they'd gone out to pasear (walk around), to go see the sunset, on Father's Day, ah I don't remember where they went. But they went there. They went to some recreo (fun thing). Sometimes I got angry because I would think, him there, enjoying his free time, he goes out to pasear and everything, and me here with the nena (daughter), not finding what to do with her [when she was sick]. Sometimes better that I didn't even answer [the phone] (laughs a bit)."

In relation to the second possible avenue of social remittance transmission - by migrants upon their return - the few examples above of shared gender-related knowledge - by Eduardo, Lucas, Cristóbal, and Brenda - may well have happened when they returned. Notably, Brenda cited a desire for further cultural diffusion of information about the benefits of smaller family sizes. While she did not see herself as the person to do it, she wanted to see increased efforts in Guatemala in these regards:

"That's what we're missing here in Guatemala, that someone tells us that it's better to plan well (laughs). But sometimes, one gets scared... one needs courage to rise up [and talk] like that, and [say] 'I need to do this for people.' But if one doesn't have the courage... Sometimes I think that, but I don't have the courage to tell all that to people."

Most of my interviews, though, revealed little in the way of cultural diffusion of gender- 
related information through in-person communication or personal behaviour. Migrants generally did not think that they had behaved differently upon their return, and the fairly limited information I have suggests that conversations with household members and friends upon migrants' return were general, focusing on "how things went" and "what it was like there." An interesting potentiality arose with Esperanza, a single woman and the most highly-educated study participant. She worked post-migration as a trainer with a health-focused women's group and said she had chatted with her compañeras (coworkers) there about her experiences in Canada and shown them pictures. Although nothing specific about gender arose in relation to those interactions, she was among the women who had noticed gender-related differences in Canada, and a women's group may have been a receptive site for diffusion of that information. Overall, however, aside from the few examples cited above, there was little evidence to suggest that migrants had shared much information about gender relations in Canada upon return to Vista Hermosa.

\section{Impact and Insights from Bourdieu}

It was not within the temporal scope of my study to assess the impact of genderrelated social remittances that did occur. Will Brenda and her husband only have one child, as she claimed they had decided - "we had thought about two, but better just one"? Will Lucas' approval of women's paid work contribute to any propensity for his wife Yaneth to devote more time to income generation, if she has the opportunity? Will Eduardo's conversations with his kids about equal capacidad for work among women and men motivate investment in his daughter's education and carry forward to a more egalitarian household division of labour in her future household? Although women's economic independence is laudable, feminist political economy scholarship is rife with 
evidence that an increase in women's labour market participation is typically not matched by other strides toward household gender equality in the performance of housework; in short, men do not tend to greatly increase their contributions in these regards and women's 'double' if not 'triple' day is well established (e.g.,Luxton 2009, Shortall 2006), including in relation to Guatemalan households (e.g.,Blacklock 1996, Menjívar 2006). As suggested in Chapter 6, men's performance of housework in Canada edged some Vista Hermosa households in this direction. Although Eduardo was among those men who were helping their wives more, he tied this to his reproductive labour in Canada, not to his wife working outside the home in Guatemala. As regards remittances of greater gender consciousness, only time will reveal the impacts in Vista Hermosa. I briefly discuss here what may condition those outcomes.

Monzón (2009) argues that if and when women in particular arm themselves with new ideas and aspire to put them into practice in their households or communities, they can often drive processes of social change. In Bourdieu's terms, this is a transfer to the migrants' home field of cultural capital, and in Sullivan's words, of gender consciousness and relational resources. However, Monzón also suggests that "the effects of migration are linked closely with the gendered condition" (2009:226), which draws our attention to how local contexts shape the impacts of social remittances (Menjívar 1999), and theoretically to how fields condition the impacts of remittances. Certain literature on Guatemala suggests that it can be difficult to translate gender-related learning into social change, often because of the power and ideological dynamics of localities to which these new ideas flow. ${ }^{146}$ Citing men's resistance to the "rigid structure and social norms," in

\footnotetext{
${ }^{146}$ Levitt draws our attention to several factors that condition the transmission and impact of social remittances. Although not directly investigated in this study, the following factors in particular may be
} 
their research on Guatemalan migrants, Taylor et al. found that "it is a rare case where women translate their personal transformations into new relationships with men" (2006:58). Other research on remittances reminds us that resistance to change can come on the part of women as well (Vullnetari and King 2011) due to their attachment to their place in gender configurations. Not so much indicative of anyone's resistance explicitly, and more an acknowledgement of the reality of 'the way things are', when I asked Yaneth what she thought about women being paid for their work in Canada, she said she would like that because she could provide better financially for her kids, "but here it's this way, that's the custom here and one can't do that." Additionally, the 'shame culture' in Vista Hermosa that I discussed in Chapter 6 may also play a role in inhibiting, for instance, a greater propensity for women to work outside the home or have their own businesses - as Eduardo, Cristóbal, and Laura had observed in Canada - especially if men feel their household authority and symbolic capital would be threatened.

Bourdieu would describe these conditioning circumstances as the present and future "objectified potentialities" of the field (Bourdieu and Wacquant 1992:128), i.e., what it is possible to do given certain social relations and power dynamics of the setting in question, which include the valuation of certain forms of capital. The gender practices in Canada - represented by the 'foreign' capital that a few of the migrants brought to Vista Hermosa as ideas and knowledge - may not be valued in the community, with its fairly established and stratified gender roles. Furthermore, key to Bourdieu's theorization of structure and agency is the "ontological complicity" (McLeod 2005:14) of field and

influential in the case of Vista Hermosa: the gendered division of household and community power between the senders and receivers of social remittances (in the case of women's migration); and other types of messages, discourses, or practices related to gender that are circulating or being enacted in the community - for instance, in churches or women's groups - that would support or contradict the substance of potential social remittances. 
habitus, the internalization of these objective circumstances in a gender habitus shared by, in this case, women or men in Vista Hermosa, disposing them - although not forcing them - to maintain the status quo: "individual action is the product of habitus in response 'to objective potentialities immediately inscribed in the present' and the 'forthcoming reality characterizing the current setting"' (Bourdieu 1977:76, quoted in Rahman 1998:60). In the Vista Hermosa setting, changing household gender practices in line with the knowledge that a few of the migrants introduced may just not be very likely.

Facilitating impact on the other hand, research suggests that the greater the saturation of similar new messages or practices, both through migration as well as other sources of transnational diffusion - such as Western media and popular culture, as well as education - the greater the likelihood that social remittances will effect change in home communities (Hadi 1999, Levitt 1998). Although a micro and isolated illustration of migration-related saturation, Brenda's husband had also migrated to Canada (separately from her) where he too had made note of smaller family sizes, so the mutual reinforcement of that information between the two of them may have influenced their openness to limiting the number of children they planned to have. From a Bourdieusian theoretical perspective, the discussions and decisions between Brenda and her husband draw attention to the always circumscribed but existing possibility in Bourdieu's oeuvre for actors' conscious deliberation and intention, even though habitus always shapes that intentionality (Bourdieu and Wacquant 1992): practices can be "aimed at realizing the intention of subverting the established order" (Bourdieu 1990:146).

\section{Conclusion and Links to Gender Consciousness}

The second of two examinations of the flows through transnational fields, from 
destination to home contexts, this chapter has examined the potential for gender-related social remittances from Canada to Vista Hermosa. Following a 'stagist' model of the process, I have demonstrated that constraints - including outright restrictions on migrants and issues of more import to migrants and their partners - limited awareness and learning, aspiration and adoption, and transmission. At the first stage, I emphasized in particular the restrictions on migrants' contact with Canadian society, which women felt more acutely than men. Impacts of the limited social remittances that did occur - for Brenda and her husband, for example - remain to be seen, which makes the case for a longitudinal study of migration from Vista Hermosa or similar communities.

This examination of social flows of gender-related information was also intended to empirically investigate the gender ideology and gender consciousness dimensions of my theoretical framework. Specifically, I was querying gender-related social remittances for their potential to shift normative ideas and attitudes about gender in the household, including, as per Sullivan's theory, a general awareness of gender issues potentially leading to "a full consciousness of the rights associated with specific gender locations" (2004:208). What observations can be drawn in these regards from the foregoing analysis? Overall, outcomes along these lines were limited, and restrictions placed on women in particular could be seen themselves as regressive messages. Furthermore, the gender-related social remittances that I did identify were never articulated in normative or rights language, which would reflect shifts in ideology. Instead, migrants and their partners framed their remarks in terms of what women and men can do - such as Eduardo saying that women and men have the same capacidad for work, and Cristóbal remarking that female farm managers can be as effective as male ones - not what they should do or have the right to do. Furthermore participants tended to draw on material or economic 
reasons for their assertions. Lucas and Yaneth, for instance, claimed that if more women were paid for their work in Guatemala, they would be better off and could provide more financially for the kids, and Brenda and her husband saw a smaller family size in terms of economic provision, not in terms of Brenda's reproductive rights, and her normative responsibility to be a mother did not seem questioned. If we reach to Bourdieu's theory here again, however, these framings may be understandable as ways in which migrants and their partners converted - in their thinking processes, anyway - foreign cultural capital into local economic capital, which is always valued in their home field. Despite their rationale, these few senders and receivers of new gender-related information did seem to have started along the continuum of gender consciousness, which begins with a greater awareness of gender issues. So in that regard, migration to Canada has had potential positive effects on the ideological dimension of gender, if only for a few migrant households in my study. 


\section{Chapter 10: \\ Conclusion}

When I embarked on fieldwork in Guatemala, much of the literature in which I was versed suggested that I would find migration contributing to change in household gender relations of labour and power - perhaps not amounting to "gender-transformative odysseys" (Resurreccion and Van Khanh 2007:212) - but shifts nevertheless, toward greater household status for women. The strength of findings to the contrary - from no más voz and "you're not even going to do the paperwork", to "I respect my husband" and "he controls things from there" - quickly disrupted my preconceptions. Not all evidence pointed toward continuity, but I was particularly surprised by the depth of complexity in the scenarios - the nuances, contradictions, 'gatekeepers', and strong stakes in the status quo. I came to better appreciate that migration and related processes of transnationalism occur within webs and hierarchies of economic, ethnic, and cultural relations that eschew straightforward shifts or continuities in gender relations, and that actors' places within those webs strongly influence their chosen objects of struggle. To conclude this dissertation, I summarize the study findings, suggest areas for further research, seize one more reflexive opportunity, and emphasize an overall message.

I have examined ways in which temporary international migration contributes to shifts and continuities in household gender dynamics by drawing on a case study of migrant households in an indigenous Guatemalan village that have pursued better life chances through agricultural work in Canada. To my knowledge, it is the first study to investigate the implications for household gender relations in Guatemala of Guatemalans' migration to Canada, and it is certainly among the few studies in gender and migration scholarship to have pursued such an investigation through multiple theoretical entry 
points, thus emerging with a more comprehensive understanding of avenues of disruption and reproduction of gender's manifestations in the household. By highlighting more continuity and reinforcement than equality-enhancing transformations in these regards, I have offered a fairly critical assessment, in line with assertions that the gendered impacts of migration may take the form of restructured "gender asymmetries" (Tienda and Booth 1991:56). However, mine is also a study that helpfully illuminates where and how the status quo is largely maintained.

Key to its delineations, this dissertation has examined the influence of migration on individual, ideological, and institutional 'sites' of gender, as well as both production and power dimensions of household gender relations. Specifically, I examined the potential for: shifts in gendered dispositions, transfer of gender consciousness, and increases in women's household authority through earning and managing income. Among the tools garnered from Bourdieu's work, habitus figured prominently, but the relationships between field and capital also lent analytical power to exploring how the Guatemalan 'home' or return context conditioned the potential impacts of remittances.

What is discernible about the findings, in comparative terms? Most suggestive of shifts in household gender dynamics - specifically the division of labour - was the significant gender-crossing by non-migrants into migrants' areas of daily activity during migration periods, and greater involvement of some returning migrant men in 'women's' domestic work, in a few cases buoyed by a greater appreciation of it. Although I think it is too strong to say that men's reproductive work in Canada "contributes to improving the situation of women" (IOM 2006:11), this was a significant finding. Among non-migrants, however, their gender-crossing practices were limited to the migration period; in no case was there any discernible continuation after migrants returned. 
Evincing the least potential to disrupt patriarchal arrangements was the resource theory of power and economic remittances avenue of inquiry. No migrant woman had assumed more enduring household authority by virtue of contributing to the household economy, and only a few had discernible autonomous authority over the management of men's remittances. Furthermore, owing to a likely simultaneity of emasculation in Canada and reinforcement of their bread-winning identities, men's remittances contributed in a few cases to women intensifying their care for returned male migrants, and also implicating men's prescriptive primary role in income-generation, in a couple of instances, men had prohibited women's subsequent migration.

Landing in the middle as regards evidence and extent of shifts was the gender consciousness and social remittances theme. There was relatively little in the way of creation of greater gender-related awareness through migrants' experiences in Canada, but those few that aspired after what they learned had communicated that information to their families and partners. The example of Brenda and family size stood out, even though she framed the importance of fewer children in economic provision terms, not through a reproductive rights lens or by questioning her obligations to be a mother at all.

In addition to the three avenues of inquiry, a second comparative lens could weigh the overall results in male-migrant versus female-migrant households. Where do we discern the greater propensity for change or continuity in gender relations? While there was much more continuity than change overall, I contend that in this study, on balance, men's migration contributed to greater shifts than women's. In Guatemala during migration, illuminating the differences in degrees of threats to masculinity versus femininity (among other factors), women were more likely to assume migrant men's practices than vice versa. In Canada during migration, female migrants were arguably 
more isolated and surveilled than male migrants, making it less likely that women than men would notice gender-related differences in Canada that could have become social remittances. Although both sets of migrants were immersed in types and intensities of work to which they were not previously accustomed, the most discernible post-migration impact in those regards was migrant men's increased involvement in domestic work. And although it did not happen to a great degree, women seemed to increase their authority over household finances and decisions more as non-migrants than as migrants. Those few instances in which migrant men's return seemed to have intensified patriarchal dynamics are not insignificant, but on balance, in this study, there was greater potential in men's migration than in women's to shift household dynamics toward greater equality. Amid all the focus in scholarship and policy circles on the 'feminization of migration' and female migrants' experiences, this contention reminds us that examinations of gender in the context of migration are made stronger by consideration of both women and men.

Overall, the findings of this study find resonance in remarks that migration often has contradictory gendered results, and certainly amounts to neither a straightforward improvement nor erosion in women's status (Carling 2005). Both the reproduction and disruption of gender relations are processes of "starts and stops" in the context of migration, circumstances that present new alternatives for expressing gender but also may well foster "previous and new forms of male dominance and privilege" (Boehm 2008:28, 27). What my study particularly adds to other research is a greater focus on explanation. Through each facet of investigation, I have highlighted the circumstances and factors that contributed to the outcomes. I couched some of these in conceptual terms, such as Bourdieu's, but I importantly tried to be attentive to the specifics of locally-active ideologies and discourses, various forms of restrictions on migrants' and non-migrants' 
experiences, and examples of agency expressed not as resistance but as embedded in intersecting social locations that impelled strategic decision-making. In examining these influences, my study illuminated that resilient expressions of gender are powerful locally, but that they also operate in spaces that transcend borders.

Both the findings and limitations of this dissertation give rise to direction for further important research. I have contributed to re-balancing migration literature toward consideration of non-migrants' experiences but we need to explore these further. Particularly, what supports and even policy initiatives would be most beneficial to nonmigrating household members in Guatemala (cf Dunn and Gibb 2010), and what are the longer-term effects of migration, especially on female unremunerated and 'substitute carers' who are not migrants' partners (Munduate 2008)? My study highlighted that grandmothers' burdens increase and older daughters may discontinue school or work, leading to concerns about health and longer-term life chances.

Methodologically, future studies could provide further insights in three key ways. First, longitudinal analyses could measure impacts more closely over time and explore the cumulative impacts of successive migrations. In my study, the number of times migrants had been to Canada topped out at three for women and at six for men, and there was mixed evidence as to whether this temporal factor made a difference. For instance, Lucas, with six seasons in Canada, represented the clearest case of helping more with housework and appreciating his wife's reproductive labour, and Rafael in my host family, who had spent among the most cumulative months in Canada, had changed perceptibly in his attitude and behaviour with Miranda. However, Lourdes and Beatriz - wives of migrants who had gone five and six times respectively - emphasized their husbands' continued authority both during and after the migration periods. Future research could 
examine the temporal factor in more detail. ${ }^{147}$ Second, future research would also benefit from methodological approaches that include being with migrant workers in Canada and essentially accompanying them when they return, thus adding important further elements of participant observation and/or less reliance on study participants' memories of events. Third, as regards feminist methodologies, a feminist participatory action research approach would be beneficial (Morris and Muzychka 2002). An engagement with a women's organization in order to investigate the experiences of women in relation to migration, through the lenses of their concerns and goals, would further contribute to 'decolonizing' approaches in this issue domain.

Analytically, although I have incorporated elements of intersectionality in my understandings and analysis, other studies would do well to investigate more fully the inter-relationships in the context of migration among gender, ethno-cultural identifications, and socio-economic status. Future research could incorporate elements of comparison by including, for instance, households that differ ethno-culturally and socioeconomically, non-migrant households, and perhaps even migrant households in different countries. Also in an effort to better capture the influences that mediate migration and gender relationships, demographic characteristics such as age, marital status, marriage or life stage, religion, and education level could be integrated into analyses such as ones that have yielded insights into Guatemalan household gender relations in general (e.g., Becker, Fonseca-Becker and Schenck-Yglesias 2006, Carter 2004).

More conceptually, further possibilities arise for investigating the 'gender and

\footnotetext{
${ }^{147}$ As footnoted earlier, the enactment in 2011 of the ' 4 and 4 rule' for most Temporary Foreign Workers whereby after they have worked in Canada for a cumulative four years, they are ineligible to work again in Canada for a period of four years - may well have implications for shifts in gender relations to the extent that time spent in Canada makes a difference. This could set up a worthwhile future comparison with the gender-related impacts of the SAWP, participants of which are not subject to this rule, but are allowed in Canada for a maximum of 8 months at a time (compared to a 24-month maximum for Guatemalan TFWs).
} 
migration' relationship, and comprehending gender's complexities. My study has hinted at the ways that could be further explored in which expressions of gender themselves condition the social - in this case, gender-related - consequences of migration (Carling 2005, Monzón 2009, Piper 2008a), thus adding complexity to the angle adopted overall, i.e., how migration influences gender relations. For instance, the gender-based protectionism of female migrants in Canada resulted in, compared to men, greater restrictions on their mobility and as such less acquisition of potential gender-related social remittances. And seeing their economic contributions as 'helping' - informed by male-as-breadwinner ideologies - contributed to limiting the extent to which migrant women claimed more household authority. As regards the conceptualization of gender, although my study embarked on a tripartite investigation of gender, it did not integrate levels of the gender structure or look very much at how one instantiation influenced the other, as some research has sought to do conceptually or empirically (Deutsch 2007, Risman 1998).

To include one more reflexive moment, pursuing this topic and undertaking this research has taught me a great deal about my proclivities, assumptions and 'blinders'. I am a better feminist researcher for it, one more inclined toward intersectional and antioppressive understandings and approaches. The process of fieldwork was particularly challenging - simultaneously inspiring, frustrating, eye-opening, and humbling. There continue to be many differences between my social position and those of the women and men in my research, and - to focus on women in particular - many ways in which our 'standpoints' differ regarding our respective places and roles in the world (Fawcett and Hearn 2004). These differences have roots in our trajectories of life experience, based particularly in race-based and class-based relative privilege and disadvantage, and access 
to education and to feminist teachings. This study presents co-created knowledge and partial truths, and while I was attentive to participants' perspectives, I cannot claim to have always 'correctly' captured and represented them. Although my study cannot shorten the distances between our respective social locations, it certainly has enabled, for me, an engagement of our understandings, and has brought mine closer to theirs.

Meanwhile, Guatemalans' migration to Canada continues unabated, fuelled in Canada by demand among agricultural producers for dependable and 'flexible' labour, and in Guatemala both by circumstances that make sufficient income difficult to secure, and social networks that foster both desire and opportunity to migrate. No longer a pilot project, the avenue through which Guatemalans migrate to Canada seems well established, and the adage of 'permanently temporary' (Hennebry 2012) remains fitting. If asked what migration to Canada means to them, participants in my study would likely emphasize the economic benefits, which were often considerable and discernible, and undoubtedly important while Guatemalans wait and struggle for a better state of affairs in which international migration is a less needed livelihood strategy. However, what of the consequences of difficult separations of family members, of increased burdens on women who remain behind, of children being parented across the miles, and of restrictions on migrants' existence in Canada? Beyond its specific contributions regarding gender relations, what my study encourages, amid all the focus on supply, demand, and income, is an accompanying mindfulness of migration's non-material and social implications. 


\title{
Appendix A \\ Information Provided about the Study to Potential Participants
}

\section{Appendix A-1: Letter of information and invitation for organizations in Canada}

\author{
Research Project: Guatemalan Agricultural Workers in Canada \\ Christine Hughes, PhD Candidate in Sociology, Carleton University, Ottawa \\ LETTER OF INFORMATION \& INVITATION
}

My name is Christine Hughes, I am a PhD student in Sociology at Carleton University in Ottawa, Canada. I am undertaking a study about the impacts on Guatemalan migrants, their partners, and their households of temporary agricultural work in Canada. I am particularly interested in the impacts on household gender relations in Guatemala. This study is for the purposes of a PhD dissertation, and is under the supervision of Professor Daiva Stasiulis, in the Department of Sociology and Anthropology at Carleton.

I am contacting you about participating in this study, specifically an interview lasting between 30 and 60 minutes. It will involve questions about your involvement with Guatemalan migrants or related issues, your thoughts on the effects of this migration on individuals and households, and what could be done to improve migrants' lives and those of their families.

Academic study requires that I inform you about what your participation will involve, how your information will be used, your rights during the interview, and how the interview may affect you:

- The information you share will only be used for the purposes of this research. Your personal information will not be shared with anyone else, and will be kept secure by storing it in electronic format that is password-protected. Any of your personal information on paper will be kept locked away in a secure place.

- With your permission, this interview would be audio-recorded. These recordings will be in electronic format and will be password-protected for security purposes.

- I do not anticipate that there are any adverse risks to you by participating. You may be slightly inconvenienced or taken away from other work. You will be given the option of anonymity (not having your name or organization's name used in any documents that follow from this research). I hope that your participation will be beneficial to you. This interview may stimulate your thinking about issues raised, which could inform you in your work, and you may learn something new by asking questions of me. While I hope that these benefits will happen, they are not guaranteed to.

- Before beginning the interview, you would sign a form saying you are informed about the study and consent to participate. You may decline to answer any question and withdraw your participation at any time without consequence. If you do withdraw, you can decide whether or not any information you have provided to that point can be used for the study. If you do not permit the use of information provided to that point, any recordings would be destroyed. 
- You will not be provided any payment for your participation.

- If you so desire, the findings of this study will be shared with you. I will discuss with you a format that would be most relevant and useful to you.

This study has been reviewed and approved by the Carleton University Research Ethics Committee. If you have any concerns about the study or your involvement, you may contact Antonio Gualtieri, Chair of this committee, at the following coordinates:

Professor Antonio Gualtieri, Chair

Carleton University Research Ethics Committee

Office of Research Services

Carleton University

1125 Colonel By Drive

Ottawa, Ontario K1S 5B6, Canada

Tel: 613-520-2517; E-mail: ethics@carleton.ca

To contact me with questions or to indicate your interest in participating, here are my coordinates:

Christine Hughes

Department of Sociology \& Anthropology, Carleton University

1125 Colonel By Drive

Ottawa, Ontario K1S 5B6, Canada

Email: chughes@connect.carleton.ca; Phone: (613) 521-3856

To contact my supervisor about this study, please use these coordinates:

Dr. Daiva Stasiulis

Department of Sociology \& Anthropology, Carleton University

1125 Colonel By Drive

Ottawa, Ontario K1S 5B6, Canada

Email: dstasi@ccs.carleton.ca; Phone: (613) 520-2600, extension 1098

Signed:

Christine Hughes, Researcher 


\title{
Appendix A-2: Letter of information and invitation for organizations in Guatemala
}

\author{
[translated to Spanish] \\ Research Project: Guatemalan Agricultural Workers in Canada \\ Christine Hughes, PhD Candidate in Sociology, Carleton University, Ottawa \\ LETTER OF INFORMATION \& INVITATION
}

I, Christine Hughes, a doctoral candidate in Sociology at Carleton University in Ottawa, Canada am undertaking a study about the impacts on Guatemalan households and families of migration to Canada to work in agriculture. This study is for the purposes of my thesis. I am writing to provide you information about the study and to invite you to participate in an interview.

More specifically, I am proposing to study the experiences of migrants (women and men) who come to the province of Quebec in Canada and of the members of their families who stay in Guatemala. I would like to know if and how domestic roles and tasks change during and after migration periods owing to experiences, learning, and circulation of ideas and money.

I would very much appreciate being able to get your knowledge and experience in your area of specialization with respect to migration. I would like to arrange an interview with you that would take about an hour and would take place at your workplace or another location convenient for you. I would conduct the interview and it would be comprised of questions related to your knowledge and/or activities that your organization undertakes in relation to labour migrants' experiences, the types of changes that might occur for families and households, and the conditions that promote or discourage socio-cultural change.

I do not think there will be any adverse effects for you from participating in this interview. You could be inconvenienced by the time taken away from your work. If you perceive that this interview poses a risk to the security of your employment or your organization, I can give you the option of anonymity (that is to say, neither your name nor the name of your organization will appear in any written work that follows from my research). If you choose to participate anonymously, I would like you to know, however, that you could be indirectly identified given that other participants may not have asked for anonymity.

I anticipate that your participation in this study could benefit you and your organization. The interview could stimulate your ideas about the issues at hand, which could be applied to your work. As well, I will share the study results with you, and in a format that will be useful for you. Furthermore, I will advise you of publications that emerge from this study.

With respect to confidentiality, the information that you share with me will be used only for the purpose of contributing to the study, and your personal information will not be shared with anyone else.

Before the interview, on site, you will be asked to sign a form that indicates that you have been informed about the study and that you are willing to participate in it. You can decline to answer any questions asked of you, and terminate your participation at any time. If you decide to stop participating in the interview, you will be able to decide if any 
of the information you have given to that point can be used for the study.

With your consent, the interview will be audio-recorded and no one else but me will listen to the recording. If you decide to stop participating in the interview, and do not permit the use of the information you have provided to that point, the recording will be destroyed.

You will be not remunerated in any way for your participation.

I work under the supervision of Dr. Daiva Stasiulis in the Department of Sociology and Anthropology at Carleton University. This study has been reviewed and approved by the Research Ethics Committee at Carleton University. If you have any concerns about your participation in this study, you can contact Dr. Antonio Gualtieri, Chair of this committee, at the following coordinates:

Professor Antonio Gualtieri, Chair

Carleton University Research Ethics Committee

Office of Research Services

Carleton University

1125 Colonel By Drive

Ottawa, Ontario K1S 5B6, Canada

Tel: 613-520-2517

E-mail: ethics@carleton.ca

To contact me with questions or to indicate your interest in participating, please use the following coordinates:

Christine Hughes

Department of Sociology and Anthropology

Carleton University

1125 Colonel By Drive

Ottawa, Ontario K1S 5B6, Canada

Email: chughes@connect.carleton.ca

Phone: Canada: (613) 521-3856

Guatemala: 4967-9284

I very much look forward to your participation and I hope to hear from you soon.

Christine Hughes, Doctoral Candidate, Sociology, Carleton University 


\title{
Appendix A-3: Information shared with potential village participants at first visits
}

\section{[translated to Spanish]}

\section{Study: Migration to Canada and Impacts in the Home \\ Name: Cristina (Christine Hughes), Phone: 4967-9284}

Seeking your kind participation..

\begin{abstract}
About Christine and the Study - My name is Christine Hughes and I am from Canada. I am here in [village name] to do a study about migration to Canada. There, I am a student at a university, and to get my degree, I have to do a study and write a report. The study is about how migrants, their wives or husbands, and daily household life are impacted by migration.
\end{abstract}

I am looking for participation in the study, first and foremost, by people who are married or in common unions, whether they are migrants, or wives or husbands of migrants. [later added: I also invite the participation of single migrants].

I have the support of local authorities - they have welcomed me to the community and are interested in what I am proposing to study.

Also, this study has been approved by my university, which is Carleton University in the city of Ottawa.

What would your participation consist of? - I would like to do interviews in each of approximately 30 households, an interview with the migrant and another with his or her partner, if applicable, or one with both of you if that is easier for you. Each interview will take between 1 and 2 hours. I would like to talk about what your lives and experiences are like while the migrant is away, and when he or she returns home. Nothing delicate or private will be discussed.

Confidentiality and Anonymity - I know that the work migrants have in Canada is very important. So that participating in this study does not cause you any problems, I am going to do 2 important things:

- First, I will give you anonymity, that is to say, I will not identify you by name, either in my report or with anyone else.

- Second, I will treat everything people say with confidentiality, that is, I will not tell anyone else what you say in a way that would identify you. I am going to use the information for 2 purposes: first, for my study; and second, to inform other people that have interest in the study, for example, those who support migrants in Canada and people here in Guatemala like authorities and other leaders. But I will always inform them in a general way that does not identify anyone.

And my assistants have agreed to these measures as well, both during and after the study.

What will you get out of participating? How results will be used - I would like to emphasize that I do not come on the part of any organization, government or union. I am only a student. I cannot take names of people who want to migrate, nor do I have any control or influence over who goes to Canada. But I hope participating will help you in other ways. 
- First, it will help you to 'get things off your chest', to talk about your experiences, about what it's like for you, how you feel, what you think. There has not been much opportunity for that to this point in time.

- Second, through this study, we can identify the good and the bad about migration concerns, problems or challenges that people have about migrating or staying behind. And when we know more, it's possible to do something at the community level. For that to happen, I would like to make a little report for local authorities and women's groups.

- Third, I cannot make any promise to you to be able to change things - it's very important to tell you that - but, again in a very general manner that doesn't identify anyone, I would like to inform organizations that manage the program about the experiences of migrants and their families. It's very important that they know about that.

- And furthermore, I have with me information that can support or inform migrants about their rights in Canada, the Labour Code, where they can go for help, etc. I am well-informed about the program.

Would you like to participate? I hope so! It would be a big help to me, but more importantly for you and the community. If we haven't yet arranged an appointment, please phone me to do that.

If you are not sure, please talk with your husband or wife, and you can contact me with any doubts or questions. I repeat again that I will not identify you.

My phone number is: 4967-9284.

\section{Things to think about before we chat...}

If you are a migrant:

- What you think about your experiences there, what you like and don't like, how you feel

- What you learn there, what are the differences between life here and there

- How you feel when you come home, and are there any changes in what you do, how you act in relation to your wife or husband [or other household members]

If you stay behind:

- Are there any changes in your daily life while the other person is away - in what you do, the daily routine

- How you feel while the other person is away, are there changes in how you act

- When he or she returns, what household life is like - any changes or back to normal

- What have you learned from him or her about what Canada is like, and what you think about that

Thanks for your time! I look forward to chatting with you soon.

$\sim$ Christine 


\section{Appendix B \\ Consent Forms and Oral Consent Script}

\section{Appendix B-1: Consent form for organizational interviews - Canada and Guatemala}

[translated to Spanish as necessary]

\section{Research Project: Guatemalan Agricultural Workers in Canada Christine Hughes, PhD Candidate in Sociology, Carleton University, Ottawa CONSENT FORM FOR INTERVIEW}

You have been invited to participate in a dissertation project being done by Christine Hughes, a doctoral student in Sociology at Carleton University in Ottawa, Canada, about how participation in temporary labour migration from Guatemala to Canada affects migrants, their partners, and their households. It is necessary that you agree to participate in this study knowing what it is about and what your participation involves.

Your participation is completely voluntary, which means you do not have to participate, that you can stop participating at any time, or you can decline to answer certain questions.

It is expected that this interview will last approximately 60 minutes. The information you share will be combined with that of other people interviewed, as well as academic literature, for the writing of Christine's doctoral dissertation. The Letter of Information and Invitation you were provided gives more information about the project. A copy of this consent form will be left with you.

Do you have any questions about this form or about the study before proceeding?

\section{Consent}

I, the participant, have read the explanation about this study. I have been given the opportunity to discuss it and my questions have been answered to my satisfaction. I know that it is my decision whether or not to participate in this interview, and that I can stop participating at any time, even after I have given my consent to participate.

I consent to take part in this study.

Participant Name

Participant Signature

Interview Date:

Furthermore (please circle Yes or No):

I permit the audio-recording of this interview.

$\mathrm{Y} / \mathrm{N}$

I permit the use of direct quotes from me, provided I am not identified. $\quad \mathrm{Y} / \mathrm{N}$

I wish to remain anonymous (my name will not be used in any written work). $\quad \mathrm{Y} / \mathrm{N}$

My organization needs to remain anonymous.

$\mathrm{Y} / \mathrm{N}$

I would like to be informed of the findings of this study.

$\mathrm{Y} / \mathrm{N}$

Researcher Signature:

Date: 


\title{
Appendix B-2: Script for oral consent process and form left with participants
}

\section{[translated to Spanish]}

\author{
Study: Migration to Canada and Impacts in the Home \\ Student: "Cristi" (Christine Hughes), Phone number: 4967-9284 \\ INFORMATION AND CONSENT FORM
}

I have invited you to participate in a study that I am doing as a university student in Canada. I am doing my doctorate in Sociology at Carleton University in Ottawa.

The study is about what it's like to migrate to Canada and how it affects migrants and their families. I would like to use what you say for my study, so I am going to tell you a little about what we'll talk about and how I'll use the information.

I would like to chat for about an hour. I would like to know about you and your family, and the story of how you (or your partner) went to Canada. Then, what your life is like here, the experiences of you (or your partner) there, (what it was like for you here while your partner was gone), and what it was like when you (or your partner) came home.

Your participation is voluntary. You can refuse to answer any question and we can stop talking at any time. And you can ask me any questions.

I am not going to identify you or the name of your village in any report that I write. I am not going to tell anyone your name, and I will use what you say only for my study. And my two assistants have promised to not tell anyone your name or what you say.

I do not come from the government or the union or the IOM. I am just a student, I cannot take names nor do I have any control over who goes to Canada. But I hope that your participation brings you some benefit. For example:

- The opportunity to get things off your chest, to talk about your experiences, to complain a bit if you want to.

- I can give you information about the program and migrants' rights in Canada, and maybe help you with a form you have.

- As well, I am going to write reports so that local leaders and those who manage the migration program know more about the good and the bad of your experiences, but only in a general way that doesn't identify you.

I am going to leave this form with you. It has my name and phone number, and also the name of the person at my university who has approved my study.

Do you have any concerns or questions? Is there anything that is not clear? Do you agree to participate and to start our chat?

It would help me a lot if I could audio-record our conversation, so that I can listen to it later. It's because of the language, and so I don't have to take as many notes, so that I can concentrate on what you're saying. No one else is going to listen to the recording and I'll destroy it when I don't need it anymore. Can we use the recorder?

If you have any problem or concern about your participation in this study, you can contact Dr. Antonio Gualtieri who heads up the Research Ethics Committee at Carleton University, at: 001 (613) 520-2517, or by emailing ethics@,carleton.ca. 


\section{Appendix C \\ Confidentiality Script \& Agreement - Research Assistants}

I, Christine Hughes, have explained to you what confidentiality and anonymity mean, and that they are very important for a study because we do not want to cause any harm to participants. I have explained to you the measures that I will take, the best that I can, to keep the anonymity of participants and treat confidentially the information they provide.

You, as an assistant, understand your role in this study is to support me, the researcher, to arrange interviews and communicate better with participants.

Do you agree with the following, to the best of your ability, both during and after the study? Please respond yes or no to each question. If you wish, you can sign below. Your words are worth the same as your signature.

- To see things from the perspective of the participant, to understand what types of information should be considered private.

- To not share with anyone - not even your family - information about the study, including who was interviewed, or information that could identify people, or what participants have said. You mustn't gossip.

- To do any necessary translation in a complete and honest manner.

- If you take notes, to not write the participant's name, but only use codes that I (Christine) can give you.

- To not attempt to see any information that belongs to me (Christine), without my permission.

- To ask me (Christine) questions if you have any doubts about what you should do in a given situation. Don't feel bad about asking!

Assistant's name

Researcher's signature
Assistant's signature

Date 


\section{Appendix D \\ Interview Guides - Migrant Households}

Note: The following two interview guides were shortened and adapted for interviews in which both the migrant and partner were present.

In those joint interviews, where appropriate, I asked the partner if she agreed with what the migrant had said, for instance about changes during or after migration.

\section{Appendix D-1: Interview Guide for Migrants}

\section{Introduction}

We're going to start by chatting about you and your family, and then how it came to be that you started to migrate to Canada. Then, I would like to chat about what it's like in two places - here and there, and in three times, so:

- During migration periods: when you're there, what it's like there for you, and what it's like here for those who stay, and what you all do to keep contact and ties

- When you return home from Canada, what is it like?

- When you are here, what is normal life like?

\section{Questions}

\section{A. About the person and their family}

1. Can you tell me a little about your home - who lives here? (Are there relatives who visit or live here from time to time?)

2. Can you tell me a little about yourself? (Age; how long you've lived in the community; if you're married and for how long; if you are religious, and if so, what religion; how do you describe yourself? How do family and friends describe you?)

3. Work - Do you work or earn money when you're not in Canada, while you're here? If so, what is your work?

\section{B. Life at Home (while migrant is at home)}

\section{In the house}

4. Responsibilities - between you and your wife/husband, what are the responsibilities in the house or to sustain the family? Who does what? (Examples: farmwork, housework, care for animals, decision-making about expenses, well-being of children)

5. Or, what is a typical day for you?

6. Who is in charge in the house?

7. How do you feel about the work that each person does?

\section{Free Time and Other Activities}

8. (If not religious, skip) You told me that you are (religion). Can you tell me a little about your involvement with your church?

9. What other activities do you do during your free time?

10. Are you involved in any groups or organizations here? (Examples: cooperatives, women's groups, political parties, etc.)

11. Studies and training - For how many years did you go to school - primary or a few 
years of secondary? Since then have you done other studies or courses or training?

\section{About migrating to Canada}

12. When did you go to Canada for work for the first time?

13. How many times have you gone, which years, and for how long each time?

14. Can you tell me how it came to pass that you migrated for the first time, the history of how you decided to go?

a) Why were interested in going? (necessity, other reasons?)

b) How did you hear about the opportunity?

c) How did you make the decision to go? (Why didn't your partner go instead?)

d) How did you partner feel about the decision?

15. Do you know if you're going again this year?

16. Had you migrated or travelled to other places as a worker, whether in Guatemala or other countries apart from Canada?

17. Before going as a worker to Canada, had you been to Canada or the United States (or another country) just to visit?

\section{Experiences in Canada}

\section{Work}

18. In what parts of Canada have you worked? On which farms? On the same farm each time?

19. What crops did you work in? Before going, did you have experience here in working the same crops?

20. What did your work consist of there? Your responsibilities, work schedule, and pay? What was a normal workday like?

21. Who did you work with? For example, where were the other workers from, and the supervisors and bosses? How did it go with them? What would you chat about?

\section{Accommodations}

22. Can you tell me a bit about how you lived there - what it was like, who you lived with?

23. And to take care of yourselves, what did you do - for instance, with respect to domestic work (food, cleaning, laundry, shopping, etc.)?

a) For men - Was it the first time you had done some of these things? What did you think or feel about having to do them? Did you think about your wife?

b) For women - Were there differences between there and here with respect to how you did or do the housework?

24. About purchases and food - What were the differences between there and here? Were you able to find your food there? Did you eat Canadian food?

\section{Free Time}

25 . What did you do in your free time, when you weren't working?

26. How often would you go to town and what did you do there?

27. Who were your friends, or with whom did you like to chat or spend free time?

28 . When you weren't working, did you have contact with Canadians? 
29. (If not religious, go to next question) When you there, did you go to church? If so, to which one and how often? Why was that important to do? If you didn't go, why not? How did you maintain your faith or religiousness?

30. Did you get involved in any groups or organizations there (support groups, unions, others)?

\section{The Experience in General}

31. In general in Canada, what were the problems or challenges?

32. What were the benefits or advantages?

a) For you personally?

b) For your spouse, home, and family?

33. What did you like best about being in Canada?

34. What did you like least about being in Canada?

\section{Differences and Learning}

35. What types of things did you learn there?

a) How much French or English have you learned?

b) What did you note or learn about Canadians' way of life? How are those ways of life different than here?

c) What other things did you learn (for example, knowledge or techniques at work, knowledge about the culture, politics, or economy in Canada)?

36. What did you notice that's different about Canada? (Follow-up: Can you remember things that you would compare between Canada and Guatemala while you were there, that would get your attention? (examples: the culture, society, in your work and accommodations, language?)

a) What do you like better about Canada in relation to Guatemala?

b) What do you like better about Guatemala?

c) What did you notice about women and men?

37. Focusing on a particular difference, what did you think about that difference or comparison - did you think there was something better about Guatemala or about Canada?

38. Focusing on something you like better about Canada, did you think about changing that thing in Guatemala that you didn't like as much?

a) If so, what did you think about doing or want to do? Have you tried to do it? What happened?

b) If not, why not?

\section{Personal Behaviours}

39. Being Guatemalan - What are the things that for you are important to keep doing while you're there, even though Canadians maybe don't do them? Or, how did you keep being yourself there?

40. Was there a sense or way in which you felt Canadian when you were there?

41. Clothing - did you dress in a different way there?

a) Women - how did you dress, both while working and after work? How did you 
feel about dressing differently?

42. Do you think you behaved or acted differently there than here? Was there some change in your behaviour, attitude or personality?

43. When you had time to yourself there, or when you were just day-dreaming, what did you think about?

\section{Remittances}

44. How often did you send money?

45. How did you decide or who decided: how often to send, how much to send, and what to do with the money?

46. What you have done with that money? (Do you still have debts?)

\section{Communication}

47. How often did you talk to your people here - your spouse, kids, etc.?

48. Who did you talk with?

49. What did you talk about? What would you say to your spouse? (worries, requests, demands, etc.) (What were conversations like, did you argue?)

50. Did you note any family problems?

\section{E. Life at Home (while the migrant is in Canada)}

51. What do you think or worry about (in relation to life at home) when you're there in Canada?

52. Do you think daily life changes while you're there? If so, in what ways?

53. Your responsibilities here, who does or assumes them while you're not here? (examples: does your spouse do them, or other people?) Why is it that way?

54. How are decisions made about the home or family while you're there?

\section{F. The Return Home}

\section{General}

55. How would you know when you were going to return home? (examples: did you know from the beginning of your contract, or did they tell you close to the return date?)

56. How did you feel when they told you your return date?

57. How did you feel the day of your return?

58. How did your return home go?

a) How did you feel when you returned? What did you think?

b) Where there things that felt different or strange?

c) How did people treat you - your relatives or neighbours - differently or no?

59. How did your spouse see or treat you? Any differently or the same?

60 . Women - when you returned, did you have more voice or did you have more of an opinion about matters at home, like in decision-making?

\section{Personal Changes}

61. (in reference to changes in behaviour or thinking there, if there were any) Do you think the personal change there - in your behaviour, attitude, thinking, or values - has stuck with you here? 
a) If so, what do you think caused those changes in you?

b) If you don't think so, do your friends or family members say that you've changed as a person somehow? If so, do you agree with them?

62. (if they noted a personal change and have migrated more than once) Did you note those personal changes after the first time you went, or is it a cumulative difference, from having gone more than once? Do you think those changes become stronger each time?

\section{Changes or not in what they do}

63. (with reference to something learned or done there) Are there differences or changes in what you do or how you act here? (Examples: in your work, in your responsibilities in the home, e.g. the domestic work, decision-making, how you communicate with or relate to your kids or spouse?)

64. If so, what do you think has provoked those changes? What are the causes?

65. (if they noted a change in what they do or how they act, and have migrated more than once) Did you note those changes after the first time you went, or is it a cumulative difference, from having gone more than once? Do you think those changes become stronger each time?

66. (if they noted a change) How do you feel or what do you think about those changes? What do they mean to you? How does your spouse feel or think? (example: are those changes good or bad according to your culture or your faith?)

\section{Ties and Memories}

67. Are there things from Canada that you miss when you're here?

68. When you're here, are there ties with Canada that you keep? Examples: do you communicate or keep in touch with someone from there or a group there?

\section{G. Suggestions or Questions}

69. Are there other things you'd like to say that I haven't asked you about?

70. Do you have a problem or question in particular about your migration or work in Canada - for instance, forms or papers that you've received?

71. Can you think of any project or support that would provide help or benefits to migrants and their families?

72. How would you like me to use the information from this study?

73. Would you be interested in receiving a little report about the study's results? 


\section{Appendix D-2: Interview Guide for Non-migrating Partners}

\section{A. About individual and family}

1. (ask only if don't already know, haven't already interviewed the migrant) About the household, who lives there (how many kids), how long they've lived there?

2. About the individual - age, whether married, how long, where from, religion, ethnicity. How would you describe yourself? How would others describe you?

3. What level of education do you have?

\section{B. Home life when partner is home}

4. Can you tell me about a typical day around the house, while your partner is here?

5. Can you tell me about how household tasks are divided up when your partner is here who does what? (Lead if necessary by asking about specific tasks)

6. How are decisions made with respect to: financials, children, purchases, division of household tasks?

7. Who's the boss in your house, who's the most responsible?

C. Work

8. Do you work outside the home? If so, doing what, and for how long?

\section{Free Time}

9. Do you and/or other members of your household go to church or some kind of religious service? If so, what religion? And what is the nature and extent of your involvement? What do you think your religion has to say about what women and men should do?

10. Can you tell me about other ways you spend your free time? (Leads: media consumption, socializing, reading, studying, crafts, etc.)

11. Are you involved in any organizations or groups (e.g., women's groups)

E. Migration and life while migrant partner is away

12. Can you tell me the story of how it came to be that your partner migrated?

a) Why did he/she decide to go, and how did he/she hear about it?

b) How did you feel about the decision that your partner would go?

13. (if haven't talked with migrant yet) How many times has your partner been away, and for how long each time?

14. Is he/she going again this year?

15. What are some of the benefits to the household from your partner's migration? (Leads: financially, culturally, for you, for your children, new knowledge)

16. What are some of the disadvantages of your partner's migration?

\section{Changes around the house}

17. How do you feel when your partner is away?

18. How do things change around the household while he/she is away? How is it different?

19. Who does the tasks that he/she is responsible for when he/she isn't here? (Do you do them, or do other people step in?) 
20. Why do you think those tasks get arranged that way?

21. How do decisions get made?

22. Is there anything you like better when he/she is away?

\section{Changes to the person}

23. Do you think you change at all while he/she is away? (Leads: behaviour, way of talking/dressing, relating with others, identity/sense of self, self-esteem, more liberty)? If so, why? If not, why not?

\section{F. Transnational Practices}

\section{Remittances}

24. How often does your partner send money home?

25 . Who decides how the money will be spent? Why is it like that?

26. What has been done with that money?

\section{Communication}

27. How often do you communicate with your partner while he/she is away?

28. What do you talk about? Worries/concerns?

29. What does he/she tell you about Canada? What have you learned?

30. Is there anything that he/she tells you about Canada that you wish was the case here?

\section{G. The Return Home}

31. How did you feel the day your partner came back?

32. What is it like around the house when your partner first comes back from Canada?

33. How do you two get along - has anything changed? Does he/she treat you any differently?

34. Do you see any changes in your partner - behaviour, way of talking/ dressing/ thinking/ relating with you?

35. Do you sense any family problems?

36. What happens with respect to the household tasks and decision-making when he/she returns - do things go back to the way they are when he/she is here, or stay different somehow?

37. If things have changed, what do you attribute these changes to? Why have things changed?

38. (If the partner's migration has happened more than once): Have you noticed any changes over time in the things we've talked about - especially changes in you or your partner, how you divide up the household tasks during his/her migration and after, how you get along, etc.?

\section{H. Suggestions or Questions}

39. Do you have any questions for me?

40. Is there anything you want to talk about that I haven't asked about?

41. Could you think of any way that wives that don't migrate could be better supported? (Would you be interested in a support group of some kind?) 


\section{Appendix E \\ Interview Guide - Organizational Representatives}

Note: I created sets of questions for every organization I interviewed, tailored to their specific roles and the information I sought. Questions followed these general lines:

\section{General Opening Questions}

1. Can you tell me about your organization, e.g., mandate, brief history, activities, etc.

2. What is your role/position - what do you do, and how long have you worked here?

For migration-related organizations or those involved in Guatemalans' migration to Canada:

3. What is your organization's role or activities with respect to the migration of Guatemalans to work in Canada?

4. What other organizations do you work with in those capacities?

5. What goals does your organization have in relation to Guatemalans' migration, or what do you think the goals of the migration program/project are?

6. How well are those goals being met?

7. What assistance or services do you provide to migrants?

8. What information can you provide about Guatemalans' migration more generally why they go, where they go, problems they face, etc.

9. What are the benefits and disadvantages of migration?

10. What gender/nationality/ethnicity differences are pertinent to migrants' experiences?

11. What are some challenges for you in the work you do?

12. What changes would you like to see made - or are you planning to make - to the migration program/project?

\section{For women's group/organization representatives:}

13. What are the key challenges facing women in Guatemala or those you work with/for? 14. How would you describe daily life for women here? (especially indigenous and rural)

15. What terms can I use or should I avoid using in my research (e.g., feminism, gender)? How are these concepts understood?

16. Where do women and men get gender-related messages from?

17. What do you think the challenges are for non-migrating women?

\section{For research or academic representatives:}

18. What related research have you done, and what were your findings?

19. What were some challenges in doing that research?

20. What do you see as areas for further research?

21. What suggestions can you provide me for doing this research - approaches, methodologies, terminology?

\section{General Closing Questions:}

22. Do you have any questions for me?

23 . Is there any way I can help you or your organization through this research?

24. Can you recommend anyone else I should/could speak with?

25 . Would you like to receive the results of this study? In what format? 


\section{References}

Adams, Matthew. 2006. "Hybridizing Habitus and Reflexivity: Towards an Understanding of Contemporary Identity?" Sociology 40(3):511-28.

Adkins, Lisa. 2002. Revisions: Toward a Sociology of Gender and Sexuality in Late Modernity. Buckingham: Open University Press.

Adkins, Lisa. 2004a. "Introduction: Feminism, Bourdieu and After." Pp. 3-18 in Feminism after Bourdieu, edited by L. Adkins and B. Skeggs. Oxford: Blackwell Publishing.

Adkins, Lisa. 2004b. "Reflexivity: Freedom or Habit of Gender?” Pp. 191-210 in Feminism after Bourdieu, edited by L. Adkins and B. Skeggs. Oxford: Blackwell Publishing.

AFL. 2007. "Temporary Foreign Workers: Alberta's Disposable Workforce. The SixMonth Report of the AFL's Temporary Foreign Worker Advocate." Edmonton: The Alberta Federation of Labour (AFL).

Ahmed, Sara. 2003. "The Politics of Fear in the Making of Worlds." Qualitative Studies in Education 16(3):377-98.

Allen, Douglas E. and Paul F. Anderson. 1994. "Consumption and Social Stratification: Bourdieu's Distinction." Advances in Consumer Research 21:70-74.

Álvarez, Danilo, Carolina Palma and Manuel Tay. 2004. "Evaluation of Improved Stove Programs in Guatemala: Final Report of Project Case Studies." Washington: Energy Sector Management Assistance Program (ESMAP), The International Bank for Reconstruction and Development/The World Bank.

Alvarez, Sonia, Elisabeth Jay Friedman, Ericka Beckman, Maylei Blackwell, Norma Stoltz Chinchilla, Nathalie Lebon, Marysa Navarro and Marcela Ríos Tobar. 2002. "Encountering Latin American and Caribbean Feminisms." Signs 28(2):537-79.

Anderson, Kathryn. 2003. Weaving Relationships: Canada-Guatemala Solidarity. Waterloo: Wilfrid Laurier University Press.

Archer, Margaret. 2007. Making Our Way through the World: Human Reflexivity and Social Mobility. Cambridge: Cambridge University Press.

Arizpe, Lourdes and Josefina Aranda. 1993. "The 'Comparative Advantages' of Women's Disadvantages: Women Workers in the Strawberry Export Agribusiness in Mexico.” Pp. 486-99 in Gender in Cross-Cultural Perspective, edited by C. Brettell and C. Sargent. Englewood Cliffs, NJ: Prentice Hall.

Ashall, Wendy. 2004. "Masculine Domination: Investing in Gender?". Studies in Social and Political Thought (9-2):21-39. 
Asis, Maruja. 2005. "International Migration and the Prospects for Gender Equality." Paper presented at the International Migration and the Millennium Development Goals conference, May 11-12, 2005, Marrakech.

Asociación de Mujeres Nuestra Voz. N.d. "Nuestra Misión, Historia y Visión", Guatemala City: Asociación de Mujeres Nuestra Voz. Retrieved April 22, 2011 (http://nuestravoz.info/index_files/Page441.htm).

Atkinson, Paul, Amanda Coffey and Sara Delamont. 2003. Key Themes in Qualitative Research: Continuities and Change. New York: AltaMira Press.

Avila, Renata. 2013. "Indigenous Demand Investigation into Massacre at Nacahuil, Guatemala." IC Magazine. Retrieved: 22 November 2013 (http://intercontinentalcry.org/indigenous-demand-investigation-massacrenacahuil-guatemala/).

Bachrach Ehlers, Tracy. 1991. "Debunking Marianismo: Economic Vulnerability and Survival Strategies among Guatemalan Wives." Ethnology 30(1):1-16.

Banco de Guatemala. 2013. "Guatemala: Ingreso de Divisas por Remesas Familiares 2008 - 2013", Ciudad de Guatemala: Banco de Guatemala. Retrieved 22 November, 2013 (http://www.banguat.gob.gt/inc/ver.asp?id=/estaeco/remesas/remfam2013.htm\&e $=104821$ ).

Barrón, Antonieta. 1999. "Mexican Women on the Move: Migrant Workers in Mexico and Canada." Pp. 113-26 in Women Working the NAFTA Food Chain: Women, Food and Globalization, edited by B. McAuley. Toronto: Second Story Books.

Basok, Tanya. 1999. "Free to Be Unfree: The Case of Mexican Migrants in Canada." Labour, Capital and Society 32(2):192-221.

Bauder, Harold. 2004. "Habitus, Rules of the Labour Market and Employment Strategies of Immigrants in Vancouver, Canada." Social and Cultural Geography 6:81-97.

Becerril, Ofelia. 2007. "Transnational Work and the Gendered Politics of Labour: A Study of Male and Female Mexican Migrant Farm Workers in Canada." Pp. 15672 in Organizing the Transnational: Labour, Politics, and Social Change, edited by L. Goldring and S. Krishnamurti. Vancouver: University of British Columbia Press.

Becker, Stan, Fannie Fonseca-Becker and Catherine Schenck-Yglesias. 2006. "Husbands' and Wives' Reports of Women's Decision-Making Power in Western Guatemala and Their Effects on Preventive Health Behaviors." Social Science \& Medicine 62(9):2313-26.

Behar, Ruth. 1996. The Vulnerable Observer: Anthropology That Breaks Your Heart. Boston: Beacon Press. 
Bernard, H. Russell and Gery W. Ryan. 2010. Analyzing Qualitative Data: Systematic Approaches. Los Angeles: Sage.

Bernhard, Judith, Patricia Landolt and Luin Goldring. 2005. "Transnational, Multi-Local Motherhood: Experiences of Separation and Reunification among Latin American Families in Canada." Early Childhood Education Publications and Research. Paper 6. Toronto: York University.

Bevan, Anne-Claire. 2013. "As Trade Unionist Attacks Continue, Guatemala Faces Tough Decisions." Ticotimes.net. Retrieved: 17 October 2013 (http://www.ticotimes.net/layout/set/print/More-news/News-Briefs/As-tradeunionist-attacks-continue-Guatemala-faces-tough-decisions_Thursday-October17-2013).

Bezanson, Kate and Meg Luxton, eds. 2006. Social Reproduction: Feminist Political Economy Challenges Neo-Liberalism. Montreal and Kingston: McGill-Queen's University Press.

Bjerén, Gunilla. 1997. “Gender and Reproduction.” Pp. 219-46 in International Migration, Immobility and Development, edited by T. Hammar, G. Brochmann, K. Tamas and T. Faist. Oxford: Berg.

Blacklock, Cathy. 1996. "Contesting Democratization in Guatemala: Women's Political Organizations and Human Rights." PhD dissertation, Political Science, Carleton University, Ottawa.

Bock, Bettina. 2006. "Rural and Gender Identity: An Overview." Pp. 279-87 in Rural Gender Relations: Issues and Case Studies, edited by B. Bock and S. Shortall. Wallingford, UK; Cambridge, MA: CABI Publishing.

Boehm, Deborah A. 2008. “'Now I Am a Man and a Woman!' Gendered Moves and Migrations in a Transnational Mexican Community." Latin American Perspectives 35(1):16-30.

Bourdieu, Pierre. 1979. Algeria 1960. Cambridge: Cambridge University Press.

Bourdieu, Pierre. 1984. Distinction: A Social Critique of the Judgement of Taste. Boston: Harvard University Press.

Bourdieu, Pierre. 1986. "The Forms of Capital." Pp. 241-60 in Handbook of Theory and Research for the Sociology of Education, edited by J. Richardson. Westport: Greenwood Press.

Bourdieu, Pierre. 1990. The Logic of Practice. Cambridge: Polity Press.

Bourdieu, Pierre and Loic Wacquant. 1992. An Invitation to Reflexive Sociology. Chicago: University of Chicago Press. 
Bourdieu, Pierre. 2001. Masculine Domination. Stanford: Stanford University Press.

Bourdieu, Pierre. 2002. "Habitus." Pp. 27-34 in Habitus: A Sense of Place, edited by J. Hillier and E. Rooksby. Aldershot: Ashgate.

Boyd, Monica and Elizabeth Grieco. 2003. "Women and Migration: Incorporating Gender into International Migration Theory." Migration Fundamentals. Retrieved: 14 November 2013 (http://www.migrationinformation.org/feature/display.cfm?ID=106).

Brandth, Berit. 2006. "Embodying Family Farm Work." Pp. 329-44 in Rural Gender Relations: Issues and Case Studies, edited by B. Bock and S. Shortall. Wallingford, UK; Cambridge, MA: CABI Publishing.

Brem, Maxwell. 2006. "Migrant Workers in Canada: A Review of the Seasonal Agricultural Workers Program (Policy Brief)." Ottawa: North-South Institute.

Brickell, Katherine and Ayona Datta, eds. 2011a. Translocal Geographies: Spaces, Places, Connections. Burlington, VT: Ashgate.

Brickell, Katherine and Ayona Datta. 2011b. "Introduction: Translocal Geographies." Pp. 3-20 in Translocal Geographies: Spaces, Places, Connections, edited by K. Brickell and A. Datta. Burlington, VT: Ashgate.

Broughton, Chad. 2008. "Migration as Engendered Practice: Mexican Men, Masculinity, and Northward Migration." Gender \& Society 22(5):568-89.

Brusco, Elizabeth. 1995. The Reformation of Machismo: Evangelical Conversion and Gender in Colombia. Austin: University of Texas Press.

Bryan, Catherine. 2011. "Ambivalent Transnationalism: Class, Gender, and Nova Scotia Nominees (Metropolis Working Paper - No. 36-2011).” Halifax, NS: Dalhousie University.

Bryman, Alan and Robert Burgess. 1994. "Developments in Qualitative Data Analysis: An Introduction." Pp. 1-17 in Analyzing Qualitative Data, edited by A. Bryman and R. Burgess. London: Routledge.

Burmesedays. 2010. "Map of Guatemala for Use on Wikivoyage, English Version." Wikimedia Commons. Retrieved 14 January 2014 (http://commons.wikimedia.org/wiki/File\%3AGuatemala_Regions_map.png).

Caballeros, Alvaro. 2009. "Migración Internacional en Tiempos de Crisis: Balance del Año 2009." Voz Itinerante: Boletín Electrónico de Información y Analisis $8(88): 1-11$.

Canadian Bar Association. 2006. "Low Skilled Worker Pilot Project." Ottawa: National Citizenship and Immigration Law Section, Canadian Bar Association. 
Carey, David. 2008a. “'Oficios de su Raza y Sexo' (Occupations Appropriate to Her Race and Sex): Mayan Women and Expanding Gender Identities in TwentiethCentury Guatemala." Journal of Women's History 20(1):114-48.

Carey, David. 2008b. “'Hard Working, Orderly Little Women': Mayan Vendors and Marketplace Struggles in Early-Twentieth-Century Guatemala." Ethnohistory 55(4):579-607.

Carey, David and M. Gabriela Torres. 2010. "Precursors to Femicide. Guatemalan Women in a Vortex of Violence." Latin American Research Review 45(3):142-64.

Carey, David Jr. 2006. Engendering Mayan History: Kaqchikel Women as Agents and Conduits of the Past. New York: Routledge.

Carling, Jørgen. 2005. "Gender Dimensions of International Migration (Global Migration Perspectives Research Paper No. 35)." Geneva: Global Commission on International Migration (GCIM).

Carrière, Denis. 2010. Immigration Program Manager, Embassy of Canada. Interview by author, Guatemala City, February 17.

Carter, Marion. 2004. "Gender and Community Context: An Analysis of Husbands and Household Authority in Rural Guatemala." Sociological Forum 19(4):633-52.

Cervone, Emma. 2007. "Building Engagement: Ethnography and Indigenous Communities Today." Transforming Anthropology 15(2):97-110.

Chant, Sylvia and Nikki Craske. 2003. Gender in Latin America. New Brunswick, New Jersey: Rutgers University Press.

Chodos, Howie and Bruce Curtis. 2002. "Pierre Bourdieu's Masculine Domination: A Critique." Canadian Review of Sociology 39(4):397-412.

CIC. 2013. "Facts and Figures 2012 - Immigration Overview: Permanent and Temporary Residents", Ottawa: Citizenship and Immigration Canada (CIC), Government of Canada. Retrieved November 21, 2013 (http://www.cic.gc.ca/english/resources/statistics/facts2012/index.asp).

CIC. 2011. "Canada - Total Entries of Temporary Foreign Workers under Low Skill Pilot Program from Guatemala as Country of Citizenship by Sex and NOC Codes, 2003-2010 [Dataset]." Ottawa: Citizenship and Immigration Canada (CIC).

CIC. 2003. "Facts and Figures 2003 - Immigration Overview: Permanent and Temporary Residents", Ottawa: Citizenship and Immigration Canada (CIC), Government of Canada. Retrieved March 12, 2014 (http://www.collectionscanada.gc.ca/webarchives/20060205133249/http://www.ci c.gc.ca/english/pub/facts2003/index.html) 
Cockburn, Cynthia. 2001. "The Gendered Dynamics of Armed Conflict and Political Violence." Pp. 13-29 in Victims, Perpetrators or Actors? Gender, Armed Conflict and Political Violence, edited by C. Moser and F. Clark. London: Zed Books.

Coffey, Amanda and Paul Atkinson. 1996. Making Sense of Qualitative Data: Complementary Research Strategies. Thousand Oaks, CA: Sage.

Coffey, Amanda. 1999. The Ethnographic Self: Fieldwork and the Representation of Identity. London: Sage.

Congreso de la República de Guatemala. 2008. "Código Civil Guatemalteco, Decreto Ley 106.” Guatemala City: República de Guatemala.

Connell, R. W. 2002. Gender. Cambridge, UK: Polity.

Connell, Raewyn. 1987. Gender and Power: Society, the Person, and Sexual Politics. Cambridge: Polity Press.

Consular official 1. 2010. Consular representative, Consulate of Guatemala in Canada. Interview by author, Montreal, January 20.

Consular official 2. 2010. Consular representative, Consulate of Guatemala in Canada. Interview by author, Montreal, January 20.

Cook, Nancy, ed. 2007. Gender Relations in Global Perspective: Essential Readings. Toronto: Canadian Scholars Press.

Cordero, Amanda. 2010. Dirección de Asuntos Migratorios, Ministerio de Relaciones Exteriores. Interview by author, Guatemala City, May 4.

Cott, Nancy. 2009. "Domesticity." Pp. 111-17 in Family Patterns, Gender Relations, edited by M. Luxton and B. Fox. Don Mills, Ontario: Oxford University Press.

Crang, Mike and Nigel Thrift. 2000. "Introduction.” Pp. 1-30 in Thinking Space, edited by M. Crang and N. Thrift. London: Routledge.

Crompton, Rosemary. 2006. Employment and the Family. New York: Cambridge University Press.

Cumes Jochola, Victoria. 2010. Coordinadora General, Asociación de Mujeres Nuestra Voz. Interview by author, Guatemala City, February 17.

Datta, Kavita and Cathy Mcllwaine. 2000. “"Empowered Leaders'? Perspectives on Women Heading Households in Latin America and Southern Africa." Gender and Development 8(3):40-49.

Davis, Kathy. 2002. "Feminist Body/Politics as World Traveller." The European Journal of Women's Studies 9(3):223-47. 
de Haan, Arjan and Shanin Yaqub. 2008. "Migration and Poverty: Linkages, Knowledge Gaps and Policy Implications [Revised Paper]." Paper presented at the Social Policy and Migration in Developing Countries conference, November 22-23, 2007, Stockholm. Retrieved Oct 2013 (http://www.unicef.org/socialpolicy/files/Migration_and_Poverty_Linkages_Kno wledge_and_Policy_Implications.pdf).

de los Reyes, Paulina. 2001. "Continuity and Change in Patterns of Female Migration in Latin America." Pp. 275-89 in Women, Gender and Labour Migration: Historical and Global Perspectives, edited by P. Sharpe. New York: Routledge.

de Munck, Victor and Elisa Sobo, eds. 1998. Using Methods in the Field: A Practical Introduction and Casebook. London: Sage.

Denzin, Norman. 1998. "The Art and Politics of Interpretation.” Pp. 313-44 in Collecting and Interpreting Qualitative Materials, edited by N. Denzin and Y. Lincoln. Thousand Oaks, CA: Sage.

Deutsch, Francine. 2007. “Undoing Gender.” Gender \& Society 21(1):107-27.

Díaz Mendíburo, Aaraón [Director]. 2011. Matices: “Temporary” Migration in Canada. DVD.

Doezema, Jo. 2001. 'Ouch! Western Feminists' 'Wounded Attachment' to the 'Third World Prostitute'." Feminist Review 67:16-38.

Doucet, Andrea. 2006. Do Men Mother?: Fathering, Care, and Domestic Responsibility. Toronto: University of Toronto Press.

Doucet, Andrea and Natasha Mauthner. 2006. "Feminist Methodologies and Epistemology.” Pp. 36-42 in Handbook of 21st Century Sociology, edited by C. Bryant and D. Peck. Thousand Oaks, CA: Sage.

Doucet, Andrea. 2009a. "Dad and Baby in the First Year: Gendered Responsibilities and Embodiment." The Annals of the American Academy of Political and Social Science 624(1):78-98.

Doucet, Andrea. 2009b. “Gender Equality and Gender Differences: Parenting, Habitus and Embodiment (the 2008 Porter Lecture)." Canadian Review of Sociology 46(2):103-22.

Dunn, Leith and Heather Gibb. 2010. "Gender, Migration and Crisis: Jamaican Female Migrants in Canada." Pp. 53-70 in A Global Crisis of Development: Responses and Responsibilities. Canadian Development Report 2010, edited by P. Heidrich. Ottawa: North-South Institute. 
Employment and Social Development Canada. 2013a. "Stream for Lower-Skilled Occupations", Ottawa: Government of Canada. Retrieved January 18, 2014 (http://www.esdc.gc.ca/eng/jobs/foreign_workers/lower_skilled/index.shtml).

Employment and Social Development Canada. 2013b. "Hiring Agricultural Workers", Ottawa: Government of Canada. Retrieved November 21, 2013 (http://www.esdc.gc.ca/eng/jobs/foreign_workers/agriculture/index.shtml).

Erel, Umut. 2010. "Migrating Cultural Capital: Bourdieu in Migration Studies." Sociology 44(4):742-660.

Ezzy, Douglas. 2002. Qualitative Analysis: Practice and Innovation. London: Routledge.

Fairey, David, Christina Hanson, Glen MacInnes, Arlene Tigar McLaren, Gerardo Otero, Kerry Preibisch and Mark Thompson. 2008. "Cultivating Farmworker Rights: Ending the Exploitation of Immigrant and Migrant Farmworkers in BC." Vancouver: Canadian Centre for Policy Alternatives.

Faist, Thomas. 1998. "Transnational Social Spaces out of International Migration: Evolution, Significance and Future Prospects." European Journal of Sociology 39(2):213-47.

Faist, Thomas. 2004. "The Border-Crossing Expansion of Social Space: Concepts, Questions and Topics." Pp. 1-36 in Transnational Social Spaces: Agents, Networks, and Institutions, edited by E. Ozveren and T. Faist. Ashgate: Burlington, VT.

Faraday, Fay. 2012. "Made in Canada: How the Law Constructs Migrant Workers' Insecurity." Toronto: Metcalf Foundation.

Fawcett, Barbara and Jeff Hearn. 2004. "Researching Others: Epistemology, Experience, Standpoints and Participation." International Journal of Social Research Methodology 7(3):201-18.

Field Belenky, Mary, Blythe McVicker Linchy, Nancy Rule Goldberger and Jill Mattuck Tarule. 1986. Women's Ways of Knowing: The Development of Self, Voice, and Mind. New York: Basic Books.

Field, Delbert. 2010. Chief of Mission, IOM-Guatemala. Interview by author, Guatemala City, April 26.

Fife, Wayne. 2005. Doing Fieldwork: Ethnographic Methods for Research in Developing Countries and Beyond. New York: Palgrave Macmillan.

Fischer, Edward and Carol Hendrickson. 2003. Tecpán Guatemala: A Modern Maya Town in Global and Local Context. Cambridge, MA: Westview. 
Fischer, Edward and Sarah Hamilton. 2005. "Maya Farmers and Export Agriculture in Highland Guatemala: Implications for Development Labour Relations." Latin American Perspectives 32(5):33-58.

Fischer, Edward and Peter Benson. 2006. Broccoli and Desire: Global Connections and Maya Struggles in Postwar Guatemala. Stanford: Stanford University Press.

Fiset, Carole. 2010. Agent d'education et de cooperation, Commission des droits de la personne et des droits de la jeunesse. Interview by author, Montreal, January 21.

Fish, Jennifer Natalie. 2006. Domestic Democracy: At Home in South Africa. New York: Routledge.

Flecker, Karl. 2010. “Canada’s Temporary Foreign Worker Program (TFWP): Model Program - or Mistake?" Ottawa: Canadian Labour Congress.

Flyvbjerg, Bent. 2001. Making Social Science Matter: Why Social Inquiry Fails and How It Can Succeed Again. Translated by S. Sampson. Cambridge: Cambridge University Press.

Fouron, George and Nina Glick Schiller. 2001. "All in the Family: Gender, Transnational Migration and the Nation-State." Identities 7:539-82.

Franck, Anja and Andrea Spehar. 2010. "Women's Labour Migration in the Context of Globalisation." Brussels: Women in Development Europe (WIDE).

Friedmann, John. 2002. "Placemaking as Project? Habitus and Migration in Transnational Cities." Pp. 299-316 in Habitus: A Sense of Place, edited by J. Hillier and E. Rooksby. Aldershot: Ashgate.

Fudge, Judy and Fiona MacPhail. 2009. "The Temporary Foreign Worker Programs in Canada: Workers as an Extreme Form of Flexible Labour." Comparative Labor Law and Policy Journal 31(5):5-45.

Galtung, Johan. 1985. "Twenty-Five Years of Peace Research: Ten Challenges and Some Responses." Journal of Peace Research 22(2):141-58.

Gálvez, Andrea. 2010. National Representative, United Food and Commercial Workers (UFCW) Canada. Interview by author, Montreal, July 7.

Gauster, Susana and S. Ryan Isakson. 2008. "Eliminating Market Distortions, Perpetuating Rural Inequality: An Evaluation of Market-Assisted Land Reform in Guatemala." Pp. 103-20 in Market-Led Agrarian Reform: Critical Perspectives on Neoliberal Land Policies and the Rural Poor, edited by S. Borras Jr., C. Kay and E. Lahiff. New York: Routledge. 
Gazso-Windle, Amber and Julie Ann McMullin. 2003. "Doing Domestic Labour: Strategising in a Gendered Domain." Canadian Journal of Sociology 28(3):34166.

Gitter, Seth R. and Bradford L. Barham. 2008. "Women's Power, Conditional Cash Transfers, and Schooling in Nicaragua." World Bank Economic Review 22(2):271-90.

Glick Schiller, Nina, Linda Basch and Cristina Szanton Blanc. 1995. "From Immigrant to Transmigrant: Theorizing Transnational Migration." Anthropological Quarterly 68:48-66.

Goldring, Luin and Sailaja Krishnamurti. 2007. "Introduction: Contexualizing Transnationalism in Canada." Pp. 1-22 in Organizing the Transnational: Labour, Politics, and Social Change, edited by L. Goldring and S. Krishnamurti. Vancouver: University of British Columbia Press.

Gould, Jeffrey. 1998. To Die in This Way: Nicaraguan Indians and the Myth of Mestizaje, 1880-1965. Durham, NC: Duke University Press.

Government of Alberta. 2010. Alberta Minimum Wage Profile. Retrieved 21 November 2013 (http://brookschamber.ab.ca/wp-content/uploads/2010/06/AB-MinimumWage-Profile-Apr-2009-Mar-2010.pdf). Edmonton: Government of Alberta.

Government of Canada. 2010. "Regulations Amending the Immigration and Refugee Protection Regulations (Temporary Foreign Workers)." Canada Gazette 144(7).

Grandin, Greg. 2000. The Blood of Guatemala: A History of Race and Nation. Durham \& London: Duke University Press.

Grbich, Carol. 2007. Qualitative Data Analysis: An Introduction. Thousand Oaks, CA: Sage.

Green, Linda. 2009. "The Fear of No Future: Guatemala Migrants, Dispossession and Dislocation." Anthropologica 51:327-41.

Guarnizo, L. E. 1997. "The Emergence of a Transnational Social Formation and the Mirage of Return Migration among Dominican Transmigrants." Identities Global Studies in Culture and Power 4(2):281-322.

Gutmann, Matthew. 1996. The Meanings of Macho: Being a Man in Mexico City. Berkeley: University of California Press.

Hadi, Abdullahel. 1999. "Overseas Migration and the Well-Being of Those Left Behind in Rural Communities of Bangladesh." Asia-Pacific Population Journal 14(1):4358 . 
Hadi, Abdullahel. 2001. "International Migration and the Change of Women's Position among the Left-Behind in Rural Bangladesh." Population, Space and Place 7(1):53-61.

Hale, Charles. 2000. "To Die in This Way: Nicaraguan Indians and the Myth of Mestizaje, 1880-1965 (Review)." Ethnohistory 47(1):268-71.

Hari, Amrita. 2013. "Foot in the Door or Double-edged Sword: The Construction of Indian Hi-tech Immigrants in Canada's Technology Triangle.” South Asian Diaspora 5(2): 197-210.

Hartmann, Heidi. 1981. "The Unhappy Marriage of Marxism and Feminism: Towards a More Progressive Union." Pp. 1-41 in Women and Revolution: A Discussion of the Unhappy Marriage of Marxism and Feminism, edited by L. Sargent. London: Pluto Press.

Harzig, Christiane. 2001. "Women Migrants as Global and Local Agents: New Research Strategies on Gender and Migration." Pp. 15-28 in Women, Gender and Labour Migration: Historical and Global Perspectives, edited by P. Sharpe. New York: Routledge.

Hellman, Judith Adler. 2008. The World of Mexican Migrants: The Rock and the Hard Place. New York: The New Press.

Hennebry, Jenna and Kerry Preibisch. 2010. "A Model for Managed Migration? ReExamining Best Practices in Canada's Seasonal Agricultural Worker Program." International Migration 50 (Supplement s1):e19-e40.

Hennebry, Jenna. 2012. "Permanently Temporary? Agricultural Migrant Workers and Their Integration in Canada (IRPP Study No. 26).” Ottawa: IRPP.

Hennebry, Jenna. 2008. "Bienvenidos a Canadá? Globalization and the Migration Industry Surrounding Temporary Agricultural Migration to Canada." Canadian Studies in Population 35(2):339-356.

Hernández, Aridane. 2011. "El Salto al Norte: Violencia, Inseguridad e Impunidad del Fenómeno Migratorio en Guatemala." Ciudad de Guatemala: UNICEF.

Hill Collins, Patricia. 2000. Black Feminist Thought: Knowledge, Consciousness, and the Politics of Empowerment, 2nd Edition. New York: Routledge.

Hillier, Jean and Emma Rooksby. 2002. "Introduction.” Pp. 3-25 in Habitus: A Sense of Place, edited by J. Hillier and E. Rooksby. Aldershot: Ashgate.

Hondagneu-Sotelo, Pierrette. 1994. Gendered Transitions: Mexican Experiences of Immigration, Edited by Anonymous. Berkeley, CA: University of California Press. 
Hondagneu-Sotelo, Pierrette and Ernestine Avila. 1997. “'I'm Here, but I'm There': The Meanings of Latina Transnational Motherhood." Gender \& Society 11:548-71.

HRSDC. 2010. "Creation of a New Agricultural Stream under the Pilot Project for Occupations Requiring Lower Levels of Formal Training”, Ottawa: Human Resources and Skills Development Canada (HRSDC). Retrieved January 19, 2011 (http://www.hrsdc.gc.ca/eng/workplaceskills/foreign_workers/communications/ag riculture.shtml).

Huberman, Michael and Matthew Miles. 1998. "Data Management and Analysis Methods.” Pp. 179-210 in Collecting and Interpreting Qualitative Materials, edited by N. Denzin and Y. Lincoln. London: Sage.

Hughes, Christine. 2012. 'Costly Benefits and Gendered Costs: Guatemalans' Experiences of Canada's 'Low-Skill Pilot Project'.” Pp. 139-57 in Legislated Inequality: Temporary Migrant Workers in Canada, edited by C. Straehle and P. Lenard. Montreal/Kingston: McGill-Queen's University Press.

Hughes, Christine. Forthcoming (2015). "Field Correspondence: Exploring the Roots of the Transnational Habitus." in Transnational Voices, edited by G. Man and R. Cohen. Waterloo, ON: Wilfrid Laurier University Press.

Hugo, Graeme. 2000. “Migration and Women's Empowerment.” Pp. 287-317 in Women's Empowerment and Demographic Processes: Moving Beyond Cairo, edited by H. Presser and G. Sen. Oxford: Oxford University Press.

Hurtig, Janise, Rosario Montoya and Lessie Jo Frazier. 2002. "Introduction: $A$ Desalambrar: Unfencing Gender's Place in Research on Latin America." Pp. 1-18 in Gender's Place: Feminist Anthropologies of Latin America, edited by J. Hurtig, R. Montoya and L. J. Frazier. New York: Palgrave MacMillan.

INE. 2008. Censo Poblacional, Tecpán Guatemala. Tecpán Guatemala: Municipalidad de Tecpán Guatemala/Instituto Nacional de Estadística (INE).

INE. 2010. "Encuesta Nacional de Empleo e Ingresos 2010 [Dataset]." Guatemala City: Instituto Nacional de Estadística (INE).

INE. 2011. "Población en Guatemala (Demografia)", Guatemala: Instituto Nacional de Estadística (INE). Retrieved October 28, 2013

(http://www.ine.gob.gt/np/poblacion/).

INE. 2013. "Encuesta Nacional de Empleo e Ingresos 2013 [Dataset]." Guatemala City: Instituto Nacional de Estadística (INE).

Inter-American Development Bank. 2007. "Tearing Down the Walls: Growth and Inclusion in Guatemala “ Mexico: Inter-American Development Bank (IDB). 
IOM. 2006. "Project Evaluation - Temporary Agricultural Workers to Canada (Working Notebooks on Migration 22)." Guatemala City: International Organization for Migration (IOM).

IOM. 2008. "Second Evaluation - Program Temporary Agricultural Workers to Canada (Working Notebooks on Migration 25).” 25. Guatemala City: International Organization for Migration (IOM).

IOM. 2014. "The International Organization for Migration in Brief." Retrieved January 10, 2014 (http://www.iom.int/files/live/sites/iom/files/About-

IOM/docs/iom_in_brief_en.pdf) Geneva: International Organization for Migration (IOM).

Jaggar, Allison. 1998. “Globalizing Feminist Ethics.” Hypatia 13(3):7-31.

James, Laura. 2009. “Generational Differences in Women's Attitudes Towards Paid Employment in a British City: The Role of Habitus." Gender, Place \& Culture 16(3):313-28.

Jasper, Melanie. 2005. "Using Reflective Writing within Research.” Journal of Research in Nursing 10(3):247-60.

Jeffries, Fiona. 2007. "Resisting Fear with the Politics of Indignant Possibility: An Interview with Sandra Moran of Guatemala's Women's Sector." Women's Studies Quarterly 35(3/4):38-48.

Jimeno, Clara. 2001. "Implementation of the Gender Demands Included in the Guatemala Peace Accords: Lessons Learned." Pp. 180-98 in Women Resist Globalization: Mobilizing for Livelihood and Rights, edited by S. Rowbotham and S. Linkogle. London: Zed Books.

Jolly, Susie and Hazel Reeves. 2005. "Gender and Migration. Overview Report." Brighton, UK: Institute of Development Studies.

José Alcalá, María. 2006. "The State of the World Population 2006 - A Passage to Hope: Women and International Migration." New York: United Nations Population Fund (UNFPA).

Kachika, Tinyade. 2012. "Women's Land Rights Project in Guatemala, India, and Sierra Leone: Empowering Poor and Excluded Women and Fighting against Poverty and Hunger through Enhanced Access to and Control over Land.” Johannesburg, South Africa: ActionAid.

Kanakarajavelu, Nina. 2010. "Legacy of Repression: Violence against Women in PostConflict Guatemala.” Master's thesis, Department of Global Studies, Brandeis University, Waltham, MA. 
Kaplan, Caren. 1994. "The Politics of Location as Transnational Feminist Practice.” Pp. 137-52 in Scattered Hegemonies: Postmodernity and Transnational Feminist Practices, edited by I. Grewal and C. Kaplan. Minneapolis: University of Minnesota Press.

Kelly, Liz, Sheila Burton and Linda Regan. 1994. "Research Women's Lives or Studying Women's Oppression? Reflections on What Constitutes Feminist Research.” Pp. 27-48 in Researching Women's Lives from a Feminist Perspective, edited by M. Maynard and J. Purvis. London: Taylor \& Francis.

Kelly, P. and T. Lusis. 2006. "Migration and the Transnational Habitus: Evidence from Canada and the Philippines." Environment and Planning A 38(5):831-47.

Keough, Leyla. 2008. “'Driven’ Women: Gendered Moral Economies of Women’s Migrant Labour in Postsocialist Europe's Peripheries.” PhD dissertation, Anthropology, University of Massachusetts Amherst, Amherst, MA.

Keung, Nicholas. 2012. "Seasonal Migrant Workers Stripped of Parental Benefits." The Star. Retrieved: 11 December 2012 (http://www.thestar.com/news/canada/2012/12/11/seasonal_migrant_workers_stri pped_of_parental_benefits.html).

Kivisto, Peter. 2001. "Theorizing Transnational Immigration: A Critical Review of Current Efforts." Ethnic and Racial Studies 24(4):549-77.

Koch, Julie. 2001. “The Power of Partnership: The Impact of Women's Work on Gender Relations among Low-Income Urban Couples, La Paz, Bolivia.” PhD dissertation, International Development Studies, Roskilde University, Copenhagen.

Korteweg, Anna. 2008. "The Sharia Debate in Ontario: Gender, Islam, and Representations of Muslim Women's Agency." Gender \& Society 22(4):434-54.

Kunz, Rahel. 2008. “'Remittances Are Beautiful'? Gender Implications of the New Global Remittances Trend.” Third World Quarterly 29(7):1389-409.

Lamphere, Louise. 2007. "The Domestic Sphere of Women and the Public Sphere of Men: The Strengths and Limitations of an Anthropological Dichotomy." Pp. 7-16 in Gender Relations in Global Perspective: Essential Readings, edited by N. Cook. Toronto: Canadian Scholars' Press.

Latreille, Martin. 2006. "Rmāyniyya. Féminisation de l'agriculture et condition féminine dans le Nord-Ouest tunisien.” PhD dissertation, Département d'anthropologie, Université de Montréal, Montréal.

Lau, Raymond. 2004. "Habitus and the Practical Logic of Practice: An Interpretation." Sociology 38(2):369-87. 
Levitt, Peggy. 1996. "Social Remittances: A Conceptual Tool for Understanding Migration and Development (Working Paper Series Number 96.04)." Harvard Center for Population and Development Studies, Boston.

Levitt, Peggy. 1998. "Social Remittances: Migration Driven Local-Level Forms of Cultural Diffusion." International Migration Review 32(4):926-48.

Levitt, Peggy. 2001. "Transnational Migration: Taking Stock and Future Directions." Global Networks 1(3):195-216.

Levitt, Peggy. 2010. “'It's Not Just About the Economy, Stupid' - Social Remittances Revisited." Migration Fundamentals. Retrieved: 15 January 2014 (http://www.migrationinformation.org/Feature/display.cfm?ID=783).

Lindsey, Linda. 1994. Gender Roles: A Sociological Perspective. New Jersey: Prentice Hall.

Lindstrom, David and Elisa Muñoz-Franco. 2005. "Migration and the Diffusion of Modern Contraceptive Knowledge and Use in Rural Guatemala." Studies in Family Planning 35(4):277-88.

Little, Walter. 2005. "Introduction: Globalization and Guatemala's Maya Workers." Latin American Perspectives 32(3):3-11.

Lovell, George. 2000a. A Beauty That Hurts: Life and Death in Guatemala. Toronto: Between the Lines.

Lovell, Terry. 2000b. "Thinking Feminism with and against Bourdieu." Pp. 27-48 in Reading Bourdieu on Society and Culture, edited by B. Fowler. Oxford: Blackwell.

Loza Torres, Mariela, Ivonne Vizcarra Bordi and Bruno Lutz Bachère. 2007. "Jefaturas de Hogar. El Desafío Feminino ante la Migración Transnacional Masculina en el Sur del Estado de México." Migraciones Internacionales 4(002):33-60.

Luxton, Meg. 1990. Through the Kitchen Window: The Politics of Home and Family. Toronto: Garamond Press.

Luxton, Meg. 2006. "Feminist Political Economy in Canada and the Politics of Social Reproduction." Pp. 11-44 in Social Reproduction: Feminist Political Economy Challenges Neo-Liberalism, edited by K. Bezanson and M. Luxton. Montreal: McGill-Queen's University Press.

Luxton, Meg. 2009. "Family Coping Strategies: Balancing Paid Employment and Domestic Labour." Pp. 453-73 in Family Patterns, Gender Relations, edited by M. Luxton and B. Fox. Don Mills, Ontario: Oxford University Press. 
Luxton, Meg and Bonnie Fox. 2009. "Conceptualizing Family.” Pp. 3-20 in Family Patterns, Gender Relations, edited by M. Luxton and B. Fox. Don Mills, Ontario: Oxford University Press.

Machum, Susan. 2006. “Commodity Production and Farm Women's Work.” Pp. 47-62 in Rural Gender Relations: Issues and Case Studies, edited by B. Bock and S. Shortall. Wallingford, UK; Cambridge, MA: CABI Publishing.

Mahar, Cheleen, Richard Harker and Chris Wilkes. 1990. "The Basic Theoretical Position." Pp. 1-25 in An Introduction to the Work of Pierre Bourdieu, edited by C. Mahar, R. Harker and C. Wilkes. London: Macmillan.

Mahar, Cheleen. 1992. "An Exercise in Practice: Studying Migrants to Latin American Squatter Settlements." Urban Anthropology 21(3):275-309.

Mahler, Sarah. 2001. "Transnational Relationships: The Struggle to Communicate across Borders." Identities 7(4):583-619.

Mahler, Sarah J. and Patricia R. Pessar. 2001. "Gendered Geographies of Power: Analyzing Gender across Transnational Spaces." Identities 7(4):441-59.

Malarek, Victor. 2003. The Natashas: The New Global Sex Trade. Toronto: Penguin Canada.

Malik, Khalid. 2013. "Human Development Report 2013. The Rise of the South: Human Progress in a Diverse World." New York: United Nations Development Programme (UNDP).

Manewal, Bryan. 2007. "Religion in the Trenches: Liberation Theology and Evangelical Protestantism as Tools of Social Control in the Guatemalan Civil War (19601996).” McNair Scholars Journal 11(1):49-62.

Martínez Salazar, Egla. 2005. "The Everyday Practice of Guatemalan Women: Confronting Marginalization, Racism, and Contested Citizenship." PhD dissertation, Sociology, York University, Toronto.

Martínez Salazar, Egla. 2012. Global Coloniality of Power in Guatemala: Racism, Genocide, Citizenship. Lanham, MD: Lexington Books.

Mason, Jennifer. 2002. Qualitative Researching. London: Sage.

Matsui, Shinichi. 2010. "Women's Social Participation and Gender Role Consciousness: Selection of 'Care' in Nonmarket-Type Social Participation." Japanese Journal of Family Sociology 22(1):64-76.

Mauthner, Natasha and Andrea Doucet. 2003. "Reflexive Accounts and Accounts of Reflexivity in Qualitative Data Analysis." Sociology 37(3):413-31. 
Mayoux, Linda and Maria Hartl. 2009. "Gender and Rural Microfinance: Reaching and Empowering Women." Rome: International Fund for Agricultural Development.

McCall, Leslie. 1992. "Does Gender Fit? Bourdieu, Feminism, and Conceptions of Social Order." Theory and Society 21(6):837-67.

McCall, Leslie. 2005. “The Complexity of Intersectionality.” Signs 30(3):1771-800.

McInturff, Kate. 2013a. "The Gap in the Gender Gap: Violence against Women in Canada." Ottawa: Canadian Centre for Policy Alternatives.

McInturff, Kate. 2013b. “Closing Canada’s Gender Gap: Year 2240 Here We Come!” Ottawa: Canadian Centre for Policy Alternatives.

McKay, Deirdre. 2001. "Migration and the Masquerade: Gender and Habitus in the Philippines." Geography Research Forum 21:44-56.

McKay, Deirdre. 2005. "Migration and the Sensuous Geographies of Re-Emplacement in the Philippines." Journal of Intercultural Studies 26(1-2):75-91.

McKie, Linda, Sophia Bowlby and Susan Gregory. 1999. "Connecting Gender, Power and the Household." Pp. 3-21 in Gender, Power and the Household, edited by L. McKie, S. Bowlby and S. Gregory. New York: Macmillan Press.

McLeod, Julie. 2003. "Why We Interview Now - Reflexivity and Perspective in a Longitudinal Study." International Journal of Social Research Methodology 6(3):201-11.

McLeod, Julie. 2005. "Feminists Re-Reading Bourdieu: Old Debates and New Questions About Gender Habitus and Gender Change." Theory and Research in Education 3(1):11-30.

McNay, Lois. 1999. "Gender, Habitus and the Field: Pierre Bourdieu and the Limits of Reflexivity." Theory, Culture \& Society 16(1):95-117.

McQuillan, Kevin. 2013. "All the Workers We Need: Debunking Canada's LabourShortage Fallacy." School of Public Policy Research Papers 6(16):1-27.

MENAMIG. 2006. "Diagnóstico de Menores de Edad y Mujeres Trabajadores Agrícolas Temporales en Chiapas, México.” Guatemala: Mesa Nacional para las Migraciones en Guatemala (MENAMIG).

Menchú, Rigoberta. 1984. I, Rigoberta Menchú: An Indian Woman in Guatemala. London: Verso.

Menjívar, Cecilia. 1999. "The Intersection of Work and Gender: Central American Immigrant Women and Employment in California." American Behavioral Scientist 42(4):601-27. 
Menjívar, Cecilia. 2006. "Global Processes and Local Lives: Guatemalan Women's Work and Gender Relations at Home and Abroad." International Labor and Working-Class History 70:86-105.

Menjívar, Cecilia and Victor Agadjanian. 2007. "Men's Migration and Women's Lives: Views from Rural Armenia and Guatemala." Social Science Quarterly 88(5):1243-62.

Menjívar, Cecilia. 2008. "Violence and Women's Lives in Eastern Guatemala." Latin American Research Review 43(3):109-36.

Metz, Brent. 2001. "Politics, Population, and Family Planning in Guatemala: Ch'orti' Maya Experiences." Human Organization 60(3):259-71.

Millen, Dianne. 1997. "Some Methodological and Epistemological Issues Raised by Doing Feminist Research on Non-Feminist Women." Sociological Research Online 2(3).

Mohanty, Chandra. 1991. "Under Western Eyes: Feminist Scholarship and Colonial Discourses." Pp. 51-80 in Third World Women and the Politics of Feminism, edited by C. Mohanty, A. Russo and L. Torres. Bloomington: Indiana University Press.

Mohanty, Chandra Talpade. 2003. Feminism without Borders: Decolonizing Theory, Practicing Solidarity. London: Duke University Press.

Moi, Toril. 1991. "Appropriating Bourdieu: Feminist Theory and Pierre Bourdieu's Sociology of Culture." New Literary History 22(4):1017-49.

Montes, Verónica. 2013. "The Role of Emotions in the Construction of Masculinity: Guatemalan Migrant Men, Transnational Migration, and Family Relations." Gender \& Society 27(4):469-90.

Montes, Verónica. 2009. "Transformaciones de las Relaciones Familiares en el Contexto Migratorio Transnacional: Pueblo Nuevo, Guatemala Como Caso de Estudio Etnográfico." Pp. 276-93 in V Congreso International Sobre Migración, edited by M. Ugalde. Guatemala City: Instituto de Investigaciones Económicas y Sociales.

Monzón, Ana Silvia. 2009. "Mujeres Migrantes en Los Ángeles, California: Comunicación, Identidad y Acción Colectiva." Pp. 224-48 in V Congreso International Sobre Migración, edited by M. Ugalde. Guatemala City: Instituto de Investigaciones Económicas y Sociales.

Morgan, David. 1999. "Gendering the Household: Some Theoretical Considerations.” Pp. 23-40 in Gender, Power and the Household, edited by L. McKie, S. Bowlby and S. Gregory. New York: Macmillan Press. 
Morris, Marika and Martha Muzychka. 2002. "Participatory Action Research: A Guide to Becoming a Researcher for Social Change." Ottawa: Canadian Research Institute for the Advancement of Women (CRIAW).

Moser, Caroline and Cathy McIlwaine. 2004. Encounters with Violence in Latin America: Urban Poor Perceptions from Colombia and Guatemala. New York: Routledge.

Munduate, Cristian. 2008. "UNICEF's Rights-Based Approach to the Gender Dimension of Migration." Paper presented at the International Conference on Gender, Migration and Development: Seizing Opportunities, Upholding Rights, September 25-26, Manila.

Nakache, Delphine and Paula J. Kinoshita. 2010. "The Canadian Temporary Foreign Worker Program: Do Short-Term Economic Needs Prevail over Human Rights Concerns?" Montreal: IRPP.

Nash, June. 2001. Mayan Visions: The Quest for Autonomy in the Age of Globalization. New York: Routledge.

Nelson, Diane. 1999. A Finger in the Wound: Body Politics in Quincentennial Guatemala. Berkeley: University of California Press.

Newman, Constance. 2002. "Gender, Time Use, and Change: The Impact of the Cut Flower Industry in Ecuador.” World Bank Economic Review 16(3):375-95.

Neysmith, Sheila, Kate Bezanson and Anne O'Connell. 2005. Telling Tales: Living the Effects of Public Policy. Black Point, NS: Fernwood.

Neysmith, Sheila, Marge Reitsma-Street, Stephanie Baker-Collins, Elaine Porter and Sandra Tam. 2010. "Provisioning Responsibilities: How Relationships Shape the Work That Women Do.” Canadian Review of Sociology 47(2):149-70.

Nguyen, Liem, Brenda Yeoh and Mika Toyota. 2006. "Migration and the Well-Being of the 'Left Behind' in Asia." Asian Population Studies 2(1):37-44.

NISGUA. 2009. "Guatemala Basics, Guatemalan History”, Oakland, CA: Network in Solidarity with the People of Guatemala (NISGUA). Retrieved February 3, 2011 (http://www.nisgua.org/resources/guatemala_basics/history.asp).

Nolin, Catherine. 2006. Transnational Ruptures: Gender and Forced Migration. Burlington, VT: Ashgate.

Oficina Municipal de Planificación. 2008a. Monografía del Municipio de Tecpán Guatemala. Tecpán Guatemala: Municipalidad de Tecpán Guatemala.

Oficina Municipal de Planificación. 2008b. Datos Generales del Municipio. Tecpán Guatemala: Municipalidad de Tecpán Guatemala. 
Oficina Municipal de Planificación. 2008c. Caracterización del Municipio de Tecpán Guatemala. Tecpán Guatemala: Municipalidad de Tecpán Guatemala.

Oficina Municipal de Planificación. 2010. "Municipio de Tecpán Guatemala [Map]." Tecpán Guatemala: Municipalidad de Tecpán Guatemala.

Palma Ramos, Danilo A. 2004. "El Uso del Tiempo en Guatemala según la ENCOVI." Revista Estudios Sociales 71:3-58.

PDH. 2011. "Resumen Estadística de Denuncias." Guatemala City: Procurador de los Derechos Humanos de Guatemala (PDH).

Peláez, Ana Victoria and Miguel Ugalde. 2006. “¿Cómo Afectan las Migraciones Internacionales a la Familia? Avances Sobre Estudios de Caso en Dos Municipios de Guatemala." Paper presented at the V Congreso de la Red Latinoamericana de Antropología Jurídica, October 16-20, Oaxtepec, Mexico. Retrieved January 10, 2012 (http://ciesas.edu.mx/proyectos/relaju/cd_relaju/Ponencias/Mesa Su\%C3\%A1rez y Sorensen/UgaldeGonzalezMiguel.pdf).

Peláez, Ana Victoria. 2009. "Más Allá de los Dólares: Una Aproximación a las Remesas Sociales y su Potencial Para el Desarrollo Económico Local.” Pp. 312-27 in $V$ Congreso International Sobre Migración, edited by M. Ugalde. Guatemala City: Instituto de Investigaciones Económicas y Sociales.

Peláez, Vicky. 2010. Coordinator of Rural Poverty Program, Instituto de Investigaciones Económicas y Sociales (IDIES), Universidad Rafael Landívar. Interview by author, Guatemala City, February 22.

Perry, Adele. 2001. On the Edge of Empire: Gender, Race, and the Making of British Columbia, 1849-1871. Toronto: University of Toronto Press.

Pessar, Patricia. 1999a. "The Role of Gender, Households, and Social Networks in the Migration Process: A Review and Appraisal." Pp. 53-70 in The Handbook of International Migration: The American Experience, edited by C. Hirschman, P. Kasinitz and J. DeWind. New York: Russell Sage Foundation.

Pessar, Patricia. 1999b. "Engendering Migration Studies: The Case of New Immigrants in the United States." American Behavioral Scientist 42(4):577-600.

Pessar, Patricia R. and Sarah J. Mahler. 2003. "Transnational Migration: Bringing Gender In.” International Migration Review 37(3):812-46.

Phoenix, Ann. 1994. "Practising Feminist Research: The Intersection of Gender and 'Race' in the Research Process." Pp. 49-71 in Researching Women's Lives from a Feminist Perspective, edited by M. Maynard and J. Purvis. London: Taylor \& Francis. 
Pine, Adrienne. 2008. Working Hard, Drinking Hard: On Violence and Survival in Honduras. Los Angeles: University of California Press.

Pintor Sandoval, Renato. 2011. "El Habitus y los Campos Transnacionales en el Proceso del Transnacionalismo Migrante." Migraciones Internacionales 6(2):159-92.

Piper, Nicola. 2005. "Gender and Migration." Geneva: Global Commission on International Migration.

Piper, Nicola. 2008a. "Feminisation of Migration and the Social Dimensions of Development: The Asian Case." Third World Quarterly 29(7):1287-303.

Piper, Nicola. 2008b. "Political Participation and Empowerment of Foreign Workers: Gendered Advocacy and Migrant Labour Organising in Southeast and East Asia." Pp. 247-73 in New Perspectives on Gender and Migration: Livelihood, Rights and Entitlements, edited by N. Piper. New York: Routledge.

Piscopo, Jennifer. 2006. "Engineering Quotas in Latin America (CILAS Working Paper 23)." San Diego: University of California.

PNUD. 2008. "Guatemala: Una Economía al Servicio del Desarrollo Humano? Informe Nacional de Desarrollo Humano 2007/2008." Guatemala: Programa de las Naciones Unidas para el Desarrollo (PNUD), Guatemala.

PNUD. 2010. "Guatemala: Hacia un Estado Para el Desarrollo Humano. Informe Nacional de Desarrollo Humano, 2009/2010." Guatemala: Programa de las Naciones Unidas para el Desarrollo (PNUD), Guatemala.

Portes, Alejandro, Luis E. Guarnizo and Patricia Landolt. 1999. "The Study of Transnationalism: Pitfalls and Promise of an Emergent Research Field." Ethnic and Racial Studies 22(2):217-37.

Pratt, Geraldine and Brenda Yeoh. 2003. "Transnational (Counter) Topographies." Gender, Place \& Culture 10(2):159-66.

Pratt, Geraldine. 2004. Working Feminism. Philadelphia: Temple University Press.

Preibisch, Kerry. 2004a. "Migrant Agricultural Workers and Processes of Social Inclusion in Rural Canada: Encuentros and Desencuentros." Canadian Journal of Latin American and Caribbean Studies 29(57/8):203-39.

Preibisch, Kerry. 2004b. "Patterns of Social Exclusion and Inclusion of Migrant Workers in Rural Canada." Ottawa: North-South Institute.

Preibisch, Kerry. 2005. "Gender Transformative Odysseys: Tracing the Experiences of Transnational Migrant Women in Rural Canada." Canadian Woman Studies 24(4):91-97. 
Preibisch, Kerry and Leigh Binford. 2007. "Interrogating Racialized Global Labour Supply: An Exploration of the Racial/National Replacement of Foreign Agricultural Workers in Canada." Canadian Review of Sociology 44(1):5-36.

Preibisch, Kerry. 2010. "Pick-Your-Own Labor: Migrant Workers and Flexibility in Canadian Agriculture." International Migration Review 44(2):404-41.

Preibisch, Kerry and Evelyn Encalada Grez. 2010. "The Other Side of el Otro Lado: Mexican Migrant Women and Labor Flexibility in Canadian Agriculture." Signs 35(2):289-316.

Preibisch, Kerry and Evelyn Encalada Grez. 2013. "Between Hearts and Pockets: Locating the Outcomes of Transnational Homemaking Practices among Mexican Women in Canada's Temporary Migration Programmes." Citizenship Studies 17(6-7):785-802.

Pu Tzunux, Rosa. 2007. Representaciones Sociales Mayas y Teoría Feminista: Crítica de la Aplicación Literal de Modelos Teóricos en la Interpretación de la Realidad de las Mujeres Mayas. Guatemala: Iximulew.

Pui-lan, Kwok. 2003. "Liberation Theology in the Twenty-First Century." Pp. 71-88 in Opting for the Margins: Postmodernity and Liberation in Christian Theology, edited by J. Rieger. New York: Oxford University Press.

Pyke, Karen. 1996. "Class-Based Masculinities: The Interdependence of Gender, Class, and Interpersonal Power." Gender \& Society 10(5):527-49.

Rahman, Aminur. 1998. "Rhetoric and Realities of Micro-Credit for Women in Rural Bangladesh: A Village Study of Grameen Bank Lending." PhD dissertation, Anthropology, University of Manitoba, Winnipeg.

Ramírez, Carlota, Mar García Domínguez and Julia Míguez Morais. 2005. "Crossing Borders: Remittances, Gender and Development." Santo Domingo, Dominican Republic: UN International Research and Training Institute for the Advancement of Women (UN-INSTRAW).

Rapley, Tim. 2004. "Interviews." Pp. 15-33 in Qualitative Research Practice, edited by C. Seale, G. Gobo, J. Gubrium and D. Silverman. London: Sage.

Ravanera, Zenaida, Roderic Beaujot and Jianye Liu. 2009. "Models of Earning and Caring: Determinants of the Division of Work." Canadian Review of Sociology 46(4).

Reed, Austina. 2008. "Canada's Experience with Managed Migration: The Strategic Use of Temporary Foreign Worker Programs.” International Journal (Spring 2008):469-84. 
Resurreccion, B. P. and H. T. Van Khanh. 2007. "Able to Come and Go: Reproducing Gender in Female Rural-Urban Migration in the Red River Delta." Population, Space and Place 13(3):211-24.

Riley, Maria. 2008. “A Feminist Political Economic Framework.” Washington: Center of Concern.

Risman, Barbara. 1998. Gender Vertigo: American Families in Transition. New Haven, CT: Yale University Press.

Rivas, Ana María and Herminia González. 2011. "El Papel de las Remesas Económicas y Sociales en las Familias Transnacionales Colombianas." Migraciones Internacionales 6(2):75-99.

Roberts, John Michael and Teela Sanders. 2005. "Before, During and After: Realism, Reflexivity and Ethnography." The Sociological Review 53(2):294-313.

Rodríguez, Manuel. 2013. "Tasa de Desempleo Sigue en 3\%, según el Ministro.” La Hora. Retrieved: 21 August 2013

(http://www.lahora.com.gt/index.php/nacional/guatemala/actualidad/182573-tasade-desempleo-sigue-en-3-segun-el-ministro).

Rollins, Judith. 1987. Between Women: Domestics and Their Employers. Philadelphia: Temple University Press.

Roncal, Federico and Guorón Ajquijay. 2004. Culturas e Idiomas de Guatemala. Guatemala: MiNEDUC (Ministerio de Educación).

Russo, Ann. 2006. “The Feminist Majority Foundation's Campaign to Stop Gender Apartheid." International Feminist Journal of Politics 8(4):557-80.

Salazar Parreñas, Rhacel. 2005. Children of Global Migration: Transnational Families and Gendered Woes. Stanford Stanford University Press.

Salgado de Snyder, Nelly. 1993. "Family Life across the Border: Mexican Wives Left Behind." Hispanic Journal of Behavioral Sciences 15(3):391-401.

Samayoa, Claudia. 2010. Oficina Municipal de la Mujer. Interview by author, Tecpán Guatemala, May 6.

Sanford, Victoria. 2006. "Introduction.” Pp. 1-18 in Engaged Observer: Anthropology, Advocacy, and Activism, edited by V. Sanford and A. Angel-Ajani. New Jersey: Rutgers University Press.

Sault, Nicole. 2001. "Godparenthood Ties among Zapotec Women and the Effects of Protestant Conversion.” Pp. 117-46 in Holy Saints and Fiery Preachers: The Anthropology of Protestantism in Mexico and Central America, edited by J. Dow. Westport, CT: Praeger Publishers. 
Schirato, Tony and Jen Webb. 2003. "Bourdieu's Concept of Reflexivity as Metaliteracy." Cultural Studies 17(3/4):539-52.

Schiwy, F. 2007. "Decolonization and the Question of Subjectivity: Gender, Race, and Binary Thinking." Cultural Studies 21(3):271-94.

Schmidt, Johanna. 2002. "Migrant Bodies: The Embodiment of Identity Amongst Samoan Fa'afafine in New Zealand." New Zealand Sociology 17(2):179-97.

Schwindt-Bayer, Leslie. 2011. “Gender Quotas and Women's Political Participation in Latin America." Papers from the Americas Barometer. Nashville, TN: Vanderbilt University.

Scott, Joan. 1986. "Gender: A Useful Category of Historical Analysis." The American Historical Review 91(5):1053-75.

Sector de Mujeres. 2011. "Quienes Somos", Guatemala City: Sector de Mujeres. Retrieved April 21, 2011 (http://www.sectordemujeres.org/quienessomos.html).

SEPREM. 2009a. Política Nacional de Promoción y Desarrollo Integral de las Mujeres y Plan de Equidad de Oportunidades, 2008-2023. Retrieved April 26, 2011. Guatemala City: Secretaría Presidencial de la Mujer (SEPREM), Presidencia de la República de Guatemala.

SEPREM. 2009b. "Seprem ¡Por y Para las Mujeres!”, Guatemala City: Secretaría Presidencial de la Mujer (SEPREM), Presidencia de la República. Retrieved April 26, 2011 (http://www.seprem.gob.gt/).

Sharpe, Pamela, ed. 2001. Women, Gender and Labour Migration: Historical and Global Perspectives. New York: Routledge.

Shih, Shu-Mei. 2002. "Towards an Ethics of Transnational Encounter, or 'When' Does a 'Chinese' Woman Become a 'Feminist'?'. Differences: A Journal of Feminist Cultural Studies 13(2):90-126.

Short, Nicola. 2007. The International Politics of Post-Conflict Reconstruction in Guatemala. New York: Palgrave Macmillan.

Shortall, Sally. 2006. "Economic Status and Gender Roles." Pp. 303-15 in Rural Gender Relations: Issues and Case Studies, edited by B. Bock and S. Shortall. Wallingford, UK; Cambridge, MA: CABI Publishing.

Siltanen, Janet and Andrea Doucet. 2008. Gender Relations in Canada: Intersectionality and Beyond. Toronto: Oxford University Press Canada.

Silva, Elizabeth. 2005. "Gender, Home and Family in Cultural Capital Theory." The British Journal of Sociology 56(1):83-103. 
Silvey, Rachel. 2004. "Power, Difference and Mobility: Feminist Advances in Migration Studies." Progress in Human Geography 28(4):490-506.

Similox, Ronaldo. 2010. Director, Presbiterio Kaqchikel. Interview by author, Chimaltenango, Guatemala, May 17.

Skeggs, Beverley. 1994. "Situating the Production of Feminist Ethnography." Pp. 72-92 in Researching Women's Lives from a Feminist Perspective, edited by M. Maynard and J. Purvis. London: Taylor \& Francis.

Skeggs, Beverley. 2004. "Context and Background: Pierre Bourdieu's Analysis of Class, Gender and Sexuality." Pp. 19-34 in Feminism after Bourdieu, edited by L. Adkins and B. Skeggs. Oxford: Blackwell Publishing.

Spence, Jack and George Vickers. 1998. Promise and Reality: Implementation of the Guatemalan Peace Accords. Cambridge, MA: Hemisphere Initiatives.

Sprague, Joey. 2005. Feminist Methodologies for Critical Researchers: Bridging Differences. Walnut Creek, CA: AltaMira Press.

Stasiulis, Daiva. 1997. "The Political Economy of Race, Ethnicity and Migration.” Pp. 141-71 in Understanding Canada: Building on the New Canadian Political Economy, edited by W. Clement. Montreal: McGill-Queen's University Press.

Stasiulis, Daiva. 1999. "Feminist Intersectional Theorizing." in Race and Ethnic Relations in Canada, edited by P. Li. Don Mills, ON: Oxford University Press.

Stasiulis, Daiva and Abigail Bakan. 2005. Negotiating Citizenship: Migrant Women in Canada and the Global System. Toronto: University of Toronto Press.

Steigenga, Timothy. 2001. The Politics of Spirit: The Political Implications of Pentacostalized Religion in Costa Rica and Guatemala. Lanham, ML: Lexington Books.

Stern-Petterssen. 1997. "Contextualizing in/Security: The Political Identity 'MayanWoman' in Guatemala.” Statsvetenskaplig Tidskrift 100(1):123-38.

Stockard, Janice. 1989. Daughters of the Canton Delta: Marriage Patterns and Economic Strategies in South China, 1860-1930. Stanford: Stanford University Press.

Sullivan, Oriel. 2004. "Changing Gender Practices within the Household: A Theoretical Perspective." Gender \& Society 18(2):207-22.

Sullivan, Oriel. 2006. Changing Gender Relations, Changing Families: Tracing the Pace of Change over Time. Oxford: Rowman \& Littlefield.

Taft-Morales, Maureen. 2013. "Guatemala: Political, Security, and Socio-Economic Conditions and U.S. Relations. CRS Report for Congress.” Washington: Congressional Research Service. 
Taylor, Matthew, Michelle Moran-Taylor and Debra Rodman Ruiz. 2006. "Land, Ethnic, and Gender Change: Transnational Migration and Its Effects on Guatemalan Lives and Landscapes." Geoforum 37:41-61.

Thapar-Bjorkert, Suruchi and Marsha Henry. 2004. "Reassessing the Research Relationship: Location, Position and Power in Fieldwork Accounts." International Journal of Social Research Methodology 7(5):363-81.

The Friday Morning Group. 1990. “Conclusion: Critique.” Pp. 195-225 in An Introduction to the Work of Pierre Bourdieu, edited by R. Harker, C. Mahar and C. Wilkes. London: Macmillan.

The World Bank. 2004. "Poverty in Guatemala." Washington: The International Bank for Reconstruction and Development / The World Bank.

Thieme, Susan. 2008. "Sustaining Livelihoods in Multi-Local Settings: Possible Theoretical Linkages between Transnational Migration and Livelihood Studies." Mobilities 3(1):51-71.

Tienda, Marta and Karen Booth. 1991. "Gender, Migration and Social Change." International Sociology 6(1):51-72.

Tierra Viva. N.d. “Quiénes Somos”, Guatemala City: Organización de Mujeres Tierra Viva. Retrieved April 15, 2011 (http://www.tierra-viva.org/quienes.htm).

Tran, Rebecca. 2011. "Guatemala's Crippled Peace Process: A Look Back on the 1996 Peace Accords." Washington: Council on Hemispheric Affairs.

Trumper, Ricardo and Lloyd Wong. 2010. "Temporary Workers in Canada: A National Perspective." Canadian Issues Spring:83-89.

Tuhiwai Smith, Linda. 1999. Decolonizing Methodologies: Research and Indigenous Peoples. London: Zed Books.

Turbide, Valérie. 2010. Senior Analyst, Temporary Foreign Worker Program, Human Resources and Skills Development Canada (HRSDC). Written Communication, Ottawa, March 11.

Turner, J. David. 1994. An Introduction to Liberation Theology. Lanham, MD: University Press of America.

Tursunzoda, Mehrangez 2010. "Plight of 'Abandoned Wives' in Tajikistan.” Reporting Central Asia (RCA) (637). Retrieved: January 31, 2011 (http://iwpr.net/reportnews/plight-\%E2\%80\%9Cabandoned-wives\%E2\%80\%9D-tajikistan).

UNDP. 2009a. "Human Development Report 2009: Overcoming Barriers: Human Mobility and Development." New York: United Nations Development Programme (UNDP). 
UNDP. 2009b. "Country Fact Sheets, Human Development Report 2009 - Guatemala." New York: United Nations Development Programme (UNDP).

UNDP. 2010. "Regional Human Development Report for Latin America and the Caribbean 2010. Acting on the Future: Breaking the Intergenerational Transmission of Inequality.” New York: United Nations Development Programme (UNDP).

UNDP. 2012. "International Human Development Indicators." United Nations Development Programme (UNDP).

UNDP. 2013. "Data - Human Development Indicators and Thematic Tables. Statistical Tables from the 2013 Human Development Report", New York: United Nations Development Programme (UNDP). Retrieved 6 January, 2014 (http://hdr.undp.org/en/data/map).

USAID. N.d. "Property Rights and Resource Governance - Guatemala." Washington, DC: USAID.

Valarezo, Giselle and Christine Hughes. 2013. "Pushed to the Edge: Political Activism of Guatemalan Migrant Farmworkers.” Mobilities 5:94-119.

VanEvery, Jo. 1997. "Understanding Gendered Inequality: Reconceptualizing Housework." Women's Studies International Forum 20(3):411-20.

Vargas-Foronda, Jacobo. 2010a. "El Programa de Trabajo Agrícola Temporal en Canadá (PTAT-C): Mano de Obra Barata de Exportación.” Diálogo 16.

Vargas-Foronda, Jacobo. 2010b. "El Programa de Trabajo Agrícola Temporal en Canadá en su VII Aniversario 2003-2010. Una Hipócrita Negociación: Exportamos Mano de Obra Barata con Enormes Rendimientos y Altos Lucros. Su Cruda Perversión y Magnificada Degradación.” Enlace Académico. Guatemala: FLACSO.

Vogler, Carolyn. 1998. "Money in the Household: Some Underlying Issues of Power." The Sociological Review 46(4):687-713.

Vullnetari, Julie and Russell King. 2011. "Gendering Remittances in Albania: A Human and Social Development Perspective." Gender \& Development 19(1):39-51.

Walby, Sylvia. 1989. “Theorising Patriarchy.” Sociology 23(2):213-2234.

Webb, Jen, Tony Schirato and Geoff Danaher. 2002. Understanding Bourdieu. London: Sage.

Weininger, Elliott. 2002. "Foundations of Class Analysis in the Work of Bourdieu." Pp. 119-79 in Alternative Foundations of Class Analysis, edited by E. O. Wright. Madison, WI: University of Wisconsin. 
Weinstein Bever, Sandra. 2002. "Migration and the Transformation of Gender Roles and Hierarchies in Yucatan." Urban Anthropology 31(2):199-230.

West, Candace and Don Zimmerman. 2007. "Doing Gender." Pp. 61-71 in Gender Relations in Global Perspective: Essential Readings, edited by N. Cook. Toronto: Canadian Scholars' Press.

Wharton, Amy. 2005. The Sociology of Gender: An Introduction to Theory and Research. Malden, MA: Blackwell.

Whiteford, Michael. 2002. "Staying Healthy: Evangelism and Health Perception Differences by Gender in a Guatemalan Marketplace." Annals of the American Academy of Political and Social Science 583:177-94.

Witz, Anne. 2004. “Anamnesis and Amnesis in Bourdieu's Work: The Case for a Feminist Anamnesis.” Pp. 211-23 in Feminism after Bourdieu, edited by L. Adkins and B. Skeggs. Oxford: Blackwell Publishing.

Wolf, Diane. 1990. "Daughters, Decisions and Domination: An Empirical and Conceptual Critique of Household Strategies." Development and Change 21:4374.

Wolf, Diane. 1992. Factory Daughters: Gender, Household Dynamics, and Rural Industrialization in Java. Los Angeles: University of California Press.

Wolf, Diane. 1993. "Feminist Dilemmas in Fieldwork." Frontiers: A Journal of Women Studies 13(3):1-8.

Wright, Erick Olin. 2006. "Class Analysis.” Pp. 143-66 in Social Class and Stratification: Classic Statements and Theoretical Debates, 2nd Edition, edited by R. Levine. Lanham, Maryland: Rowman \& Littlefield Publishers.

Yashar, Deborah. 2004. "Citizenship and Ethnic Politics in Latin America. Working Paper for UNDP 2004 Report.” United Nations Development Programme (UNDP), New York. 